\title{
"Whose Streets?"
}

The Visual Culture of Resistance during the 2001 Mass Demonstrations Against the Free Trade Area of the Americas in Quebec City

\author{
By \\ Claudette Lauzon, B.A. (Honours), University of Toronto
}

\author{
A thesis submitted to the Faculty of \\ Graduate Studies and Research in partial fulfilment \\ of the requirements for the degree of \\ Masters of Arts \\ in Canadian Art History
}

Carleton University

OTTAWA, Ontario

11 August 2003

(C) 2003, Claudette Lauzon 


\author{
National Library \\ of Canada \\ Acquisitions and \\ Bibliographic Services \\ 395 Wellington Street \\ Ottawa ON K1A ON4 \\ Canada
}

Bibliothèque nationale

du Canada

Acquisisitons et services bibliographiques

395 , rue Wellington Ottawa ON K1A ON4 Canada
Your file Votre référence ISBN: 0-612-93886-7

Ourfile Notre référence ISBN: 0-612-93886-7
The author has granted a nonexclusive licence allowing the National Library of Canada to reproduce, loan, distribute or sell copies of this thesis in microform, paper or electronic formats.

The author retains ownership of the copyright in this thesis. Neither the thesis nor substantial extracts from it may be printed or otherwise reproduced without the author's permission.
L'auteur a accordé une licence non exclusive permettant à la Bibliothèque nationale du Canada de reproduire, prêter, distribuer ou vendre des copies de cette thèse sous la forme de microfiche/film, de reproduction sur papier ou sur format électronique.

L'auteur conserve la propriété du droit d'auteur qui protège cette thèse. $\mathrm{Ni}$ la thèse ni des extraits substantiels de celle-ci ne doivent être imprimés ou aturement reproduits sans son autorisation.
In compliance with the Canadian Privacy Act some supporting forms may have been removed from this dissertation.

While these forms may be included in the document page count, their removal does not represent any loss of content from the dissertation.
Conformément à la loi canadienne sur la protection de la vie privée, quelques formulaires secondaires ont été enlevés de ce manuscrit.

Bien que ces formulaires aient inclus dans la pagination, il n'y aura aucun contenu manquant. 
PAGINATION ERROR.

ERREOR DE PAGINATION.

LE TEXTE EST COMPLET.

IEXI COMPLETE. 


\begin{abstract}
On an April weekend in 2001, a colourful parade of medieval knights, ethereal fairies, stilt walkers, bongo drummers, frenetic dancers, Radical Cheerleaders, and Raging Grannies flooded the streets of Quebec City in a saturnalian exhibition of camaraderie and resistance. This thesis explores the visual culture generated for and during these demonstrations against the Free Trade Area of the Americas (FTAA), an agreement that will extend free trade to the entire Western hemisphere. Applying an interdisciplinary theoretical approach to the contemporary cultural phenomenon of creative dissent, I explore the various oppositional art practices employed in Quebec City as both strategies and manifestations of a collective objective to physically and symbolically contest the conventional exclusions of politics and public space. I also consider the extent to which the carnivalesque nature of contemporary protest can be theorized as a strategy for the construction of spaces of resistance. I conclude that the enactment of creative performances of dissent functions as a vehicle for bearing witness to social injustice, constructing collective identity, and reclaiming the public sphere as a site of oppositional politics.
\end{abstract}




\section{ACKNOWLEDGEMENTS}

Any major project requires a great deal of nurturance, and the writing of this thesis was no exception. I am extremely grateful to Dr. Caroline Alexander-Stevens, who supplied a steady stream of wisdom and insights; to Dr. Carol Payne, who provided constant advice and encouragement; and to my mother Connie Lauzon, who fed me an unending supply of love and lasagna. Special thanks to Alice and Sebastien, who I hope will forgive me for frequently interrupting their own feeding schedules. Finally, I would like to acknowledge the many artists and activists whose work has nourished in me the belief that another world is indeed possible. 
TABLE OF CONTENTS

THESIS ACCEPTANCE $\quad$ ii

$\begin{array}{ll}\text { ABSTRACT } & \text { iii }\end{array}$

ACKNOWLEDGEMENTS $\quad$ iv

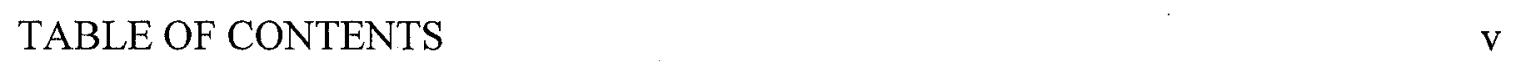

LIST OF ILLUSTRATIONS

LIST OF ABBREVIATIONS $\quad$ x

LIST OF APPENDICES X xi

INTRODUCTION

CHAPTER 1. "Don't hate the media! Become the media!": 22

Photography and the Framing of Resistance

CHAPTER 2. "So! So! So! Solidarité!": 59

The Art of Collective Resistance

CHAPTER 3. "Whose Streets? Our Streets!": 98

Spaces and Carnivals of Resistance

$\begin{array}{ll}\text { CONCLUSION } & 136\end{array}$

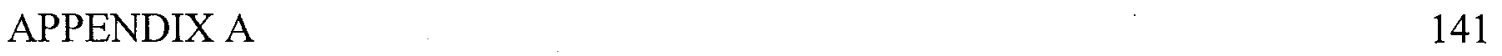

$\begin{array}{lr}\text { APPENDIX B } & 142\end{array}$

$\begin{array}{ll}\text { APPENDIX C } & 144\end{array}$

$\begin{array}{lr}\text { ILLUSTRATIONS } & 150\end{array}$

$\begin{array}{ll}\text { BIBLIOGRAPHY } & 187\end{array}$ 


\section{LIST OF ILLUSTRATIONS}

Figure 1.1. Globe and Mail, Saturday, 21 April 2001, A1.

Figure 1.2. Montreal Gazette, Saturday, 21 April 2001, A1.

Figure 1.3. Le Devoir (Montreal), Saturday, 21 and Sunday, 22 April 2001, A1.

Figure 1.4. Ottawa Citizen, Saturday, 21 April 2001, A1.

Figure 1.5. Montreal Gazette, Monday, 23 April 2001, A18-A19.

Figure 1.6. Montreal Gazette, Sunday, 22 April 2001, A7.

Figure 1.7. ; Globe and Mail, Monday, 23 April 2001, A10-A11.

Figure 1.8. "The KKKorporate media gets a rough ride at this event!" Graeme Bacque, Quebec City, 2001.

Source: Graeme Bacque, "Summit of the Americas: Quebec City, April 20-22," <http://graemesgallery.tripod.com/Quebec/A20-21>, June 2003.

Figure 1.9. "This officer got as good a shot of my face as I did of his." Rob Breadner, Quebec City, 2001.

Source: Rob Breadner, "Quebec City FTAA Summit April 22, 2001," 30 April 2001, <http://www3.sympatico.ca/hioctane/quebec_pics1. html>, June 2003.

Figure 1.10. Barricada (Boston, Mass.) 7 (May 2001), front cover.

Figure 1.11. "Yours truly, taking in tribal drumming at the massive bonfire, late into the evening. It was a bonding experience of many protest-weary warriors."

Rob Breadner, Quebec City, 2001.

Source: Rob Breadner, "Quebec City FTAA Summit April 22, 2001," 30 April 2001, <http://www3.sympatico.ca/hi-octane/quebec_pics1. html>, June 2003.

Figure 1.12. "This pig shot a concussion grenade towards my back as I retreated after taking these pics (Bastard!)."

Graeme Bacque, Quebec City, 2001.

Source: Graeme Bacque, "Summit of the Americas: Quebec City, April 20-22," <http://graemesgallery.tripod.com/Quebec/A20-21>, June 2003. 
Figure 2.1. Nemesis, the Goddess of Just Anger.

Barbara Walker Graham, Quebec City, 2001.

Source: Barbara Walker Graham, "Whose Nemesis? Feminist Action against the FTAA," Awakened Woman e-magazine, 16 May 2001, $<\mathrm{http}$ //www.awakenedwoman.com/walker_report.htm>, December 2002.

Figure 2.2. Weaving a Web of Solidarity action.

Tom Hanson, Quebec City, 2001.

Source: Photowire Archive, Infoshop.org Web site, $<$ http://www.infoshop.org/news6/capt_canada_summit_protests_qbc120 .jpg>, June 2003.

Figure 2.3. R.I.P. puppet.

Photographer unknown, Quebec City, 2001.

Source: Progressive Valley Forum Web site, $<$ http://www.progressive valley.com/images/albums/quebec/P4210666-01.jpg >, December 2002 (no longer operational).

Figure 2.4. "Cycloptopus' corporate puppet with tentacles reaching into every household."

Photographer unknown, Quebec City, 2001.

Source: "Quebec City-Summit of the Americas. Anti-FTAA/ZLEA Protest," Student Christian Movement Canada Web site, <http://www. scmcanada.org/quebecFTAA.html>, June 2003.

Figure 2.5. Ronald McDonald puppet during People's March.

Claudette Lauzon, Quebec City, 2001.

Figure 2.6. George W. Butcher.

Rob Breadner, Quebec City, 2001.

Source: Rob Breadner, "Quebec City FTAA Summit April 22, 2001," 30 April 2001, <http://www3.sympatico.ca/hi-octane/quebec_pics1. html>, June 2003.

Figure 2.7. The Living River.

Claudette Lauzon, Quebec City, 2001.

Figure 2.8. "A woman writes a poem on the streets of Quebec City, April 2001." Tish Stringer, Quebec City, 2001.

Source: Tish Stringer, "Photo Diary of a Revolution," Journal of Aesthetics and Protest 1 , no. 1 (July 2002), <http://www.journalof aestheticsandprotest.org/1/photodiary/3.html>, June 2003. 
Figure 2.9. "Members of a political awareness group from Ottawa, the 'Raging Grannies,' sing anti-globalization songs before a march at the 'People's Summit,' in Quebec City, Canada, Saturday, April 21, 2001." John Moore, Quebec City, 2001. Source: Photowire Archive, Infoshop.org Web site, <http://www.info shop.org/news6?thumb_canada_summit_protests_qccm104.jpg $>$, June 2003.

Figure 2.10. Radical Cheerleaders.

Liz Highleyman, Quebec City, 2001.

Source: Liz Highleyman, "Photos from Quebec City Summit of the Americas/ FTAAProtest19-22 April 2001," Black Rose Web Pages, $<$ http://www.black-rose.com/quebec-photos/radcheer2-sm.jpg >, June 2003.

Figure 2.11. "Pro-FTAA" demonstrators.

Claudette Lauzon, Quebec City, 2001.

Figure 2.12. Equiterre demonstration.

Richard Swift, Quebec City, 2001.

Source: Richard Swift, "From the Streets: Live from Quebec City," New Internationalist Web site, 21 April 2001, <http://www.newint.org/ streets/Images/qprotestors.jpg>, June 2003.

Figure 2.13. "No talk."

Richard Swift, Quebec City, 2001.

Source: Richard Swift, "From the Streets: Live from Quebec City," New Internationalist Web site, 21 April 2001, <http://www.newint.org/ streets/Images/qnotalk.jpg>, June 2003.

Figure 2.14. World March of Women performance.

Claudette Lauzon, Quebec City, 2001.

Figure 2.15. Ya Basta.

Photographer unknown, Quebec City, 2001.

Source: "Quebec City, April, 2001," New York City Ya Basta Collective Web site, <http://free.freespeech.org/yabasta/quebec.html>, May 2003.

Figure 3.1. "Fairy princess blowing bubbles." Andrew Mefferd, Quebec City, 2001. Source: Andrew Mefferd, "Summit 4/20," Cannabis Culture Web site, 12 July 2001, <http://www.cannabisculture.com/articles/2002.html>, March 2003. 
Figure 3.2. Boarded windows with graffiti.

Dru Jay, Quebec City, 2001.

Source: Dru Jay, "Photos From Quebec City," Misnomer Web site, 28

April 2001, <http://misnomer.dru.ca/2001/04/entries.html>, June 2003.

Figure 3.3. "The parade boasted numerous thoughtful statements."

Rob Breadner, Quebec City, 2001.

Source: Rob Breadner, "Quebec City FTAA Summit April 22, 2001,"

30 April 2001, <http://www3.sympatico.ca/hi-octane/quebec pics3.

html>, June 2003.

Figure 3.4. "The People's March."

Photographer unknown, Quebec City, 2001.

Source: "Quebec City Photos," Ecumenical Council for Economic Justice Web site, <http://www.ecej.org/people.htm>, December 2002 (no longer operational).

Figure 3.5. Billboard jam.

Claudette Lauzon, Quebec City, 2001.

Figure 3.6. "Drummers."

Chaitanya K. Kalevar, Quebec City, 2001.

Source: Chaitanya K. Kalevar, "From Seattle to Quebec City-FTAA," Citizens on the Web Web site, <http://photos.citizensontheweb.com /quebec.htm>, February 2003.

Figure 3.7. Deconstructionist Institute for Surreal Topology catapult.

Photographer unknown, Quebec City, 2001.

Source: "Quebec Photos," Ibiblio: The Public's Library and Digital Archive Web page, 24 May 2001, <http://www.ibiblio.org/quebec/ Photos/catapulte.jpg>, December 2002.

Figure 3.8. Carnival Against Capitalism poster.

Produced by Anti-Racist Action Toronto, November 2000.

Source: Anti-Racist Action Toronto, "Anti-Racist Action Art-Archive," Anti-Racist Action Toronto Web site, December 2001, <http://www. web.net/ ara/Art/carnival.htm>, June 2003.

Figure 3.9. Masked Blac Bloc anarchists "reclaim" a barricade. Claudette Lauzon, Quebec City, 2001.

Figure 3.10. Carnivalesque activity.

Mike Reshitnyk, Quebec City, 2001.

Source: Mike Reshitnyk, "Summit of the Americas Photo Album," Ukrainian Directory in Montreal Web site, 2001, <http://ukemonde. com/summit/photos1a.html>, June 2003. 


\section{LIST OF ABBREVIATIONS}

$\begin{array}{ll}\text { CAE } & \text { Critical Art Ensemble } \\ \text { CASA } & \begin{array}{l}\text { Comité d'acceuil du sommet des Amériques/Summit of the Americas } \\ \text { Welcoming Committee }\end{array} \\ \text { CLAC } & \text { Convergence des luttes anti-capitalistes/Anti-Capitalist Convergence } \\ \text { DIST } & \text { Deconstructionist Institute for Surreal Topology } \\ \text { FTAA } & \text { Free Trade Area of the Americas } \\ \text { IMF } & \text { International Monetary Fund } \\ \text { OAS } & \text { Organization of American States } \\ \text { PWGSC } & \text { Public Works and Government Services Canada } \\ \text { RCMP } & \text { Royal Canadian Mounted Police } \\ \text { TAZ } & \text { Temporary Autonomous Zone } \\ \text { WTO } & \text { World Trade Organization }\end{array}$




\section{LIST OF APPENDICES}

Appendix A: Map of Quebec City during April 2001 Summit of the Americas

Appendix B: Classification of newspaper photographs

Appendix C: Classification of newspaper headlines and captions 


\section{INTRODUCTION}

"So! So! So! Solidarité! So! So! So! Solidarité!" On an April weekend in 2001, the streets of Quebec City played host to tens of thousands of demonstrators from North, Central and South America, and beyond. They included anarchists, labour unionists, and environmental activists, who were joined by French farmers, Haitian workers, and American pagans, as well as a bevy of musicians, dancers, actors, puppeteers, medieval knights, and glittering fairies. Chanting the international slogan of solidarity, this lively parade of activists converged in Quebec City to bear witness to the perceived injustices of global economic integration, and to communicate alternative visions of transnational convergence. The occasion was the third Summit of the Americas, an assembly of thirtyfour heads of state whose purpose was to set the agenda for hemispheric free trade.' The response was an eclectic mix of collective fury and exuberant absurdity, manifested in the donning of gas masks and costumes, the clutching of cameras and projectiles, the waving of flags and banners, and the beating of drums and barricades.

I was one of the thousands of demonstrators who travelled to Quebec City to take part in some of the myriad protests against the proposed adoption of the Free Trade Area of the Americas (FTAA), the basic tenets of which will be discussed below. My objective, like that of my fellow demonstrators, was to bear witness to what I believe is a deeply flawed model of neo-liberal economic policy, and to the undemocratic manner in which this model is imposed upon an increasingly marginalized global citizenry. ${ }^{2}$ What I also witnessed during this weekend of protest events was a collective spirit of creative resistance that belied conventional wisdom positing contemporary mass demonstrations as 
chaotic, incoherent, and violent manifestations of the juvenile urge to "have fun..., protest, and blah blah blah."

This thesis explores the visual culture generated for and during the mass demonstrations in Quebec City as a case study of the contemporary phenomenon of creative public dissent. I argue that what unified the protesters who converged in Quebec City in April 2001 — and one of the unifying features of the "anti-globalization" movement or "global justice" movement in its entirety-is a collective objective to physically and symbolically reclaim public spaces as sites in which to contest conventional exclusions of politics and space. ${ }^{4}$ Applying an interdisciplinary theoretical approach to the visual culture of resistance, I examine the role of art as both a strategy of space reclamation and a tool for building solidarity. I also consider the role of the carnivalesque as a strategy for creating spaces of resistance. I conclude that creative tactics of dissent operate as vehicles for bearing witness to social injustice, constructing collective identity, and reclaiming the public sphere as a site of oppositional politics.

This introduction presents a brief overview of the political context surrounding the demonstrations against the FTAA and a brief introduction to the global justice movement. ${ }^{s}$ In addition, it outlines the subsequent chapters and introduces the theoretical frameworks applied to the analysis of the visual culture of collective dissent.

The Quebec City anti-FTAA demonstrations, which took place on the weekend of 20 to 22 April 2001, were arranged to coincide with the Summit of the Americas, a meeting of hemispheric heads of state hosted by Canadian Prime Minister Jean Chrétien and Canada's Department of Foreign Affairs and International Trade (DFAIT), and attended by 9,000 delegates representing the member-nations of the Organization of 
American States (OAS). ${ }^{6}$ This was the third Summit of the Americas. At the first, held in Miami, U.S., in 1994, an agreement was reached by the thirty-four participating nations to work toward creating a Free Trade Area of the Americas, which would provide free market access across the continent by 2005 . The second summit, convened in Santiago, Chile, in 1998, saw the initiation of dialogue concerning the draft text of the FTAA. The objective of the third summit was to begin negotiating the terms of the agreement. While a complete draft of the FTAA has yet to be made public, the accord is modelled on the North American Free Trade Agreement (NAFTA) ${ }^{7}$ and the World Trade Organization (WTO). ${ }^{8}$ Nine specific areas of interest are addressed in the FTAA implementation process: investment; market access; services; government procurement; dispute settlement; agriculture; intellectual property rights; subsidies; antidumping and countervailing duties; and competition policy.

The FTAA is an extension of the process of global trade liberalization that has, in the past two decades, overseen a rapid worldwide increase in free trade agreements and a parallel retraction of transnational trade barriers. Correspondingly, a series of institutions mandated to administer and regulate global trade policies have come into existence, including the World Trade Organization (WTO), formed in 1995 to enforce international agreements and settle trade disputes among member nations. While international trade regulating bodies are not new, what distinguishes the WTO from institutions such as the General Agreement on Tariffs and Trade (GATT), initiated in 1948 to monitor international trade agreements, is its status as a "legal personality," with the "legislative and executive powers of a global governing body."

The increasing integration of the global economy and the privileged status of the 
WTO and its partner institution, the International Monetary Fund (IMF), "' as global governing bodies, has led to the emergence of an international movement in opposition to what is perceived as an economic model of globalization that privileges corporate profit and global capital flow over citizens' rights. According to Canadian political analysts Maude Barlow and Tony Clarke, this movement can be characterized by six fundamental concerns - substinence, economic, ecological, social, cultural, and human rights—all related to the unifying theme of "defence of democracy and the commons." "For Barlow and Clarke, transnational corporate culture and its promulgation through national governments has resulted in an escalating deterioration of these fundamental rights, while the primary role of governments has become "to provide safeguards for investors, not citizens." The common objective of the emergent civil society movement, they argue, is "to completely reverse the trend before it's too late."

While opponents of economic globalization have organized on a vast number of fronts deploying a diversity of tactics, that which has generated the most enthusiastic support and vociferous condemnation has been the mobilization of mass demonstrations during meetings of global leaders and institutions. Using the Internet as a tool of communication and dissemination, civil society groups in numerous countries have united to construct what the Canadian Security Intelligence Service (CSIS) acknowledged in 2000 to be a "rapidly spreading phenomenon" $" 15$ of confrontational direct-action resistance to the perceived hegemony of corporate-driven globalization. While the mass demonstrations during the 1999 WTO/IMF "Millennium Round" negotiations in Seattle, Washington, were not the first manifestation of this emerging phenomenon, it was the "Battle of Seattle" that brought the nascent global justice movement to wide public attention. ${ }^{16}$ The 
events in Seattle were followed by a succession of mass demonstrations, including protests during an annual meeting of the WTO and IMF in Washington, D.C., in April 2000 that drew ten to fifteen thousand demonstrators; protests against the meeting of the OAS in Windsor, Ontario, in June 2000; and a mass demonstration during the annual meeting of the World Bank and IMF in Prague, Czech Republic, in September 2000. ${ }^{17}$

Opposition to the proposed Free Trade Area of the Americas is based on the contention that the FTAA will weaken labour and environmental standards and lead to the privatization of such public services as health care and education. Critics argue that the FTAA represents and promotes a model of trade and development that privileges corporate interests over those of citizens, and that weakens domestic governments' power to protect public services and social policy. Of particular concern is the proposed implementation of NAFTA's Chapter Eleven, a controversial investor-state clause that grants corporations the right to sue governments whose domestic laws are deemed to infringe on a corporation's profit-making capacity. ${ }^{18}$

The Quebec City summit was promoted by its proponents as the "democracy summit," thus described for the planned negotiation of a "democracy clause" that would bind trading nations to an as-yet undisclosed core set of democratic principles. ${ }^{19}$ Indeed, the negotiation of the FTAA was downplayed by world leaders and delegates, who chose to focus on the meetings' agenda of "strengthening democracy, creating prosperity and realizing human potential. ${ }^{20}$ Global justice activists were prompt to call attention to the apparent irony of this pronouncement. For anti-FTAA protesters, the massive security measures put into effect for the Summit of the Americas represented a flagrant violation of the principles of democracy that the "democracy clause" purported to serve. These 
measures, which the Royal Canadian Mounted Police (RCMP) acknowledged to be the "largest security force ever deployed in Canada,,$"$ included the erection of a 3.8 kilometrelong, four-metre-high concrete and chain-link fence that cordoned off a nine-kilometre area of Quebec City; the deployment of over 6,000 federal, provincial and municipal police officers; and the evacuation of Quebec City's Orsainville Prison in anticipation of protestrelated arrests. In response to what was perceived as an infringement of constitutional freedoms of speech and peaceful assembly, several challenges were initiated, including a press release and petition launched by a group of prominent Canadians (lawyer Clayton Ruby and writer Margaret Atwood among them) which argued: "When the streets are blocked off and hundreds of meeting halls in Quebec City are out of reach to citizens because they are inside a sprawling 'security zone,' it is democracy itself that is marginalized. ${ }^{22}$

A common perception was that these security measures, ostensibly designed to avoid the violent confrontations manifested at prior mass demonstration, were instead intended to create a context of fear that would dissuade "peaceful" activists from attending the demonstrations. This perception was likely a factor in the mobilization of tens of thousands of activists from across the hemisphere. Indeed, it was the apparently undemocratic nature of the summit proceedings, as much as the content of the summit agenda itself, which provoked the most clamorous dissent.

In response to the Quebec City Summit of the Americas, a hemispheric network of labour unions and non-governmental organizations arranged a parallel conference, the second People's Summit of the Americas, to be held 17 to 21 April in Quebec City. The summit was organized by the Hemispheric Social Alliance, a coalition that emerged during 
a meeting held parallel to the FTAA Trade Ministerial Meetings in Belo Horizonte, Brazil, in May $1997 .^{23}$ Delegates to the second People's Summit, including international labour leaders, politicians, academics and activists, attended a weeklong series of symposia and conferences that culminated in the Saturday, 21 April People's March of the Americas, which was attended by upwards of 60,000 demonstrators. ${ }^{24}$ On 19 April the Declaration of the People's Summit was released, which asserted the Hemispheric Social Alliance's opposition to the FTAA based on the non-transparent nature of the agreement's design and on the conclusion that the FTAA "will result in the deepening of the democratic deficit and the exacerbation of existing inequalities. ${ }^{25}$

Although the second People's Summit drew more than two thousand delegates, it was also heavily criticized in several activist communities for its position of "apolitical reformism," manifested in the Hemispheric Social Alliance's unwillingness to condone or participate in direct-action protest, and in the fact that the People's Summit was financed by the Canadian government. ${ }^{26}$ Accordingly, peripheral actions and events were organized by several more radical organizations and coalitions, including Quebec City's Opération printemps 2001 (OQP 2001), Montreal's Opération SalAMI, the Montreal-based Convergence des luttes anti-capitalistes (Anti-Capitalist Convergence/CLAC), and its Quebec City partner Comité d'acceuil du sommet des Amériques (Summit of the Americas Welcoming Committee/CASA). These groups organized a variety of events, including carnivals, teach-ins, symposia, and summit disruptions, and also arranged for food, accommodation, and art-making spaces for visiting activists.

A significant characteristic of the principles guiding these organizations - and the myriad other coalitions and affinity groups that will be discussed in the subsequent 
chapters-is an emphasis on the construction of what has been referred to as a "radically creative ambience" on the streets of Quebec City. ${ }^{27}$ The intention was threefold: to foreground creativity over the typically emphasized confrontational aspects of public dissent; to build solidarity through art and creativity; and to create a visually stunning context in which to galvanize and communicate with a broader range of activists and audiences. In this thesis, I apply a wide range of theoretical frameworks in order to investigate why, and to what effect, the strategy of creative dissent was employed so abundantly during the Quebec City demonstrations.

My decision to explore the visual culture of public dissent is rooted in three premises. First, the performative politics of public protests demonstrate an affinity with the contemporary phenomenon of "new genre public art," and thus both merit - and are better understood through - the application of theoretical models associated with this practice. Second, contemporary theory correlated to new genre public art, performance art, and carnival activity provides useful frameworks for analysis of the overall phenomenon of mass demonstrations. Finally, the contemporary global justice movement is actually a multifaceted web of movements whose very complexity renders the process of analyzing the phenomenon equally complex. To explore the various ways in which it is manifested visually is to arrive at a more comprehensive understanding of the movement itself than that which is offered in conventional forums such as mainstream media.

New genre public art is defined by artist and theorist Suzanne Lacy as an art practice "whose public strategies of engagement are an important part of its aesthetic language. ${ }^{, 28}$ For Lacy, new genre public art is distinguished from conventional forms of public art by its commitment to social interventions that connect artist and audience in a 
relationship "that may itself become the artwork." ${ }^{29}$ Such interventions are invariably collaborative and process-oriented, and inevitably lead to the problematization and reevaluation of the terms of reference related to both "public" and "art.", Much of this thesis draws on the rich body of literature emanating from activist and new genre public art in an exploration of the ways in which the art generated for and during mass demonstrations emphasizes a collaborative approach to art-making and itself problematizes conventional notions of public art and public space.

If the more easily categorized art projects discussed in the subsequent chapters, such as puppets, banners, and theatrical performances, are disposed to analysis based on the terms of public art, so too can mass demonstrations in their entirety be analyzed according to this framework. Mass demonstrations are performative gestures intended to mobilize and publicly demonstrate both solidarity and counter-hegemonic opposition to the perceived undemocratic nature of contemporary governance. In the thesis, I apply theory related to community art, witness art, and the carnivalesque as I develop the argument that contemporary activists employ the vocabulary of creative resistance as a tool to enhance the efficacy and affectivity of such actions.

Creativity is an increasingly integral strategy of collective engagement in oppositional politics, but it is also a strategy that is inadequately addressed in both mainstream media and critical discourse. In a June 2002 article in the Globe and Mail titled "Never Mind the Anarchy-Where's the Art?", cultural critic Hal Niedzviecki condemns the "antiglobalization" movement for its paucity of creative vision. Asking "Where is this movement's Electric Kool-Aid Acid Test or 'I Have a Dream' speech?", Niedzviecki accuses the movement of lacking a "visual or literary flare" that is "equal to 
the task of igniting outrage." The author compares the contemporary social justice movement to the "fervent sixties," concluding: "The sixties had Abbie Hoffman and Timothy Leary. Antiglobalization has a dour French farmer who travels the world agitating against fast food. ${ }^{31}$ What Niedzviecki appears to seek is a cultural leader, a creative guru who will synthesize and package the movement into a cutting-edge but accessible work of art. What he fails to acknowledge is that the global justice movement's rejection of conventional political models is an integral part of its political program. And, like the movement that generates it, the art of contemporary resistance is adamantly collaborative, process-oriented, non-hierarchical, and leaderless. The collective creative impulse that manifested itself on the streets of Quebec City in April 2001 cannot be effortlessly subsumed within the categories of art and politics. It is perhaps for this reason that analyses of creative expressions of dissent tend to lack depth.

The creative aspects of the contemporary justice movement are, on the whole, marginalized in mainstream media and poorly analyzed in political discourse. The options seem limited to three. Advocates of the global justice movement, such as John Jordan and Jennifer Whitney in the 2001 "Resistance is the Secret to Joy," sing the praises of creative resistance in a manner that is striking for the absence of critical distance and political nuance. Jordan and Whitney argue: "Carnival and revolution have identical goals: to invert the social order with joyous abandon and to celebrate our indestructible lust for life, a lust that capitalism tries so hard to destroy. ${ }^{, 32}$ Detractors of the movement ridicule the festive nature of contemporary mass demonstrations; Prime Minister Jean Chrétien's comment, noted above, is exemplary in this respect. Mainstream media emphasizes the violent confrontations that occur during mass demonstrations, while disregarding non-violent 
creative activity. One of the objectives of this thesis is to explore the visual manifestations of the global justice movement in order to arrive at a more nuanced understanding of the movement itself.

In chapter one, I analyze the ways in which the demonstrations were framed and interpreted in mass media coverage. As it would not be feasible to investigate the complete spectrum of media coverage of events surrounding the Summit of the Americas, I chose to limit my focus to press photography representations. This choice was made for three reasons. First, because this thesis attends primarily to the visual culture of public dissent, it was important to explore how a visual medium of communication-photojournalismcontributes to the discourse surrounding mass demonstrations. Second, photography holds the potential to be one of the most democratic representational media; indeed, as I note in the first chapter, cameras were in such abundance during the Quebec City demonstrations that it was often difficult to distinguish activists from journalists. Finally, because I myself attended the demonstrations armed with a camera, the focus on photographic representations of the protests allowed me to interrogate my own role as both activist and observer, and thus to explore how these roles are negotiated in activists' representations of the demonstrations.

The first section of the chapter consists of an analysis of photographic representations of the Quebec City demonstrations in six major Canadian daily newspapers (the Globe and Mail, Le Devoir [Montreal], the Montreal Gazette, the National Post, the Ottawa Citizen, and the Toronto Star). I discuss the ideological narrative constructed through the selection and contextualization of these photographs through the application of Roland Barthes's structuralist analysis of photographic messages as developed in his 1961 
"The Photographic Message.." In this essay, Barthes argues that all photographs contain signifying codes or "connotative messages" that add layers of meaning to their ostensibly neutral "denotative messages." I also draw on Stuart Hall's "The Determination of Newsphotographs," an essay that expands on Barthes's theory by attending to the options available to the readers of photographic messages, which he argues are limited to inhabiting, negotiating, or rejecting the dominant ideology embedded in the photograph. ${ }^{34}$ Uniting this idea with Louis Althusser's notion of "interpellation," of photographic representations of the Quebec City demonstrations are interpellated as neutral witnesses to a series of archetypal confrontations lacking ideological coherence, context, and ethical foundations.

Although the structuralist analysis of news photographs is a useful framework for analyzing how photograph selection, syntactic concatenation, and language bias imbue seemingly neutral photographic representations with cultural and ideologically inflected messages, it is also a tool with limitations. Photographic messages can also be subjected to, and sometimes engage in, resistant readings. In order to explore a less deterministic approach to photography, I apply the notion of the "gaze," which seeks to interrogate the power relations implicit in the act of looking. The concept of "intersecting gazes," employed by Catherine A. Lutz and Jane L. Collins in their analysis of National Geographic photographs, ${ }^{36}$ provided a particularly useful framework. Lutz and Collins argue that by attending to the multitude of gazes that operate within the photographic field, it is possible to reveal and undermine the myriad ways in which dominant messages are imposed upon photographs. Employing Lutz and Collins's notion of the "refracted gaze of the other," which the authors argue functions to disrupt the institutional gaze embedded in 
photographic messages, I discuss the photographic practice of two Canadian activists, Rob Breadner and Graeme Bacque, both of whom attended the Quebec City demonstrations and published collections of photographs related to the events on personal Web sites. Drawing on Michel Foucault's notion of the surveillance society and Steve Mann's emerging concept of sousveillance (a counter-hegemonic strategy of reverse scopophilia), ${ }^{37} \mathrm{I}$ conclude that the "refracted gaze of the other" functions as a tool of self-reflection and counter-surveillance. This gaze both challenges the hegemony of the panoptic gaze and provides a model for investing photographic practice with counter-hegemonic agency.

In the second chapter, I challenge mainstream media's representation of the antiFTAA demonstrations as violent, chaotic, and ideologically incoherent by attending to the art of creative resistance that was manifested on the streets of Quebec City. I position the art practices under consideration within two frames - art as conversation and art as witness-in order to explore the various ways in which art practice contributes to the activist objective of building solidarity, communicating ideas, and bearing witness to perceived truths. In the first of these sections, I draw on the discourses of performance and community art as elaborated by theorists such as Homi K. Bhabha, Baz Kershaw, Augusto Boal and Suzi Gablik as I examine the extent to which creative, "conversational" art projects are able to mobilize communities of resistance and communicate complex political ideas in visually accessible ways. I conclude that the collaborative, process-oriented nature of the art manifested in Quebec City functioned to generate solidarity, "affective investment, ${ }^{, 38}$ and counter-hegemonic dialogue.

In the second section of this chapter, I explore the notion that art functions as a powerful vehicle for the bearing of witness. Of particular interest to me was the idea that 
the human body can be employed as both a physical and a symbolic tool of opposition in the collective effort to counter virtual power with immanent resistance. Taking issue with media-arts collective Critical Art Ensemble's argument that material, street-level resistance against the "nomadic flow" of corporate power is futile, ${ }^{39}$ I argue that performative, embodied enactments of oppositional politics can operate as effective, and affective, levers with which to expose and bear witness to perceived social injustices.

In my discussion of embodied tactics of resistance, I draw heavily on feminist discourse concerning the efficacy of embodiment as a tool of social activism. I address the issues raised by the 1970 s feminist tactic of "body art" and the ensuing 1980 s model of deconstructionist feminism, which censured the "essentialist" nature of body art as a reinscription of the problematic naturalization of the female body as both commodity and object of the "male gaze." Applying Amelia Jones's reevaluation of body art, developed in her 1998 Body Art/Performing the Subject, ${ }^{40}$ I argue that the employment of the body in performative acts of resistance creates a space for engagement in questions of subjectivity and agency.

Feminist discourse also provided a useful model for analysis of the several antiFTAA art actions that employed the tactic of parody as a vehicle for bearing witness. In my discussion of the performative politics of parody, Judith Butler's consideration of the performance of gender as a strategy of political activism was valuable. In her 1990 Gender Trouble, Butler argues that to parody conventional codes of femininity is to destabilize these codes and to assert subjective agency. ${ }^{41}$ In my discussion of several actions during the Quebec City demonstrations, I argue that the parodic embodiment of dominant ideological conventions is an effective political strategy for bearing witness to the hegemonic 
imposition of these conventions.

But feminist thought is more than simply a model or framework for the collective creative impulses of the global justice movement. Many of the art actions discussed in the second chapter convey explicitly feminist critiques of contemporary global politics. This should not be surprising, for, as feminist and political theorist Manisha Desai demonstrates in her examination of women, solidarity, and globalization, "Research by academics, policymakers, and various UN [United Nations] agencies overwhelmingly shows that women and children have suffered disproportionately as a result of global economic restructuring., ${ }^{42}$ Thus, in this chapter feminist theory is applied both as a framework for analysis of the performative politics of art activism as manifested in Quebec City, and as a lens through which to explore the many feminist actions that contributed to the festive spirit of collective resistance to the implementation of the Free Trade Area of the Americas.

In the third chapter, I take a step back from specific art projects in order to attend to the ways in which the visual culture of Quebec City was transformed during the April 2001 demonstrations, and to address the attendant implications for the construction of communities of resistance in spaces of resistance. I begin by invoking Henri Lefebvre's notion of a socio-spatial dialectic that is concealed in capitalist society by the reduction of the public sphere to an "abstract space" that encourages active consumption and passive acquiescence to dominant ideology. ${ }^{43}$ Employing theory emanating from social geography discourse, I discuss the idea that spaces of resistance are most effectively created within the inevitable cracks in the spaces of domination. Michel de Certeau's proposal for "everyday" tactics of resistance against strategies of domination, and the Situationist 
International's advocacy of "situations" enacted to undermine and disrupt the conquest of public space by capitalist culture, are particularly useful in this context. ${ }^{44}$

I then argue that the cracks in capitalist culture's "abstract space" were revealed even before demonstrations began, and propose that the alterations to Quebec City's visual culture (including the construction of a massive perimeter fence and the concealing of commercial signage), ostensibly designed to prevent conflict from occurring, had the unintended effect of exposing the heretofore concealed conquest of public space to contestation. I discuss a variety of manifestations of this contestation, including graffiti, culture jamming, and the creation of festive spaces or "temporary autonomous zones," the term coined by Hakim Bey to describe the enactment of radical democracy in transitory, marginal spaces. ${ }^{45}$ Employing Kevin Hetherington's observation that counter-cultural zones of "marginal utopics" are most productively constructed as transgressions into dominant spaces, ${ }^{46}$ I counter Bey's advocacy of a "will to disappearance." I propose that the enactment of oppositional culture on the streets of Quebec City was effective, and affective, precisely because it was enacted as the reclamation of a contested space.

I also apply this proposal to the discussion of carnivalesque resistance as a strategy for the reclamation of public space. I theorize the points of intersection between Mikhail Bakhtin's treatise on late-medieval/early-Renaissance carnivals and contemporary versions of carnivalesque as performed during mass demonstrations. ${ }^{47}$ I argue that the fundamental difference between the Bakhtinian version of carnival and its contemporary manifestation is the difference between the acting out of utopia and the acting out of "oppositional utopia." Whereas medieval carnivals provided an outlet for citizens to engage in performances of "utopian freedom" during a period of "suspension of all hierarchical rank, 
privileges, norms, and prohibitions, ${ }^{, 48}$ the carnival of resistance performed during the Quebec City demonstrations was characterized by its enactment in a time and space during which privileges and prohibitions were not suspended, but rather rigorously enforced. I conclude that while carnivalesque strategies of opposition are limited by their temporary and liminal occupation of the public sphere, they nonetheless contribute to the making of communities and spaces of resistance by operating as a compelling tool of collective empowerment and agency through the development of what Victor Turner refers to as "spontaneous communitas." In the symbolic and physical occupation of a contested public space, the anti-FTAA demonstrations in Quebec City took advantage of the altered visual culture of this space and transformed it into a site of oppositional utopianism in a carnivalesque performance of community and resistance.

I conclude that the visual culture of resistance plays a significant role in the manifestation and articulation of the global justice movement. The application of critical theory associated with performance and art historical discourses demonstrates that conversational art, witness art, and carnivalesque performances function as catalysts for the mobilization of solidarity and affective investment, and furthermore provide creative channels for the occupation of the public sphere for the expression of counter-hegemonic resistance. 


\section{NOTES}

${ }^{1}$ Cuba's Fidel Castro was excluded from both the summit and the FTAA negotiation process.

${ }^{2}$ Indeed, my own politically subjective position informs, and is interrogated in, the body of this thesis.

3

3 This comment, attributed to Canadian Prime Minister Jean Chrétien in response to the planning of demonstrations against the Summit of the Americas, was: "Ils se disent: On va aller passer une fin de semaine à Québec. On va avoir du fun. On va protester et bla bla bla." See Manon Cornellier, "Le Sommet des petits pas," Le Devoir (Montreal), Saturday, 14 April 2001, A11.

"This phenomenon is most often described using the term "anti-globalization." Increasingly this term is viewed as inaccurate and confining; indeed, the movement has revealed itself to be an equally global phenomenon that confronts a specifically corporate-driven model of globalization. Political analyst Joseph Boski has argued that the terms "anti-globalization" and "anti-corporate-globalization" are both unduly negative labels, and advocates the term "global justice movement." "The Costs of Global Governance: Security and International Meetings Since WTO-Seattle," paper presented at the CIBER conference, "Globalization: Governance and Inequality," Ventura, California, 31 May-1 June 2002, available online at $<\mathrm{http}: / /$ www.anderson.ucla.edu/research/ciber/intseminar/ciber-boski.pdf $>$, April 2003. Throughout this thesis, the term "global justice movement" is applied.

${ }^{5}$ A detailed discussion of these complex issues is beyond the scope of this study. Though brief, this introduction is intended to contextualize the Quebec City anti-FTAA interventions.

${ }^{6}$ The OAS, a partnership of hemispheric foreign affairs ministers mandated to administer free-market economic integration of the Americas, is the forum that proposed and formulated the FTAA.

${ }^{7}$ NAFTA, implemented in January 1994, lowered trade barriers between Canada, Mexico, and the U.S.

${ }^{8}$ The WTO, formed in 1995 during the "Uruguay Round" of the General Agreement on Tariffs and Trade (GATT) negotiations, is an international body whose mandate is to enforce trade agreements and adjudicate trade disputes between member nations.

See Marc Lee, "The FTAA After Quebec," Canadian Centre for Policy Alternatives Web site, September 2001, <http://www.policyalternatives.ca>, June 2003.

10

See Maude Barlow and Tony Clarke, Global Showdown: How the New Activists are Fighting Global Corporate Rule (Toronto: Stoddart Publishing, 2001), 70-71.

11

The IMF, established in 1944 to oversee international currency exchange, is now mandated to secure loans to impoverished nations and supervise the structural adjustment programs upon which these loans are contingent.

${ }^{12}$ Barlow and Clarke, 207-209.

${ }^{13}$ Ibid., 209.

${ }^{14}$ Ibid. 
${ }^{15}$ Canadian Security Intelligence Service, "Anti-Globalization-A Spreading Phenomenon," Perspectives, August 2000, <http://www.csis-scrs.gc.ca/eng/miscdocs/200008_e.html>, June 2003.

${ }^{16}$ The mandate of the "Millenium Round" in Seattle was to accelerate and expand global trade liberalization, but due to the interruptions of thousands of demonstrators, the summit was dissolved before an accord was reached. See Barlow and Clarke, 7-16.

${ }^{17}$ See Barlow and Clarke, 29-43, for a brief history and analysis of the mass demonstrations of the global justice movement following the Seattle protests.

${ }^{18}$ For example, in 1998, the U.S. company Ethyl Corporation sued Canada's Federal Government under Chapter 11 after Canada banned the gasoline additive MMT. The three-member NAFTA tribunal ruled against Canada, obliging it to drop the ban and pay Ethyl US\$13 million for lost profits. Barlow and Clarke, 48.

${ }^{19}$ The "Summit of the Americas 2001 Declaration of Quebec City," released on 22 April 2001, states that "any unconstitutional alteration or interruption of the democratic order in a state of the Hemisphere constitutes an insurmountable obstacle to the participation of that state's government in the Summit of the Americas process." Available online at the AmericasCanada.org, Government of Canada Web site, $<$ http://www.americas canada.org/eventsummit/declarations/declara-e.asp>, June 2003.

20 John Manley and Pierre S. Pettigrew, "What the Summit is Really About," National Post, Saturday, 21 April 2001, A16.

21 Royal Canadian Mounted Police in Quebec, "Just a Few Days Away from the Summit of the Americas," RCM P Web site, April 2001, <http:/grcquebecrcmp.com/pages/english/con_p_une_e/pag_avr_e.html>, March 2003. According to Quebec's Public Security Minister Serge Ménard, the total cost of security was approximately $\$ 100$ million. "Quebec Looks to Ottawa for Lion's Share of Summit Expenses," National Post, Monday, 23 April 2001, A10.

${ }^{22}$ The text of the petition, titled "Citizen Caged," is available on the Web site of PEN Canada, $<$ http://www.pencanada.ca/censor/citizen.htm>, June 2003. In February 2001, Montreal lawyer Marc F. Tremblay mounted a legal challenge to the constitutional legitimacy of the perimeter fence at the Quebec Superior Court. In his April 18 ruling, Mr. Justice Gilles Blanchet ruled that the fence, despite restricting constitutionally guaranteed freedoms of speech and peaceful assembly, was justifiable "because of the security requirements dictated by the nature of the event, by its scope, unprecedented in Canada, and by the violent incidents that have occurred at similar summits held elsewhere in the world in recent years." Quoted in Graeme Hamilton, "Security Fence is Justifiable, Judge Rules," National Post, Thursday, 17 April 2001, A17.

${ }^{23}$ Hemispheric Social Alliance's Canadian partners are Common Frontiers and Réseau québécois sur l'intégration continentale. The first People's Summit of the Americas was held in Santiago, Chile, in 1998.

${ }^{24}$ Estimates vary in terms of the number of activists who attended the Quebec City anti-FTAA demonstrations. The Toronto Star estimated the attendance at the Saturday People's March at 25,000 (Allan Thompson and Jim Rankin, "Dozens Hurt as Protests Continue: Riots Contrast with Peaceful March by 25,000," Toronto Star, Sunday, 22 April 2001, A1), while Le Devoir put the figure at 60,000 (Eric Derosiers, "Rendez-vous à Porto Alegre pour le prochain Sommet des peuples: La grande marche de samedi aurait attiré près de 60,000 manifestants," Le Devoir [Montreal], Monday, 23 April 2001, A3). 
${ }^{25}$ Hemispheric Social Alliance, "Declaration of the People's Summit," 19 April 2001, available online at the Parliamentary Confederation of the Americas Web site, <http://www.copa.qc.ca/Anglais/Reunions missionsa/Avril2001a/Dec_Peup_A.html>, June 2003.

${ }^{26}$ The People's Summit received $\$ 287,000$ in federal funding. André C. Drainville, "Québec City and the Making of Transnational Subjects," in Socialist Register 2000: A World of Contradictions, ed. Colin Leys and Leo Panitch (London, Ont.: Merlin Press; Halifax: Fernwood, 2001), available online at $<$ http://www.yorku.ca/socreg/Drainville.htm>, June 2003.

27

Ibid. Indeed, while members of CLAC and SalAMI quarrelled in the days prior to the summit over whether to denounce confrontational activity (Magnus Isacsson and Paul Lapointe's documentary film View from the Summit: Quebec City-April 20-22, 2001, 75 min., National Film Board of Canada, 2002, contains several scenes in which CLAC and SalAMI members hotly debate the merits of direct-action protest and the advocacy of a "diversity of tactics," considered by SalAMI a provocation to aimless violence), both groups were firm in their dedication to providing spaces for creative dissent.

${ }^{28}$ Suzanne Lacy, "Cultural Pilgrimages and Metaphoric Journeys," in Mapping the Terrain: New Genre Public Art, ed. Suzanne Lacy (Seattle: Bay Press, 1995), 19.

29

Ibid., 20. Emphasis in original.

30

Lucy Lippard's definition of new genre public art is also cogent: "I would define public art as accessible work of any kind that cares about, challenges, involves, and consults the audience for or with whom it is made, respecting community and environment. The other stuff is still private art, no matter how big or exposed or intrusive or hyped it may be." Lucy Lippard, "Looking Around: Where We Are, Where We Could Be," in Mapping the Terrain: New Genre Public Art, ed. Suzanne Lacy (Seattle: Bay Press, 1995), 120.

${ }^{31}$ Hal Niedzviecki, "Never Mind the Anarchy-Where's the Art? G8 Protesters Could Learn a Lesson from Sixties Counterculture," Globe and Mail, Wednesday, 26 June 2002, A1. The dour French farmer to whom Niedzviecki refers is José Bové, a member of Confédération Paysanne, the coalition that in 1999 organized a "festive deconstruction" that involved the bulldozing of a local McDonald's franchise in Millau, France.

32 John Jordan and Jennifer Whitney, "Resistance is the Secret to Joy," New Internationalist 338 (September 2001): 24 .

${ }^{33}$ Roland Barthes, "The Photographic Message" (1961), in Image, Music, Text, tr. Stephen Heath (New York: Hill and Wang, 1977), 15-31.

${ }^{34}$ Stuart Hall, "The Determination of Newsphotographs," Working Papers in Cultural Studies 3 (fall 1972): 53-87.

${ }^{35}$ Louis Althusser, "Ideology and Ideological State Apparatuses (Notes Toward an Investigation) (1970)," in Lenin and Philosophy, and Other Essays, tr. Ben Brewster (New York: Monthly Review Press, 1971).

36

Catherine A. Lutz and Jane L. Collins, Reading National Geographic (Chicago and London: University of Chicago Press, 1994), 187-216.

37

Michel Foucault, Discipline and Punish: The Birth of the Prison (1975), tr. Alan Sheridan (New York: Pantheon Books, 1977); Steve Mann, Wearcam.org, <http://wearcam.org>, June 2003. 
${ }^{38}$ See Lawrence Grossberg, "Is There a Fan in the House? The Affective Sensibility of Fandom," in The Adoring Audience: Fan Culture and Popular Media, ed. Lisa A. Lewis (London and New York: Routledge, 1992), 50-65.

39

Critical Art Ensemble, The Electronic Disturbance (New York: Autonomedia, 1994), 22-23.

40

Amelia Jones, Body Art/Performing the Subject (Minneapolis: University of Minnesota Press, 1998).

${ }^{41}$ Judith Butler, Gender Trouble: Feminism and the Subversion of Identity (London: Routledge, 1990).

${ }^{42}$ Manisha Desai, "Transnational Solidarity: Women's Agency, Structural Adjustment, and Globalization," in Women's Activism and Globalization: Linking Local Struggles and Transnational Politics, ed. Nancy A. Naples and Manisha Desai (New York and London: Routledge, 2000), 32. In her contribution to the same publication, "Changing the Terms: Community Activism, Globalization, and the Dilemmas of Transnational Feminist Praxis," 10-11, Nancy A. Naples concurs, adding that "in response to increased economic, social, and environmental pressures, women are organizing within their communities, across national borders, and challenging neoliberal policies as well as oppressive labour demands."

Henri Lefebvre, The Production of Space (1974), tr. Donald Nicholson-Smith (Oxford: Basil Blackwell, 1991).

${ }^{44}$ Michel de Certeau, The Practice of Everyday Life (1974), tr. Steven Rendall (Berkeley: University of California Press, 1984); Raoul Vaneigem, The Revolution of Everyday Life (1967), tr. John Fullerton and Paul Sieveking (New York: Black and Red, 1972).

45

Hakim Bey, TAZ: The Temporary Autonomous Zone: Ontological Anarchy, Poetic Terrorism (New York: Autonomedia, 1985), available online at the Public Netbase to Institute for New Culture Technologies Web site, $<\mathrm{http}: / / \mathrm{www} . t 0 . o r . a t / h a k i m b e y / t a z / t a z . h t m>$, May 2003.

${ }^{46}$ Kevin Hetherington, Expressions of Identity: Space, Performance, Politics (London: Sage Publications, 1998).

47

Mikhail M. Bakhtin, Rabelais and His World (1965), tr. Hélène Iswolsky (Bloomington: Indiana

University Press, 1984).

48

Ibid., 89, 10.

${ }^{49}$ Victor Turner, The Ritual Process (Chicago: Aldine, 1969), 138-140. 


\title{
CHAPTER ONE
}

\section{"Don't hate the media! Become the media!": Photography and the Framing of Resistance}

\author{
More than any other textual system, the photograph presents itself as \\ "an offer you can't refuse."
}

\author{
Victor Burgin, "Looking at Photographs"1 \\ Media is their fire, but we can steal it, and use it. \\ Eric Galatas, "Pixel Visions",
}

Demonstrations staged during the April 2001 Summit of the Americas in Quebec City were framed by the mainstream press as an occasion for violence and hooliganism long before the first protester entered the confines of this fortified city. In the days and weeks immediately preceding the summit, the possibility that protests against the proposed Free Trade Area of the Americas (FTAA) would become violent was emphasized by political leaders and police spokespersons, and widely reported in the press. Indeed, the decision to erect a concrete and chain-link fence surrounding a nine-square-kilometre area of Quebec City was justified on the basis that violence was not only possible, but likely, to occur.

The expectation that protests would turn violent was based on the pattern of confrontations between protesters and police forces at previous global summits in Vancouver (1997), Seattle (1999), and Prague (2000), and on the need to protect the leaders of the thirty-four nations who would be attending the weekend meetings. ${ }^{4}$ Demonstrations against corporate hegemony over global governance were beginning, 
according to many, to follow a predictable script involving pitched street battles between baton-wielding riot police and rock-wielding protesters.

The extent to which the mainstream media bears responsibility for overemphasizing and sensationalizing the scale of confrontations at the expense of "balanced" coverage of demonstrations against corporate globalization has been explored by several media analysts, all of whom conclude that mainstream media tends to frame the global justice movement as a series of shocking confrontational actions without ideological coherence, context, or ethical grounding. ${ }^{5}$ In this chapter, I discuss the role that press photography plays in this framing process. I investigate the ideological narrative constructed through the selection and contextualization of photographs related to the Quebec City anti-FTAA demonstrations in six major daily Canadian newspapers (the Globe and Mail, Le Devoir [Montreal], the Montreal Gazette, the National Post, the Ottawa Citizen, and the Toronto Star), and discuss the extent to which confrontational imagery was emphasized over images of creative dissent. I then employ the concept of "intersecting gazes" in order to explore the ways in which photographic practice can be subject to, or indeed engage in, resistant readings. I conclude that the "refracted gaze of the other," the gaze cast by activists upon demonstration and anti-demonstration activity, functions as a strategy of both self-reflection and counter-surveillance.

\section{The Photographic Message}

Though written over four decades ago, Roland Barthes's structuralist analysis of news photography continues to provide useful tools for investigating the ways that photography is employed as a maker of meaning in mainstream media. In "The 
Photographic Message," Barthes identifies two means by which the photographic message is relayed. The "denotative message" is a seemingly uncoded descriptor which links the signifier to the signified by virtue of mimetic resemblance. The "connotative message," on the other hand, is described by Barthes as the overlay of secondary messages that convey "the manner in which the society to a certain extent communicates what it thinks of it." Though obscured by the photograph's apparent neutrality, connotative meaning can nonetheless be deduced through the close reading of signifying codes inscribed upon the photographic message. Thus a photograph depicting a young man wearing a balaclava standing in front of a group of police in riot gear will denote simply that what one is viewing is a direct representation of a young man facing a group of police in riot gear. The same photograph, as I demonstrate below, will connote any number of messages depending upon the context in which it is presented and the codes inscribed within it.

Connotative messages exist in all forms of visual culture, but in the case of photography they tend to be obscured by the medium's overdetermined status as a purely neutral denotative signifier. ${ }^{9}$ Thus a fundamental connotation of every photograph is that it is, in Barthes words, "a message without a code." photography, and in particular press photography, whose denotative authority is relied upon to legitimate the recording and reporting of "reality."

Barthes identifies six procedures through which connotative codes are inscribed upon the photographic message: trick effects, subjects' pose, the placement of objects within the frame, photogenia (technical effects such as lighting and exposure), aestheticism, and syntax or photo sequencing. Each of these procedures functions to transform the photograph from a "natural" to a "cultural" representation. Connotative 
signification, in other words, introduces and presumes cultural values within the photographic message.

In his 1972 reading of photojournalism, "The Determination of Newsphotographs," Stuart Hall expands on Barthes' inventory of connotative messages. ${ }^{11}$ Inscribed upon the "formal-denotative" level of signification is a "signifying chain" comprised of seven levels of connotation. Compositional codes involve choices regarding point-of-view and proximity to subject, and expressive codes use culturally legible facial expressions to impose adjectival qualities on a subject. News production codes privilege the subject with apparent news value, and integration of the photograph—related to Barthes's notion of syntax-serves to rank, class, and contextualize the photograph. Hall coalesces Barthes's "trick effects" and "photogenia" into the category of manipulations, including such techniques as cropping and enlargement. Both Hall and Barthes also acknowledge the symbiotic relationship that emerges when the photographic message is combined with language. Whereas Barthes emphasizes that the proximity of a photograph to a verbal message endows that (parasitic) message with spillover denotative value, ${ }^{12}$ Hall notes that captions and headlines adjacent to news photographs can also wield "a repressive force over the relative freedom of the signifieds of the photo."13

According to Hall, specific ideological messages are projected through the connotative codes embedded in press photography. While he acknowledges a degree of reader agency in the recognition that such codes are rarely able to produce stable meanings, Hall argues that they do nevertheless "tend to delimit meaning within a preferred range or horizon." ${ }^{\text {14 }}$ Hall concludes that three options exist for "decoding" connoted messages: the reader may inhabit, negotiate, or reject the dominant ideology 
expressed by the code. ${ }^{15}$ This semiotic reading of photographic messages has since been critiqued for its privileging of structure over the complex processes of ideological signification, ${ }^{16}$ and for its weak acknowledgement of the myriad meanings that photographs may contain (if unintentionally) and the unlimited ways in which viewers demonstrate critical agency when reading them. ${ }^{17}$ More recent investigations into the gaze, which will be the focus of the second half of this chapter, have attempted to address these issues in a less deterministic manner. Nevertheless, the structuralist analyses of Barthes and Hall are valuable insofar as they provide a framework for reading the dominant messages embedded in news photography. As such, they will be applied here in the "reading" of photographic representations of the Quebec City demonstrations in six daily Canadian newspapers.

It is a common misconception that the media reports news. Rather, the press engages in something more akin to news making in the selection of stories to cover and angles of coverage. The process of news making, also referred to as "selection bias," is contingent on a number of value-based judgements, from perceived public interest, to time and space allocation, to a news organization's specific ideological agenda. The role of photography in contributing to and concealing selection bias is significant. As Barthes points out, the ostensible neutrality of photography renders the "parasitic" text accompanying it equally unbiased: "...caught as it were in the iconographic message, the verbal message seems to share in its objectivity; the connotation of language is 'innocented' through the photograph's denotation." ${ }^{319}$ But photographs never merely record news; rather, through the selection process, they contribute to the construction of a narrative that is then presented as news reportage. As literary theorist Clive Scott puts it 
succinctly, "The...photograph is a record not of reality but of a set of judgements made in front of reality. ${ }^{20}$

A primary level of signification in the making of photographic meaning, then, is that of "news production." According to Hall, it is at this privileged level that the "power of the image can be mobilized for the purpose of articulating 'news values'.,"21 In press coverage of the anti-FTAA demonstrations, what photographs were selected for publication in daily newspapers, and to what effect? As noted above, predictions that the demonstrations would follow the increasingly familiar script of violent protest were prevalent in the days leading to the summit. On Saturday, 21 April 2001, print media demonstrated an almost unanimous allegiance to the equally predictable and familiar "if it bleeds it leads" script of mainstream news coverage. Of the six daily newspapers analyzed, five carried front-page banner headlines related to the first day of anti-FTAA demonstrations, and accompanying the headlines were large-size photographs portraying confrontations between protesters and police.

On the front page of the Globe and Mail under the headline "Fortress Quebec is breached," a photograph depicts a young man in handcuffs, flanked by helmeted police officers, screaming in apparent agony as blood spills from a wound to his forehead (fig. 1.1). ${ }^{22}$ The front page of the Toronto Star features a group of protesters described as members of the "shadowy anarchist group Black Bloc" in an altercation with riot police. The Montreal Gazette, Le Devoir, and the Ottawa Citizen likewise carry front-page photographs in which lines of riot police figure prominently (figs. $1.2,1.3,1.4$ ). In all cases, scenes of violent confrontation are selected over images of People's Summit symposia, Carnival Against Capital teach-ins, marches and parades, and the myriad 
performances that will be discussed in the following chapters. This privileging of confrontation extends to the inside of the newspapers. A quantitative analysis of all photographs related to the summit and counter-summit demonstrations in the weekend and Monday newspapers reveals that a significant majority are devoted to scenes of conflict. ${ }^{23}$

The National Post's front-page coverage diverges significantly from the "norm." Beneath the headline "Bush vows "hemisphere of liberty" is a photograph of Canadian Prime Minister Jean Chrétien and U.S. President George W. Bush smiling for photographers at a press conference. A secondary article covers the demonstrations with the headline "Chrétien lashes out at protesters after anarchists skirmish with police at fence," but is not illustrated. The absence of "skirmish" imagery seems uncharacteristic, but is clarified implicitly in the headline of a front-page opinion piece by columnist Andrew Coyne, which reads, "It's a summit, not an abyss: CBC wallows in hours and hours of hooliganism." This reference to CBC Newsworld's around-the-clock coverage of the weekend demonstrations appears to articulate the National Post's refusal to participate in the spectacle of conflict in which its competitors engaged. This repudiation, however, does not extend to the inside pages of the National Post's weekend coverage. Like the Globe and Mail, Le Devoir, the Montreal Gazette, the Ottawa Citizen, and the Toronto Star, the National Post devotes the majority of its photographic representations of summit events to scenes of conflict and confrontation. ${ }^{24}$

The front-page photographs in the Gazette, Le Devoir, and the Citizen are remarkably similar in composition. In each, the frame is dominated by a sea of helmets, batons, and shields bearing police insignias. On the extreme left of the Ottawa Citizen and Le Devoir photographs, two demonstrators face the line of riot police with hands raised in 
a sign of peace or victory. ${ }^{25}$ In the Montreal Gazette version, two protesters are pushed to the ground by advancing troops. In all three cases, historical references are implicit. The scene invokes a classic David and Goliath confrontation, harbouring references-whether intentional or not-to an iconic photograph depicting an anti-Vietnam War protester facing a line of National Guardsmen at the Pentagon in Washington, D.C., to plant a flower in a rifle, and more recently the photograph of a lone Beijing man standing in the path of an approaching line of tanks during China's 1989 Tiananmen Square stand-off.

The very predictability of the selection of photographs with familiar images of confrontation or violence is itself an indication of the ideological codes inherent in the selection process, for it emphasizes not only the media's tendency to highlight violence, but the ostensible predictability of violence itself. Not only do the newspapers produce a discourse in which confrontation is privileged with significant news-value, but by selecting recognizable, indeed archetypal compositions to illustrate protest activity, the media also constructs a narrative in which global or hemispheric summits are inevitably linked to protests, which are inevitably linked to violence. This sense of inevitability, produced by front-page photographs that call to mind a host of prior demonstrations and reiterated by an almost fetishistic recurrence of such imagery inside the papers, serves two obvious purposes. First, the media is vindicated for its pre-summit predictions of violence. Second, the demonstrations in their entirety are characterized by the actions of what the press tends to refer to, without apparent irony, as the "handful of troublemakers" who, nonetheless, receive more than a handful of coverage. ${ }^{26}$

At another connotative level, the suggestion that public demonstrations transform inevitably into violent conflict can be understood as an ideological lever with which 
photographs "interpellate" the viewer. Interpellation, as theorized by Louis Althusser, is a process of normalization in which the viewer is called upon to recognize, and therefore become complicit in, the construction of an ideological discourse through identification or familiarity with the subject matter. ${ }^{27}$ In the photographs discussed above, the use and repetition of familiar images of stand-offs and confrontations between protesters and riot police interpellates the viewer as neutral witness to a spectacle of ostensibly normal (though implicitly deviant) protest behaviour.

Yet there is clearly an element of horror embedded within this narrative of inevitability and normalcy. The repetition of images of armed stand-offs, clashes, and arrests is certainly striking, and can be assumed to provoke fear and revulsion in the interpellated viewer, no doubt unaccustomed to battle scenes in a Canadian context. Indeed, it is this tense dichotomy of shock and familiarity that renders such images compelling. As media analyst Peter D. Moss argues, images of violent conflict create "an elaborate spectacle that both wounds (in the selection of varieties of threat stories) and heals (by the encompassing of all stories within a predictable, and therefore reassuring, repetitive structure). ${ }^{, 28}$ Much like a fetish or stereotype, interpellation can function to simultaneously familiarize and distance the viewing subject and the photographed object. ${ }^{29}$ This effect is produced by a process in which the referent is transformed into an archetype or symbol. As John Tagg argues, the ideological narrative embedded within a photographic representation is concealed by its reduction to the "archetypal level of the natural and universal. ${ }^{, 30}$

An investigation of the connotative codes of composition reveals how this process is effected. In the front-page photographs discussed above, and indeed in the majority of 
photographs published in relation to the summit demonstrations, protesters are depicted either alone or in groups of two or three. One example is a photograph in the Monday, 23 April 2001 issue of the Globe and Mail (fig. 1.5) in which a protester, in the foreground, prepares to use a hockey stick to shoot an exploded tear-gas canister toward a line of police in riot gear depicted in the background. The effect of this composition, and that of another photograph on the same page (of a naked protester defying a spray of water from a cannon), is paradoxical. On one hand, the portrayal of one demonstrator against a line of riot police serves to personalize and humanize the protester, while simultaneously dehumanizing the phalanx of police officers, who appear distant and menacing. On the other hand, the selection of an image of a single actor, engaged in a transgressive action, serves to isolate the activist from the movement. (The effect would be markedly different, for instance, had the newspaper's editors selected a photograph of a Raging Granny singing to a line of riot police, and the difference would be even more emphatic if the photograph depicted twenty Raging Grannies singing to a line of riot police.)

The emphasis on individual protesters can function to marginalize their actions by suggesting, as Smith, McCarthy, and McPhail note, "individual responsibility rather than social systemic causes of a problem" in such a way as to "encourage shallow understandings of these issues and discourage the critical engagement of audiences." ${ }^{31}$ Thus the "handful of troublemakers," whose actions are foregrounded by the newspaper's editors, are simultaneously divested of both agency and contextual significance as they are transformed into symbols of violence and transgression, objects of quasi-fetishistic fascination and repulsion.

Yet the composition of such photographs also functions to isolate, homogenize, and 
"other" the ubiquitous riot police. To a degree, this process is rendered unavoidable by the police uniforms, which conceal the officers' faces and bodies under helmets, masks, padded clothing, and shields. ${ }^{32}$ But the media's fascination with these officers is unmistakable. Of the one hundred thirty photographs analyzed in Appendix B, forty-three depict police in full riot gear. Initially, it seems unlikely that police forces would be subject to the same dehumanizing coverage as the protesters. Indeed, as I will discuss further, the captions accompanying such illustrations tend overwhelmingly to divorce the police presence from violent activity at the demonstrations. The photographs, however, offer a different perspective. The repetitive imagery of police in full riot gear, carrying batons and shields, is both tantalizing and fearsome, and produces a similarly alienating effect.

The extent to which this effect was intentional is impossible to discern; as Victor Burgin observes, "still photographs are texts built upon coincidences." However, the fetishistic fascination of the mass media with the police presence signals an inclination to implicate the police in the same process of "wounding" (by depicting Quebec City as a police-state) and "healing" (by reassuring the audience that the situation is "under control"). It also produces a scenario in which the demonstrators and riot police confront each other on a "battlefield" far removed from the official summit. This narrative construction, which in a sense employs the police as scapegoats or stand-ins for what might otherwise be perceived as state repression, also renders it easier for the press to engage in episodic, as opposed to thematic, coverage. ${ }^{34}$ By emphasizing war-like battle scenes with easily identified opponents, the press succeeds in constructing an event without a context. The battles are so far removed from the official summit, ${ }^{35}$ and from any indication that there are issues underlying the conflict, that there is no apparent need to 
explain or analyze the themes surrounding the episode.

Indeed, it is this failure to contextualize the dramatic events during the Quebec City demonstrations, rather than the tendency to emphasize confrontational activity, that best reveals mainstream media's problematic coverage of the events. The press, it must be acknowledged, does not invent conflict and confrontation as elements of a mass demonstration. In fact, as I will argue in chapter three, the introduction of conflict into the public sphere is perceived in the global justice movement as a crucial strategy for constructing spaces of radical democracy. When, however, conflict is covered in the mainstream media without adequate indications of the political and ideological motives behind it, such events are reduced to scenes of aimless violence, devoid of logic and coherence.

This narrative of aimless violence furthermore restricts responsibility for conflict to the demonstrators. The photographs selected for publication tend overwhelmingly to present the riot police as passive and immobile in response to aggressive or provocative protester action. For instance, of the eighty-one photographs in Appendix B identified as confrontational, three show demonstrators throwing or preparing to throw tear-gas canisters at police. In no photographs are police depicted firing tear gas, in stark contradiction to the fact that police fired 4,709 canisters of tear gas during the weekend demonstrations. ${ }^{36}$

Another compositional code that imbues photographs with connotative meaning involves angle or point-of-view. This code is rich with interpellative value, for it may be assumed that the point-of-view of the photographer is intended to function as the point-ofview of the viewing subject. A photograph in the Montreal Gazette on Sunday, 22 April 
2001 depicts a young protester, with a scarf covering his face, looking intently through the perimeter fence (fig. 1.6). The photograph is taken from the "secure" side of the perimeter, the fence acting in the frame as both frontispiece and barrier. Shot at eye level, the photograph can be understood to interpellate the viewer as an active target of protesters' hostilities. Likewise, a photograph on the same page of the Gazette portrays a demonstrator throwing a tear-gas canister. The photograph, which appears to have been shot from immediately in front of the subject, places the viewer directly in the line of fire, again constructing a direct confrontation between the protester and the viewing audience.

However, no discernible pattern was identified in the photographs analyzed, which were taken from a variety of angles, distances, and points-of-view. Indeed, the restlessness of the media's gaze, which produces an omniscient point-of-view for the viewing subject, itself reveals a level of connotative meaning. An investigation of the syntax or concatenation of photographs in two photo-stories demonstrates how this effect is achieved. On Monday, 23 April 2001, both the Montreal Gazette (fig. 1.5) and the Globe and Mail (fig. 1.7) produced two-page-spread photo-stories in relation to the summit. The Gazette photo-story contains ten photographs. Of the two that depict official summit activity, one portrays U.S. President George W. Bush waving to photographers outside Quebec City's Ursuline Chapel, and the other shows the wife of Canadian Prime Minister Jean Chrétien, Aline Chrétien, with Lourdes de Flores, wife of Salvadoran President Francisco Flores. These photographs, in the top centre field of the photo spread, suggest a calmness and serenity-legitimated by the statue of the convent's founder, Marie de 1'Incarnation, rising from behind the U.S. President - that is disrupted on all sides by scenes of chaos and conflict. Seven of the photographs depict scenes from the protests, 
including an image of two police officers pinning a demonstrator to the ground and a familiar representation of a lone protester facing a line of police in riot gear. The largest photograph in the spread is the newspaper's single representation of the People's March which, despite its size, is marginalized both by the scenes of disruption around it and by the bird's-eye view, which renders it distant and insignificant.

As Barthes points out, every photograph can be mapped for connotative messages. Photographs take on added meaning, however, when they are grouped in a sequence: "The signifier of connotation is then no longer to be found at the level of any one of the fragments of the sequence but at that-what the linguists would call the suprasegmental level—of the concatenation." ${ }^{37}$ At this suprasegmental level, the Montreal Gazette photostory reveals at least two connotative messages. First, the official, legitimate summit process is surrounded by violent and confrontational protest activity, which threatens to disrupt the enclosure of civility in which it is framed. But the photo-story serves another function. The roving eye of the cameras captures these ten scenes from such a great variety of angles and perspectives as to suggest that the images, together, represent the "whole story." By virtue of photography's status as what W.J.T. Mitchell terms a "transparent window onto reality," the photo-story sets out to embody "a socially authorized and credible 'eyewitness perspective'.,"38 The interpellated viewer is thus presented with a seemingly omniscient view of the summit, and reassured that everything worth seeing and understanding has been captured, coalesced and contained in two pages of photographs. This reassurance is pivotal to the construction and management of fear and repulsion in which conflict images traffic. The "wound" is the publication of scenes of direct confrontation and violence. The "healing" is the containment of these scenes in a tightly 
wrapped package of knowledge, and thus closure.

The Globe and Mail photo-story is similarly reassuring, though the tactics of reassurance diverge considerably. The story is composed of nine photographs. The largest, which portrays an activist preparing to shoot a tear-gas canister at a line of riot police, is one of four that depict scenes of conflict or conflict-reaction. Four photographs show official summit delegates, and the ninth photograph depicts police officers at rest. The difference in tone between protest and official summit photographs is striking. In each of the protest depictions, the subject is alone or facing one or more police officers. Facial expressions are either pained or concealed. Each of the official summit photographs, instead, portrays the subjects in groups of two or three, usually smiling, and in two cases shaking hands. The acute contrast between individual acts of resistance and group acts of solidarity and goodwill is sharpened by the layout of the photo-story. Notwithstanding the photo-story's headline, "Breaking the Barriers," the protest photographs are arranged on the left page and the official summit photographs on the right, suggesting a more explicit division between fear and reassurance, or "wounding" and "healing."

The degree to which the weekend's demonstrations are framed by the mass media as disruptive, chaotic, and ideologically incoherent is heightened by the use of headlines and captions. An analysis of these textual accompaniments reveals an overwhelming tendency to portray the demonstrators as anonymous but active agents of confrontational activity, and the police as passive witnesses to violence. As Clive Scott reminds us, photographs can be remarkably pliant signifiers, susceptible to myriad readings. Language, he argues, "exploits the photograph, puts it to any number of ideological uses, calls upon it as evidence in many different kinds of cause. ${ }^{, 39}$ Caroline Brothers, writing about war 
photography, likewise contends that although an image rarely if ever contains a single message, captions and annotations serve to "direct, if they cannot dictate, how an image is to be understood. ${ }^{40}$ Indeed no photograph is framed so tightly that it is impermeable to the imposition or seepage of meaning through intertextual interaction, whether by the concatenation of images as discussed above or by the proximity of verbal pointers and descriptors in the form of captions and headlines.

An analysis of the captions and headlines accompanying photographs related to the anti-FTAA demonstrations in the Globe and Mail, Le Devoir, the Montreal Gazette, the National Post, the Ottawa Citizen, and the Toronto Star reveals a number of ways in which language serves to codify dominant photographic messages within specific linguistic structures. The first noticeable trend is the inequitable way in which protagonists are named. Of forty photograph captions that refer to one or more demonstrators, none reveal the subjects' names or affiliations. This is in sharp contrast to the treatment of photographic representations of official summit participants, who are invariably referred to by name, status, and country of origin. The failure to nominalize demonstration participants conveys an absence (or rather a deletion) of subjective agency, and contributes to a mechanistic, archetypal representation of protesters that alienates their actions from ideological, ethical, and geographical contexts. Imagine, for instance, the substitution of this characteristic caption, "A defiant protester stands his ground as police mass on Grand Allée Friday,", with the following fictitious one: "Hugo Sanchez of Venezuela's 'Justice Alliance' stands his ground." It might be argued that the chaotic, highly charged and often dangerous context of the demonstrations rendered it difficult, if not impossible, for photojournalists to compile the names of their subjects. However, there are many 
protagonists in the global justice movement-_Jaggi Singh of Montreal's CLAC, Maude Barlow of the Council of Canadians, and Judy Rebick of Rabble.ca to name just a fewwhose names and faces are well known, and who participated actively in the Quebec City protests. Their absence from photographic representations of the demonstrations suggests an inclination, if not an intention, to portray demonstrators as nameless actors without coherent political objectives, and without social context.

The deletion of subjective agency resulting from the characterization of demonstrators as anonymous, aimless archetypes is contradicted by the captions' use of verbs to constitute protesters as active agents in the conflict. Stuart Hall writes that newspaper captions tend to present events using the non-progressive present tense, which he describes as the "historic instantaneous." is converted into 'today,' cashable and explicable in terms of the immediate. In the same moment, all history is mythified - it undergoes an instantaneous mythification." ${ }^{43}$ The simple present tense is both timeless and contemporary. Simultaneously, it interpellates the viewer into the "here and now" of the action, and creates a sense that the scene is both inevitable and infinitely repeatable. It also confers agency onto the subject, who is "activized" by the verb. The headlines and captions in proximity to newspaper photographs were coded for the presence of verbs and discovered that indeed, the simple present tense is employed in the majority of headlines and captions. ${ }^{44}$ Interestingly, in forty-one sentences the simple present tense is used to describe protesters' actions, as for instance in a Globe and Mail photograph caption that reads: "Protesters topple fence at summit." Police action, rather, is described in the simple present tense a total of seven times. The inordinate stress placed on demonstrators as active agents of the events portrayed conveys 
the idea that the demonstrators are unilaterally responsible for the confrontations emphasized in the photographic coverage.

This assignment of active responsibility to demonstrators, and the concurrent representation of police forces as passive witnesses, extends to the use of police weaponry. Appendix $\mathrm{C}$ lists all references to tear gas, plastic bullets, and water cannons, the weapons authorized for use by the more than 6,000 police officers present at the demonstrations. Of the thirty-six references, police are assigned an active role in their deployment a total of eight times, as for example in the headline, "Police break in water cannons." made on six occasions to protesters' deployment of police weapons, for example, "A demonstrator lobs a tear-gas canister back at police yesterday." ${ }^{47}$ This belies the fact that, as mentioned above, 4,709 canisters of tear gas were fired by the RCMP and Sûreté du Québec during the weekend, and the unlikelihood that demonstrators, without tear-gas launchers, were capable of a correspondingly liberal deployment. Instead, demonstrators and police are rendered almost equally responsible for the use of such weaponry.

While the presence of tear gas and water cannons is mentioned repeatedly in captions and headlines, their presence is most often described in terms that dissociate them from police action. Often, tear gas appears to materialize as if spontaneously, as in this caption from the Toronto Star: "Amid the tear gas, the skirl of the pipes: A gas-masked bagpiper plays his way through blasting water cannon spray and tear gas." ${ }^{48}$ Also notable is the frequent occurrence of captions and headlines that refer to police weapons in relation to demonstrators, but not police, for example, "Tear-gassed activists defiant." situations in which demonstrators respond to police action, it is the actions of the demonstrators, not the police, which are emphasized. 
As Barthes notes, the text accompanying a press photograph "produces (invents) an entirely new signified which is retroactively projected into the image, so much as to appear denoted there." ${ }^{50}$ Such textual accompaniment can imbue otherwise ambivalent photographs with descriptive bias (as when water cannons are deemed to respond to protester action), and conversely it can create ambivalence in otherwise straightforward messages (as when tear gas is described as a spontaneous condition, rather than a policedeployed weapon). In the captions and headlines in proximity to photographic representations of the Quebec City demonstrations, the overwhelming tendency is to emphasize the violence alluded to in the images, and to divorce these images from any substantive context.

Thus do the connotative codes such as photograph selection, syntactic concatenation, and language bias imbue the seemingly neutral photographic representations of the Quebec City anti-FTAA demonstrations with culturally and ideologically inflected messages. However, despite its status as an objective signifier of reality, and despite its susceptibility to the imposition of connotative messages, photography is a remarkably contingent and flexible apparatus. As Clive Scott notes, photography is "artful in its evasions and slippages." The photograph, he argues, is inherently unpredictable: “Apparently one hundred percent evidence, the photograph never, finally, gives itself away. ${ }^{, 51}$ It is this flexibility and unpredictability that renders photography as susceptible to resistant readings as it is to the decoding of dominant messages. 


\section{The Photographic Gaze}

In an early critique of structuralist approaches to photographic meaning, Victor Burgin argues that theoretical methodology must attend not only to that which is "uttered," but also to the "performance of the utterance," and by extension the performance of reception. ${ }^{52}$ Burgin concludes that the photograph, which "presents itself as 'an offer you can't refuse'," can nevertheless be subjected to critical reading by privileging what he terms the "photographic discourse" over the photographic message. ${ }^{53}$ One of the more useful frameworks to emerge in this context has been that surrounding the gaze, a critical term stemming from Lacanian psychoanalytic theory ${ }^{54}$ that has been employed in anthropological, film, and art historical discourses to interrogate the power dynamics associated with looking. Much of this work has drawn on Laura Mulvey's approach to the male gaze in mainstream cinema, which posits the spectatorial position as one imbued with the power of the (male) gazing subject over the (female) object of the gaze. John Berger's configuration of male-female looking relations, "Men look at women. Women watch themselves being looked at," functions as a gendered apparatus of ocular agency.

Though useful in this respect, these theories have been critiqued for their tendency to disregard other, non-gendered relationships of scopic power. In post-colonial discourse, for instance, the gaze has been employed as a tool with which to investigate the "colonial gaze" as an apparatus of oppression. ${ }^{57}$ In art historical discourse, Norman Bryson has explored how vision is "formed by paths or networks laid down in advance of my seeing. ${ }^{58}$ By attending to the discursive systems underlying the act of looking, Bryson reveals how "power disguises and conceals its operations in visuality, in myths of pure 
form, pure perception, and culturally universal vision." ${ }^{59}$ What these theories contribute to photographic discourse is the notion that the gaze is never inaugural, and never disconnected from power relations. They are, however, less useful in providing strategies for employing the gaze as a lever to contest, resist, or disrupt these power relations.

In their 1994 analysis of ethnographic photography, Reading National Geographic, anthropologist Catherine A. Lutz and sociologist Jane L. Collins develop a theory of the gaze that draws upon, but diverges significantly from, the model proposed by Mulvey and Berger. While Lutz and Collins acknowledge that the spectator position can be a powerful one, they seek to uncover "a route by which the photograph threatens to break frame and reveal its social context. ${ }^{, 60}$ The authors propose that rather than one steady, predetermined gaze that inscribes and reinforces power relations, seven gazes operate within (and without) the picture frame. These gazes are: the photographer's gaze; the institutional (magazine) gaze; the reader's gaze; the non-Western subject's gaze; the direct Western gaze; the reflected gaze of the non-Western subject; and the academic spectator's gaze. ${ }^{61}$ Their complex intersections allow for the negotiation of identities and the interplay of subject-object relations. It is here, in the intersection of gazes, that the photograph's ambiguity is most fruitfully explored.

The photographer's gaze and the institutional gaze are the first discussed by Lutz and Collins. The photographer frames the image, chooses a point-of-view, and constructs a narrative through the lens of the camera. The institution (in the cases above, six news agencies, each with their own social and ideological perspectives) selects the images to be published and creates a context for them by choosing their size, layout, and position vis-àvis headlines, articles, and advertisements. These gazes, privileged in the above readings of 
photographic representations of the Quebec City anti-FTAA demonstrations, present the viewer with coded messages as to how the photographs are intended to be read, and as such are instructive in seeking to understand the ideological perspectives through which the photographs are mediated. But upon these gazes are inscribed those of a multitude of other actors, both within and without the frame of the photograph, whose own gazes mediate, interact with, and sometimes disrupt the "official" gaze.

In the context of newspaper images of the Quebec City demonstrations, the activist's gaze can be particularly disruptive. In the above-discussed Montreal Gazette close-up photograph of a demonstrator peering through the perimeter fence into the lens of the photographer's camera (fig. 1.6), the subject's gaze is direct and unwavering. Lutz and Collins posit that the direct gaze of the "other" within the photographic frame (in this case the status of "other" is connoted by the man's position on the "other" side of the fence, his partially obscured face, and the caption which names him only as "a protester") can be interpreted in a variety of ways. While the newspaper's intention might be to position him as a dangerous, confrontational actor, trapped and contained by the chain-link fence and the camera's lens, the subject's close piercing gaze can also be read as a resolute expression of agency and resistance, as an appeal directed at the viewer to identify vicariously with the demonstrations, or, perhaps most subversively, as a counter-surveillant gaze that informs the audience that they, too, are being watched. Of course how this subject's gaze is to be read is dependent on its intersection with the reader's gaze which, Lutz and Collins emphasize, is never universal, for "each individual looks with his or her own personal, cultural, and political background or set of interests. "62 To acknowledge the agency of the reader is also to acknowledge that the process of interpellation, or the 
imposition of the institutional gaze upon the reader, always intersects with and risks being disrupted by the reader's own gaze.

In order to implicate their own position as viewers of photographic representations, Lutz and Collins identify the academic spectator's gaze, a subset of the reader's gaze, as one whose aim is "to make the pictures tell a different story than they were originally meant to tell, one about their makers and readers rather than their subjects. ${ }^{, 63}$ Indeed, my own academic gaze has acted as an implicit mediating device throughout this chapter, and has been inflected with theoretical methodologies through which I have attempted to read press photographs not as objective signifiers of events, but rather as elements of ideologically and culturally inscribed media discourses. Likewise, your own academic gaze as a reader of this thesis will intersect with the multitude of gazes inside and outside the photographic frames to form yet another stratum of meaning.

The academic gaze with which I have been "reading" photographic representations of the anti-FTAA demonstrations is itself complicated by my role as a participant in the demonstrations, and as a photographer whose own camera provided a lens through which to observe them. Thus even at an individual level, there can exist a multitude of gazes--in my case the photographer's gaze, the academic gaze, and what Lutz and Collins refer to as the "refracted gaze of the other" — which themselves intersect with and, in so doing, disturb the ostensible stability of the viewing subject.

Lutz and Collins use the term "refracted gaze" to describe National Geographic photographs in which a non-Western subject is photographed holding a camera or mirror. Though the authors conclude that the refraction effect is ultimately pacifying in that it takes "the distance between Western viewer and non-Western subject one step farther,", 
they also concede that a camera in the hands of the "other" is a potentially unsettling acknowledgement of the viewed "object" returning the gaze of the viewing "subject." Not strictly in keeping with the authors' employment of the term to discuss the appearance of cameras in ethnographic photographs, the notion of the refracted gaze as a tool of "selfreflection and surveillance" ${ }^{, 66}$ is nonetheless a useful framework for analyzing activists' use of cameras during the anti-FTAA demonstrations in Quebec City.

I was one of hundreds of demonstrators who carried still and video cameras during the weekend demonstrations. ${ }^{67}$ Indeed, in numerous "field-guides" and activist manuals disseminated prior to the summit, demonstrators planning to attend the protests were strongly encouraged to carry cameras and video equipment. ${ }^{68}$ This resolve to document the demonstrations from an activist perspective is part of a larger media activism movement that has burgeoned in the past five years. ${ }^{69}$ One of the most notable factors of this phenomenon has been the emergence of Independent Media Centres (IndyMedia), a coalition of alternative media outlets that now comprises one hundred and fifteen independent, but interconnected, Web sites worldwide. ${ }^{70}$

The popularity of contemporary media activism has been attributed to a growing distrust of mainstream news coverage of the global justice movement, based on the perception that mainstream media lacks both depth of content and democratic access to news production. IndyMedia's motto, "Don't hate the media. Become the media!", is indicative of this distrust, and of the conviction that news production can and should be democratically accessible. The intent is not to provide "unbiased" coverage, but rather to acknowledge bias in all media, and to provide news sources that give access to a greater variety of perspectives. One of the underlying goals of media activism is to create a space 
for self-reflection that will mitigate the gaze of mainstream media.

This goal, to document or bear witness to the events surrounding the Quebec City summit, underlies the photographic practice of the many activists who attended the demonstrations armed with cameras and video equipment. Toronto photographer Rob Breadner and Montreal activist Graeme Bacque, for example, both attended the Quebec City demonstrations with the intention of participating in the protests and documenting the events. $^{71}$ The photographs taken and published online by Breadner and Bacque demonstrate that the refracted activist's gaze points in two directions: as a self-reflexive gaze directed toward the demonstrations, and as a gaze of counter-surveillance directed at both mainstream media and the police.

Notions of the gaze as an apparatus of power relations are heavily indebted to Michel Foucault's theory of the nineteenth-century emergence of a society of surveillance. In his 1975 Discipline and Punish: The Birth of the Prison, Foucault discusses the panopticon, developed as a surveillance system by eighteenth-century prison-reform advocate Jeremy Bentham, as a model for modern society's use of visibility as a disciplinary apparatus. ${ }^{72}$ According to Foucault, photography is implicated in this disciplinary process by promoting "the normalizing gaze, a surveillance that makes it possible to qualify, to classify, and to punish. It establishes over individuals a visibility through which one differentiates and judges them." The surveillance of protesters' activities during the Quebec City summit was enacted at two levels: by the police, who photographed and videotaped activists throughout the weekend; ${ }^{74}$ and by the media, whose ubiquitous presence was noted by several observers, and which was itself the target of vandalism. A photograph by Graeme Bacque, which depicts a graffiti-covered CanWest 
Global television news van (fig. 1.8) with the caption "The KKKorporate media gets a rough ride at this event!" indicates both the extent to which many activists perceive the media's spectacularizing gaze as inimical to the objectives of political protest, and Bracque's intention to counter that gaze.

Foucault is emphatic in his rejection of the notion that modern society is premised on the spectacle: "Our society is not one of spectacle but of surveillance.... We are neither in the amphitheatre nor on the stage but in the Panoptic machine." ${ }^{.75}$ What Foucault could not have predicted when he made this statement in 1975 was a contemporary convergence of spectacle and surveillance, manifested most notably in "reality television" and "madefor-television" wars, which renders his binary construction problematic. Indeed, it is on the amphitheatre of the spectacle that the "Panoptic machine" operates most obliquely—ours has arguably become a society in which the hegemony of the spectacle has normalized the panoptic gaze that accompanies it. If the overarching function of the "society of the spectacle" is to transform citizens into passive consumers of dominant messages, that of the "society of surveillance" is to trap them under the constant gaze of the panopticon, such that consumption and acquiescence to these messages is guaranteed. As W.J.T. Mitchell notes, a dialectic relationship now exists between spectacle and surveillance, whereby "spectacle is the ideological form of pictorial power" and "surveillance is its bureaucratic, managerial, and disciplinary form." ${ }^{176}$ The result of this dialectic relationship is that citizens, reduced to voyeurs and objects of the gaze, are isolated and alienated from active production of knowledge and meaning, and divested of subjective agency. One of the objectives of contemporary media activism has been to engage in what Thomas Levin describes as "panoptical détournement," 
resist this phenomenon.

A significant trend in media activism has been the development of what theorist and cyber-activist Steve Mann refers to as "sousveillance." ${ }^{, 78}$ Sousveillance, a neologism that substitutes watching from above (surveillance) with watching from below (sousveillance) is a strategy that seeks to trap the watcher in the gaze of the watched. Rob Breadner's photograph of a police officer filming him (fig. 1.9) exemplifies this trope. With the caption, "This officer got as good a shot of my face as I did of his," the photograph is a characteristic example of the "refracted gaze of the other," in which the surveillance gaze of the police intersects with, and in a sense is disarmed by, the sousveillance gaze of the activist-photographer. What Breadner's and Bacque's photographs reveal is how activist photographic practice can subvert the hegemony of the panoptic gaze, and invest photographic practice with counter-surveillant, and selfreflexive, agency.

Many issues surround the self-reflexive gaze of the activist as filtered through the lens of a camera. One significant question is raised by Susan Sontag's claim that photography is "essentially an act of non-intervention." ${ }^{.79}$ To an extent, this contention applies to the activist-photographer. The camera is a physical apparatus that is positioned necessarily between the photographer and the event being photographed. As such, it is not clear whether it is ever possible to fully erase the boundary that separates actor from spectator, and that dissociates the spectator-photographer from full involvement in the act. ${ }^{80}$ It is perhaps this dissociation, inherent in the act of observing and representing acts of resistance, that accounts for the photographers' inclination to emphasize the confrontational aspects of the demonstrations in a manner reminiscent of mainstream 
media's coverage of the events. ${ }^{81}$ This inclination is not unique to the work of Breadner and Bacque. Another characteristic example is the photographic representation of the Quebec City demonstrations on the front cover of the May 2001 issue of Barricada, published by the Boston-based anarchist group Barricada Collective. ${ }^{82}$ This collage (fig. 1.10) consists of twenty-four photographs, all of which depict violent scenes from the protests, and which together form a concatenation of spectacularized conflict that rivals that constructed by mainstream media.

Several factors, however, distinguish Breadner's and Bacque's photographs from those published in the mainstream press. For instance, while the proportion of photographs depicting confrontational activity is similarly high, a notable percentage of the photographs in these collections draw attention to non-confrontational, often festive protest activity. These include photographs of parades, puppets and banners, dancing and drumming on the streets, and corollary activities such as food-preparation and art making. Certainly, the freedom to publish an unlimited quantity of photographs is one not afforded to press agencies. Then, it bears recalling that personal photo albums also construct a subjective and selective narrative that is somewhat obscured by the pretence of exhaustiveness. However, what distinguishes Breadner's and Bacque's photographic practice is their engagement in a self-reflexive acknowledgement of presence and subjectivity. First, both photographers include personal accounts of the demonstrations that make no attempt to conceal political bias. Then, unlike news photographs, in which the photographer's presence is concealed in order to present an ostensibly unobstructed, "objective" view for the reader, the photographs in these collections refer repeatedly to the photographers' presence, and to their active engagement in the demonstrations. A photograph of Breadner, 
taken by a friend, is characteristic in this respect (fig. 1.11). The caption, "Yours truly, taking in drumming at the massive bonfire, late into the evening. It was a bonding experience of many protest-weary warriors," reveals Breadner's desire to remove the seemingly impenetrable barrier between actor and spectator. The employment of first and second person pronouns in the captions, as in Breadner's "No matter how far back you stood, face protection was required," also conveys this intention. The viewer is interpellated not as a passive voyeur of a far-removed spectacle, but as a sympathetic observer. Indeed, the photographs of Bacque and Breadner address an audience that is implicitly constructed as pro-activist, in contrast to the interpellated "neutral" audience of mainstream media.

A conscious effort at self-reflexivity is also revealed in the photographs depicting police officers. As mentioned above, the majority of photographs in the collections refer to confrontations between demonstrators and police. However, they differ significantly from newspaper depictions. Language is one clear marker of self-consciously biased positioning; both Breadner and Bacque refer to police variously as "goons," "stormtroopers," "riot cops," "pigs," and "cowboys," and describe police actions using verbs such as "attack," "fire," "shoot," "beat," and "hit." Interestingly, while newspaper photographs tend to portray large groups of riot police, several of Breadner's and Bacque's photographs are close-up, portrait-like depictions, and in almost all cases the police officer is photographed carrying or shooting a weapon. A photograph by Bacque of a police officer aiming what appears to be a plastic bullet gun directly at the camera (fig. 1.12) reveals several characteristics of both collections. First, there is an inclination to implicate the photographer in the action. The caption to this photograph reads, "This pig shot a 
concussion grenade towards my back as I retreated after taking these pics (Bastard!)." The photograph, and a similar one taken by Breadner with the caption, "This goon tried to hit me a couple times. But I shot him... and this is the picture," also epitomize a tendency in both collections to personalize the police officers--despite, or perhaps in tandem with, the inflammatory name-calling. In sharp contrast to press photographs that tend to dehumanize and distance the police force, these photographs make explicit the fact that behind the masks and shields are men and women, active-and responsible-agents in the violent activities depicted.

Here the notion of sousveillance becomes pivotal. If one of the aims of media activism is to cast an empathetic gaze upon activist activity, another is to cast a critical gaze toward obvious opponents. In this respect, the camera functions as both weapon and tool of self-defence: a weapon, in that it is a strategy of "shooting back"; and self-defence, in that it can document, and sometimes deter, police use of force. ${ }^{83}$ It is also seen as a strategy that reflects and diffuses what is perceived to be an incessant panoptical gaze.

At a concrete level, the photographs in Breadner's and Bacque's collections also reveal that photography, discussed in the first portion of this chapter as a tool for the construction of a narrative that presents mass demonstrations as violent, agent-less, and ideologically incoherent, can also be used to construct productive counter-narratives. While Breadner's and Bacque's photographs are certainly liberal in their depiction of conflict and destruction, they also provide a glimpse into the myriad aspects of the Quebec City demonstrations that were creative and constructive. Examples include photographs of puppets, banners, and performers, all of which contributed to a creative ambience that the mainstream media neglected to depict. ${ }^{84}$ If the objective of these photographers was to bear 
witness to the conflict from an activist perspective, it was also to document this abundance of creative energy. This is also the objective of the next chapter, which will explore the role of art in the conceptualization and performance of collective resistance. 


\section{NOTES}

${ }^{1}$ Victor Burgin, "Looking at Photographs" (1977), in Representation and Photography: A Screen Education Reader, ed. Manuel Alvarado, Edward Buscombe, and Richard Collins (New Hampshire and New York: Palgrave, 2001), 69.

${ }^{2}$ Eric Galatas of Free Speech TV, quoted in Rachel Rinaldo, "Pixel Visions: The Resurgence of Video Activism," Lip Magazine, 7 September 2001, <http://www.lipmagazine.org/articles/featrinaldo_115.shtml>, June 2003.

${ }^{3}$ See Appendix A for a map of Quebec City with the security fence outlined.

${ }^{4}$ RCMP Constable Julie Brongel explained; "If we look at the history of past international summits, there has been a prevalence of violent protest. That is why we've been preparing for over a year for the strategies we will employ to minimize the violence." Quoted in Alexandra Panetta, "Quebec Summit Security will be the Tightest in Canada's History," Canadian Press, 17 February 2001, available online at the Stop the FTAA Web site, <http://www.stopftaa.org/news/news_qcsecurity.html>, June 2003.

5 These include: Jackie Smith, John D. McCarthy, and Clark McPhail, "From Protest to Agenda Building: Description Bias in Media Coverage of Protest Events in Washington, D.C.," Social Forces 79, no. 4 (June 2001): 1397-423; James K. Hertog and Douglas M. McLeod, Anarchists Wreak Havoc in Downtown Minneapolis: A Multi-Level Study of Media Coverage of Radical Protest, Journalism and Mass Communication Monographs, no. 151 (Columbia, S.C.: Association for Education in Journalism and Mass Communication, 1995); and Peter D. Moss, "Conflict and Containment in Television News: A Case Study," in Framing Friction: Media and Social Conflict, ed. Mary S. Mander (Urbana and Chicago: University of Illinois Press, 1999). Though many analysts conclude that television is more likely to sensationalize its coverage than print journalism, press photography plays a significant role.

${ }^{6}$ Quebec City's daily newspaper, Le Soleil, was not selected for analysis due to its lack of availability outside Quebec.

7 The theory of "intersecting gazes," discussed further in this chapter, is developed by Catherine A. Lutz and Jane L. Collins in Reading National Geographic (Chicago and London: University of Chicago Press, 1994).

${ }^{8}$ Roland Barthes, "The Photographic Message" (1961), in Image, Music, Text, tr. Stephen Heath (New York: Hill and Wang, 1977), 17.

${ }^{9}$ This status is ascribed to photography via the assumption that in Piercean terms, photography is a signifier that is both iconic (bearing a resemblance to the signified) and indexical (bearing a physical connection to the signified).

${ }^{10}$ Barthes, "Photographic Message," 19. Emphasis in original.

11 Stuart Hall, "The Determination of Newsphotographs," Working Papers in Cultural Studies 3 (fall 1972): 53-87.

12

Barthes, "Photographic Message," 25-26.

${ }^{13}$ Hall, 60. 
${ }^{14}$ Ibid., 69. Emphasis in original.

15

Ibid., 66.

${ }^{16}$ See Burgin, 68.

${ }^{17}$ In his later publication, Camera Lucida: Reflections on Photography (1980), tr. Richard Howard (New York: Hill and Wang, 1981), 97, Barthes acknowledges that "the reading of public photographs is always, at bottom, a private reading."

${ }^{18}$ See Smith, McCarthy, and McPhail, 1398-99, for a discussion of selection and description bias in relation to coverage of protest movements.

19

Barthes, "Photographic Message," 26.

${ }^{20}$ Clive Scott, The Spoken Image: Photography and Language (London: Reaktion Books, 1999), 33.

${ }^{21}$ Hall, 59.

${ }^{22}$ The photograph, by Ryan Remiorz of the Canadian Press, also appeared in the Montreal Gazette, Saturday, 21 April 2001, A11, and the Toronto Star, Saturday, 21 April 2001, A19.

${ }^{23}$ Sixty percent of all photographs examined depict confrontational scenes. Official Summit of the Americas photographs account for twenty-five percent, and images depicting non-confrontational demonstration activity account for fourteen percent. When photographs of the official Summit of the Americas are removed from the equation and only demonstration photographs are analyzed, the average percentage of photos devoted to confrontational images of the demonstrations is eighty-two percent, and that devoted to nonconfrontational images is eighteen percent. For a breakdown of data and an explanation of the coding of confrontational and non-confrontational imagery, see Appendix B.

${ }^{24}$ Of fifteen photographs in the National Post, forty-seven percent portray scenes of violence, while forty percent depict political leaders at the official summit. Thirteen percent depict non-confrontational demonstration activity. See Appendix B.

${ }^{25}$ Though the photographs in the Ottawa Citizen and Le Devoir were taken by separate photographers (Julie Oliver and Jacques Madeau respectively), it is possible, and perhaps even likely given the resemblance of the protester depicted in both photographs, that the scene is the same.

26

${ }^{26}$ The headline of Mark Steyn's column in the National Post on Saturday, 21 April 2001, A7, reflects the prevailing attitude: "A small number of protesters are violent...the rest are idiots."

${ }^{27}$ Louis Althusser, "Ideology and Ideological State Apparatuses (Notes Toward an Investigation) (1970)," in Lenin and Philosophy, and Other Essays, tr. Ben Brewster (New York: Monthly Review Press, 1971), 172174.

${ }^{28}$ Moss, 163. 
${ }^{29}$ In his essay "The Other Question: Stereotypes, Discrimination, and the Discourse of Colonialism," in The Location of Culture (New York and London: Routledge, 1994), 67, Homi K. Bhabha theorizes the stereotype as an ambivalent and anxious form of representation that relies upon fetishistic repetition to construct an "other" that is "at once an object of desire and derision."

${ }^{30}$ John Tagg, "The Currency of the Photograph," in The Burden of Representation: Essays in Photographies and Histories (Minneapolis: University of Minnesota Press, 1993), 160.

${ }^{31}$ Smith, McCarthy, and McPhail, 1403.

${ }^{32}$ It is possible that the decision of Alberta police officers to dress in casual attire (i.e. shorts and buttondown shirts) and ride bicycles during the Calgary demonstrations against a meeting of G8 heads of state in 2002 was precipitated by the acknowledgement that images of police in riot gear at Quebec City were deleterious to the positive image of peaceful authority.

Burgin, 72. Emphasis in original.

34

Smith, McCarthy, and McPhail, 1420-21, use the term "episodic" to describe coverage that focuses on the details of a demonstration, with minimal attention paid to the issues underlying the demonstrations.

"Thematic" coverage focuses on the issues raised by a demonstration. The authors conclude that television news coverage tends to be episode-oriented, while newspaper reporting inclines toward a more thematic approach.

${ }^{35}$ The term "official summit" is used here and elsewhere to distinguish the third Summit of the Americas, a meeting of hemispheric leaders hosted by Canadian Prime Minister Jean Chrétien, held in Quebec City from 20 to 20 April 2001, from the second People's Summit, sponsored by the Hemispheric Social Alliance, a coalition of non-governmental organizations, that took place in Quebec City from 16 to 21 April 2001.

36

At a press conference on 2 May 2001, the RCMP divulged that it used 3,009 canisters of tear gas during the summit. This was in addition to 1,700 canisters fired by Quebec provincial police. "3,009 Cans of Tear Gas, 502 Plastic Bullets Used at Summit," Toronto Star, Thursday, 3 May 2001, A3. Sam Boskey, a member of the Quebec human rights watchdog Ligue des Droits et Libertés who monitored events surrounding the summit, concluded that police "did not overreact, except for a Niagara of tear gas." Quoted in Charlie Fidelman, "Abuse on Both Sides: Ligue des Droits Observers Critical of Cops, Cop-beaters," Montreal Gazette, Sunday, 22 April 2001, A7. There are no reports indicating the number of exploded tear-gas canisters thrown by demonstrators.

${ }^{37}$ Barthes, "Photographic Message," 24.

${ }^{38}$ W.J.T. Mitchell, Picture Theory: Essays on Verbal and Visual Representation (Chicago and London: University of Chicago Press, 1994), 325.

${ }^{39} \mathrm{Scott}, 328$.

${ }^{40}$ Caroline Brothers, War and Photography: A Cultural History (London and New York: Routledge, 1997), 28.

${ }^{41}$ Montreal Gazette, Monday, 23 April 2001, A18.

${ }^{42}$ Hall, 84. Emphasis in original. 
${ }^{43}$ Ibid.

${ }^{44}$ Of the sixty-seven captions and headlines analyzed, fifty-eight contain verbs. Of these, forty-three refer to action in the simple present tense. See Appendix $\mathrm{C}$ for a detailed analysis of photograph captions and headlines.

45

Globe and Mail, Saturday, 21 April 2001, A9.

46

Montreal Gazette, Sunday, 22 April 2001, A7.

${ }^{47}$ Ibid.

${ }^{48}$ Toronto Star, Sunday, 22 April 2001, A8. Of thirty-six references to police weapons, twenty-three imply this spontaneous appearance. See Appendix C.

${ }^{49}$ Montreal Gazette, Sunday, 22 April 2001, A1. This occurs in nineteen of thirty-six references.

${ }^{50}$ Barthes, "Photographic Message," 27.

${ }^{51}$ Scott, 327-28.

${ }^{52}$ Burgin, 68. Emphasis in original.

${ }^{53}$ Ibid., 69.

${ }^{54}$ The gaze, one of Jacques Lacan's four fundamental concepts of psychoanalysis, emanates from the theory of the mirror-stage, his account of the construction of subjectivity. Briefly, Lacan argues that the gaze is projected from the object of viewing onto the viewer; the viewer is thus forced to recognize him or herself as the object of the gaze: "In the scopic field, the gaze is outside.... I am looked at...that is to say, I am a picture." The Four Fundamental Concepts of Psycho-analysis (1964), tr. Alan Sheridan (Harmondsworth: Penguin Books, 1977), 196.

${ }^{55}$ Laura Mulvey, "Visual Pleasure and Narrative Cinema," Screen 16, no. 3 (1975): 6-18.

${ }^{56}$ John Berger, Ways of Seeing (London: British Broadcasting Corporation and Penguin Books, 1972), 47.

${ }^{57}$ A key text and precedent for the development of recent theory surrounding the colonial gaze is Frantz Fanon, Black Skin, White Masks (1952), tr. Charles Lam Markman (New York: Grove Press, 1967).

58 Norman Bryson, "The Gaze in the Expanded Field," in Vision and Visuality, ed. Hal Foster (Seattle: Bay Press, 1988), 93.

59

Ibid., 108.

${ }^{60}$ Lutz and Collins, 187.

${ }^{61}$ Ibid., 187-188. 
62

Ibid., 196.

${ }^{63}$ Ibid., 207-214.

${ }^{64}$ Ibid., 207.

${ }^{65}$ Ibid., 213.

${ }^{66}$ Ibid., 207.

${ }^{67}$ Houston-based video activist Tish Stringer has remarked that during the Quebec City demonstrations, "so many people in the crowd had cameras that it appeared that groups of journalists were getting tear-gassed instead of groups of demonstrators." Quoted in Rinaldo, n.p.

${ }^{68}$ The School of the Americas Watch (SOAW) field guide to the demonstrations, which was widely circulated on the Internet, placed cameras on the top-ten list of "things to pack." School of the Americas Watch, "Field Guide to the FTAA Protests," School of the Americas Watch Web site, <http://www.soawne.org/FTAAGuide.html>, December 2002 (no longer operational). Similarly, the Ottawa-based social documentary organization "Griot Photo" initiated a project named "Reframing Resistance," which offered activists single-use black-and-white film cameras with which to document the Quebec City demonstrations. According to the organization, the objective of the project was to "empower the participants through the process of representing themselves in a way that they feel accurately portrays their reasons for protesting." "Reframing Resistance," Griot Photo Web site, <http://www.griotphoto.org/resist.htm>, June 2003.

69

Of course media activism is not a new phenomenon. What is new is the speed with which media activism has become embedded in the contemporary global justice movement and the role of new media as a tool for rapid dissemination of information and perspectives.

${ }^{70}$ IndyMedia first appeared during demonstrations against the 1999 WTO/IMF meetings in Seattle, in the form of an interactive multi-media news centre where demonstrators were given the opportunity to upload articles, photographs, and video clips onto the IndyMedia Web site for instantaneous transmission.

IndyMedia was also present during the demonstrations in Quebec City, where the Quebec affiliate Centre des Medias Alternatives du Québec (CMAQ) set up a media centre with free access to computers and equipment. For a history and analysis of the IndyMedia phenomenon, see Gene Hyde, "Independent Media Centres: Cyber-Subversion and the Alternative Press," First Monday 7, no. 4 (April 2002), <http://firstmonday.org/ issues 7 4/hyde/index.html $>$, June 2003. See also the IndyMedia Web site, with links to international affiliates, <http://indymedia.org >, June 2003.

71

Rob Breadner's eighty photographs can be found on his personal Web site, Quebec City FTAA Summit April 22, 2001, <http://www3.sympatico.ca/hi-octane/quebec_pics.html>, June 2003. In a personal correspondence, 7 May 2003, Breadner told me that he considers himself an activist, an observer, and a photographer. Graeme Bacque's forty-seven photographs are available at "Summit of the Americas Quebec City, April 20-22," Graeme Bacque Web site, <http://graemesgallery.tripod.com/Quebec/A20-21.html>, June 2003.

${ }^{72}$ Michel Foucault, Discipline and Punish: The Birth of the Prison (1975), tr. Alan Sheridan (New York: Pantheon Books, 1977).

${ }^{73}$ Ibid., 25 . 
${ }^{74}$ See Rhéal Séguin, "Quebec Summit Site is a Forbidden City, Barricaded by Police, Surveyed by Video," Globe and Mail, Saturday, 21 April 2001, A3. Ibid., 217. Guy Debord's theory of the "society of the spectacle" is discussed at length in the third chapter.

${ }^{76}$ Mitchell, 327.

${ }^{77}$ Thomas Y. Levin, "Denis Beaubois and the Performative Politics of Panoptical Détournement," CTRL [SPACE] Web site, <http://hosting.zkm.de/ctrlspace/e/texts/05?print-friendly=true>, March 2003.

78

Steve Mann, also known as "Cyberman," is a Professor of Electrical Engineering at the University of Toronto who is best known for inventing the wearable computer. His personal Web site, with links to essays on the radical applications of digital technology, is at $<\mathrm{http}$ ://wearcam.org $>$. On 24 December 2001, Mann inaugurated the annual "World Sousveillance Day," during which participants are encouraged to film or photograph surveillance cameras in public places.

${ }^{79}$ Sontag further argues that the photographer is more akin to a tourist than a passive observer, "always trying to colonize new experiences." Susan Sontag, On Photography (New York: Farrar Strauss and Giroux, 1977), 12, 42.

80

The ambiguous divide between participation and observation is also raised in regard to video activism. In Hand-Held Visions: The Impossible Possibilities of Community Media (New York: Fordham University Press, 2002), video activist and historian Dee Dee Halleck argues that media intervention is an essential part of political protest.

${ }^{81}$ Of Breadner's eighty photographs, fifty (63\%) depict confrontational scenes and thirty $(37 \%)$ depict nonconfrontational scenes from the demonstrations. In Bacque's collection of forty-seven photographs, thirtythree (74\%) depict confrontation and twelve (26\%) depict scenes of carnivalesque activity.

82

Barricada (Boston, Mass.) 7 (May 2001).

${ }^{83}$ In a guide for activists planning to attend protests against the June 2002 meeting of the G8 in Kananaskis, Alberta, one coalition urged protesters to "bring a video camera to protect yourselves from getting batoned." "Summit," Deconstructionist Institute for Surreal Topology Web site, May 2002,

$<$ http://www.tao.ca/ wrench/dist/g8/ewok.html $>$, June 2003.

${ }^{84}$ Rob Breadner's photograph of the Saturday, 21 April People's March (fig. 3.3), with the caption "The parade boasted numerous thoughtful statements," is one of several examples. 


\title{
CHAPTER TWO
}

\section{"So! So! So! Solidarité!": The Art of Collective Resistance}

\begin{abstract}
Conversational art, dedicated to constructing its "object" and its "audience" through a process of ongoing dialogue, is committed to exploring contextual contingency in defining the nature and values of the aesthetic experience.
\end{abstract}

\author{
Homi K. Bhabha, "Conversational Art" \\ A person who bears witness to an injustice takes responsibility for \\ that awareness. That person may then choose to do something or stand by, \\ but he may not turn away in ignorance.
}

\section{Steven Durland, "Witness"}

Mainstream media's framing of the Quebec City demonstrations against the FTAA as a series of violent and ideologically incoherent riots can, to a certain extent, be understood by the complexity of the global justice movement itself, which is indeed more like many movements than one. An intricate web of issues and visions, it is a phenomenon that both invites and defies superficial coverage and analysis. The objective of this chapter is to explore the visual manifestations of the global justice movement in order to arrive at a more nuanced understanding of the movement itself, and to investigate how creative acts of resistance function as tools with which to mobilize community, communicate political ideas, and bear witness to the consequences of dominant models of globalization.

In March 2001, the women's caucus of the activist coalition Opération SalAMI (Operation Dirty Friend), ${ }^{3}$ issued an invitation to women's groups around the world to participate in a collective action entitled "Weaving a Web of Solidarity: A Feminist Action Against Globalization." The SalAMIelles' invitation appealed to women's affinity groups 
to produce and contribute quilts and other woven objects to a giant web-like banner that would be fastened to the chain-link fence surrounding the site of the third Summit of the Americas in Quebec City. Starhawk, a prominent activist in the global justice movement who aided in the circulation of the proposal, described it in the following way:

We are taking action because we will no longer tolerate the web of corporate control that binds us down and constricts our lives. We will not allow this system to continue.... Instead, we will spin a new web of connection, of solidarity out of our rage, out of our love.

On Thursday 19 April, the eve of the inauguration of the official summit, approximately three hundred fifty women joined a march organized by the Montreal-based Anti-Capitalist Convergence (CLAC) from Laval University to the summit perimeter. They were led by "Nemesis, the Goddess of Just Anger," a three-metre-high puppet with rosy cheeks, flaming red hair and billowing skirts (fig. 2.1). When the group arrived at the perimeter fence, they negotiated with a delegation of municipal police officers for permission to hang the banner of ribbons, photographs, balloons, quilts, flags, signs, poems, brassieres and girdles that, once appended to the fence, stretched to more than ten metres (fig. 2.2). ${ }^{5}$ Following a series of speeches, the women formed a circle, held hands, and began dancing in a spiral formation as they wove lengths of ribbon into a web. When it was completed, the woven ribbon was hung on the fence beside the banners. The event, which marked the first of many collective actions in the following three days, was accomplished without violence or altercation. It also went entirely unnoticed in mainstream media. ${ }^{6}$

A concrete example of the numerous creative acts of dissent during the demonstrations against the Free Trade Area of the Americas, the Weaving a Web of 
Solidarity action is also an apt metaphor for the demonstrations in their entirety - a loud, colourful and multifarious collection of individuals and affinity groups that took advantage of an existing web (the Internet) to organize their participation, ${ }^{7}$ and then came together for three days to weave a complex web of solidarity in opposition to perceived global corporate hegemony. The Web of Solidarity action also drew attention to the issue of exclusion at global summit meetings. The perimeter fence, a physical barrier erected to minimize the likelihood of disruption at the Summit of the Americas, quickly became a manifest symbol of the invisible barriers between those on the "inside," makers of social, economic and political policy, and those on the "outside," who contested the exclusion of dissenting voices. The women used their web to bear witness to the exclusionary function of the fence, and in turn used the fence as a palimpsest onto which they inscribed alternative visions of globalization.

Moreover, Weaving a Web of Solidarity signalled what was to become a conspicuous feminist presence at the demonstrations against the FTAA. Indeed, the action borrowed directly from a number of strategies of feminist activism, including the employment of the metaphor of weaving, which, like quilting, connotes both feminine domesticity and a more subversive notion of women's community-building. The act of weaving, traditionally devalued as a "woman's" chore, has also been considered as a useful means by which women have historically created community bonds. ${ }^{8}$ Inserted into the public political sphere, the women's web challenged conventional and exclusionary distinctions between public and private, and even many of the objects used to create itphotographs of children, quilted blankets, and intimate apparel-drew on the feminist model of erasing binary oppositions that subjugate the private to the public, craft to art, and 
"women's work" to "real work." The action utilized the feminist conception of performance as a way to manifest the idea that "the personal is the political." ${ }^{, 10}$ By drawing attention to the tangible local consequences of ostensibly abstract global socio-economic policies, the action furthermore demonstrated that the political is also intensely personal.

Weaving a Web of Solidarity was a performance art piece whose aesthetic and political efficacy was situated in the dialogue or conversation that it created. The action functioned furthermore to bear witness to perceived exclusion and injustice. It is through these two lenses - of conversational art and witness art-that this chapter will endeavour to analyze and theorize a variety of actions that imbued the demonstrations against the FTAA with a collective spirit of creative resistance."

\section{Art as Conversation: Building Solidarity}

I have borrowed the term "conversational art," coined by Homi K. Bhabha, to describe art's role as a tool to a) create and foster communities of politically engaged citizens, b) communicate political ideals in a creative way, and c) enlarge the communicative circle to include both predisposed and accidental audiences. Bhabha, who argues that the value or "truth" of art is contingent upon the ongoing dialogue that is created when product meets audience, attends primarily to the "performative act by which the work at once encounters its audience and constructs its community of interpretation." However, he also acknowledges that the conversations fostered by art can occur during the art-making process itself or, as he puts it, "in the contingent relations that come to be constructed through the working out of a particular practice." ${ }^{\prime 2}$ The idea that art's significance is located not in an "end product" but rather in the process of art-making itself 
is an impetus behind the contemporary community arts movement. Applying this movement's criteria for the development of group solidarity, I will analyze the role of art production as a collaborative tool in the building of social movements.

A salient question is whether the activists who converged at Quebec City can be conceptualized as a community whatsoever; the only defining characteristic of the global justice movement appears to be an expansive diversity of interests, from water issues to workers' rights and from agricultural concerns to developing-world debt. In fact, this very diversity renders the notion of community art a useful one. The term "community" is itself problematic; its perceived overuse as a term to describe, localize, and thereby re-inscribe the marginalization of non-dominant socio-economic groups has led many theorists and practitioners to reject community as a viable field of critical social engagement. ${ }^{13}$ While aware of the problematics of community as a conceptual framework, community arts practitioners have sought to reclaim the term in order to avoid the potential foreclosure of communal agency that community activism is perceived to foster.

In order to distinguish between weakly conceptualized or divisive notions of community and one that might accommodate the construction of collective agency, theorist Baz Kershaw identifies two categories of community: communities of location, which are relationships formed within a geographical area, and communities of interest, which are formed by a "commitment to a common interest," which is either implicitly or explicitly ideological. ${ }^{14}$ The thousands of activists who travelled from North, Central and South America to participate in the Quebec City demonstrations might be understood most expediently as a community of interest. However, their convergence at a specific and significant place in time also creates a context for them to be understood as a community 
of location, or perhaps more accurately a "community of resistance," the term used by Toronto artist and architect Adrian Blackwell to describe "members of a geographical community who have a stake in the configuration of that space." ${ }^{15}$ While the majority of participants in the Quebec City demonstrations were not permanent members of one geographical community, they nevertheless convened at Quebec City in order to express, among other things, their stake in the configuration of that city as a site of closed-door, fenced-in global policymaking.

Community art, often initiated by a professional artist in collaboration with a community group or organization, generally seeks to engage members of a community in a creative process in order to generate a field of individual and collective agency with which participants can tackle social issues that concern their community. Often, the first stage in this process of collective engagement involves the recognition of previously unacknowledged community. As sociologist Seana Lowe observed in her study of two community arts projects in Denver, Colorado, community art can provide a context for the creation of solidarity and collective identity: "Community art serves as a catalyst for developing community because it is both the setting for group solidarity building and the symbol of group identity."

The premise that communal art-making can foster group solidarity is a significant one for the development of a cohesive social movement. Of even greater significance in the context of the global justice movement's ostensibly unwieldy scope of interests and tactics of resistance is the possibility that collaborative creative practice can build solidarity from a foundation of diversity. As community art practitioner Maxine Greene argues, community art can function as "a way of speaking of an expanded community 
[that] takes shape when diverse people, speaking as who and not what they are, come together in both speech and action to constitute something in common among themselves."

In this context, the woven web is a cogent metaphor for the community of resistance that manifested itself in Quebec City, as is Suzi Gablik's concept of "connective aesthetics." According to Gablik, the radical political efficacy of communal art-making lies in its "dialogical structure," which undermines the alienation of contemporary consumer culture by rejecting modernism's privileging of "radical individualism" and denigration of the role of the audience: "Connective aesthetics strikes at the root of this alienation by dissolving the mechanical division between self and world that has prevailed.":

The notion of a "connective aesthetics" was central to the Web of Solidarity action, which functioned both metaphorically and physically to weave a diverse and geographically dispersed coalition of women's groups into a web of collective opposition to corporate globalization. Likewise, the global justice movement itself seeks to challenge the perceived contemporary phenomenon of alienation through the mobilization of collaborative resistance. One of the ways to achieve this has been to foreground the role of creativity as a tool of dissent. Another call to action, issued by the affinity group Stop the FTAA prior to the Quebec City demonstrations, clarifies this objective:

Taking to the streets with giant puppet theatre, dance, art, music, poetry, and spontaneous eruptions of joy breaks through the numbness of our current society. Corporations are attempting to homogenize us into passive, unquestioning consumers while exploiting and oppressing the poorest among us. We strive to utilize all of our creativity and imagination to create an enduring symphony of resistance. $^{19}$

This symphony, or web, of resistance was initiated and facilitated using the vocabulary of 
collaborative creativity. Like "new genre public art" as defined by artist and theorist Suzanne Lacy, the art that emerged from this context was one whose "public strategies of engagement" were "an important part of its aesthetic language." ${ }^{, 20}$ Significantly, the development of an aesthetic language was itself conceived as a public strategy of engagement.

A key ingredient in community-based art practice is the notion that creative collaboration produces what Lawrence Grossberg describes as "affective investment." Grossberg defines affect as a "quantitatively variable level of energy...or volition" that "determines how invigorated we feel in particular moments of our lives." ${ }^{21}$ An affective investment in certain practices is generated when an actor feels that his or her actions "matter." For Grossberg, such investments are empowering because they generate further investment. He concludes: "Such empowerment is increasingly important in a world in which pessimism has become common sense, in which people increasingly feel incapable of making a difference. ${ }^{92}$ In order to facilitate a space for collaborative art-making, the Montreal-based activist organization Anti-Capitalist Convergence (CLAC), formed in April 2000 in direct response to Quebec City's plans to host the Summit of the Americas, hosted an art space at Ilôt Fleurie, an outdoor area under a lowertown overpass, where activists were invited to participate in the making of placards and banners. In this space, and at another art centre at Laval University, art production became a vehicle for "affective investment" through the mobilization of solidarity and affinity groups, such as the group that formed ad-hoc to build a giant marionette in the form of a skeleton to protest the destruction of old-growth forests under economy-driven models of natural resource management (fig. 2.3). ${ }^{23}$ 
"Nemesis," the puppet that accompanied the Weaving a Web of Solidarity action, was also built collaboratively at the Laval University art centre. Chicago journalist Chris Kaihatsu, who witnessed the puppet's construction, recounts how its makers acknowledged the difficulty of preparing and mounting such an enormous object: "The artists described their test run with Nemesis... as being unwieldy. One pothole was enough to throw the topheavy puppet off-balance.... All the artists have never made any puppet this elaborate before, and they're still concerned about the height of the puppet and the way its skirt catches the wind." ${ }^{24}$

This account of the making of Nemesis demonstrates the effort required to produce art collaboratively, and also conveys how collective art-making can function as a metaphor for the production of a solidarity movement that stresses the comparatively unwieldy principles of non-hierarchical decision-making and coalition-building. The role of puppet making as both metaphor and vehicle of collective political action is also noted by Shawn Whitney, co-founder of Toronto's Artists Against the FTAA. This coalition of artistactivists participated in the Quebec City demonstrations with the assistance of a giant oneeyed blue puppet (fig. 2.4). Whitney recalls:

The preparations for the protest against the Summit of the Americas were a bit like our experience building our "genetically modified capitalist cycloptopus" puppet, The Mister of Cog. It took months of planning and improvisation with found materials. It took the involvement of all kinds of people and their enthusiasm. It took a political sense of the importance of being in Quebec and being visible. But we didn't really know how the puppet would work until the event itself. Would it be too top-heavy? Would the wind blow it over? Would the tentacles, inflated with helium, actually float?

The construction of The Mister of Cog reveals how puppets can function as catalysts for affective collaboration and community building. Whitney also hints at the 
significant role that puppets play in rendering counter-hegemonic messages both visibly and conceptually accessible. Perhaps surprisingly given the innocuous nature of much contemporary puppet theatre, puppetry has a long history of exploiting its accessibility in order to engage in subversive, anti-authoritarian discourse. ${ }^{26}$ The most renowned contemporary example of puppetry employed as a tool for social activism is the work of Bread and Puppet Theatre, founded by Peter and Elka Schumann in 1963 as a creative strategy of protest against the Vietnam war, and still active in the social justice movement. ${ }^{27}$ Although Bread and Puppet was not in official attendance at the Quebec City demonstrations, they are widely acknowledged catalysts of the current resurgence of radical puppet theatre; their puppets are frequent sights at mass demonstrations, and their influence was surely manifested in the plethora of puppets that participated in the People's March on Saturday, 20 April. $^{28}$ Among these were an effigy of Ronald McDonald carrying black bags inscribed with dollar signs (fig. 2.5) and a monstrous puppet dressed in a business suit known as "George W. Butcher" (fig. 2.6).

As Whitney notes, puppets can function as powerful media of visual communication. According to John Bell, who has worked with and written extensively about Bread and Puppet Theatre, puppetry is a singularly effective communicative tool: "While the bodies and voices of masses of performers have great theatrical potential in the massive space of the street, even more powerful are material objects, which the performers can animate." ${ }^{29}$ The ability to animate an over-life-sized inanimate object is a forceful metaphor for the mobilization of resistance in the perceived milieu of contemporary alienation. The status of puppets as animated inanimate objects also contributes to their popularity as "fun" voices of dissent. As Matthew Hart of Philadelphia's Spiral Q Puppet 
Theatre argues, "People have different affinities for puppets--they're silly and infantile and animated." Hart notes that the use of puppets allows activists to "illustrate ideas in a clear and effective visual way that allows the media to gain access, builds esprit de corps within a group, refreshes long-term activists because it's fun and wacky, and gains you access to new people who would be unresponsive to traditional ways of addressing issues." 30

While it would be futile to attempt to gauge the efficacy of puppets as conversational art objects, there is little doubt that among activists, puppetry as a mode of political activism is considered a highly effective, and affective, strategy for manifesting oppositional politics. For Jason Norris of Bread and Puppet Theatre, the legibility that goes along with puppets' limited vocabulary is key: 'It's very hard to verbally explain everything, on a large scale for people who don't even know the language. But a big beautiful image that sweeps down the street — that's emotional, and means something to everyone. That's the original statement, the thesis can come later in a pamphlet or literature. ${ }^{, 31}$ Thus, puppets are perceived as affective and effective communicative tools at both the production and performance stages.

The ongoing popularity of radical puppetry can be attributed in part to the perception among artist-activists that puppetry is increasingly treated as a criminal activity. ${ }^{32}$ This should not be surprising, for, as John Bell notes, puppets on parade are a profound "misuse of the street's public space," which, he argues, is under constant threat of privatization. ${ }^{33}$ The perceived criminality of radical puppetry has contributed to both its critical edge and its growing popularity. Puppets are now an almost inevitable presence at mass demonstrations, and puppet makers now often refer to themselves as "puppetistas.",34 
The Living River puppet (fig. 2.7), a large blue papier-mâché head mounted on a beam festooned with hundreds of long blue ribbons, was the creation of the American Pagan Cluster group, headed by noted author and activist Starhawk. Accompanied by a banner reading "Our water is not for sale," the puppet symbolized "the sacredness of water, and its vital necessity to peoples. ${ }^{, 35}$ Also accompanying the puppet was a contingent of eco-activists dressed in blue who spent much of the weekend distributing bottles of water labelled "May You Never Thirst," much coveted by the hundreds of activists coping with the effects of police-fired chemical irritants. ${ }^{36}$ The action was guided by two objectives: to call attention to the threat posed by corporate ownership of water; and to provide symbolic and spiritual support to fellow demonstrators during the marches. To achieve the first goal, the Cluster distributed copies of the Cochabamba Declaration, a manifesto in support of universal access to water written by activists in December 2000 following months of conflict in Bolivia over the privatization of the water supply in that country's third largest city, Cochabamba. ${ }^{37}$

As well as being a creative means of communicating a political message, the Living River action was designed as a symbolic way to generate energy for the protests. During the demonstrations, the Pagan Cluster and their giant blue mascot literally became a living river that flowed through zones of tension and conflict. Participant Ruby Perry's recollections of the action encapsulate the power of the action: "Over those several days, we flowed into the centre of whatever was going on, like a river bringing fresh water and energy to a confrontation or a stand-off. ${ }^{, 38}$ Vermont activist and journalist Robin Lloyd recalls encountering the Living River action. In an IndyMedia dispatch, Lloyd describes a critical moment during the protests when the Pagan Cluster group placed themselves 
between protesters and riot police in order to diffuse a tense standoff. Lloyd then explains how the Living River transformed her self-perceived status as observer: "It was an intense theatre event: performance art, perhaps, or a ritual. But who was the audience and who were the performers? Or were we all participants?"39

The extent to which creative, "conversational" acts of resistance such as the Living River action can produce a transformative effect on their participants and audiences is highly contested. Do such actions, which engage their audience in performative acts of social protest, actually generate a cathartic effect that releases the audience from the responsibility to transform their participation into postperformance action? Harry Elam, who attributes this line of thought to the influence of Aristotelian logic, acknowledges: "The inability to link postperformance social action directly to interperformance participation leaves audience participation and its role in social protest performance open to speculation."

In response to this argument, Brazilian dramatist Augusto Boal has spent three decades developing his Theatre of the Oppressed, a performative model that evolved from the notion that through socially engaged and engaging theatre, passive spectators are transformed into "spect-actors," active participants of social change. ${ }^{41}$ Boal draws on Paolo Freire's Pedagogy of the Oppressed, a revolutionary approach to education that favours reciprocal learning over what Freire refers to as the "banking method" of education, wherein students are akin to empty vessels into whom knowledge is deposited. ${ }^{42}$ In Boal's conception of revolutionary theatre, audience response is not a cathartic, but rather a radicalizing experience. While he acknowledges that efficacy can never be measured precisely, Boal maintains that participation in performances of social engagement 
stimulates revolutionary commitment. ${ }^{43}$

The intention of Theatre of the Oppressed is to engage otherwise passive spectators in the process of rehearsing social change. But can this model be applied to an audience composed of already committed social activists? For Boal, Theatre of the Oppressed is a strategy best suited to otherwise disengaged populations: "Big rallies are for people who are already convinced. You make a manifestation of force and many people will see that you are strong, and by seeing the support of those who are undecided may join along. The other way...reaches very few people. But it modifies peoples' opinions. "94 However, while the potential transformative effect of performance-based activism on "passive" or "neutral" audiences should not be discounted, neither should the potential for galvanizing already engaged "spect-actors."

As noted above, the community of interest formed by the global justice movement is a diverse and multifaceted one. Actions such as the Living River seek to mobilize an already predisposed audience by providing both information on a specific issue, and the means to further disseminate it. As Baz Kershaw argues, performative acts that create a space for the "transaction of meaning" contribute to the formation of ideological communities: "Community is... a potential site of ideological opposition to the status quo, and a performance which engages with the ideological identity of a particular community may enlist powerful forces for change." ${ }^{45}$ Again, this is a powerful notion for the conceptualization of a movement whose ideological coherence has been widely discounted.

In addition to mobilizing dissent, creative performances of resistance can generate and renew collective energy, and mitigate what many refer to as "activist burnout." 
Activism, as Claire Peeps notes, can be an exhausting experience. Peeps argues that "Artists can transform our dissatisfaction with the world into the image of something better...and it may be in this imaginative transformation that we find hope, and rejuvenation.. ${ }^{46}$ Danielle Gauld, a Victoria, British Columbia-based activist who participated in both the Weaving a Web of Solidarity and Living River actions, later described how her own involvement affected her personally:

I was inspired, empowered and renewed by the Quebec City protests. It was an unforgettable and educational experience.... The sheer diversity and creativity of the activists there was awe-inspiring, and the way we worked from a basis of respect, solidarity, consensus and mutual care gave me a precious glimpse of what a society built on true community and equality would feel like. And I found it very exciting to be surrounded by so many beautiful people willing to put themselves at great risk to fight for what they believed in.

In order for a demonstration to be both effective and affective, it must develop strategies for communication among a wide coalition of activists, and with an even wider body of observers. The artists' projects discussed above illustrate how art that functions as a collaborative, process-oriented, and communicative tool, or "art as conversation," can foster solidarity and provoke dialogue. But the term "demonstration" has another significant connotation. To demonstrate, as social movement theorist Andrew Barry has noted, is to point to a fact or truth. ${ }^{48}$ Thus, a demonstration always involves the act of bearing witness. As a medium capable of distilling complex political messages into legible visual symbols, art can function as a powerful vehicle for bearing witness to perceived social injustices. This will be the focus of the remainder of this chapter. 


\section{Art as Witness: Building Awareness}

Every Thursday afternoon for the past twenty-five years, a group of women in Buenos Aires has gathered in that city's Plaza de Mayo wearing white kerchiefs and carrying photographs of family members who "disappeared" under a series of brutal military juntas in Argentina. The Mothers of the Plaza de Mayo, as they have come to be known, circle the plaza silently in groups of two, bearing witness to their collective loss. Using their visibility as a weapon against state-imposed silence and brutality, the Mothers also compel their audience to bear witness, and to bear as well "the responsibility that comes with knowledge." ${ }^{49}$ The weekly action of the Mothers of the Plaza de Mayo is now a well-known and well-documented example of witness performance. It is also a precursor to - and perhaps even a source of inspiration for-many of the feminist actions that transpired during the Quebec City protests.

It is perhaps appropriate that one of the Mothers of the Plaza de Mayo, Nora Cortines, participated in the Quebec City Weaving a Web of Solidarity action, ${ }^{50}$ which itself bears much in common with the Mothers' project. It drew, for example, upon the notion that a group of women gathered to bear witness to a demonstrable truth-in this case by calling attention to the Summit security perimeter as an agent of exclusion-has the potential to shame the perpetrators of this truth and catalyze those who resist it. Moreover, like the Mothers, who used the seeming implausibility of their presence as political actors as an apparatus of subversion, the weavers of the web enacted what might be termed a strategic embodiment of femininity by inserting ostensibly "feminine" objects—quilts, family photographs, and brassieres—into the public sphere, where they became weapons against the exclusion of women's issues from that sphere. 
The question of efficacy in regards to embodiment as a strategy of social activism is one that has been addressed in feminist discourse. The emerging distrust of what is now considered an "essentialist" position regarding female subjectivity led in the 1980 s to the generation of a new discourse on gender, one that challenged the biological determinacy of gender identity. According to this deconstructionist model, gender is understood as a socio-psychic construction, contingent on naturalized systems of discourse, practice, and representation. A question that emerged was whether female cultural producers could represent or perform the female body in ways that would not reinscribe its conventional role as a commodity or object of the "male gaze." Feminist "body art" practices of the 1970s underwent a rigorous critique. Artist and theorist Mary Kelly, who played a pivotal role in the development of anti-essentialist feminist discourse, argued in 1982 that "when the image of the woman is used in a work of art, that is, when her body or person is given as a signifier, it becomes extremely problematic., ${ }^{51}$

By the 1990s, however, feminist discourse began to reconsider the evacuation of the female body in performance and representation, and to question whether such strategies actually foreclose on the potential of the body to mediate female subjectivity and agency. In her 1998 Body Art/Performing the Subject, Amelia Jones launches a spirited defence of performative body art of the 1970 s from a theoretical perspective that she describes as "phenomenologically inflected feminist poststructuralism." From this position, Jones argues that body art and performance art interrogate, rather than reinscribe, the simplistic binary logic of gender difference. ${ }^{53}$ The body is also considered a radical site of "engagement and exchange,", which allows the subject to "exacerbate, perform, and/or negotiate the dislocating effects of social and private experience in the late capitalist, 
postcolonial Western world." Jones posits that an embodied strategy of engagement with the social world creates a space for performers to assume "multiplicitous, dispersed, nonnormative subjectivities. ${ }^{, 56}$ For a social justice movement that foregrounds the strategy of embodied resistance, this notion has radical implications. Suggest a strategy, it suggests, creates a space for the performance of individual and collective identity that is not inscribed by convention or hegemony, but rather constantly involved in a dynamic process of becoming.

But if contemporary society can be understood as one predicated on the coercive production of alienation by virtual, non-identifiable powers, how can immanent or embodied resistance to this power be effective? In other words, as counter-culture theorist Mark Dery asks, how is it possible to "box with shadows?" ${ }^{97}$ According to Critical Art Ensemble (CAE), a media-arts collective engaged in critical theory and political activism, the political efficacy of material resistance is limited. In their 1994 The Electronic Disturbance, CAE contends that public spaces, which have been abandoned by corporate power in favour of nomadic virtuality, are obsolete as sites of resistance:

They are secure places revealing mere traces of power. As with all monumental architecture, they silence resistance and resentment by the signs of resolution, continuity, commodification and nostalgia. These places can be occupied, but to do so will not disrupt the nomadic flow. At best such an occupation is a disturbance that can be made invisible through media manipulation. ${ }^{58}$

The notion that immanent resistance to virtual power is futile has been instrumental in the development of a methodology of virtual or cyber resistance, known as "hacktivism." Perhaps ironically, the communication apparatuses created and exploited by cyber activists have themselves been instrumental in the building of a global solidarity 
movement that is equally at ease online and on the streets. ${ }^{60}$ Indeed, the rapid growth and popularity of a global justice movement that perceives the street as the optimum site of political resistance to corporate hegemony seems to belie the argument that immanent, embodied tactics of disobedience are ineffectual. ${ }^{61}$

The artists discussed in this chapter have demonstrated just such a commitment to perfomative, embodied enactments of resistance, many of which were themselves inflected with an implictly feminist critique of contemporary capitalist culture. If the sight of quilts and brassieres in the midst of Blac Bloc anarchists, tear gas and riot police was absurdlyand beautifully-incongruous, so too was the presence of a solitary woman in a glimmering, pale blue gown who spent the weekend strolling leisurely through the streets of Quebec City, stopping periodically to blow bubbles and write poems of peace in chalk on the road (fig. 2.8). The Gummy Worm Fairy, as she was labelled, also applied a politics of generosity to mitigate against the perceived politics of avarice associated with corporate globalization, by distributing gummy worm candy to passers-by. This random act of kindness offset in a small but significant way the tense confrontational atmosphere that surrounded the weekend's events.

The strategic embodiment of femininity as a tool of political activism is a common, if controversial, strategy of creative resistance. ${ }^{62}$ The 1980 s emergence of gender deconstruction discourse interrogated the efficacy of so-called essentialist gender performance, and concluded that it was an excessively reductive and objectifying model for feminist theory and practice. ${ }^{63}$ However, more recent feminist analysis has begun to reconsider gender performance as a useful tactic of political activism. The work of Judith Butler has been pivotal in this respect. For Butler, a deconstructionist herself, it is in the 
parodic performance of gender that the contingency of gender identity is most productively exposed. In her 1990 Gender Trouble, Butler argues that gender parody destabilizes the perpetual quest for an originary identity, and indeed renders the entire notion of an essential identity absurd: "Just as bodily surfaces are enacted as the natural, so these surfaces can become the site of a dissonant and denaturalized performance that reveals the performative status of the natural itself., ${ }^{94}$

The parodic performance of conventional codes of femininity is a strategy employed to great advantage by a loosely knit coalition of activists known as the Raging Grannies. Dressed in outlandish "old lady" costumes, Raging Grannies attend rallies and demonstrations regularly, where they sing political protest songs to the tune of old standards such as "She'll be coming down the mountain" and "Moon River" (fig. 2.9). Initiated by a group of Victoria, British Columbia, women in the late 1980 s as a creative vehicle of protest against nuclear proliferation, there are now "Granny Gaggles" across North America. ${ }^{65}$ The criteria for membership are strict and straightforward: one must be over the age of fifty-five, committed to social activism, and female. ${ }^{66}$ It has been estimated that three hundred Raging Grannies participated in the Quebec City demonstrations.

Much like the Mothers of the Plaza de Mayo, whose deliberate performance of motherhood paradoxically "freed them from the socially restrictive role of motherhood that had previously kept them in their place, ${ }^{, 67}$ the Raging Grannies use their perceived collective identity as politically ineffectual members of society against itself. By performing ostensibly apolitical roles in a highly charged political space, the Grannies transgress and contest the usual boundaries of this space, from which they are conventionally excluded. Perhaps even more significantly, the Raging Grannies exploit the 
legitimacy of their elder status, which affords them a certain authority, to bear witness to the myriad social injustices against which they sing. As Ottawa Raging Granny Alma Norman remarks, "We've lived through things. A lot of us have lived through the Depression, the Second World War, the Korean War. We can't be dismissed as a bunch of young radical students." ${ }^{68}$

Radical Cheerleading is another performative gesture that introduced a feminist critique of capitalism into the Quebec City demonstrations. A relatively new phenomenon that has grown exponentially in the past few years, radical cheerleading was conceived in California by a group of young women intent on transforming cheerleading - a conventionally corollary sport in which women "cheer" male athletes-into a strategy of political intervention. There are now over one hundred radical cheerleading contingents in North America and Europe. They typically dress in red and black clothing-anarchist colours-and sport black pom-poms as they chant their way through cheers such as, "Hey NAFTA! Hey NAFTA! We know what you're afta!" Approximately ten North American Radical Cheerleading squads attended the Quebec City protests, where they performed regularly during the weekend (fig. 2.10$)^{69}$

Like the Raging Grannies, Radical Cheerleaders assume a feminine role that is conventionally marginalized in the public sphere in order to disrupt its traditional meanings. Such performances are intended to catalyze audiences, and participants, to question gender issues in a light-hearted but meaningful manner. Rachel Engler-Stringer, a Saskatoon student whose first foray into Radical Cheerleading was during the Quebec City demonstrations, explains how the process radicalized her own feminist position:

I became more aware of gender and sexuality issues as a result of Radical 
Cheerleading. I always considered myself a feminist, but I became a different kind of feminist partially as a result of the analysis around gender that is common among Radical Cheerleaders. I also learned more about other political issues, when I learned cheers on different topics. ${ }^{70}$

Engler-Stringer also acknowledges that the collaborative nature of radical cheerleading functions to galvanize creative energy: "I do not consider myself a very creative person, I am more an appreciater of creativity in others. I can make up cheers and moves, and I can do the cheers, but I cannot do it alone, I need the inspiration of others to help me. So for me, the creativity I can tap into, is only tapped into when I am working with others." "1 Engler-Stringer's comments demonstrate how creative collaboration contributes to affective empowerment and identity-formation, both within a collective and at a more personal level-an idea that relates radical cheerleading to the above focus on conversational art. But radical cheerleading is also a creative example of the art of bearing witness. Through the parodic embodiment of femininity, radical cheerleaders bear witness to the normalization of conventional codes of femininity that render women's roles in the public sphere marginal and submissive, while simultaneously bearing witness to the issues of social justice referred to in their chants.

The femininity enacted by radical cheerleaders is both excessive and ambivalent. Radical cheerleading is a parodic performance whose efficacy rests largely on its deviation from the norm, much like colonial mimicry as described by Homi K. Bhabha: "The excess or slippage produced by the ambivalence of mimicry (almost the same but not quite) does not merely 'rupture' the discourse, but...rearticulates presence in terms of its 'otherness,' that which it disavows." ${ }^{72}$ Indeed, deviation from the norm is a key element of politically effective parody. Judith Butler, acknowledging that not all parody is subversive, identifies 
"variation" as the component of parody that enables the assertion of agency: "In a sense, all signification takes place within the orbit of the compulsion to repeat; 'agency,' then, is to be located within the possibility of a variation on that repetition." ${ }^{73}$

Transgressive behaviour, such as the wearing of "granny hats" that are excessively large and floral or cheerleader costumes that are blatantly "unfeminine," is one component of subversive parody. Another is the enactment of parody outside the hegemonic or conventional context of that which is being parodied. As Canadian theorist Linda Hutcheon has argued, parody's capacity to contribute to social change is limited by its reliance on maintaining a tension between complicity and subversion. ${ }^{74}$ For parody to function as a transgression of cultural codes, it must be enacted as "repetition with critical distance that allows ironic signalling of difference at the very heart of similarity." ${ }^{75}$ For Pierre Bourdieu, critical distance involves parodic intervention presented "before an audience corresponding structurally to the other extremity." ${ }^{76}$ In such cases, parody has the potential to transform a "field of forces" (or a structured set of codes) into a "field of struggles" (wherein the field of forces is undermined). Parody enables subjective empowerment when it is performed in a "non-congruent context" that renders it "incongruous or even absurd, simply by making it perceptible as the arbitrary convention it is.",77

Parodic mimicry, employed as a strategy of subversion by Raging Grannies and Radical Cheerleaders, was a prevalent strategy among performance artists in Quebec City, and one of the most ubiquitous tropes of this strategy was the business suit. A business suit may conjure up a number of ideals. It may symbolize power, security, wealth, protection, and success. Alternately, it may be understood as a marker of patriarchy, Western values 
and corporate culture. The presence of protesters in business suits at Quebec City played upon both the homogeneity of corporate culture and the (implicitly gendered) power that the donning of a business suit presumably conveys. One such performance was a satirical parody of corporate power by Montreal activists Alexis O'Hara, Leslie Farley, Catherine Kidd and Marc Tuters. During the Saturday People's March, O'Hara, Farley and Tuters, wearing men's three-piece suits, wove through the crowd clutching briefcases and cellular phones. Media activist and journalist Vince Tinguely witnessed the performance:

Occasionally O'Hara and Farley would pause, face each other like two football players, and begin frenetically shaking hands and pounding each other's shoulders chanting, "Money! Money! Money! Dollar, dollar, pognon, pognon!" Tuters confronted protesters with flow charts indicating falling profits and shouted, "I'm drunk!" Catherine Kidd, seizing on the power of [her] police uniform, raced briskly along, directing the advancing protesters, "Move to the right! Keep to the right!" She protected the rambunctious "businessmen" by ordering the protesters, "Look away! Stand back at least ten feet!"

Parodic interpretations of capitalist culture such as this function to underline and undermine both the authoritative underpinnings of corporate hegemony and the homogeneous conformity that the business suit - corporate culture's most pervasive symbol-is perceived to impose.

Parody also bears witness to the invisibility of corporate power in public political discourse. Here, the business suit again plays a pivotal role. A sign of power and wealth, the business suit is also, by virtue of its conservatively anonymous nature, an apt metaphor for the cloak of secrecy that surrounds such power and wealth. ${ }^{79}$ In another parodic performance of corporate culture on the streets of Quebec City, this invisibility was revealed and ridiculed. Along the route of the Saturday, 21 April People's March, a group of ten to fifteen picketers stood at the entrance to a Holiday Inn hotel carrying placards 
with messages such as "Le Marche ou La Mort," "Ne touchez pas à mon comfort," and "Les investeurs sont aussi citoyens" (fig. 2.11). Shouting pro-FTAA slogans and wearing business suits, these protesters appeared initially to be sincere, if overly zealous, proponents of free trade. It took a moment to realize that these would-be capitalists were engaged in a performance of "almost the same but not quite" mimicry. Hairstyles tended toward the unconventional, shoes revealed a preference for comfort over corporate fashion, and suits hung awkwardly on their wearers. ${ }^{80}$ Reflecting the uniformity of business culture "as though through a funhouse mirror,", this parodic intervention produced an excessive duplication of that culture and its underlying principles, a duplication that rendered it absurd. Moreover, simply by manifesting a pseudo-capitalist presence on the streets of Quebec City, the performance reduced the virtual nature of corporate power to material form, where the legitimacy of its codes of conduct could be exposed for interrogation. In so doing, the capitalist parody also revealed the ridiculousness of the notion that capitalists might be compelled, in the present global context, to picket on street corners. The corporeal performance of corporate power bore witness, in effect, to its guise of incorporeality.

Equiterre, a Montreal-based non-governmental organization that promotes community-based organic agriculture, also engaged in a performance art piece that employed the business suit as a signifier of disciplined conformity in the contemporary climate of perceived corporate hegemony. Accompanied by a giant papier-mâché puppet representing a top-hatted capitalist, thirty to forty performers marched stiffly and silently in disciplined lines along Saturday's parade route, wearing black business suits and Universal Product Codes covering their mouths (fig. 2.12). At staged intervals the entire contingent 
stopped and — with exaggerated and well-choreographed motions-shrugged their shoulders, consulted their watches, and clutched their heads. This parody of self-inflicted conformity under corporate governance bore witness to the hegemonic forces of capitalism that contemporary social activists believe reduce political decision-making to economic number-crunching, citizens to passive consumers, and producers to voiceless workers.

The muzzled mouths of the action's participants also drew attention to the silencing of voices of dissent in contemporary political discourse. There is a strong argument to be made for the role of sound as a weapon of resistance. Insistent drum beats, clamouring pots and pans, whistling bells, and voices of dissent raised in anger and in song, all of which helped to infuse Quebec City with a radically festive atmosphere, can play a crucial role in the material reclamation of the right to be heard in a political context that is perceived to deny this right. Indeed, American civil rights activist Bernice Johnson Reagon has emphasized that music, in the context of a political demonstration, has a powerful capacity to render a movement physically present by occupying a space "in a way that police [cannot] reclaim. ${ }^{, 82}$ But is there an argument to be made that silence, too, can have a viable role in the iteration of a justice movement's aims? Peter Schumann of Bread and Puppet Theatre believes there is. For Schumann, language is an easily manipulated and exploited commodity that, like all commodities, belongs to those who can afford to own it. Puppets, by virtue of their silence, have the unique ability to subvert—and to teach their users to subvert-hegemonic control over the use of language:

The fighting against language, the uprising against purposeful, capitalistic and deceptive language, is at the heart of any movement that counters the disaster which in genteel and sweet tones calls itself our government and claims to govern our traffic only, but in truth governs our souls as well.... The mutes of our profession, our puppets, who teach us silence, also teach 
us the language which protests silence. ${ }^{83}$

During a mass demonstration, silence can operate on several levels of signification. As a parodic strategy, silence mimics the silencing of marginalized voices under dominant regimes of truth and knowledge. In sharp contrast to the noise and music characteristic of mass demonstrations, a silent moment can have a powerfully startling effect that renders the act of bearing witness almost spiritual. For silence has an inherently ritualistic quality; as children, we are taught to be silent during religious services, at funerals, and during moments of remembrance-all contexts during which we are compelled into a state of contemplation and reflection. Such moments remind us that silence, as the saying goes, can speak louder than words.

The participants of Equiterre's silent action, like the Mothers of the Plaza de Mayo, demonstrated that their actions had the capacity to speak through, and of, silence. Also representative of this genre of resistance is the group of young protesters who, resembling the Equiterre performers, marched mutely through Quebec City with large black "X" marks over their mouths (fig. 2.13). This action bore witness to the silencing of dissent in contemporary politics, while the "X" marks, echoing the cross-hatching of the chain-link perimeter fence, reflected the silencing of exclusion. It also, more bleakly, drew attention to the potentially dire consequences of failing to vocalize dissent. As a reminder that to bear witness is to accept responsibility for the knowledge that accompanies it, the participants each wore on their backs a sign reading, "Demain, c'est la mort."

The streets of Quebec City also witnessed a number of organized theatrical productions, including one, mounted by the World March of Women, which likewise drew upon the power of silence (fig. 2.14). Three women and one man, wearing red kerchiefs, 
stood on the road with lengths of nylon, which they pulled to and fro in an awkward dance of manual labour. Behind them on stools, three men wearing jackets and ties beat out a slow, methodical rhythm on improvised drums and rattles. As the rhythm accelerated, so too would the motions of the workers, whose harried faces expressed the monotony of their labour. Periodically, as the rhythm reached a fevered pitch, one of the "bosses" would descend from his makeshift dais to disrupt the workers with wild gesticulations, and the drumming would stop momentarily, only to resume its slow, steady beat. On the sidelines sat a woman who wore an expression of misery as she rocked a toy child to the rhythm of the drums. This street performance depended to a certain extent on the sounds made by the instruments, but its affective power lay in its ability to communicate without words the dignity of international workers, the desolation of their working conditions, and the silent invisibility of these conditions in the developing world.

Just as silence can be an effective method of voicing dissent, so too can the trope of invisibility be used to articulate the visibility of resistance. Ya Basta is an activist coalition that employs a unique brand of spectacularized invisibility with this aim in mind. Based in Italy, Ya Basta, whose name ("enough already" in Spanish) pays homage to a Zapatista rallying cry, ${ }^{84}$ grew out of the "centri sociali" movement, a hotbed of political dissent in Italy since the 1970s. Dressed in white coveralls - from which their alternate name, "tute bianche," is derived - and well ensconced under rubber padding and cardboard shields, members of Ya Basta attend mass rallies masquerading as "ghosts on the margins." explain that their costumes, and particularly the white coveralls, "symbolize the condition of invisibility imposed upon all those people forced to live without guarantees, without social security, on the margins of a 'normal' life." ${ }^{86}$ While the group's most noted action 
took place during anti-IMF demonstrations in Prague, Czech Republic in 2000, members also attended the Quebec City demonstrations (fig. 2.15), where they were joined by the Bonhomme Bloc, a uniquely Québecois version of the tute bianche.

As a strategy of oppositional politics, invisibility is akin to silence in that it underlines, and undermines, the marginality of the "silent," "invisible" majority. But the tactic of rendering invisibility visible also relies upon the notion that resistance to hegemony requires visible, embodied expressions of opposition. One of the tactics favoured by Ya Basta is that of approaching police barricades as human shields. This confrontational strategy, which employs the human body as a barrier, is at once a highly theatrical spectacle and a classic employment of non-violent direct action techniques. ${ }^{87}$ Drawing on Foucault's notion of biopower, a strategy by which the state maintains hegemonic control over the bodies of its citizens, ${ }^{88}$ Ya Basta proposes a counter-hegemonic tactic of biopower as embodied resistance to dominant regimes: "The body is back as a concrete symbol of civil disobedience and a paradigm of the 'bio-political' era, which is based upon corporate control of life itself."

The notion that the human body can be an effective political tool is addressed by sociologist Graeme Chesters. Discussing the British anti-road movements of the 1990 s, Chesters argues that "the body has been 'rediscovered' as a locus of resistance combining physical, symbolic and affective dimensions which contribute to the construction of a collective identity." 90 Noting that barricades have often been used by activists to defend contested spaces, Chesters adds that these spaces "may be as symbolic as they are physical, and the very desire to inhabit them a form of resistance." ${ }^{91}$ In a sense, the demonstrations against the FTAA in Quebec City can be read in their entirety as a symbolic barricade 
against the perceived phenomenon of corporate-driven models of globalization. But the human barricades erected by activists during mass demonstrations are also physical embodiments of resistance. Like the members of Ya Basta, the 60,000-plus participants of the anti-FTAA demonstrations believed their physical presence on the streets of Quebec City to be an effective and affective weapon against what they perceived to be the antidemocratic proceedings of the Summit of the Americas. As radical cheerleader Rachel Engler- Stringer explains; "I wanted to put my body in the way of capitalism."

This determination to employ the body as both symbolic and physical barricade is also demonstrated by the following account of a group of Raging Grannies who used their elder status to defuse a standoff between police and protesters. Ottawa Raging Granny Peggy Land describes the incident during which a Granny group advanced into a cloud of tear gas:

They were warned by fleeing protesters to turn back but continued on. Soon they came across a group of heavily armed police in full combat gear. The police were unaccountably preventing the peaceful progress of a small group of protesters trying to make their way down a street. "The police looked more like armadillos," according to the small band's fearless leader, aged 78.... One "armadillo" stepped forward, fingering his rubber-bullet gun. Undeterred, the Granny group linked arms and put themselves between the small group of protesters and the police. First they sang their "Hysteria" song to the tune of "Rule Britannia" then took small steps towards the police. Then it was "We shall overcome," and a few more steps forward, voices cracking a little, according to the youngest, an apprentice Granny. Finally Alma, the tiny 78-year-old Granny leader explained to the police that they could indeed be their mothers or their grandmothers, and same for the protesters, but that they were simply there for peaceful purposes and posed no danger. Amazingly, the police then retreated a few steps. The Granny group blew them a few kisses, and turned and made their way back down the hill.

I suggest that one of the underlying collective goals of the demonstrations was to bear witness to the virtual and invisible power of corporate hegemony by countering it 
with immanent, embodied resistance. Employing the tools of community art practice, the strategies of new genre public art activism, and the models of feminist art discourse, thousands of artist-activists converged on the streets of Quebec City to engage in collaborative art-making, generate spaces for "conversation," and bear witness to perceived regimes of truth and knowledge. What many of these artists also share is a commitment to creating a space for the enactment of what I refer to as "oppositional utopianism," wherein the state of the world (what Starhawk referred to at the start of this chapter as the "web of corporate control") is momentarily displaced by the state of how-the-world-mightbe (or "a new web of connection, of solidarity"). In the following chapter, I discuss the notion of oppositional utopianism as a strategy of collective resistance, and a vehicle for claiming public space as a site for the creation of "spaces of resistance." 


\section{NOTES}

${ }^{1}$ Homi K. Bhabha, "Conversational Art," in Conversations at the Castle, ed. Mary Jane Jacob (Cambridge: MIT Press, 1998), 40.

Steven Durland, "Witness: The Guerilla Theatre of Greenpeace" (1987), in Radical Street Performance: An International Anthology, ed. Jan Cohen-Cruz (London and New York: Routledge, 1998), 69.

The Montreal-based SalAMI promotes itself as a citizens' coalition committed to "fighting against the globalization of misery and for the globalization of resistance." Opération SalAMI Web site, $<$ http://www.alternatives .ca/salami>, December 2002 (no longer operational). Emphasis in original.

${ }^{4}$ Starhawk, "Weaving a Web of Solidarity: A Feminist Action Against Globalization," Peacework Magazine, April 2001, <http://www.afsc.org/pwork/0104/010405.htm>, December 2002.

5 Sophia Delauney, "Women March Peacefully on A19, Hang Banners on Wall in Quebec," Chicago IndyMedia Web site, 20 April 2001, <http://chicago.indymedia.org/front.php3?article_id=1969\&group $=$ webcast $>$, January 2003 .

${ }^{6}$ While none of Canada's major daily newspapers covered the Women's March of 19 April, it was reported in several dispatches to IndyMedia Web sites.

7 The Women's Action was organized entirely on the Internet, as were most of the demonstrations against the FTAA. The role of the Internet as a powerful vehicle for social activism has been widely acknowledged. In "Civil Society Activism on the World Wide Web: The Case of the Anti-MAI Lobby," in Street Protests and Fantasy Parks: Globalization, Culture, and the State, ed. Janice Gross Stein and David R. Cameron (Vancouver and Toronto: University of British Columbia Press, 2002), 90, Ronald J. Deibert argues that the Internet "has become the sinew of power for the coalescing nebulae of global civil society." Harry M. Cleaver Jr. refers to the growth in electronic activist networks as the "Zapatista Effect," arguing that the mobilization of worldwide pro-Zapatista support over the Internet has inspired the "increasingly global organization in opposition to the dominant economic policies of the present." Harry M. Cleaver Jr., "The Zapatista Effect: The Internet and the Rise of an Alternative Political Fabric," Journal of International Affairs 51, no. 2 (spring 1998): 622.

8

For a history and analysis of the transgressive capabilities of "women's work," see Rozsika Parker, The Subversive Stitch: Embroidery and the Making of the Feminine (London: Women's Press, 1984).

${ }^{9}$ In a related context, the Ithaca, New York-based Activist Knitting Troupe organized a knitting action or "knit-in" for the Quebec City demonstrations during which they knit scarves in retaliation against the proposed ban on the wearing of scarves in the cities of Quebec and Ste. Foy during the summit. See Activist Knitting Troupe, "Knitters of the World, Unite and Take Over!" February 2001, available online at the Stop the FTAA Web site, <http://www.stopftaa.org/organize/cta_knitters.html>, January 2003.

10

${ }^{10}$ In her introduction to the politics of new genre public art, Suzanne Lacy acknowledges feminist art as a precedent for contemporary art activism, and argues that feminist artists of the 1970s, who explored the fundamental feminist notion that "the personal is the political," provided an ethical framework with which to consider the politics of identity as "central to their aesthetic." Suzanne Lacy, "Cultural Pilgrimages and Metaphoric Journeys," in Mapping the Terrain: New Genre Public Art, ed. Suzanne Lacy (Seattle: Bay Press, 1995), 26. 
${ }^{11}$ These categories are intended to be neither discrete nor mutually exclusive; the art projects discussed may fall easily into both categories.

12

Bhabha, "Conversational Art," 40-41. A growing body of literature seeks to locate art in the process of artmaking rather than the finished art product. See, for instance: Steven Durland, "Looking For Art in the Process," in Conversations at the Castle, ed. Jacob, 142-149; and Judith Baca, who argues in "Whose Monument Where? Public Art in a Multi-Cultured Society," in Mapping the Terrain, ed. Lacy, 138: "We can evaluate ourselves by the processes with which we choose to make art, not simply by the art objects we create."

${ }^{13}$ In "Parables of Community and Culture for a New World (Order)," in Questions of Community: Artists, Audiences, Coalitions, ed. Daina Augaitis, Lorne Falk, and Sylvie Gilbert (Banff: Banff Centre Press, 1995), 3 , Dot Tuer describes community as an "over-determined cultural catch-phrase" that "can end up collapsing differences in the name of difference, sweeping away history in the name of solidarity."

14 Baz Kershaw, The Politics of Performance: Radical Theatre as Cultural Intervention (London and New York: Routledge, 1992), 30-31. In a similar vein, community arts practitioner and theorist Richard Owen Geer divides communities into the three categories of location, spirit, and tradition. "Of the People, By the People and For the People: The Field of Community Performance," High Performance 64 (spring 1993): 28.

15

Adrian Blackwell, untitled lecture presented during the lecture series "Unboxed: 9 Dialogues on Art and Architecture", Carleton University School of Architecture, Ottawa, 21 October 2002. André C. Drainville also uses the term "community of resistance" to refer to the Quebec City demonstrations in "Québec City 2001 and the Making of Transnational Subjects," Socialist Register 2002: A World of Contradictions, ed. Colin Leys and Leo Panitch (London: Merlin Press; Halifax: Fernwood, 2001), available online at $<$ http://www.yorku.ca/socreg/Drainville.htm>, June 2003.

16

Seana Lowe, "Creating Community: Art for Community Development," Journal of Contemporary Ethnography 29, no. 3 (June 2000): 381.

"

${ }^{17}$ Maxine Greene, Releasing the Imagination: Essays on Education, the Arts, and Social Change (San Francisco: Jossey-Bass, 1995), 155.

${ }^{18}$ Suzi Gablik, "Connective Aesthetics: Art After Individualism," in Mapping the Terrain, ed. Lacy, 76-77, 86.

${ }^{19}$ Stop the FTAA, "Why Nonviolent Direct Action?" Stop the FTAA Web site, <http://www.stopftaa.org/ activist/act directaction.html>, June 2003.

${ }^{20}$ Lacy, 19.The positing of a connection between aesthetics and social engagement has radical implications for conventional understandings of the term aesthetic. While a detailed examination of the debate surrounding the applicability of aesthetic discourse to contemporary art practice is outside the purview of this thesis, it bears noting that theorists such as Lacy and Gablik, much of whose work involves questioning and expanding the boundaries of what constitutes art, are also attempting to broaden definitions of aesthetics, which, they argue, can be located in both the content and the structure of art production.

${ }^{21}$ Lawrence Grossberg, "Is There a Fan in the House? The Affective Sensibility of Fandom," in The Adoring Audience: Fan Culture and Popular Media, ed. Lisa A. Lewis (London and New York: Routledge, 1992), 57. 
Ibid., 65.

${ }^{23}$ Chris Kaihatsu, "Puppet-Making at the Art Centre," Chicago IndyMedia Web site, 16 April 2001, $<$ http://chicago.indymedia.org/front.phps?article_id=1863\&group=webcast $>$, November 2002 .

24 Ibid.

${ }^{25}$ Shawn Whitney, "Outside the O-fence-ive Barricade: The Journal of an Artist in Town to Do a Little Street Theatre," Briarpatch 30, no. 5 (June 2001): 10.

${ }^{26}$ See Kerry Mogg, "A Short History of Radical Puppetry," Fifth Estate 35, no. 1 (spring 2000): 14-15.

${ }^{27}$ See John Bell, "Louder Than Traffic: Bread and Puppet Parades," in Radical Street Performance, ed. Cohen-Cruz, 271-279.

28

Radical puppeteers Jan Burger and Donovan Zimmerman both acknowledge the influence of Bread and Puppet Theatre in the development of their practice. See Linda Burnham, "The Men Behind the Masks," The Independent Weekly (Durham, N.C.), 12 April 2000, <http://www.indyweek.com/durham/2000-04-

12/ae.html>, January 2003.

29

Bell, "Louder Than Traffic," 278.

"Matthew Hart, quoted in "Matthew Hart: Puppet-Maker and Theatre Activist," The ArtBiz Web site, July 2002, <http://www.theartbiz.com/peerarchive.asp?WHICH=21>, December 2002.

31 Jason Norris, quoted in Joanne Hinkel, "A Parade of Puppeteers: How Art is Helping Activism," Attnspan Web site, 29 April 2001, <http://www.attnspan.com/revolution/1>, March 2003.

${ }^{32}$ For example, in August 2000 police officers in Philadelphia invaded a puppet warehouse, arrested all of its occupants, and destroyed the puppets. As John Bell notes, police actions of this kind tend to intensify puppeteers' sense of political activism. John Bell, "Entertainment, Spectacle, Crime: Puppetry in the Year 2000," in Puppets, Masks, and Performing Objects, ed. John Bell (London and Cambridge: MIT Press, 2001), 4 .

33 Bell, "Louder Than Traffic," 278-79. Efforts to re-publicize public space, a crucial aspect of the global justice movement, are a major focus of chapter three of this thesis.

${ }^{34}$ Bell, "Entertainment, Spectacle, Crime," 4.

${ }^{35}$ Barbara Walker Graham, "Water is Sacred: Support for the Cochabamba Declaration," Awakened Woman e-magazine, 16 May 2001, <http://www.awakenedwoman.com/cochabamba.htm>, December 2002.

${ }^{36}$ Ibid. As noted earlier, police fired 4,709 canisters of tear gas during the demonstrations. 
${ }^{37}$ In January 2000, in exchange for a US\$25 million loan from the World Bank, the government of Bolivia agreed to lease Cochabamba's water utility to Bechtel Enterprises, a San Francisco-based multinational corporation. In order to guarantee the sixteen percent average annual profit included in the agreement, water tariffs were more than doubled. Following months of fierce protests and the death of one protester, in April 2000 the Bolivian government ceded to public pressure and rescinded the agreement. The Cochabamba Declaration, written by international water activists attending a seminar, "Water: Globalization, Privatization, and the Search for Alternatives" (convened by the Coordinadora de defensa del agua y de la vida in Cochabamba on 8 December 2000) calls for an international treaty to ensure that water, "a fundamental human right and a public trust to be guarded by all levels of government...should not be commodified, privatized or traded for commercial purposes." See Coordinadora de defensa del agua y de la vida (Coalition in Defense of Water and Life), "The Cochabamba Declaration on Water: Globalization, Privatization, and the Search for Alternatives," in Global Backlash: Citizen Initiatives for a Just World Economy, ed. Robin Broad (Lanham, Md.: Rowman and Littlefield Publishers, 2002), 273.

${ }^{38}$ Ruby Perry, quoted in Robin Lloyd, "And the Wall Came Tumbling Down," Nadir Web site, 30 April 2001, <http://www.nadir.org/nadir/initiativ/agp/a20/tumbling.htm>, October 2002.

39

Ibid.

${ }^{40}$ Harry J. Elam Jr., "Social Urgency, Audience Participation, and the Performance of Slave Ship by Amiri Baraka," in Crucibles of Crisis: Performing Social Change, ed. Janelle Reinelt (Ann Arbor: University of Michigan Press, 1996), 31.

${ }^{41}$ Augusto Boal, Theatre of the Oppressed (1974), tr. Charles A. McBride and Maria-Odilia Leal McBride (New York: Urizen Books, 1979). See also Mady Schutzman and Jan Cohen-Cruz, ed., Playing Boal (London: Routledge, 1994), an anthology of essays devoted to various aspects of Boal's teaching.

42

Paolo Freire, Pedagogy of the Oppressed (1968), tr. Myra Bergman Ramos (New York: Herder and Herder, 1970).

43 Augusto Boal, interviewed in Alex Sierz, "How to Play Boal," Red Pepper, March 1995, available online at the Theatre of the Oppressed Laboratory Web site, <http://www.toplab.org/boalint.htm>, November 2002.

${ }^{44}$ Augusto Boal, quoted in Jan Cohen-Cruz, "Theatricalizing Politics: An Interview with Augusto Boal," in Playing Boal, ed. Schutzman and Cohen-Cruz, 232.

45

Kershaw, 28-30.

${ }^{46}$ Claire Peeps, "Getting in History's Way," in Activists Speak Out: Reflections on the Pursuit of Change in America, ed. Maria Cieri and Claire Peeps (New York: Palgrave, 2001), available online at the Community Arts Network Web site, <http://www.communityarts.net/readingroom/resmul.php>, April 2003.

${ }^{47}$ Danielle Gauld, "There Ain't No Power Like the Power of the People: My Experiences in Quebec City," Women's Voices Newsletter (Kenora, Ont.), summer 2001, <http://www.voyageur.ca/ womens place/summer\%202001.html>, September 2002. 
${ }^{48}$ Barry illustrates how the term "demonstration" is applied in several contexts: In a laboratory, a scientist demonstrates an observable phenomenon; in a commercial context, a salesperson demonstrates a new product; likewise, in a political demonstration, activists demonstrate a perceived social injustice. In all cases, demonstration involves pointing to an observable fact. Andrew Barry, "Demonstrations: Sites and Sights of Direct Action," Economy and Society 28, no. 1 (February 1999): 75-94.

${ }^{49}$ Diana Taylor, "Making a Spectacle: The Mothers of the Plaza de Mayo," in Radical Street Performance, ed. Cohen-Cruz, 78.

${ }^{50}$ See Starhawk, "Dances with Tear Gas," Beliefnet Web site, May 2001, <http://www.beliefnet.com/ story/80_8008.html>, November 2002.

${ }^{51}$ Paul Smith, "No Essential Femininity: A Conversation Between Mary Kelly and Paul Smith," Parachute 37 , no. 26 (spring 1982): 32.

52 Amelia Jones, Body Art/Performing the Subject (Minneapolis: University of Minnesota Press, 1998), 11.

${ }^{53}$ While Jones, 12-14, acknowledges that body art is often embedded in performative practice, she differentiates between the two in order to draw attention to the role of the body in the art projects explored in her study, and to refer to body art projects that are not necessarily performed for an audience.

${ }^{54}$ Ibid., 10. Emphasis in original.

${ }^{55}$ Ibid., 1 .

${ }^{56}$ Ibid., 215.

${ }^{57}$ Mark Dery, Culture Jamming: Hacking, Slashing and Sniping in the Empire of Signs (San Francisco: Open Magazine Pamphlet Series, 1993), available online at <http://www.levity.com/markdery/ culturjam.html>, June 2003.

58

Critical Art Ensemble, The Electronic Disturbance (New York: Autonomedia, 1994), 23.

${ }^{59}$ For a discussion of hacktivism in relation to contemporary social activism, see Tim Jordan, "Hacktivism: Direct Action on the Electronic Flows of Information Societies," in Challenges to Democracy: Ideas, Involvement and Institutions, ed. Keith Dowding, Jim Hughes, and Helen Margetts (London: Palgrave, 2001). Jordan argues that far from being the antithesis of physically engaged activism, hacktivism is part of a worldwide trend in the practice of communal involvement in issues of global significance.

60

See note 7 , above.

${ }^{61}$ In a more recent discussion regarding the role of the street as a site of resistance, CAE has expressed a more approving attitude, perhaps though not explicitly attributed to the resurgence since 1998 of street-level social activism: "The street still acts as a key pedagogical base (at present it's more useful than the net because it has greater tactical visibility). It's still a place where the discourse of resistance can be developed, and it is still a place where localized power vectors can be challenged. The streets may be 'dead capital,' but they are by no means dead." Jon McKenzie and Rebecca Schneider, "Critical Art Ensemble: Tactical Media Practitioners," The Drama Review 44, no. 4 (winter 2000): 144. 
${ }^{62}$ The employment of femininity as a trope of feminist discourse dates as far back as the early-twentiethcentury suffrage movements. In The Spectacle of Women: Imagery of the Suffrage Campaign 1907-14 (Chicago: University of Chicago Press, 1988), 222-223, Lisa Tickner shows how suffragists "forged a feminist critique of the patriarchal control of women's sexuality in the family and by the state... largely by mobilizing the ideology of womanliness."

${ }^{63}$ Mary Kelly's Post-Partum Document (London: Routledge; Boston: Kegan Paul, 1983) is paradigmatic of this discourse.

${ }^{64}$ Judith Butler, Gender Trouble: Feminism and the Subversion of Identity (London: Routledge, 1990), 146. Rosi Braidotti is another key proponent of gender performance. Braidotti, who introduces the notion of a "nomadic female subjectivity" that can accommodate both a politics of location and a reinvestigation of the female body as a site on which these politics can be located, advocates a revisiting of conventional tropes of femininity as a means of reclaiming female subjectivity. Rosi Braidotti, "Sexual Difference as a Nomadic Political Project," in Nomadic Subjects: Embodiment and Sexual Difference in Contemporary Feminist Theory (New York: Columbia University Press, 1994), 169-71.

${ }^{65}$ A history of the Raging Grannies is available on the Raging Grannies of Seattle Web site, $<$ http://www.raginggrannies.com>, June 2003.

${ }^{66}$ Ottawa Raging Granny Alma Norman clarifies: "We would encourage men to go out and form a group of 'grouchy grandpas' but we are all women here." Quoted in Kate Keating, "Raging Against the Machine (and everything else) Granny Power!" in Peace and Environment News, Peace and Environment Resource Centre, April 1998, <http://perc.ca/PEN/>, June 2003.

${ }^{67}$ Taylor, 83 .

68

Alma Norman, quoted in Keating, n.p.

${ }^{69}$ Information about radical cheerleading is available on the Radical Cheerleaders Web site, <http://www. geocities.com/radicalcheerleaders>, June 2003.

${ }^{70}$ Rachel Engler-Stringer, personal communication with author, 21 November 2002.

${ }^{71}$ Ibid.

${ }^{72}$ Homi K. Bhabha, The Location of Culture (New York and London: Routledge, 1996), 120-121.

73 Butler, 145.

${ }^{74}$ Linda Hutcheon, A Theory of Parody: The Teachings of Twentieth Century Art Forms (New York and London: Methuen, 1985), 26, 32.

${ }^{75}$ Linda Hutcheon, The Poetics of Postmodernism: History, Theory, Fiction (New York: Routledge, 1988), 26. Emphasis added.

${ }^{76}$ Pierre Bourdieu, The Field of Cultural Production: Essays on Art and Literature (New York: Columbia University Press, 1993), 30. 
${ }^{77}$ Ibid., 30-31.

Vince Tinguely, "The Politics of Appearance (and Disappearance) at the FTAA Summit in Quebec City," La Voce del Popolo (Montreal) 1 (fall 2001), <http://www.casadelpopolo.com/voce010/0109threereviews. html\#appearance>, January 2003.

79

It is perhaps no coincidence that businesspeople are often referred to as "suits."

In a related context, John Berger argues in "The Suit and the Photograph," in About Looking (New York: Vintage Press, 1991), 34-35, that in August Sander's 1914 photograph, "Peasants Going to a Dance," the illfitting suits worn by the peasants reveal that the suit is a "professional ruling class costume" designed to "idealize purely sedentary power." The peasants' uneasy occupation of these costumes reveals that their submission to the cultural hegemony imposed by the suit will always be "second-rate, clumsy, uncouth, defensive." In "Re-presenting Colonial Canada through Collected Photographs: Interpretations of Travel Albums Assembled by Nineteenth-Century British Army Officers" (master's thesis, Carleton University, 2002), Robert Evans compares this reading to Bhabha's notion of colonial mimicry.

${ }^{81}$ This phrase is used by Jan Cohen-Cruz to describe a troupe of cross-dressing pro-choice activists in "At Cross-Purposes: The Church Ladies for Choice," in Radical Street Performance, ed. Cohen-Cruz, 95.

Bernice Johnson Reagon, quoted in Peeps, n.p.

${ }^{83}$ Peter Schumann, Puppetry and the New World Order (Vermont: Bread and Puppet Press, 1993), n.p.

${ }^{84}$ The Zapatistas or EZLN is a revolutionary anti-capitalist and anti-imperialist coalition of workers and peasants based in Chiapas, Mexico. For a discussion of the performative politics of the Zapatista movement, see Guillermo Gomez-Peña, "The Subcomandante of Performance," in First World, Ha Ha Hal: The Zapatista Challenge, ed. Elaine Katzenberger (San Francisco: City Lights, 1995).

In autumn of 1994 the mayor of Milan, while issuing an order to evict a squatter camp at the Leoncavallo Social Centre, is reported to have said; "From now on, squatters will be nothing more than ghosts wandering about in the city." His pronouncement prompted the adoption of ghost-like white costumes by members of social centre, who later formed Ya Basta. See Arthur Nelson, "A Bunch of Bastas: The Inspiration for AntiFree Trade Foes Everywhere Find Themselves at a Crossroads," NOW Magazine Online Edition 20, no. 30 (29 March - 4 April 2001), <http://www.nowtoronto.com/issues/2001-0329/news spread.html>, June 2003. The colour white, chosen by Ya Basta to symbolize the invisibility of their status as "ghosts on the margins," is also the colour of the scarves worn by the Mothers of the Plaza del Mayo as a signifier of invisibility. Conversely, Bread and Puppet puppeteers often wear white in order to make themselves visible--black is the colour conventionally worn by puppeteers in order to remain invisible behind their puppets. No doubt, an entire thesis could - and perhaps should - be written on the rich symbology of the colours of dissent.

Ya Basta spokesperson, quoted in "When Masks Are Outlawed...Only Revolutionaries Will Wear Masks!" Maori Independence Web site, 11 March 2001, <http://aotearoa.wellington.net.nz/int/mask/masks.htm>, April 2003.

${ }^{87}$ Human chains, sit-ins, and other more site-specific actions such as tree hugging are common direct-action techniques that employ the body as a barricade.

${ }^{88}$ See Michel Foucault, The History of Sexuality. Volume 1: An Introduction (1976), tr. Robert Hurley (New York: Vintage Books, 1990), 133-159. 
${ }^{89}$ Ya Basta, "An Address to Civil Society," New York City Ya Basta Collective Web site, 29 May 2001, $<\mathrm{http}: / /$ free.freespeech.org/yabasta/genoa.html>, June 2003.

90

The anti-road movement emerged in the early 1990s in opposition to the demolition of residential neighbourhoods for the building of highways. Favoured methods of protest were sit-ins, blockades, and house squats. Graeme Chesters, "Bodies as Barricades: Bodies as Messages," paper presented at the British Sociological Association Annual Conference, University of Edinburgh, April 1998, available at the Shifting Ground Resource Area Web site, <http://ktru-main.lancs.ac.uk/CSEC/NSCMRsrc.nsf/0/e204d0a20923e 73b802565e6003913c1/\$FILE/BSAPAP\%7E1.htm>, May 2003. See also John Jordan, "The Art of Necessity: The Subversive Imagination of Anti-Road Protest and Reclaim the Streets," in DiY Culture: Party and Protest in Nineties Britain, ed. George McKay (London: Verso, 1998).

91

Chesters, n.p.

${ }^{92}$ Engler-Stringer, personal communication.

${ }^{93}$ Peggy Land, "Raging Grannies Save Young Protesters From Police: Moments of Faith at the Wall, Quebec City April 21," Straight Goods Web site, 31 May 2001, <http://goods.perfectvision.ca/FTAA/View

Brief.cfm?REF=62>, February 2003. 


\section{CHAPTER THREE}

\section{"Whose Streets? Our Streets!": Spaces and Carnivals of Resistance}

The carnival celebrated temporary liberation from the prevailing truth and from the established order; it marked the suspension of all hierarchical rank, privileges, norms, and prohibitions.

\section{Mikhail M. Bakhtin, Rabelais and His World ${ }^{1}$}

It is difficult to find anyone who has fully participated in such an action whose sense of human possibilities has not been profoundly transformed as a result. It's one thing to say, "Another world is possible." It's another to experience it, however momentarily.

David Graeber, "The New Anarchists",

Puppets and street theatre, Radical Cheerleaders and Raging Grannies-the performers and performing objects discussed in the preceding chapter are representative, but by no means exhaustive, illustrations of the exuberant atmosphere of creative dissent on the streets of Quebec City during the anti-FTAA demonstrations in April 2001. In this chapter, I take a broader look at the demonstrations in their entirety in order to discuss the ways in which they were staged as a collective act of reclaiming public space and as a carnivalesque "rehearsal for revolutionary change." In theorizing the ways in which the visual culture of public space is transformed during mass demonstrations, I discuss the idea that "spaces of resistance" are created in opposition to, but also within, spaces of domination. I argue that what unified the anti-FTAA demonstrators in Quebec City was a collective will to reclaim the public sphere as a space in which to demonstrate opposition to the perceived privatization of all aspects of contemporary life under the neo-liberal economic model of globalization. Finally, I apply Mikhail Bakhtin's theory of the 
"carnivalesque" in order to analyze the strategy of festive dissent and its contribution to the creation of spaces of resistance. I argue that what distinguished the carnivalesque performance of resistance in Quebec City was its enactment in a time and space in which prohibition was not suspended, but rather strictly enforced. Similar to, but divergent from the utopian impulse of Bakhtinian carnival, festive demonstrations perform an oppositional utopianism — embedded in, and in conflict with, what is perceived to be a dystopian climate. I conclude that carnivalesque performances of dissent in the context of conflict generate an "affective investment" that itself generates a field of collective agency.

\section{Spaces of Resistance}

In The Production of Space, Henri Lefebvre argues that space, far from being an inert, empty stage for social interaction, relates dialectically to the social. Space, in other words, both produces and is produced by the social. In a capitalist society, Lefebvre continues, this dialectic is submerged under the domination and homogenization of space by the bureaucratic state. The resulting condition, which Lefebvre terms "abstract space," reduces the public sphere to a site of profit and consumption: "The dominant form of space, that of the centres of wealth and power, endeavours to mould the spaces it dominates, and it seeks...to reduce the obstacles and resistance it encounters there. ${ }^{94}$ In recognition of the spatial implications of social relations, analysts of new social movements have begun increasingly to draw on geographical metaphors in order to "map" the positions of these movements. "Geographies of resistance" and "spaces of resistance" have become common terms to denote the significance of space, and particularly public space, as both field and objective of political struggle. Resistance, explains Steve Pile, "not 
only takes place in place, but also seeks to re-appropriate space, to make new spaces. ${ }^{5}$

Pile acknowledges that the control over space by dominant regimes severely limits the potential for the creation of spaces of resistance. He draws on the work of Michel de Certeau, who argues in The Practice of Everyday Life that opposition to hegemonic control over social and spatial practices must adopt "tactics" of quotidian resistance against "strategies" of domination within the spaces in which these strategies are enacted. ${ }^{6}$ Pile, however, rejects the potentially fatalistic connotations of de Certeau's theory, which implies that domination over spaces and social relations can be undermined, but never eliminated. Instead, Pile emphasizes the productive capability for "everyday" resistance to infiltrate and rupture the terrains of domination, which he considers "incomplete, fluid, liable to rupture, inconsistent, awkward and ambiguous." ${ }^{8}$ Resistance, rather than being conceptualized as an alternative space, is conceived as a transgression across and into dominant spaces: "The interactions within and between dominant relations of power produce simultaneously fixed and fluid spatialities... Resistance occurs as a rupture in the fabric of these interactions." Before analyzing the ways in which dominant space was transgressed and re-appropriated during the Quebec City demonstrations, it will be useful to explore the ways in which the "inconsistent, awkward and ambiguous" nature of official space was revealed even before the protests began.

In the 1960 s, the Paris-based Situationist International, whose ideas regarding the erosion of public space in capitalist culture coincided with Lefebvre's, ${ }^{10}$ postulated that the capitalist conquest of space is both achieved and concealed by "exhortations to the authority of objective use." "Public space, in other words, is misleadingly objectified in order to naturalize and neutralize its status as a theatre of mass consumption, and to avoid 
challenge and conflict. The Situationists, like de Certeau, advocated a "revolution of everyday life" that would reveal and challenge the capitalist conquest of public space through radical "situations" enacted within it. ${ }^{12}$ What the Situationists did not address is the unique window of opportunity that opens when the conquest of public space is exposed by the dominant regime itself, and the ways in which this exposure also reveals the ambivalence and vulnerability of that power.

On 7 January 2001, the Royal Canadian Mounted Police, the body that coordinated security measures for the Summit of the Americas, held a press conference to confirm and detail its plans to erect a concrete and chain-link fence surrounding a nine-square-kilometre area of Quebec City. ${ }^{13}$ Summit delegates and accredited journalists, along with residents and workers within the perimeter, would be issued personal passes in order to enter and exit the vicinity. The erection of a perimeter fence was one aspect of a wide-ranging series of security measures based, as discussed in chapter one, on the pattern of violent confrontations between protesters and police at previous global summits. The security measures, which were decried by activists, constitutional lawyers, citizens' coalitions, and some Quebec City residents, ${ }^{14}$ included, along with the erection of the perimeter fence, the deployment of over 6,000 officers from municipal, provincial and federal police agencies. The unprecedented scope of these measures conveys the extent to which organizers of the Summit of the Americas recognized the contested nature of the Summit. For some analysts, the security operation was perceived as a deliberate strategy to provoke fear and divide the global justice movement along violent/non-violent lines. In an article written one month before the Summit, journalist Naomi Klein argued that the proposed perimeter fence represented the federal government's efforts to frame dissent as a violent activity and 
to dissuade "peaceful" citizens from attending the demonstrations. ${ }^{15}$

Klein also noted that the fence functioned as a physical manifestation of "usually invisible walls of exclusion. ${ }^{, 16}$ In the preceding chapter, I argued that the performance tactics of the Weaving a Web of Solidarity action used the perimeter fence as a focal point at which to bear witness to the politics of exclusion. Actions such as this one, and those that will be discussed below, demonstrate how the perimeter fence functioned inadvertently to expose-thereby exposing to contestation-the heretofore-concealed “conquest of space."

The perimeter fence was not the only example of the (involuntarily) radical alteration of "abstract" public space in the days leading up to the summit. A sense of tension permeated the city, aggravated by the presence of armed police and military personnel, as well as the boarding of storefront windows and the closing of streets near the perimeter fence. ${ }^{17}$ These measures, designed to mitigate the possibility of conflict, had the unintended consequence of dramatically altering the visual culture of the city. As Toronto artist and architect Adrian Blackwell has noted, the covering of shop windows and signage resulted in a temporary erasure of the "spectacular presence of commerce" in the city. ${ }^{18}$ The prohibition of vehicles from several streets further transformed Quebec City's public sphere, temporarily displacing what Guy Debord refers to as the "dictatorship of the automobile., ${ }^{, 19}$ These alterations to the visual makeup of the city, intended to protect the "abstract space" of capitalist hegemony from potential conflict, instead exposed its vulnerability, and exposed it also to the transgressions and infiltrations of counterhegemonic resistance.

One of the most abundant manifestations of resistance before and during the 
Quebec City demonstrations was the proliferation of graffiti and "culture jams." Both tactics relate to the Situationist International strategy of "détournement," a term used to describe the manipulation of mass culture communication in order to critique its message. According to Michel Gardiner, the strategy of détournement functions on two levels: to target specific ideological messages, and to attack more generally the monologue of dominant culture. ${ }^{20}$ Détournement was perceived by the Situationist International as a method of infiltrating the spaces of dominance by inscribing messages of resistance onto them.

In Quebec City, the perimeter fence and boarded shop windows were transformed overnight into canvases of dissent. The concrete plinth on which the fence was erected became a sort of "democracy wall" onto which protesters inscribed messages such as "Wall of Shame," "This is what democracy looks like!" and "Bienvenue à Berlin '89". The fence itself was festooned with the web woven by the Women's Action, and with banners, posters, balloons, letters, and even toilet paper (fig. 3.1). In an effort to express opposition to the exclusion of Cuba from official summit proceedings, Cuban flags were abundant, as were humorous references to the prison-like appearance of the fence itself ("Corporate Penitentiary" read one sign) and the zoo-like appearance of police in riot gear grouped behind it ("Please do not feed the animals" read another). The boards erected by local merchants to avoid damage to glass windows were also adorned with colourful messages, both literal and figurative, that bore witness to a diversity of issues, from the Zapatista movement in Chiapas, Mexico, to the environmental damage wrought by corporate-driven global economic policies (fig. 3.2). The perimeter fence, erected to impede access to the summit events, instead became a liminal space where the boundaries between dominant 
and marginal discourses were contested.

Likewise, the streets of Quebec City during the Friday and Saturday marches were host to a rich array of banners addressing a multitude of themes. Some, with messages such as "Bow your heads: The corporations will now lead us in prayer"(fig. 3.3), ridiculed the perceived ascendancy of multinational corporations as neo-demigods. Others focused attention on the domination of U.S. foreign economic policy, while many, with messages such as "Human need not corporate greed" and "Fair trade not free trade" (fig. 3.4) expressed alternative visions of globalization. What these graffiti, banners, and placards shared was an insistent desire to transform a non-dialogical space into a forum for oppositional communication.

Anthropologist Marcel Hénaff and political theorist Tracy B. Strong, who theorize the public sphere as an inherently theatrical space, posit two modes of communication within it. The first is communication that encourages what they term an "intransitive nonreciprocal relationship" between speaker and audience. Related to conventional theatre, such communication "does not admit of a response or only of a response in another space." ${ }^{21}$ The second possibility is that of a "transitive" relationship. With such communication, "I act with the expectation that my actions will elicit a response, from you. The response can be positive or negative, but my action is undertaken with the sense that you will not be able to remain indifferent. ${ }^{, 22}$ In contemporary urban space, most communication is arguably intransitive and nonreciprocal. The most ubiquitous form of street communication, commercial advertising, is designed to invoke not response but rather reception and absorption. As Hénaff and Strong comment, the result is that public space "is entirely taken up by that staging of the social performed by advertising. Thus, the 
main public space of our time is that of consumption.."23 Communication via placards and banners, on the contrary, invokes response by broadcasting counter-hegemonic messages that are necessarily incongruous in the context of the commercialized public spaces into which they are inserted.

It is this incongruity that creates the opportunity for a transitive relationship to arise-a condition that Hénaff and Strong consider crucial for the transformation of public space into democratic public space. ${ }^{24}$ One favoured tactic of transitive communication, in which individuals on the street choose to become producers, rather than consumers, of meaning, is culture jamming. Culture jamming, the alteration of existing communicative vehicles such as billboards, involves undermining the codes of advertising by obscuring or re-writing their messages. Like radio signal jamming from which its name derives, culture jamming "introduces noise into the signal as it passes from transmitter to receiver, encouraging idiosyncratic, unintended interpretations. ${ }^{, 25}$ Because it enacts a communication with both the intransitive messages of corporate advertising and their intended audience, culture jamming opens a field in which intransitive communication is forced into a transitive mode. Culture jamming responds to, and challenges, messages that encourage only passive consumption. As Lucy Lippard notes, the result is a transgression into geographies of power: "'Parasitic' art forms, like corrected billboards, can ride the dominant culture physically while challenging it politically, creating openly contested terrains that expose the true identities of existing places and their function in social control. ${ }^{26}$

A bus-shelter billboard on rue Charest in Quebec City demonstrates that culture jamming can function as a multi-layered critique of dominant messages (fig. 3.5). This 
advertisement for Buffalo Jeans, which features a provocatively posed female model, was "corrected" by several jammers—a sticker reading "NO!" has been applied to the poster, the words "This insults all women!" have been written over the woman's mouth, and "Women are not comodities [sic]" is emblazoned across the entire advertisement. By exposing and interrogating the messages inherent in consumer advertising, culture jammers such as those who responded to the Buffalo Jeans advertisement transform monological commercial spaces into dialogical public spaces, and transform their own status as passive consumers of commercial messages into active producers of meaning. ${ }^{27}$

Graffiti can also be read as a response to the intransitivity of public space. Like culture jamming, graffiti is a subversive activity that contests the contemporary condition of public space as a site where communication is regulated and citizens relegated to passive consumers. Theorist Anne Norton argues that the differences between advertising and graffiti are merely naturalized conventions that sanction one form of public speech while criminalizing another. For Norton, these conventions function to prohibit open access to political discourse: "We must not see graffiti responses as part of a political debate. We must see these as defacement of property rather than as public responses to public speeches. ${ }^{, 28}$

The insistence of graffiti artists to engage in political debate despite—or perhaps because of-the criminality of the act renders graffiti a potentially powerful strategy of dissent. In his last essay, Pierre Bourdieu contended that the most insidious aspect of corporate globalization is its capacity to conceal its politics under the guise of free market economics. Bourdieu calls upon anti-globalization activists to "expose and counter the hegemony of globalization" by openly defying efforts to "depoliticize' the way we are 
ruled. ${ }^{29}$ Graffiti and culture jamming function to demystify and denaturalize the processes of capitalism and corporate globalization by openly debating and contesting the politics of corporate hegemony in public spaces. If culture jamming and graffiti have a role to play in the struggle over the meaning of globalization, it lies in their ability to communicate counter-hegemonic messages via hegemonic media, and their propensity to reclaim public space as a site of political discourse. Graffiti and culture jamming have the capacity, by virtue of their always already subversive status, to expose and emphasize what Homi K. Bhabha refers to as the "contingent and contradictory enterprise" of global politics.

This is not to suggest that graffiti and culture jamming are uniquely effective tactics for the reclamation of public space. In fact, there is some question as to the efficacy of "semiotic guerrilla warfare." "Naomi Klein suggests that in an age of hyperbolic irony, in which marketers are increasingly adept at transforming oppositional messages into advertising gimmicks and lifestyle choices, "we are beyond being abruptly awakened by a startling image, a sharp juxtaposition or even a fabulously clever détournement. ${ }^{, 32}$ Indeed, commercial marketers have demonstrated a remarkable capacity to capitalize on anticapitalist sentiment by co-opting the semiotic weapons used against them. In 2001, for example, the American clothing manufacturer and retailer The Gap launched a campaign that involved "defacing" their store windows with pre-fabricated graffiti that read "Freedom" and "We the People." ${ }^{, 33}$ This ability to recuperate or re-appropriate counterhegemonic messages into a hegemonic system, which Debord refers to as "spectacular rebellion, ${ }^{34}$ suggests that expressions of dissent, in order to maintain efficacy, must be as fluid and adaptable to change as their opponents, and that opposition to "strategies" of domination requires multiple "tactics" of resistance. 
Perhaps in recognition of the limitations of altering dominant representations as a tactic for creating viable spaces of resistance, a collective sense has emerged that the reclamation of public space requires sustained physical engagement. Anarchist theorist Hakim Bey has provided one such model of engagement. Bey's notion of the Temporary Autonomous Zone (TAZ), detailed in his 1985 TAZ: The Temporary Autonomous Zone: Ontological Anarchy, Poetic Terrorism, involves the clandestine, transitory occupation of spaces in which to enact radical cultural democracy. Bey proposes that the TAZ is "like an uprising which does not engage directly with the State, a guerrilla operation which liberates an area... and then dissolves itself to re-form elsewhere/elsewhen, before the State can crush it., ${ }^{36}$

Bey is quick to point out that temporary autonomous zones do not preclude the deployment of other strategies of dissent. He does, however, advocate what he terms a "tactic of disappearance," arguing that confrontations with power, "which has lost all meaning and become sheer simulation, ... only result in dangerous and ugly spasms of violence. ${ }^{, 37}$ In this sense, Bey's model recalls that of Critical Art Ensemble which, as discussed in chapter two, promotes nomadic, virtual resistance as the most effective strategy against nomadic, virtual power. Temporary autonomous zones are also reminiscent of a tactic described by Kevin Hetherington as the occasionalism of marginal utopics. For Hetherington, the enactment of utopic practice requires a spatial play wherein a community of resistance acquires a marginal position in which to constitute collective identity and contest the hegemonic production of space. ${ }^{38}$ What differentiates Hetherington's conception of utopic margins from Bey's temporary autonomous zones is Hetherington's analysis of marginality as a liminal, transgressive space. While he 
acknowledges that counterculture communities such as squats and communes often operate in spaces that are considered geographically marginal, Hetherington argues that "margins do not exist only at the metaphorical edges of society but also as spaces between. Neither are there always clearly defined, unified spaces.",39

Steve Pile is more emphatic in his insistence that in order to achieve efficacy, spaces of resistance must transgress spaces of power: "Resistance does not just act on topographies imposed through the spatial technologies of domination, it moves across them under the noses of the enemy, seeking to create new meanings out of imposed meanings, to re-work and divert space to other ends. ${ }^{, 40}$ Temporary autonomous zones, in other words, are most effective when they infiltrate non-autonomous zones to expose the fluidity and rupturability of those spaces. This is a lesson learned by activist organizations such as London's Reclaim the Streets, which organize unauthorized street festivals in the spirit of temporary autonomous zones, but without the "will to disappearance" advocated by Hakim Bey. ${ }^{41}$

During the anti-FTAA demonstrations, a temporary autonomous zone was organized by Montreal's Anti-Capitalist Convergence (CLAC) and Quebec City's Summit of the Americas Welcoming Committee (CASA) in a downtown park on rue Charest in Quebec City. In this park, activists went to rest between battles with tear gas and to dance to the relentless beat of hip-hop music blaring from a cube van (fig. 3.6). Determinedly non-confrontational and certainly transitory, the Quebec City TAZ was also a radical misuse of public space. Permission was not sought, nor were licenses issued. ${ }^{42}$ Perhaps what most distinguishes Quebec City's temporary autonomous zone from Bey's conception is the fact that the CLAC/CASA zone was established not in a remote, 
"marginal" area of the city, but metres away from the summit perimeter fence. ${ }^{43}$ As such, it became a space of resistance that encroached both symbolically and physically on the "abstract space" that had so quickly transformed into a battlefield. The extent to which the Quebec City TAZ was considered a transgressive, confrontational use of space was made evident when, on the evening of Saturday 21 April, riot police advanced on the area and dispersed the dancers with waves of tear gas. ${ }^{44}$

As Hakim Bey acknowledges, the TAZ strategy of resistance is only one weapon in the growing arsenal of contemporary public dissent. Non-violent direct action is another, and in many ways it is as symbolic in terms of reclaiming public space as it is a direct strategy of confrontational opposition. One of the more controversial tactics of non-violent direct action in Quebec City was the breaching of the perimeter fence, which was torn down at several areas during the weekend. What is most revealing about these breaches is the extent to which the fence was perceived as a symbolic, rather than actual, barrier. Indeed the ease with which the fence was torn down suggests that it was not intended to function as a physical fortification, but rather as a symbolic barrier. ${ }^{45}$

At the same time, the actions of the protesters who breached the fence reveal that the tactic was deployed as a symbolic transgression. At no point did the protesters attempt to advance into the summit area. Some danced on the fallen fence, while others engaged in stand-offs with riot police positioned several metres behind the perimeter. Certainly, the copious use of tear gas was a real impediment to further action. But the protesters' equally abundant use of gas masks and other protective gear suggests that the objective in breaching the fence was not to advance into the summit, but simply to breach the fence. ${ }^{46}$ The fence, a visual metaphor of exclusion, epitomized Lefebvre's notion of spatial forms 
producing social structures. As a liminal space where the intransigence of centres and margins were tested and contested, the fence also revealed and exploited the productive value of resistance enacted in marginal spaces.

As discussed in chapter one, much space has been devoted in mainstream media to the prevalence of violence during "anti-globalization" protests. A key distinction is to be made, however, between violence inflicted upon humans and vandalism done to property. During the Quebec City demonstrations, violence was minimal, though vandalism did occur. $^{47}$ Beside the actions at the perimeter fence, several activists—notably members of the infamous Black Bloc_-engaged in less nuanced methods of culture jamming by smashing some of the few unprotected glass windows at stores and banks. ${ }^{48}$ Whether this oppositional strategy has any merit or efficacy is open to debate. More interesting is the question of intent: Are such actions simply manifestations of nihilistic rage and adolescent destructiveness? Or do they, as art activist Robbie Herbst has proposed, possess a poetic resonance? Herbst cites a communiqué issued by the ACME Black Bloc faction, in which the group defends property destruction as the conversion of "limited exchange value" into "expanded use value": "A storefront window becomes a vent to let some fresh air into the oppressive atmosphere of a retail outlet. A newspaper box becomes a tool for creating such vents or a small blockade for the reclamation of public space or an object to improve our vantage point by standing on it.".49

Without engaging in a futile argument over the myriad differences and similarities between vandalism, art, and poetry, I would like to argue that property damage in the context of mass demonstrations is at once a manifestation of festering adolescent anger and an attempt to symbolically repossess public space as a site of political debate. Indeed, these 
two phenomena are not entirely unrelated. The fury demonstrated by Black Bloc anarchists derives at least in part from the perception that alternative avenues for the expression of dissent are inaccessible. To shatter a storefront window or topple a fence is to reveal the intransitivity—-to use Hénaff and Strong's term-of public space, and to introduce conflict into that sphere as a means of provoking debate. ${ }^{50}$

In his 1992 essay "The Violence of Public Art," W.J.T. Mitchell argues that the notion of a unified public sphere devoid of conflict is a mythic one designed to obscure its actual function as an exclusionary field: "The fictional ideal of the classic public sphere is that it includes everyone; the fact is that it can be constituted only by the rigorous exclusion of certain groups - -slaves, children, foreigners, those without property, and (most conspicuously) women." ${ }^{, 51}$ Mitchell contends that the conventional function of public art has been to conceal the violence of public space under a cloak of "monumentalized and pacified spaces. ${ }^{.52}$ If the erection of fences is a physical manifestation of the exclusionary nature of public space, the invocation to a unified public sphere is its symbolic expression. $^{53}$

Art historian Rosalyn Deutsche concurs. In her 1996 Evictions: Art and Spatial Politics, Deutsche contends, like Mitchell, that public art tends to reject confrontation in favour of homogeneous conceptions of public space. In response, Deutsche proposes a model for public art that would re-introduce conflict into the public sphere. Conflict, she concludes, is not only not anathema to the democratic use of public space, but is indeed a condition of its existence: "Social space is produced and structured by conflicts. With this recognition, a democratic spatial politics begins. ${ }^{, 54}$ The intention here is not to conflate conflict with violence, or even vandalism. Indeed, Deutsche uses the term conflict to 
connote, and advocate, the introduction of open dialogue into the public sphere. My argument is simply that activists who engage in direct action trespass both physically and metaphorically into the spaces of dominant society; their actions, which reveal the closed nature of public spaces, also reveal chinks in the armour of those spaces, and introduce these chinks as weapons in the conflict to create radical spaces of resistance.

One particularly metaphorical introduction of conflict during the anti-FTAA demonstrations was the deployment of a medieval catapult that launched stuffed animals over the security fence. The catapult action was devised by the Deconstructionist Institute for Surreal Topology (DIST), an Edmonton-based activist group formed in 1997. Prior to the Quebec City demonstrations, the group published an online list of suggestions for the formation of tactical "blocs." As DIST member Marika Schwandt explains, "Our basic premise was that the Black Bloc was getting a little tired and that we should keep up the same tactics, but with a more creative approach that would throw off the authorities and the media." Suggestions included the Country Club Cluster ("Throwing bottles and rocks over a fence? Ugh. The Association of Anarchist Golfers are very well dressed, in baggy pants, long socks, and colourful shirts. Damn, those golf balls go far!"') and the Circus Cluster ("What's a Carnival without clowns?"). ${ }^{56}$ For Schwandt, the use of humour as a tactic of resistance is more than simply a means of entertaining the converted. It is also a way to participate more pro-actively in the movement and its representation: "We didn't want to see the same-old, same-old protests where every street scene and news story is prescripted and completely anticipated. We'd like to exercise a little more control than that." ${ }^{57}$ Although DIST did not intend to carry through with the Medieval Bloc proposal, its dissemination over the Internet caught the eye of Rabble.ca's Judy Rebick, who offered to 
fund the action. ${ }^{58}$ Thus on Friday, 20 April, DIST members participated in a "Carnival March," organized by CLAC and CASA, from Laval University to the perimeter fence armed with colander helmets, pot-lid shields, and an exact replica of a typical medieval catapult (fig. 3.7). The catapult, which was promptly confiscated by the Sûreté du Québec and held as evidence in the arrest of prominent activist Jaggi Singh on charges of possession of a dangerous weapon, ${ }^{59}$ was designed to ridicule the fortress-like Summit security perimeter. As a DIST press release later explained,

We used it to mock the whole absurdity of the siege mentality that the elite find themselves it. They were having the Summit behind closed doors in a fortress, like kings in a castle. We tried to evoke the feeling of being the unwashed masses, who are completely shut out from decision-making. ${ }^{60}$

The catapult action, intended as a humorous parody of the Summit security operations, did not simply introduce conflict into the "objectified space" of the public sphere. Rather, it exploited the newly revealed conquest of space--made manifest by the presence of a chain-link fence guarded by armed police—in order to transform that space into a spontaneous and unsanctioned representational battlefield.

The limitations of direct-action confrontation as a strategy of dissent are numerous. For one, property damage is often interpreted, and thus censured, as violent activity. Thus even attempts such as those by DIST to exercise control over dominant representations of activism can be appropriated, as demonstrated in chapter one, by mainstream media's ability to interpret ideologically imbued conflict as aimless violence. Vandalism can function as an easy target at which to aim salvos against political protest in general. More significantly, perhaps, activists in the global justice movement recognize that in order to sustain a viable movement, attention must be paid not only to contesting the spaces of 
domination through resistant activities, but also to proposing alternative spaces of resistance, spaces in which to emphasize that, in the words of the motto of the 2002 Porto Alegre World Social Forum, "another world is possible.", Steve Pile theorizes this proposition in geographic terms: "Tactics of resistance have at least two 'surfaces': one facing toward the map of power, the other facing in another direction, towards intangible, invisible, unconscious desires, pleasures, enjoyments, fears, angers and hopes. ${ }^{, 62}$

During the anti-FTAA demonstrations in Quebec City, creative spaces of productive resistance emerged seemingly effortlessly. Cutting through the smoke of tear gas and the noise of military helicopters, ignoring the advancing lines of riot police and the derisory comments of world leaders, activists created, if momentarily, the world they believed was possible. An example of this was at the Ilôt Fleurie, discussed in chapter two as the site of an art space. This area under a lowertown overpass also hosted Winnipeg's Food Not Bombs, whose members spent the weekend supplying meals to protesters; a citizen-medics area where hundreds of activists were treated for injuries and tear-gas inhalation; and a stage that functioned as both speaker's corner and live music venue.

The reclamation of public space for the purpose of imagining and rehearsing a new world was not limited, however, to one venue. Instead, many new worlds were envisioned in the radically open spaces vacated by commerce and automobiles. The spaces of resistance that sprung up on the streets of Quebec City should not be confused with Hakim Bey's temporary autonomous zones, for they were spaces whose very existence was in constant dispute, and which were repeatedly targeted and dispersed by police forces. ${ }^{63}$ It was indeed the vacillation of these areas between spaces of liberation and spaces of resistance that rendered them most subversive in terms of the creation of a marginal 
utopics. And it is this tension between oppositional and utopic performances that renders the notion of "carnivalesque" a useful one for the analysis of these performances.

\section{Carnivals of Resistance}

The carnivalesque is a term coined by Russian social philosopher and cultural theorist Mikhail Bakhtin in his 1940 treatise on late-medieval/early-Renaissance carnivals. ${ }^{64}$ For Bakhtin, carnival was not simply an innocuous occasion for festivity. Rather, it was a period of "temporary liberation from the prevailing truth" during which hierarchical structures were disregarded or inverted, and habitual conformity rejected.

The carnivalesque has been an attractive framework for analysts of twentiethcentury counterculture. While, as Baz Kershaw notes, elements of carnivalesque have been adopted as strategies of festive resistance since at least the $1960 \mathrm{~s}$, only since the late $1980 \mathrm{~s}$ have theorists begun to draw connections between Bakhtin's carnivalesque and counterculture performance. ${ }^{66}$ What distinguishes contemporary manifestations of carnivalesque is the degree to which they draw explicitly on Bakhtin's terminology, as well as his overall framework for carnivalesque performance. The CLAC/CASA call for a "Carnival Against Capitalism" during the anti-FTAA demonstrations in Quebec City is a prime example of the employment of Bakhtinian notions of the carnivalesque as a strategy of creative resistance.

CLAC, formed in April 2000 in direct response to Quebec City's decision to host the Summit of the Americas, was one of the more vocal organizing committees in the months leading up to the Quebec City demonstrations. An organization that advocates a variety of forms of civil disobedience or what it refers to as a "diversity of tactics," CLAC 
proposes that "it is possible to be both radical and effective, militant and creative." ${ }^{.67} \mathrm{CLAC}$ organized three colour-coded avenues of mobilization in preparation for the demonstrations: disruption (red), obstruction (yellow), and festive demonstration (green). ${ }^{68}$ Whereas disruption consisted of confrontational tactics such as the tearing down of the perimeter fence, and obstructive strategies included occupations, non-violent civil disobedience, and other non-confrontational tactics, the mobilization of festive resistance was designed to nurture what André Drainville described as the "radically creative ambience ${ }^{, 69}$ that pervaded Quebec City during the demonstrations.

In keeping with this objective, CLAC, in collaboration with the Quebec City-based affinity group Summit of the Americas Welcoming Committee (CASA), organized a "Carnival Against Capitalism" for April 20, which included conferences, teach-ins, concerts, workshops, street theatre and protests (fig. 3.8). Calling on activists to contribute their "talents and creativity" to the demonstrations, the "Carnival Against Capitalism" press release offered a number of suggestions for how to transform "just another exercise of civil disobedience or boring picketing [into] the biggest Carnival of Protest ever." With considerable variation, the suggestions included: "help paint colourful banners, write catchy songs, create wild costumes, build giant marionettes, form a walking choir, join in a rowdy, anarchist marching band, work out chants and slick moves for radical cheerleaders, create street theatre, go Web crazy, write flyers, produce stickers, develop innovative street dances, spin records, work a portable sound system..." ${ }^{\text {70 }}$ The CLAC/CASA call for a "Carnival against Capitalism" at Quebec City was not the first effort to recreate a carnivalesque atmosphere during "anti-globalization" rallies, nor was it the last. In fact, carnivals and festivals of resistance have become common features at demonstrations and 
rallies around the world."

The similarities between Bakhtin's description of medieval carnival and contemporary carnivals of resistance are striking. Like the Bakhtinian carnival, festive demonstrations act outside of existing institutions. As in Bakhtin's carnival, they are conceived as celebrations of community through music, dance, and humour. Both are characterized by excessive exaggerations and parodies of conventional behaviour through the use of masks and costumes. Finally, and significantly, contemporary carnivals of resistance, like medieval carnival, undermine conventional distinctions between participant and spectator, thus transforming monological or "intransitive" spaces into radically dialogical ones. In the final section of this chapter, I will explore the ways in which carnivalesque strategies of resistance during the anti-FTAA demonstrations in Quebec City functioned to produce creative spaces of resistance to the perceived hegemony of the "society of the spectacle" and, through the enactment of oppositional utopianism, became "rehearsals for revolution." I will also theorize the limitations of the Bakhtinian model as applied to contemporary mass demonstrations, and the extent to which the efficacy and affectivity of oppositional utopian activity relies upon a dialectic interaction with dystopian spaces.

The carnival of resistance that manifested itself at Quebec City can itself be regarded as a spectacle. Political analyst Richard Gwyn, for instance, has drawn connections between the theatricality of the protests and the spectacle of party politics. ${ }^{72}$ Indeed, adherents of carnivalesque strategies of protest themselves often call attention to their theatrical nature. David Solnit of San Francisco's Art and Revolution, a radical puppet troupe that organizes and participates in mass demonstrations, argues: "Everything 
is theatrical. Traditional protest--the march, the rally, the chants-is just bad theatre." ${ }^{, 73}$ The differences between spectacular theatre and carnivalesque, however, are manifold, and they relate back to Hénaff and Strong's differentiation between intransitive and transitive communication in the theatrical public sphere. The spectacle is an inherently intransitive use of public space as a stage for communication, whereas carnivalesque introduces transitivity into the public realm.

Embedded in the term "spectacle" is the implicit assumption of a binary division between spectacle and spectator. In The Society of the Spectacle, Guy Debord theorizes the spectacle as a one-way medium of communication through which dominant society epitomizes and justifies its system of domination: "By means of the spectacle the ruling order discourses endlessly upon itself in an uninterrupted monologue of self-praise. ${ }^{, 74}$ Debord argues that capitalism, a system designed to produce collective isolation in order to generate a rapt market for consumer goods ranging from automobiles to televisions, employs the spectacle as a complex web of mediations that produce and naturalize the hegemony of consumer culture, while simultaneously isolating spectators/consumers both from the processes of production and from each other. ${ }^{75}$

The spectacle, then, can be understood as a heavily scripted monologue designed to pacify and isolate the consumer/spectator. Carnivalesque on the contrary is an impromptu theatrical occasion during which producer/consumer and spectacle/spectator divisions are subverted. Like Boal's Theatre of the Oppressed, carnivalesque transforms spectators into spect-actors. It is theatre without a stage, without an audience, "without footlights," writes Bakhtin, ${ }^{76}$ who adds that carnival "is not a spectacle seen by the people; they live in it, and everyone participates because its very idea embraces all the people." 
According to political economist David Boje, who has written extensively aboutand participated in - the contemporary social justice movement, Debord's spectacle and Bakhtin's carnival are reproduced faithfully on every occasion during which the "corporately orchestrated performance" of summit politics is contested by "carnivalesque theatrics of citizen resistance. ${ }^{, 78}$ But Boje's binary construction is perhaps too neat. For while contemporary counterculture carnivals bear much in common with Bakhtin's medieval carnival, there are also key differences. The collective performance of dissent enacted during the anti-FTAA demonstrations in Quebec City rejected hierarchy, conformity, and the role of passive, isolated spectator perceived to be thrust upon them by the society of the spectacle. In the absence of these "scripts," forty to sixty thousand demonstrators performed a colourful, exuberant theatrics of opposition that radically undermined hegemonic structures and underlined the radically democratic potential of public space. But to what extent were they "outside of and contrary to all existing forms of the coercive socioeconomic and political organization"? ${ }^{79}$ To begin with, it is unlikely that complete, even temporary liberation from the "society of the spectacle" is ever possible. As Debord notes and the media analysis in chapter one of this thesis argues, the spectacle permeates every aspect of contemporary culture, managing to fold opposition into its system of representation. If opposition to this system is to be effective it must, as Steve Pile explains above, operate within and across systems and spaces of domination.

Then, it would be naïve to ignore the extent to which contemporary carnivals of resistance rely upon the spectacle apparatus in order to broadcast an oppositional message. For as much as mass demonstrations are performed "of, by, and for" self-identified communities of resistance in an attempt to suture the gap between actors and spectators, 
there are nonetheless several layers of secondary spectators-political leaders, mass media, and the consumers of those media-with whom mass demonstrators must communicate. To deny such audiences is to reduce mass demonstrations to the significant, but limiting, level of communicating with the "converted." And indeed, the attendance to visually arresting vehicles of communication such as those discussed in the preceding chapter demonstrates the degree to which activists acknowledge that their messages must reach an audience far beyond the site of demonstrations.

But there is another sense in which carnivalesque demonstrations "piggyback" on dominant systems and spaces, thus distinguishing them from Bakhtinian carnival. Whereas the carnival as described by Bakhtin was enacted during a "temporary suspension of the entire official system with all its prohibitions and hierarchical barriers" in which "life is subject only to its laws, that is the laws of its own freedom, ${ }^{980}$ the carnival of resistance in Quebec City was performed in a highly contested space that many have likened to a "war zone." In this dystopian battlefield context of fences, riot police, and tear gas, the utopian play of carnivalesque took on additional subversive significance.

One of the elements of Bakhtinian carnivalesque that was reproduced during the anti-FTAA demonstrations was the use of masks. According to Bakhtin, the wearing of masks during carnival time was intended to defy convention and coercion. The mask, which violates boundaries and creates spaces for metamorphosis, "is connected with the joy of change and reincarnation, with gay relativity and with the merry negation of uniformity and similarity; it rejects conformity to oneself." ${ }^{81}$ Masks, scarves and bandanas, which were a ubiquitous presence at Quebec City, functioned on a number of levels. During the Quebec City demonstrations, a Montreal-based art collective distributed four 
thousand bandanas to protesters. ${ }^{82}$ The bandanas, silk-screened with caricatured laughing mouths, provided an injection of humour, for Bakhtin a crucial aspect of carnivalesque. According to Bakhtin, humour-and especially grotesque or transgressive humourinfuses the carnival with a unique brand of fantastic radicalism. Creative costumes and ridiculous masks convey the freedom of the people in their rejection of conformity, and also convey the perceived absurdity of status quo homogeneity. Humour is a similarly crucial tactic of contemporary carnivalesque resistance. Along with balaclava-clad Black Bloc anarchists, the streets of Quebec City were populated with legions of Che Guevaras and Fidel Castros, George W. Bushes and Jean Chrétiens, as well as skeletons, fairies, clowns, and aliens, all of whom contributed to the festive atmosphere and demonstrated a profound rejection of conformity (fig. 3.9).

But bandanas, eye goggles, and particularly gas masks were also worn for the purpose of self-defence. First, they protected their wearers from the more than four thousand canisters of tear gas fired by police forces during the protests. ${ }^{83}$ Concealing headgear also protected protesters from the surveillance of security forces-members of the Black Bloc have often commented on the use of the balaclava for this purpose. ${ }^{84}$ Concealment took on additional symbolic value when the city of Ste. Foy near Quebec City issued a bylaw, later revoked, which banned the wearing of scarves and masks during the month of April 2001. ${ }^{85}$ For the Black Bloc, the wearing of balaclavas also represents solidarity with the Zapatistas of Chiapas, Mexico, who are well known for the strategy of concealed identity.

The Zapatistas, like the Black Bloc, rely on masks for protection and anonymity, but they also employ them as metaphors for the "faceless global majority" on whose behalf 
they struggle. ${ }^{86}$ In this sense, the mask can represent not the concealment, but instead the deliberate expression of political identity, an objective articulated in the following excerpt from a message attached to nine thousand masks distributed at a 1999 Carnival Against Capital in London: "Our masks are not to conceal our identity but to reveal it.... Today we shall give this resistance a face; for by putting on our masks we reveal our unity; and by raising our voices in the street together, we speak our anger at the facelessness of power." ${ }^{87}$ Strategies of carnivalesque resistance such as the use of masks thus reflect Bakhtinian carnival, but take on added significance in a "war zone" context.

As discussed above, the society of the spectacle was largely replaced by a spectacle of authority and defence long before the demonstrations began. The presence of the perimeter fence, along with over six thousand police and military officers in full riot gear, was acknowledged by RCMP officials to be the most overwhelming security presence in Canadian history. ${ }^{88}$ This massive military presence was in sharp contrast to the various manifestations of carnivalesque resistance, and itself contributed to the visual potency of these manifestations. Richard Schechner is a performance theorist who has studied the tense dichotomy between what he terms "street carnival demonstrations" and official displays of power. He argues that such demonstrations, "moving in spirals and circles without easy to locate centres or heads," stand out against displays of official culture, characterized by actors in "neat rectangles, uniformly garbed, carrying identical or coordinated posters, banners, and weapons.."

Schechner applies his theory to the 1989 student-led protests at Tiananmen Square in Beijing, China. During the struggle, he argues, "the students improvised in public, while the officials, as always, rehearsed their options behind closed doors. ${ }^{, 90}$ He might easily 
have been referring to the April 2001 events in Quebec City. Here the police forces, dressed in identical riot gear, formed orderly lines as they guarded the perimeter fence or advanced into the streets, their dark helmets and Plexiglas shields subsuming individual identity under a homogenizing collective display of force. The protesters, in contrast, engaged in what Schechner refers to as "organized theatrical chaos." ${ }^{\text {91 }}$ In wildly colourful costumes that resolutely rejected conformity, they danced, beat drums, played bagpipes, and in myriad other creative ways challenged and confronted the orderly spectacle of authority before them (fig. 3.10). The difference between Bakhtinian carnival and the "organized theatrical chaos" of contemporary mass demonstrations is, I argue, the difference between utopianism and oppositional utopianism, or the performance of utopia in a contested space.

For Bakhtin, the acting out of utopia was an integral aspect of carnival: "For a short time life came out of its usual, legalized and consecrated furrows and entered the sphere of utopian freedom." ${ }^{92}$ What the utopian impulse of medieval carnivals shared with the utopian project of contemporary carnivals is an element implicit in all enactments of utopia, which Paul Ricoeur describes as utopia's ability to "make the actual world seem strange." The utopia, he emphasizes, "introduces a sense of doubt as it shatters the obvious. ${ }^{93}$ One of the key notions in the organization of carnivals of resistance is that opposition to the prevailing order must also enact and embody the alternatives it seeks. Carnival is a vehicle through which contemporary activists articulate their message that "another world is possible." By engaging in what José Muñoz refers to as "worldmaking"- the simultaneous deconstruction and reshaping of reality — carnivalesque performance "engenders worlds of ideological potentiality that alter the present and map 
out a future. ${ }^{.94}$ What is unique to carnivals of resistance is that this utopian conceptualization of "another world" transgresses into the territory of the "actual world" and transforms it into a site of oppositional utopianism.

"Every Mardi Gras," however, "meets its Ash Wednesday." Indeed, the temporary nature of carnival as described by Schechner characterizes both medieval and contemporary versions of the carnival. Both Schechner and Hetherington question the overall efficacy of carnivalesque as a strategy of resistance, emphasizing its temporary and liminal occupation of the public sphere. While committed adherents insist that "carnival and revolution have identical goals: to invert the social order with joyous abandon and to celebrate our indestructible lust for life, ${ }^{, 96}$ there is considerable debate over the limitations of carnivalesque resistance as a revolutionary strategy. "The difference between temporary and permanent change distinguishes carnival from revolution," concludes Schechner. ${ }^{97}$

Along with the temporality of mass demonstrations, the question of Aristotelian catharsis again emerges. As Baz Kershaw has noted, carnival can be perceived as a safety valve that temporarily, and innocuously, releases the steam of exuberant youthful energy, ultimately strengthening the prevailing order; " for at the end of the carnivalesque day the revellers return to a living whose rules are set by the dominant ideologies, with energies dissipated and their sense of the liberality of the regime re-animated. ${ }^{.98}$ If, however, the revolutionary efficacy of carnivalesque resistance is questionable, it can nonetheless be theorized as a powerful tool of collective empowerment via Lawrence Grossberg's notion of "affective investment," or the generation of energy based on the belief that one's actions "matter." "99 According to Schechner, the affective efficacy of performances of theatrical chaos lies largely in the generation of spaces for the development of a community of 
resistance, or what Victor Turner refers to as "spontaneous communitas." "Likewise, Hetherington argues that carnivalesque practices are most significant for their contribution to the formation of "alternative and expressive identities." ${ }^{\text {,101 }} \mathrm{He}$ argues, "It is not the momentary overthrow of authority that we should see as the most important aspect of carnivalesque cultural forms but rather the free flow of symbols and identity positions, uses of the body, and the repertoire of acts and their development into an ordering of identities. ${ }^{.112}$ Indeed, numerous accounts of the Quebec City demonstrations written by participants and published in online forums and journals testify to the extent to which their participation in carnivalesque performances of resistance contributed to their sense of communitas. ${ }^{103}$

Again, however, the spatial context of such performances is key. Writing in 1934 about the affectivity of art as experience, John Dewey noted that "under conditions of resistance and conflict, aspects and elements of the self and the world that are implicated in this interaction qualify experience with emotions and ideas so that conscious intent emerges." ${ }^{104}$ Indeed, it is the context of conflict that renders carnivalesque performances during mass demonstrations most affective in terms of the development of collective agency. As David Graeber notes in the epithet to this chapter, "It is difficult to find anyone who has fully participated in [a mass demonstration] whose sense of human possibilities has not been profoundly transformed as a result." ${ }^{105}$

This returns us to the notion that spaces of resistance are most effectively created when they transgress into spaces of domination. According to Lawrence Grossberg, agency is contextually contingent upon the mapping of activity onto specific terrains: "Agency is the empowerment enabled at particular sites, along particular vectors. ${ }^{, 06}$ Like Schechner, 
Grossberg references the 1989 events at Tiananmen Square in Beijing. He argues that it was the terrain on which resistance was mounted as much as the resistance itself that contributed to the efficacy and affectivity of the student-led revolt: "There is no common identity, no property that defines them apart from the fact that they were there, together, in that place. It was the fact of belonging that constituted their belonging together." ${ }^{107}$ Indeed, if there are revolutionary implications to the anti-FTAA demonstrations in Quebec City, they are to be located in the mapping of that city as a particular site at which to engage in the counter-hegemonic construction of a community of resistance. By exploiting the already altered visual culture of this space and transforming it into a site of oppositional utopianism, these demonstrations performed a carnivalesque rehearsal for revolutionary change through the symbolic and physical occupation of a contested public space. 


\section{NOTES}

${ }^{1}$ Mikhail M. Bakhtin, Rabelais and His World (1965), tr. Hélène Iswolsky (Bloomington: Indiana University Press, 1984), 10.

${ }^{2}$ David Graeber, “The New Anarchists," New Left Review 13 (January-February 2002): 72.

3 In "The Nature of Mass Demonstrations," in The Look of Things: Selected Essays and Articles, ed. Nikos Stangos (Harmondsworth: Penguin, 1972), John Berger argues that all mass demonstrations can be understood as rehearsals for revolution.

${ }^{4}$ Henri Lefebvre, The Production of Space (1974), tr. Donald Nicholson-Smith (Oxford: Blackwell, 1991), 54.

5 Steve Pile, "Opposition, Political Identities and Spaces of Resistance," in Geographies of Resistance, ed. Steve Pile and Michael Keith (London and New York: Routledge, 1997), 16.

${ }^{6}$ Michel de Certeau, The Practice of Everyday Life (1974), tr. Steven Rendall (Berkeley: University of California Press, 1984).

${ }^{7}$ The limitations of everyday tactics of resistance are addressed by Nigel Thrift, who cautions against confusing jaywalking and "washing your car on a Sunday" with revolutionary transgression. "The Still Point: Resistance, Expressive Embodiment and Dance," in Geographies of Resistance, ed. Pile and Keith, 124-126.

${ }^{8}$ Pile, 14.

${ }^{9}$ Ibid.

${ }^{10}$ See Michael E. Gardiner, Critiques of Everyday Life (London and New York: Routledge, 2000), for a discussion of the relationship between the theories and ideas of Lefebvre and the Situationists.

11 Attila Kotányi and Raoul Vaneigem, "Elementary Program of the Bureau of Unitary Urbanism" (1961), in Situationist International Anthology, ed. Ken Knabb (Berkeley: Bureau of Public Secrets, 1981), 65.

${ }^{12}$ Raoul Vaneigem, The Revolution of Everyday Life (1967), tr. John Fullerton and Paul Sieveking (New York: Black and Red, 1972).

${ }^{13}$ The perimeter fence was designed by Public Works and Government Services Canada (PWGSC) in collaboration with an independent contractor hired by the RCMP, and after consultation with the Organization of American States (OAS), the City of Quebec, the police department of the City of Quebec, and representatives from the local business community. From a personal communication from Anne Murray, Conference Sites Design Supervisor, PWGSC, 16 April 2003.

${ }^{14}$ See introduction, note 22 , for a discussion of pre-summit challenges to the ethical and constitutional validity of the fence. 
${ }^{15}$ Klein argues; "A month before the summit, postcard-perfect Quebec City has been successfully transformed into a menacing place, inhospitable to regular people with concerns about corporate-driven trade and economic deregulation. Protesting, rather than being a healthy part of democracy, seems like an extreme and dangerous sport, suitable only for hard-core activists, with bizarre accessories and doctoral degrees in rock climbing." "Keeping Us Out Before We Get There," Globe and Mail, Wednesday, 21 March 2001, A13.

${ }^{16}$ Ibid.

${ }^{17}$ The Friday, 20 April 2001 National Post reported that several storekeepers were nervous about the upcoming demonstrations, and that the mayor of Quebec City, Jean-Paul L'Allier, regretted hosting the summit. Graeme Hamilton, "Police Foil Protesters by Locking Summit Gates," A15.

${ }^{18}$ Adrian Blackwell, quoted in Alan Antliff, "Art, Anarchy, and Activism," Ideas, Canadian Broadcasting Corporation, 15 October 2001, radio broadcast.

${ }^{19}$ Guy Debord, The Society of the Spectacle (1964), tr. Donald Nicholson-Smith (New York: Zone Books, 1994), 174. As is conventional, all numerical references to this source refer to thesis numbers (there are 221 in total) rather than pages, in deference to the format of Debord's original French language publication.

20

Gardiner, 121.

${ }^{21}$ Marcel Hénaff and Tracy B. Strong, "Introduction: The Conditions of Public Space: Vision, Speech, and Theatricality," in Public Space and Democracy, ed. Marcel Hénaff and Tracy B. Strong (Minneapolis:

University of Minnesota Press, 2001), 8.

${ }^{22}$ Ibid., 8.

${ }^{23}$ Ibid., 26.

${ }^{24}$ Ibid., 8-9.

${ }^{25}$ Mark Dery, Culture Jamming: Hacking, Slashing and Sniping in the Empire of Signs (San Francisco: Open Magazine Pamphlet Series, 1993), available online at $<\mathrm{http}: / /$ www.levity.com/markdery/culturjam. html $>$, June 2003.

${ }^{26}$ Lucy Lippard, "Looking Around: Where We Are, Where We Could Be," in Mapping the Terrain: New Genre Public Art, ed. Suzanne Lacy (Seattle: Bay Press, 1995), 129.

${ }^{27}$ The explicitly feminist discourse in this billboard jam also reflects the fact that culture jamming has been heavily influenced by the feminist practice of critiquing both the objectification of women in advertising and consumer culture in general. As Susan J. Douglas notes in Where the Girls Are (New York: Time Books, 1994), 227, "Of all the social movements of the 1960s and '70s, none was more explicitly anti-consumerist than the women's movement. Feminists had attacked the ad campaigns for products like Pristeen and Silva Thins, and by rejecting makeup, fashion and the need for spotless floors, repudiated the very need to buy certain products at all."

${ }^{28}$ Anne Norton, "Writing Property and Power," in Public Space and Democracy, ed. Hénaff and Strong, 192. 
${ }^{29}$ Pierre Bourdieu, "The Politics of Globalization," tr. Sarah Verblow and Anthony Barnett, Open Democracy Web site, 20 February 2002, <http://www.opendemocracy.net/debates/article-6-27-283.jsp>, March 2003.

${ }^{30}$ Homi K. Bhabha, "Conversational Art," in Conversations at the Castle, ed. Mary Jane Jacob (Cambridge: MIT Press, 1998), 45.

${ }^{31}$ This is the term used by Mark Dery to describe the "hijacking" of commercial messages for counterculture purposes. Culture Jamming, n.p.

${ }^{32}$ Naomi Klein, No Logo: Taking Aim at the Brand Bullies (Toronto: Vintage Canada, 2000), 296-97. Klein quotes prominent activist Jaggi Singh, who argues: "When you're jamming, you're sort of playing their game, and I think ultimately that playing field is stacked against us because they can saturate.... We don't have the resources to do all those billboards, we don't have the resources to buy up all that time."

${ }^{33}$ Another example of popular culture's appropriation of counterculture is Sony Playstation 2's "State of Emergency," a video game released in February 2002 in which players, members of an anarchist freedom movement, engage in pitched street battles with the enforcers of a quasi-military regime known only as "The Corporation."

${ }^{34}$ Debord, 15, maintains that spectacular rebellion is inherent to the "society of the spectacle":

"Dissatisfaction became a commodity as soon as economic abundance could extend production to the processing of such raw materials."

${ }^{35}$ As Laura U. Marks argues in her discussion of art activism, "if we've learned anything from decades of protest art it's that the front shifts constantly as global powers incorporate and pacify it." "Plunging Into the Event: Political Struggle Between Language and the Earth," in Better Worlds: Activist and Utopian Projects by Artists, ed. Jan Allen and Laura U. Marks (Kingston: Agnes Etherington Art Centre, 2002), 37.

${ }^{36}$ Hakim Bey, TAZ: The Temporary Autonomous Zone: Ontological Anarchy, Poetic Terrorism (New York: Autonomedia, 1985), available online at the Public Netbase t0 Institute for New Culture Technologies Web site, <http://www.t0.or.at/hakimbey/taz/taz.htm>, May 2003. Emphasis in original.

${ }^{37}$ Ibid.

${ }^{38}$ Kevin Hetherington, Expressions of Identity: Space, Performance, Politics (London: Sage Publications, 1998), 123-129.

${ }^{39}$ Ibid., 126.

${ }^{40}$ Pile, 16.

${ }^{41}$ For a discussion of Reclaim the Streets, see John Jordan, "The Art of Necessity: The Subversive Imagination of Anti-Road Protest and Reclaim the Streets," in DiY Culture: Party and Protest in Nineties Britain, ed. George McKay (London: Verso, 1998). 
${ }^{42}$ This is in marked contrast to what André C. Drainville refers to as the "apolitical reformism" of the People's Summit, not only sanctioned by all levels of government but also granted $\$ 287,000$ in federal funding. "Québec City and the Making of Transnational Subjects," in Socialist Register 2002: A World of Contradictions, ed. Colin Leys and Leo Panitch (London: Merlin Press; Halifax: Fernwood, 2001), available online at $<$ http://www.yorku.ca/socreg/Drainville.htm $>$, June 2003.

${ }^{43}$ Again, this contrasts with the co-ordination of People's Summit activities. The Saturday People's March, planned in collaboration with security officials, travelled away from the perimeter fence to the parking lot of the Parc de l'exposition, several kilometres away from the summit, causing General Counsel of the Canadian Civil Liberties Union Alan Borovoy to comment that "in Canada we don't ban demonstrations, we reroute them." "Protest Movements and Democracy," Policy Options, September 2002, 54.

44

See Drainville, n.p.

${ }^{45}$ Anne Murray, the Conference Sites Design Supervisor for PWGSC who led the team whose mandate it was to design the venues inside the perimeter and the perimeter fence itself, informed me in her personal communication that the intention of the fence was to "outline" the perimeter, although she also conceded that architects from PWGSC might have indicated a need for stronger footing at the base of the fence. At a news conference on Friday, 20 April 2001, Sûreté du Québec Inspector Robert Poéti confirmed that the fence "was never meant to be an impenetrable barrier." Quoted in Kate Jaimet, Mike Trickey, and James Baxter, "BlackMasked Anarchists Set the Stage for Today's Larger Demonstration," Ottawa Citizen, Saturday, 21 April 2001, A5.

${ }^{46}$ An unnamed demonstrator who participated in tearing down a section of the fence exemplified this objective by stating, "What would be the point of trying to get inside? What would we say?" Quoted in Sarah McGregor, "Report from Quebec Ground Zero," Ottawa X Press, Thursday, 26 April 2001, 3.

${ }^{47}$ Sixty protesters and nineteen police officers were injured during the demonstrations. Robert McKenzie, "Quebec Defends Security Response," Toronto Star, Monday, 23 April 2001, A7.

${ }^{48}$ A Black Bloc is any anarchist affinity group that organizes to engage in direct-action tactics during a public demonstration. The main goals of the Black Bloc are "to provide solidarity in the face of a repressive police state and to convey an anarchist critique to whatever is being protested that day." "Black Bloc for Dummies," Infoshop.org Web site, 7 April 2003, <http://www.infoshop.org/blackbloc.html>, June 2003.

${ }^{49}$ ACME Communiqué, quoted in Robbie Herbst, "My Friends Are the Universe: Globalization's Protests Expand the Political," Journal of Aesthetics and Protest 1, no. 1 (July 2002), <http://www.journalof aestheticsandprotest.org/1/globalization/index.html>, December 2002.

${ }^{50}$ This strategy reflects the underlying goals of anarchism, the political philosophy most directly connected to direct-action activism.

${ }^{51}$ W.J.T. Mitchell, "The Violence of Public Art: Do the Right Thing," in Art and the Public Sphere, ed. W.J.T. Mitchell (Chicago and London: University of Chicago Press, 1992), 35. It is a striking coincidence that Mitchell uses, as an example of art that productively expresses the conflicts and exclusions inherent in the contemporary public sphere, Spike Lee's 1989 film Do the Right Thing, whose pivotal scene is one in which a main character, Mookie, hurls a trash bin through the window of a Brooklyn restaurant.

${ }^{52}$ Ibid., 39-40. 
${ }^{53}$ The notion of the vanishing public sphere, posited most notably by Jürgen Habermas in The Structural Transformation of the Public Sphere: An Inquiry into a Category of Bourgeois Society (1962), tr. Thomas Burger with Frederick Lawrence (Cambridge: MIT Press, 1989), has been heavily critiqued by contemporary scholars such as W.J.T. Mitchell for its nostalgic invocation of a public sphere that, it is argued, existed, if at all, for a chosen few. See also Bruce Robbins, ed., The Phantom Public Sphere (Minneapolis: University of Minnesota Press, 1993).

${ }^{54}$ Rosalyn Deutsche, Evictions: Art and Spatial Politics (Cambridge: MIT Press, 1996), xxiv.

${ }^{55}$ Marika Schwandt, personal communication with author, 20 February 2003.

${ }^{56}$ The Deconstructionist Institute for Surreal Topology's list of Quebec City "bloc" suggestions, including the Bonhomme Bloc, the Gary Coleman Bloc, and the League of Radical Toy Airplane Pilots Bloc, is archived on their Web site at $<$ http://www.tao.ca/ wrench/dist.html $>$, June 2003.

${ }^{57}$ Schwandt, personal communication.

${ }^{58}$ The catapult was built by the Society for Creative Anachronism, a Lanark, Ontario-based medieval theatrical troupe, and funded by Judy Rebick and Rabble.ca. Judy Rebick, "Of Catapults and Teddy Bears," Rabble.ca Web site, 8 May 2001, <http://www.rabble.ca>, November 2002 (no longer available).

${ }^{59}$ Singh, who was arrested by undercover police officers during the Friday, 20 April demonstration, was held in custody for 17 days. Singh denied any connection to the catapult, and charges were later dropped. Despite its designation by security officials as a dangerous weapon capable of hurling heavy objects over the perimeter fence, the medieval catapult was specially designed, according to Judy Rebick, ibid., with a spring that limited its force to that of a human arm, and there is no evidence to suggest that the catapult was used to project anything but stuffed animals over the fence.

${ }^{60}$ DIST press release, quoted in Marina Jiménez, "Anti-Globalization Activists Practice for this Weekend's G8 Summit in Genoa," National Post, Monday, 16 July 2001, A8.

${ }^{61}$ Walden Bello, "Porto Alegre Social Summit Sets Stage for Counteroffensive Against Globalization," January 2002, available online at the World Social Forum Web site, < $<$ ttp://www.forumsocialmundial.org.br/ dinamic/eng_b_WaldenBello.asp>, June 2003.

62 Pile, 16 .

${ }^{63}$ For instance, in an account of the weekend's activities, Canadian Union of Public Employees member Laurie Kingston describes a situation on Saturday, 21 April, during which police officers attacked a group of peaceful demonstrators: "At one point, police lob tear-gas canisters directly into a group of youth sitting on a side street, singing anti-war songs. The fence is not even in sight, yet the police block off all exits to make sure no one can escape the noxious effects of the gas." "Our World at a Crossroads: Quebec City Diary," Our Times: Canada's Independent Labour Magazine, June-July 2001, <http://www.ourtimes.ca/features/01jun_ jul_quebec.html>, June 2003.

${ }^{64}$ Written in 1940 as a doctoral dissertation, Bakhtin's Rabelais and His World was published in 1965 and first translated into English in 1968.

65

Bakhtin, 10. 
${ }^{66}$ Kershaw cites John McGrath's 1990 study of twentieth-century carnivalesque performances, which provides a persuasive argument as to carnivalesque's appeal: "His [Bakhtin's] idea of carnival expressing the 'whole' human being... is something that has meaning when set against the narrowness of the concept of humanity in mass telly-culture. And it is to this general area of celebratory, public, all-inclusive theatre that we should turn." John McGrath, The Bone Won't Break: On Theatre and Hope in Hard Times (London: Methuen, 1990), 153-154. Quoted in Baz Kershaw, The Politics of Performance: Radical Theatre as Cultural Intervention (London and New York: Routledge, 1992), 72.

${ }^{67}$ Unidentified CLAC spokesperson, quoted in Arnie Alperf, "Mobilizing for Quebec," Peacework Magazine, March 2001, <http://www.afsc.org/pwork/0103/010312.htm>, January 2003.

${ }^{68}$ This colour coding strategy is explained by CLAC member Tania Hallé in Magnus Isacsson and Paul Lapointe, View from the Summit: Quebec City-April 20-22, 2001, 75 min., National Film Board of Canada, 2002 , videocasette.

69 Drainville, n.p.

${ }^{70}$ The CLAC Cultural Committee press release, "Creative People Against the Quebec City Summit," 12 March 2001, was circulated widely on the Internet, and is available online at $<\mathrm{http} / /$ members.tripod.com/ infobank1/>, October 2002.

${ }^{71}$ The most famous Carnival Against Capitalism was organized by Reclaim the Streets and took place on 18 June 1999 in London's financial district. More recently, and locally, the Ottawa-Outaouais Social Forum held 1-4 May 2003 was promoted as a "community carnival for change." Information about the Social Forum can be found on its Web site, <http://socialforum.digitalindependence.org>, June 2003.

72 In "Hearing the Protest Message," Toronto Star, Sunday, 18 March 2001, A17, Gwyn argues: "Surely only the terminally pompous could be shocked that anti-globalization sentiments are expressed in the form of street theatre. All the 'democratic' governments...present at Quebec City won their elections by the political equivalent of street theatre-photo ops, spin doctoring, negative advertising and the rest."

73 David Solnit, quoted in Andrew Boyd, "Extreme Costume Ball: A New Protest Movement Hits the Streets in Style," Village Voice, 19-25 July 2000, available online at $<\mathrm{http}: / / \mathrm{www}$.villagevoice.com/issues/0029/ boyd.php>, May 2003.

Debord, 24.

75 Ibid., 26-28. Susan Sontag has cautioned strongly against ongoing references to the spectacle society. In her 9 December 2001 New Yorker essay, "Looking at War: Photography's View of Devastation and Death," 97, Sontag argues that such a framework reveals a "breathtaking provincialism" that "universalizes the viewing habits of a small, educated population living in the rich part of the world, where news has been converted into entertainment." While Debord's analysis certainly centres on the Western world, it is precisely this conversion of reality into entertainment that his thesis attacks. Indeed, his argument is as relevant today-if not more so-than when The Society of the Spectacle was originally published.

76

Bakhtin, 265. 
${ }^{77}$ Ibid., 7. This idea is echoed by Julia Kristeva, who writes that "the scene of the carnival introduces the split-speech act: the actor and the crowd are each in turn simultaneously subject and addressee of discourse." "The Bounded Text" (1968), in Desire in Language: A Semiotic Approach to Literature and Art, ed. Leon S. Roudiez, tr. Thomas Gora, Alice Jardine, and Leon S. Roudiez (New York: Columbia University Press, 1980), 46.

${ }^{78}$ David Boje, "Carnivalesque Resistance to Global Spectacle: A Critical Post-Modern Theory of Public Administration," Administrative Theory and Praxis 23, no. 3 (2001): 433-4.

${ }^{79}$ Bakhtin, 255. Emphasis added.

${ }^{80}$ Ibid., 89,7 .

${ }^{81}$ Ibid., 39-40.

${ }^{82}$ John Jordan and Jennifer Whitney, "Resistance is the Secret of Joy," New Internationalist 338 (September 2001): 24-25.

${ }^{83}$ This fact became painfully clear to me on Saturday, 21 April. When my travelling companion decided to purchase a bandana before attending the demonstrations, I chose not to partake in what I denigrated as a "counterculture fashion trend." Hours later, as we participated in the People's March, my friend was somewhat protected from the acrid tear gas that wafted through the city while my own face remained unprotected.

${ }^{84}$ See "When Masks Are Outlawed...Only Revolutionaries Will Wear Masks!" Maori Independence Web site, 11 March 2001, <http://aotearoa.wellington.net.nz/int/mask/masks.htm>, April 2003.

85

Drainville, n.p.

${ }^{86}$ Guillermo Gomez-Peña, "The Subcomandante of Performance," in First World, Ha Ha Ha!: The Zapatista Challenge, ed. Elaine Katzenberger (San Francisco: City Lights, 1995), 91.

87

Quoted in "When Masks Are Outlawed," n.p.

${ }^{88}$ Royal Canadian Mounted Police in Quebec, "Just a Few Days Away from the Summit of the Americas," Royal Canadian Mounted Police Web site, April 2001, <http://grcquebecrcmp.com/pages/english/ con_p_une_e/pag_avr_e.html>, March 2003.

${ }^{89}$ Richard Schechner, The Future of Ritual: Writings on Culture and Performance (New York and London: Routledge, 1993), 88.

${ }^{90}$ Ibid., 58.

${ }^{91}$ Ibid., 63.

${ }^{92}$ Bakhtin, 89.

${ }^{93}$ Paul Ricoeur, Lectures on Ideology and Utopia, ed. George H. Taylor (New York: Columbia University Press, 1986), 299-300. 
${ }^{94}$ José Muñoz, Disidentifications: Queers of Colour and the Performance of Politics (Minneapolis: University of Minnesota Press, 1999), 163.

95 Schechner, 71.

${ }^{96}$ Jordan and Whitney, 25.

${ }^{97}$ Schechner, 83 .

${ }^{98}$ Kershaw, 73.

${ }^{99}$ Lawrence Grossberg, "Is There a Fan in the House? The Affective Sensibility of Fandom," in The Adoring Audience: Fan Culture and Popular Media, ed. Lisa A. Lewis (London and New York: Routledge, 1992), 50-65.

${ }^{100}$ Turner defines spontaneous communitas as a sentiment of camaraderie and collective agency that emerges during periods of festival: "Spontaneous communitas has something 'magical' about it. Subjectively there is in it the feeling of endless power." Victor Turner, The Ritual Process (Chicago: Aldine, 1969), 138-140, quoted in Schechner, 92-93.

${ }^{101}$ Hetherington, 143.

102

Ibid., 143.

${ }^{103}$ The comments of Victoria, B.C., activist Danielle Gauld are characteristic: "The feeling of solidarity, community and collective strength on the streets was thrilling, as was the sense of mass resistance." Personal correspondence with author, 13 January 2003. For author Naomi Klein, this sense of community was heightened by the copious presence of police forces and tear gas. "The Bonding Properties of Tear Gas," Globe and Mail, Wednesday, 25 April 2001, A15.

${ }^{104}$ John Dewey, Art as Experience (New York: Minton, Balch \& Company, 1934; New York: Putnam, 1958), 35 .

105

Graeber, 72.

${ }^{106}$ Lawrence Grossberg, "Identity and Cultural Studies: Is That All There Is?" in Questions of Cultural Identity, ed. Stuart Hall and Paul Du Gay (London: Sage Publications, 1996), 102.

${ }^{107}$ Ibid., 104. Compare this to Schechner, 58, who writes: "For their stage the students claimed not just any old spot, but the symbolic and operational focus of Chinese political power. And despite the orderliness of their demonstrations and the seriousness of their intentions, the students acted up a carnival." 


\section{CONCLUSION}

It didn't start in Seattle, and it isn't going to stop in Quebec City!

Anti-Capitalist Convergence (CLAC) ${ }^{1}$

The destruction of New York City's World Trade Center on 11 September 2001, less than five months after the events discussed in this thesis, precipitated the impression among both proponents and detractors of the global justice movement that the momentum of mass demonstrations against corporate globalization had likewise collapsed. Even prior to the terrorist attacks, debate had begun to intensify regarding the efficacy of direct-action opposition to global governance, particularly following the death of Italian activist Carlo Giuliani during July 2001 demonstrations against a meeting of G8 heads of state in Genoa, Italy. After September 11, however, this "rapidly spreading phenomenon" seemed destined for an equally rapid demise. One week after the attacks, American activist L.A. Kauffman discussed their consequences for the global justice movement:

...one part of the deep mourning I feel is for the global justice movements as they were before these planes crashed into the Twin Towers: steadily growing in scope and influence, increasingly occupying a central place on the global stage. We were blown off that stage on September 11, and the context for our ongoing activism is now utterly transformed. ${ }^{2}$

Kauffman's pessimism had several bases. First, a wellspring of patriotism in the U.S. drowned out all but the most defiant voices of opposition to American international policy. Then, the destruction of the World Trade Center, perhaps the world's most imposing symbol of international capitalism, rendered it difficult to conceive that any actions against the institutions of global corporate hegemony would be met with public 
support. Finally, the events of September 11 led to a string of anti-terrorism laws in the U.S. and abroad, including Canada's bills C-35, C-36, and C-42, which broadened definitions of terrorism and expanded state powers of investigation, detainment, and prosecution. These measures contributed to a perception that not only was dissent being increasingly criminalized, but that oppositional activity - and particularly that emanating from the global justice movement—was increasingly being conflated with terrorist activity. ${ }^{4}$ As a result, mass demonstrations against global governing bodies witnessed a rapid decline. ${ }^{5}$

However, the energy that the global justice movement had generated prior to September 11 was harnessed, just as rapidly, into a force for the mobilization of a broadbased movement against the threat of war between the U.S. and Iraq that arose in September 2002. Indeed, the global anti-war demonstrations of 15 February 2003 were widely acknowledged to be unprecedented in scale, with over a million citizens taking to the streets of London and Rome, and thousands more taking part in demonstrations around the world. ${ }^{6}$ Two aspects of this global day of protest are significant in the context of the present study. First, the demonstrations were notable for the ubiquitous and familiar presence of masks, puppets, stilt-walkers, pink-clad fairies, radical cheerleaders, and raging grannies. These and myriad other examples of creative opposition to the proposed war in Iraq suggest that the promotion and manifestation of creative tactics of dissent within the global justice movement have had a profound impact on the perception that communities of resistance are effectively mobilized through the visual culture of resistance. Then, the enormity of the 15 February anti-war protests confirmed that increasingly, public space is perceived as a viable site for the demonstration of opposition 
to perceived injustice. If it is impossible to discern the long-term effects of the global justice movement on the future of globalization, it is not an exaggeration to conclude that the movement has revived the notion that immanent, embodied performances of dissent in the public sphere have the potential to transform that sphere into a space for the expression of oppositional politics.

The apparent criminalization of dissent in the period following September 11 has had a marked effect on the perceived role of visual art and creativity in the mobilization of resistance. There is increasing acknowledgement among global justice activists and proponents that creative expressions of dissent are crucial weapons against the conflation of opposition with terrorism. As L.A. Kauffman notes; "Our movement's vision of global justice is needed more than ever; we will simply need to take greater care in presenting that vision in a way people can hear." Indeed, as the photojournalistic representations of the Quebec City anti-FTAA demonstrations in chapter one indicate, one of the greatest challenges for the global justice movement is to construct vehicles of expression that are able to circumvent its spectacularization and trivialization in mainstream forums. By employing "conversational art," "witness art," and carnivalesque practices, the artistactivists discussed in the second and third chapters demonstrate that art can function as an effective, and affective, tool for mobilizing and expressing solidarity and counterhegemonic resistance in the public sphere. "Conversational art," or art that emphasizes collaborative, process-oriented, and dialogical strategies of visual communication, serves as a catalyst for the development of "affective investment," the construction of collective identity, and the communication of political messages that cross linguistic and cultural barriers. "Witness art," or art that calls attention to perceived injustice, employs the human 
body as a tool with which to demonstrate immanent opposition to virtual power. Finally, creative acts of resistance enacted in the public sphere-from graffiti and culture jamming to carnivalesque performances of "theatrical organized chaos"-interrogate, infiltrate, and challenge the capitalist "conquest of public space." Such performances transform the public sphere, if temporarily, into a site of oppositional utopianism where communities of resistance are mobilized in spaces of resistance.

There are several avenues of study alluded to briefly in this thesis that merit further investigation. The events of September 11 and their aftermath have led the global justice movement in a number of interesting directions. For instance, the ensuing ebb in the tide of the movement has created a space for re-evaluations of its tactics of opposition. For many, the conclusion has been that resistance to global corporate hegemony must, in order to be effective, be enacted at both global and local levels. While, as I have argued in this thesis, mass demonstrations can function as highly effective strategies for constructing communities and spaces of resistance, there is also a growing recognition within the global justice movement that "summit-hopping" is an activity restricted to those who can afford to do so, and one that risks obscuring the message beneath the medium. ${ }^{8}$ Further study into the art of resistance will benefit from deeper analysis of specific organizations that promote and develop communities of resistance within communities of location, using the vocabulary and tools of collaborative art making. Groups such as CLAC in Montreal, Ya Basta in Milan and New York, Reclaim the Streets in London, and Art and Revolution in San Francisco, all of which employ art and creativity in the mobilization of dissent, merit both documentation and further analysis through the lens of interdisciplinary critical theory. 


\section{NOTES}

1 CLAC, "Resist the Summit of the Americas and the FTAA-Quebec City Spokescouncil: March 24-25," available online at the Infoshop.org Web site, <http://www.infoshop.org/octo/texts/quebec_spokes.html>, June 2003.

2 L.A. Kauffman, "All Has Changed," Free Radical 19 (17 September 2001), <http://www.free-radical.org>, July 2003.

Bill C-35 expands the definition of "internationally protected persons" to include government and business personnel participating in international conferences. Bill C-36 broadens the definition of "terrorist activity," and Bill C-42 enables the federal government to declare and create military security zones. See Tony Clarke, "The Recriminalization of Dissent," Policy Options, September 2002, 49.

${ }^{4}$ Comments attributed to Italian Prime Minister Silvio Berlusconi in the International Herald-Tribune reveal the roots of this conflation. Berlusconi is reported to have said: "The terrorists were trying to stop the corrupting effect of Western civilization on the Islamic world," while "the anti-globalization movement criticizes, from within Western civilization, the Western way of life, trying to make Western civilization feel guilty. That's why I see a singular coincidence between this action and the anti-globalization movement." Steven Erlanger, "Berlusconi Vaunts West's 'Superiority'," International Herald-Tribune, Thursday, 27 September 2001, 1 .

${ }^{5}$ For instance, Judy Rebick reports that demonstrations against a meeting of the WTO in Qatar, in November 2001, were a spectacular failure, and attributes this failure to a "polarizing climate of fear where any critical viewpoint faces immediate and vicious attack." Judy Rebick, "Qatar Reveals Impact of September 11 on Trade Battle," Z Magazine, 17 November 2001, <http://www.zmag.org/sustainers/content/2001-11/17rebick. cfm>, June 2003.

${ }^{6}$ See Judy Rebick, "Making History: It Was the Largest Protest in Human History," Canadian Dimension, 17 February 2003, available online at <http://www.canadiandimension.mb.ca/extra/d0217jr.htm>, June 2003.

${ }^{7}$ Kauffman, n.p.

${ }^{8}$ See, for instance, Naomi Klein, "Talk to Your Neighbours: It's a Start," Globe and Mail, Wednesday, 2 May 2001, A11. 


\section{APPENDIX A}

Map of Quebec City during April 2001 Summit of the Americas

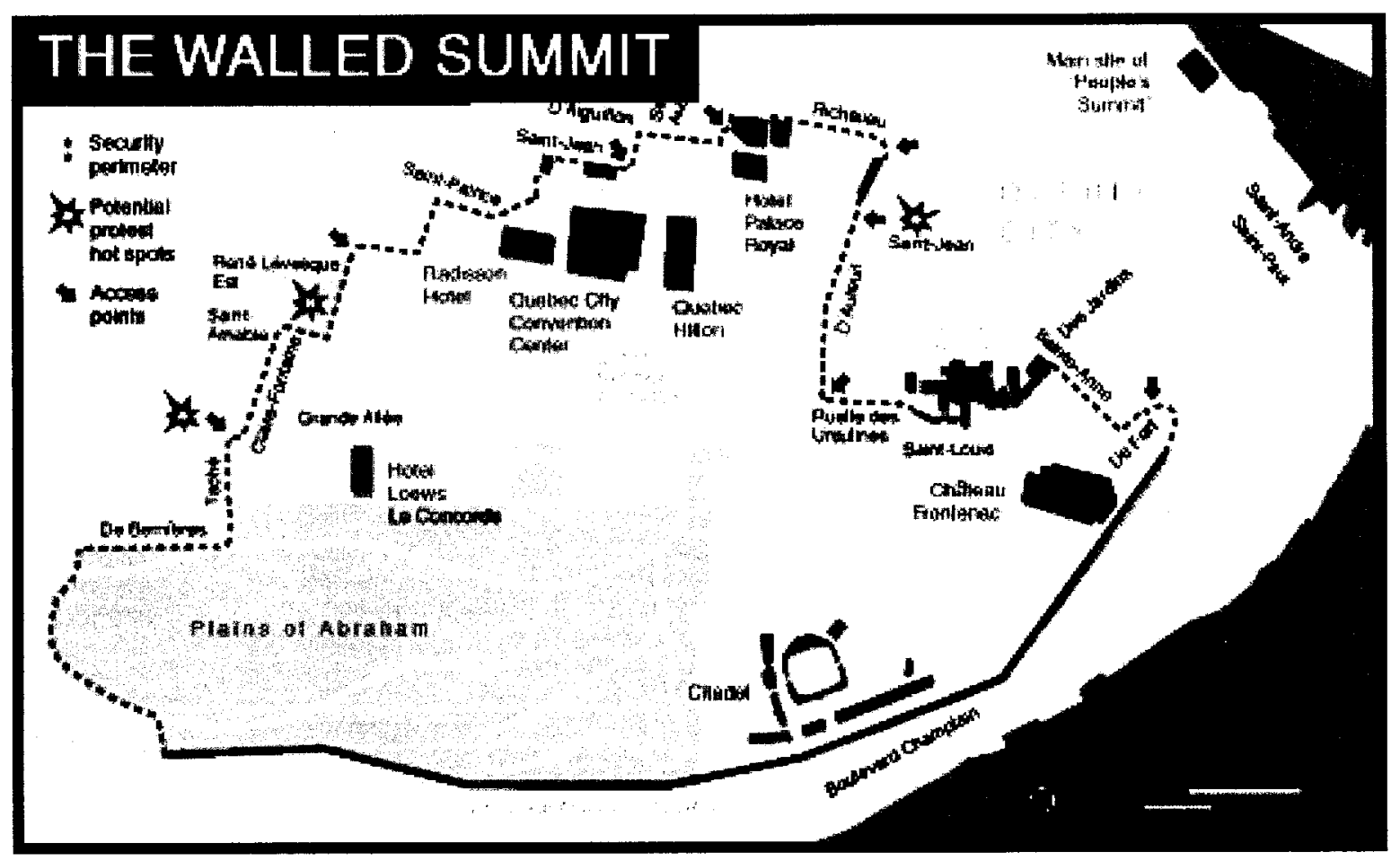

Source: "Special Report: Summit of the Americas," TIME Magazine Online Edition, Thursday, 19 April, 2001, <http://www.time.com/time/world/article/0,8599, 106949,00.html>, June 2003. 


\section{APPENDIX B \\ Classification of newspaper photographs}

I have classified all photographs that appeared in the Saturday, 21 April, Sunday, 22 April, and Monday, 23 April issues of the Globe and Mail, Le Devoir (Montreal), the Montreal Gazette, the National Post, the Ottawa Citizen, and the Toronto Star relating to the Summit of the Americas in Quebec City. The newspapers were selected for their relatively high level of coverage of the summit, and their nation-wide availability. The photographs have been classified into three categories: confrontational protest activity, non-confrontational protest activity, and official summit portraits. Confrontational protest activity includes photographs depicting standoffs between police and demonstrators, acts or evidence of vandalism, protesters breaching the security fence, and other photographs that denote or connote aggressive or confrontational behavior. Non-confrontational protest activity includes images of marches, parades, dancing, and all other activity that is clearly protest-oriented but without connotations of confrontation. Official summit portraits consist of photographs of hemispheric leaders and their immediate family members.

The classifications are mutually exclusive. The numbers in parentheses indicate the percentage of photographs represented in that category.

The purpose of this analysis is to clarify my discussion of image content. It is not intended as media critique as currently employed in communications discourse. 


\begin{tabular}{|c|c|c|c|c|}
\hline Newspaper & $\begin{array}{c}\text { Confrontational } \\
\text { protest activity }\end{array}$ & $\begin{array}{c}\text { Non- } \\
\text { confrontational } \\
\text { protest activity }\end{array}$ & $\begin{array}{c}\text { Official } \\
\text { summit } \\
\text { portraits }\end{array}$ & $\begin{array}{c}\text { Total } \\
\text { number of } \\
\text { photographs }\end{array}$ \\
\hline Globe and Mail & $16(67 \%)$ & $1(4 \%)$ & $7(29 \%)$ & 24 \\
\hline Le Devoir & $13(59 \%)$ & $3(14 \%)$ & $6(27 \%)$ & 22 \\
\hline Montreal Gazette & $20(67 \%)$ & $6(20 \%)$ & $4(13 \%)$ & 30 \\
\hline National Post & $7(47 \%)$ & $2(13 \%)$ & $6(40 \%)$ & 15 \\
\hline Ottawa Citizen & $11(55 \%)$ & $6(30 \%)$ & $3(15 \%)$ & 20 \\
\hline Toronto Star & $14(67 \%)$ & $1(5 \%)$ & $6(28 \%)$ & 21 \\
\hline & & & & \\
\hline Totals & 81 & 19 & 32 & 132 \\
\hline Average percentage & $60 \%$ & $14 \%$ & $25 \%$ & \\
\hline
\end{tabular}




\section{APPENDIX C \\ Classification of newspaper headlines and captions}

I have coded the captions accompanying all newspaper photographs in the six selected newspapers related to the anti-FTAA demonstrations and all headlines in the vicinity of these photographs for verb usage and terminology. Table 1 lists all captions and headlines that refer to demonstrators' actions in the present simple tense (e.g. "A demonstrator taunts police"). The total refers to the number of present tense verbs, not the number of captions. Table 2 lists captions and headlines referring to police actions in the present simple tense (e.g. "Riot police arrest an injured demonstrator after a violent clash yesterday"). Table 3 is a list of all captions and headlines that refer to the use of police weapons, including tear gas, water cannons, and plastic bullets. It is followed by a tabulation of the number of times these weapons are mentioned with a) direct reference to police usage (e.g. "Police break in water cannons"); b) direct reference to protesters' use of these weapons (e.g. "A protester lobs a tear-gas canister back at police yesterday"); c) protesters, but not police, are referenced in relation to these weapons (e.g. "Tear-gassed activists defiant"); and d) references to the weapons suggesting their spontaneous appearance (e.g. "Clouds of tear gas sent people running for cover").

The tables are not classified according to newspaper. The newspaper in which the caption or headline appears is included in parentheses in abbreviated form (GM=Globe and Mail; $\mathrm{LD}=$ Le Devoir [Montreal]; $\mathrm{MG}=$ Montreal Gazette; $\mathrm{NP}=$ National Post; $\mathrm{OC}=$ Ottawa Citizen; $\mathrm{TS}=$ Toronto Star), followed by the date of its appearance. Lists are arranged alphabetically. 


\section{Table 1: Captions and headlines referring to demonstrators' actions in present simple tense:}

- Activists topple riot fence, delaying summit's opening. (GM 21 April)

- After knocking over a section of the summit perimeter fence yesterday, protesters use their body weight to try to keep security forces from propping it back up. (GM 21 April)

- Amid the tear gas, the skirl of the pipes: A gas-masked bagpiper plays his way through blasting water cannon spray and tear gas yesterday at the summit in Quebec City. (TS 22 April)

- Black-masked anarchists set the stage for today's larger demonstration.... Black Bloc storms Quebec City security fence. (OC 21 April)

- A defiant protester stands his ground as police mass on Grand Allée Friday. (MG 23 April)

- A demonstrator gestures before an approaching array of police in riot gear during yesterday afternoon's frantic confrontations in Quebec City. (MG 21 April)

- A demonstrator gestures defiantly under a rainbow created by a police water cannon yesterday in Quebec City. (TS 22 April)

- A demonstrator lobs a tear-gas canister back at police yesterday. (MG 22 April)

- A demonstrator wearing a mask throws a tear-gas canister back at security forces. (GM 21 April)

- Demonstrators battle riot cops into morning. (MG 21 April)

- A demonstrator taunts police. Protesters at the broken down barrier meet tear gas then blue line of riot police. (TS 21 April)

- Four protesters try to climb the security fence protecting the leaders.... Other protesters try to pull the fence down with ropes. (TS April 22)

- A gas-masked, bag-piping protester ignores the police water cannon that swept a nearby protester off his feet Saturday. (MG 23 April)

- Left, a protester stares at police through the security fence as another smashes the windshield of a TV station cruiser during yesterday's summit riots. (TS 21 April)

- A line of demonstrators flash a sign that means both peace and victory. (MG 23 April)

- A man wearing a balaclava and helmet smashes the windshield of a Global TV news vehicle. (GM 21 April)

- One young man, left, shows the wound left by the impact of a rubber bullet. (OC 23 April)

- Posté a front, un des deux manifestants tentait de se soulanger les veux du picotemant provoqué par les gaz lacrymogénes lancés par les policiers. (LD 21-22 April)

- A protester covers his face in fog of tear gas during pitched street battles. (MG 21 April)

- A protester defiantly stands amidst a sea of water blasted by riot police water cannons. (OC 22 April)

- Protester grimaces in pain as he is treated for exposure to tear gas. (MG 22 April)

- A protester peers outside the security fence prior to the start of yesterday's demonstrations. (MG 22 April) 
- A protester scales the perimeter fence on Grande Alleé before it was knocked down yesterday afternoon. (MG 21 April)

- Protesters stand defiantly against the onslaught of the water cannon on René Lévesque Blvd in Quebec City. (MG 22 April)

- A protester stares defiantly at the security contingent. (GM 21 April)

- A protester stares down police in Quebec City yesterday. (NP 21 April)

- A protester swings a baton at an officer who is trying to make an arrest. (GM 21 April)

- Above, a protester with an anarchist symbol flashes a peace sign at riot police while a demonstrator, top right, is arrested as another stands in a cloud of tear gas. (TS 21 April)

- Protesters carry a barricade into a clash with baton-wielding police officers yesterday in Quebec City. (NP 21 April)

- Protesters confront wall of water. (OC 22 April)

- Protesters throw barriers at police while peaceful demonstrators look on. (MG 23 April)

- Protesters topple fence at summit. (GM 21 April)

- Rioter aims a slingshot at riot police at the security fence... (TS 21 April)

- A summit protester gives the peace sign yesterday to a faceless line of police wearing riot helmets and carrying shields and large night sticks. (GM 21 April)

- The weekend was marred by the heavy use of tear gas to control protesters. One man washes his eyes after an altercation with police protecting the security fence around the summit. (GM 23 April)

- Yesterday was a day of faceoffs between police and demonstrators. This masked protester confronts police as tear gas swirls about him near the $\mathrm{QC}$ security fence. (MG 22 April)

Total number of references to demonstrators' actions in present simple tense: 41 
Table 2: Captions and headlines referring to police actions in present simple tense:

- Police in riot gear overpower protesters yesterday. (MG 21 April)

- Police officers form a line on Grand Allée, surrounded by the tear gas they'd shot moments before. (MG 21 April)

- A defiant protester stands his ground as police mass on Grand Allée. (MG 23 April))

- Police break in water cannons. (MG 22 April)

- Police turn a water cannon on protesters trying to scale the security fence at the Summit of the Americas in Quebec City yesterday. (OC 22 April)

- Riot police arrest an injured demonstrator after a violent clash yesterday. (TS 21 April)

- Riot police take a break in and around a bus after confrontations with protesters. (GM 23 April)

Total number of references to police actions in present simple tense: 7 


\section{Table 3: References to police weapons, including tear gas, water cannons, and plastic bullets:}

- Above, a protester with an anarchist symbol flashes a peace sign at riot police while a demonstrator, top right, is arrested as another stands in a cloud of tear gas. (TS 21 April)

- Amid the tear gas, the skirl of the pipes: A gas-masked bagpiper plays his way through blasting water cannon spray and tear gas yesterday at the summit in Quebec City. (TS 22 April)

- After protesters breached the infamous security fence that cordons off part of Quebec City, riot police went to work. The shielded men in their uniforms marched and marched until they came nose to nose with protesters, who stood their ground until overcome by tear gas. (OC 21 April)

- A demonstrator gestures defiantly under a rainbow created by a police water cannon yesterday in Quebec City. (TS 22 April)

- A demonstrator has her eyes washed after police used tear gas and pepper spray. (GM 21 April)

- A demonstrator lobs a tear-gas canister back at police yesterday. (MG 22 April)

- A demonstrator wearing a mask throws a tear-gas canister back at security forces. (GM 21 April)

- (F)or every area where good vibes prevailed, there was another where clouds of tear gas sent people running for cover. Parts of the old city looked like a battlefield enveloped by acrid clouds of tear gas with helicopters circling overhead and fires burning along garbage-strewn streets. About 400 people were arrested in violent clashes involving rubber bullets, bottles, chunks of sidewalk, Molotov cocktails and powerful water cannons. One young man, left, shows the wound left by the impact of a rubber bullet. (OC 23 April)

- A gas-masked, bag-piping protester ignores the police water cannon that swept a nearby protester off his feet Saturday. (MG 23 April)

- Many tear-gas canisters were hurled by both riot police and demonstrators during the weekend. (GM 23 April)

- A naked protester mooning police is answered with a blast from a water cannon, one of the weapons authorities used against demonstrators, along with tear gas and plastic bullets. (GM 23 April)

- One young man, left, shows the wound left by the impact of a rubber bullet. (OC 23 April)

- Police break in water cannons. (MG 22 April)

- Police officers form a line on Grande Alleé, surrounded by the tear gas they'd shot moments before. (MG 21 April)

- A police tear-gas canister is thrown back by a demonstrator during rioting yesterday outside the summit. (MG 21 April)

- Police turn a water cannon on protesters trying to scale the security fence at the Summit of the Americas in Quebec City yesterday. (OC 22 April)

- Posté a front, un des deux manifestants tentait de se soulanger les veux du picotemant 
provoqué par les gaz lacrymogénes lancés par les policiers. (LD 21-22 April)

- A protester covers his face in fog of tear gas during pitched street battles. (MG 21April)

- A protester defiantly stands amidst a sea of water blasted by riot police water cannons. (OC 22 April)

- Protester grimaces in pain as he is treated for exposure to tear gas. (MG 22 April)

- A protester has his eyes washed out after tear gas burns yesterday. (TS 21 April)

- Protesters at the broken down barrier meet tear gas then blue line of riot police. (TS 21 April)

- Protesters confront wall of water. (OC 22 April)

- Protesters stand defiantly against the onslaught of the water cannon on René Lévesque Blvd in Quebec City. (MG 22 April)

- Some groups came with disruptive strategies that dissolved in clouds of tear gas almost as soon as the protest began. (NP 21 April)

- Street-hockey skills came in handy for one activist who prepares to hit a tear-gas canister back at riot police. The air was thick with the gas during the weekend, causing discomfort to hundreds of people in the city, as canisters were lobbed back and forth during running clashes. (GM 23 April)

- Tear gas battle launches summit. (TS 21 April)

- Tear-gassed activists defiant. (MG 22 April)

- This masked protester confronts police as tear gas swirls about him near the QC security fence. (MG 22 April)

- A week of dancing, debates and tear gas. (GM 21 April)

- The weekend was marred by the heavy use of tear gas to control protesters. One man washes his eyes after an altercation with police protecting the security fence around the summit. (GM 23 April)

Total number of references to police weapons: 36

References to police weapons with direct reference to police usage: 8

References to police weapons with direct reference to protesters' use of them: 6

References to police weapons that include reference to protesters, but not police: 19

References to police weapons in which they seem to appear spontaneously: 23 


\section{THE GLOBE AND MAIL Fortress Quebec is breached
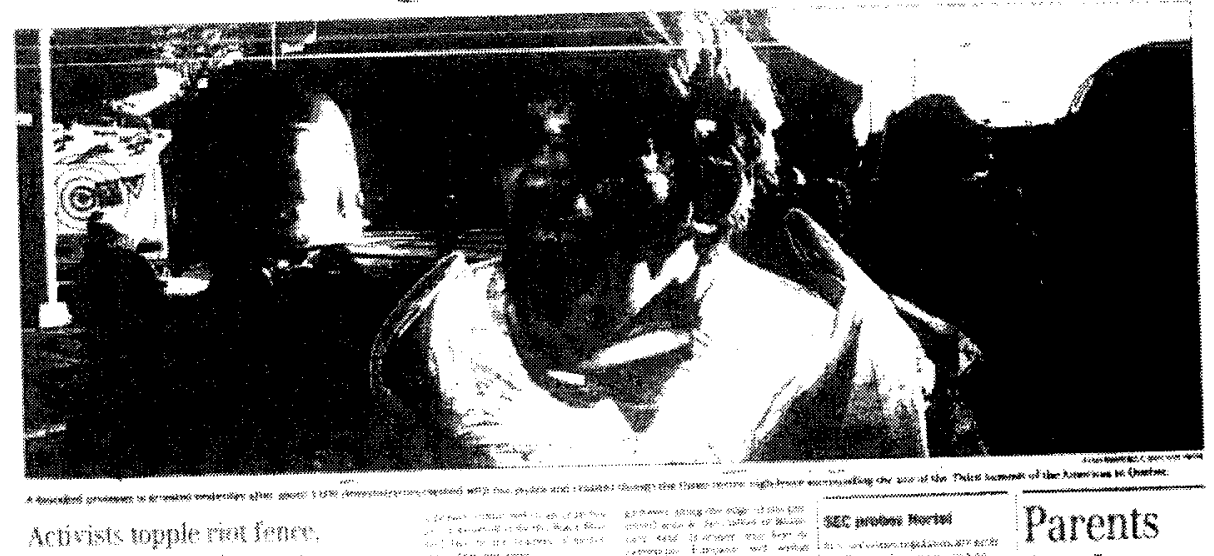

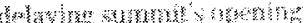

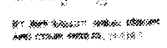 \\ zan feud over obese

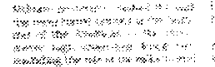 \\ twin tots}

Figure 1.1. Globe and Mail, Saturday, 21 April 2001, A1. 


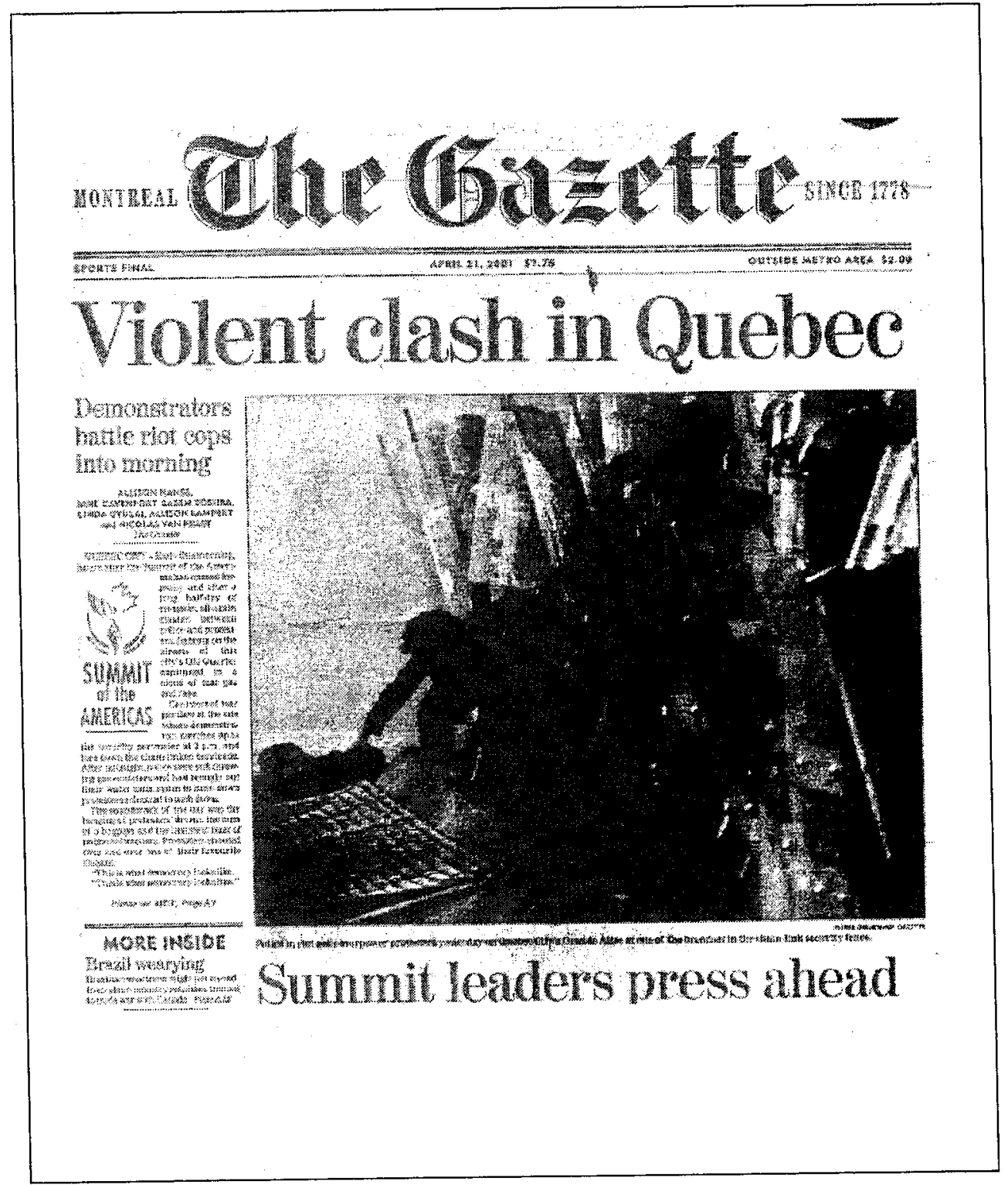

Figure 1.2. Montreal Gazette, Saturday, 21 April 2001, A1. 


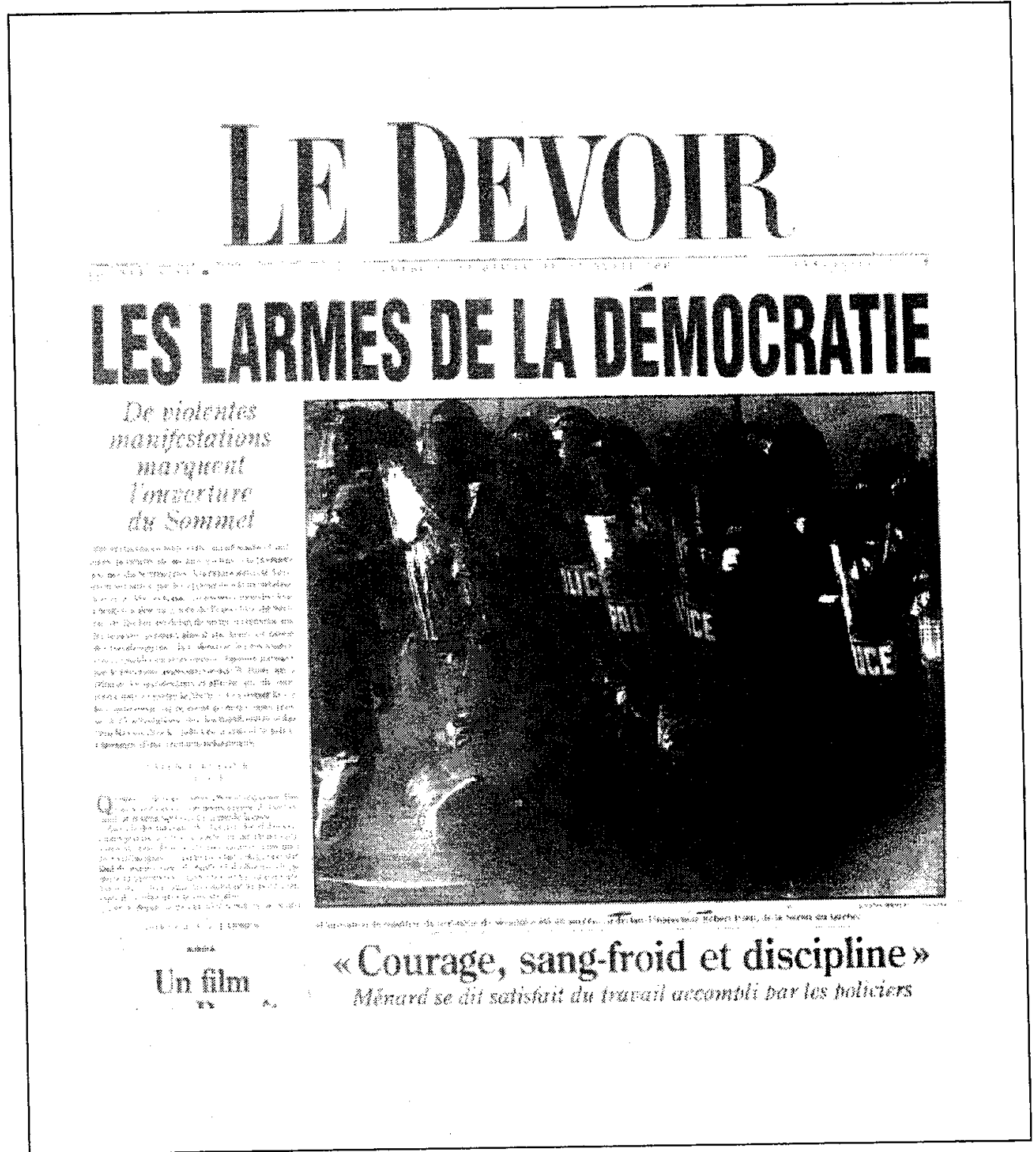

Figure 1.3. Le Devoir (Montreal), Saturday, 21 and Sunday, 22 April 2001, A1. 
- On to the Plains of Abraham

Black-masked anarchiss set the sting for today's larger denonstration

" Fisick Blare

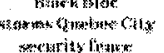

siram

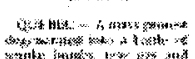

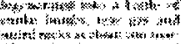

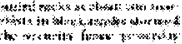

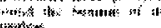

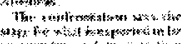

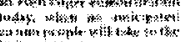

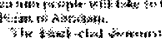

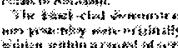

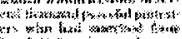

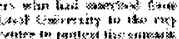

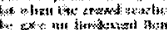

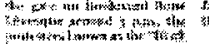

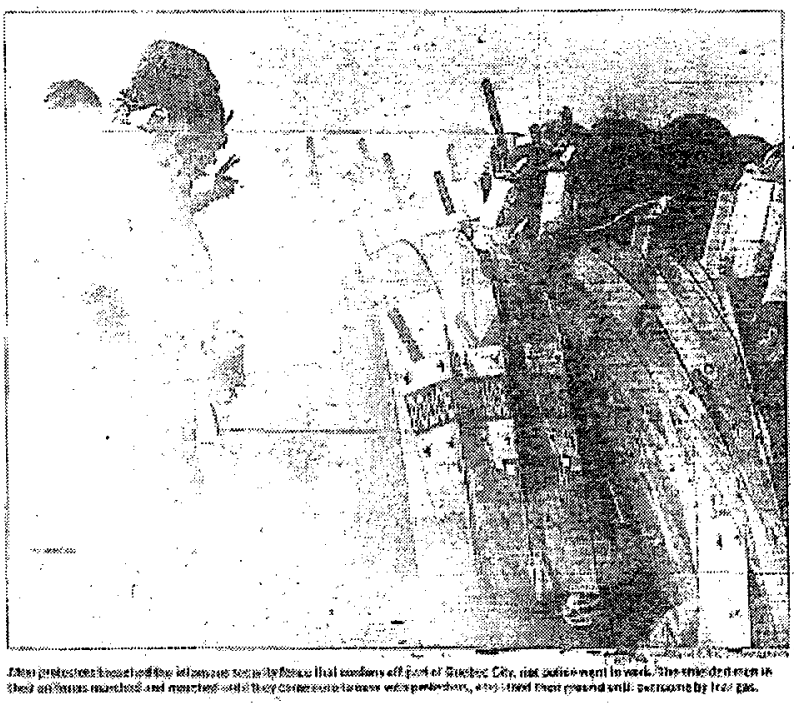

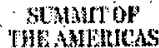

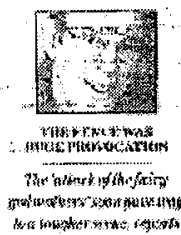

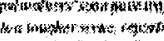

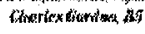

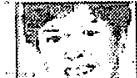

(1)

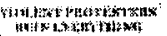

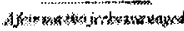

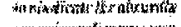

tinch

-

Figure 1.4. Ottawa Citizen, Saturday, 21 April 2001, A1. 


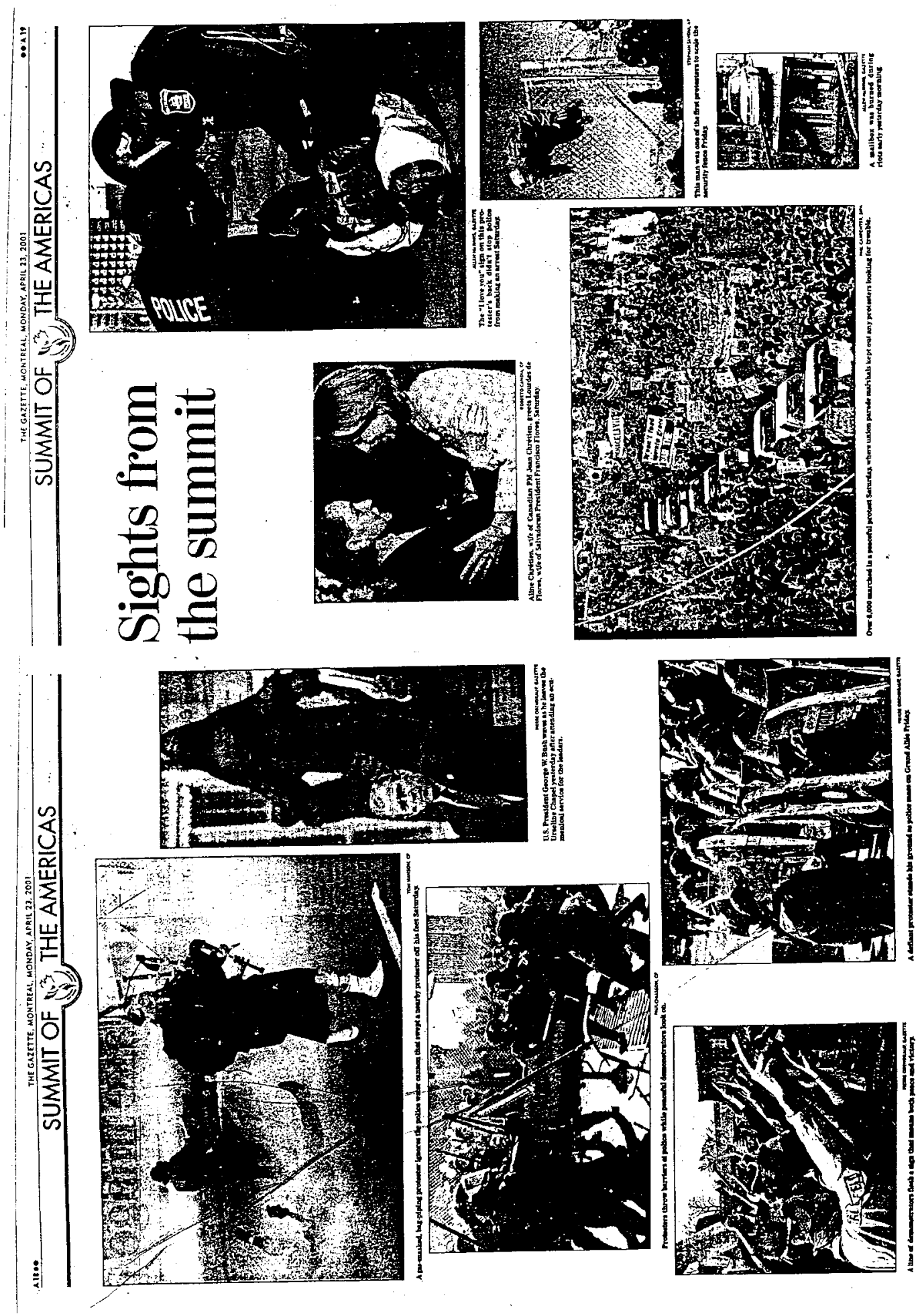

Figure 1.5. Montreal Gazette, Monday, 23 April 2001, A18-A19. 


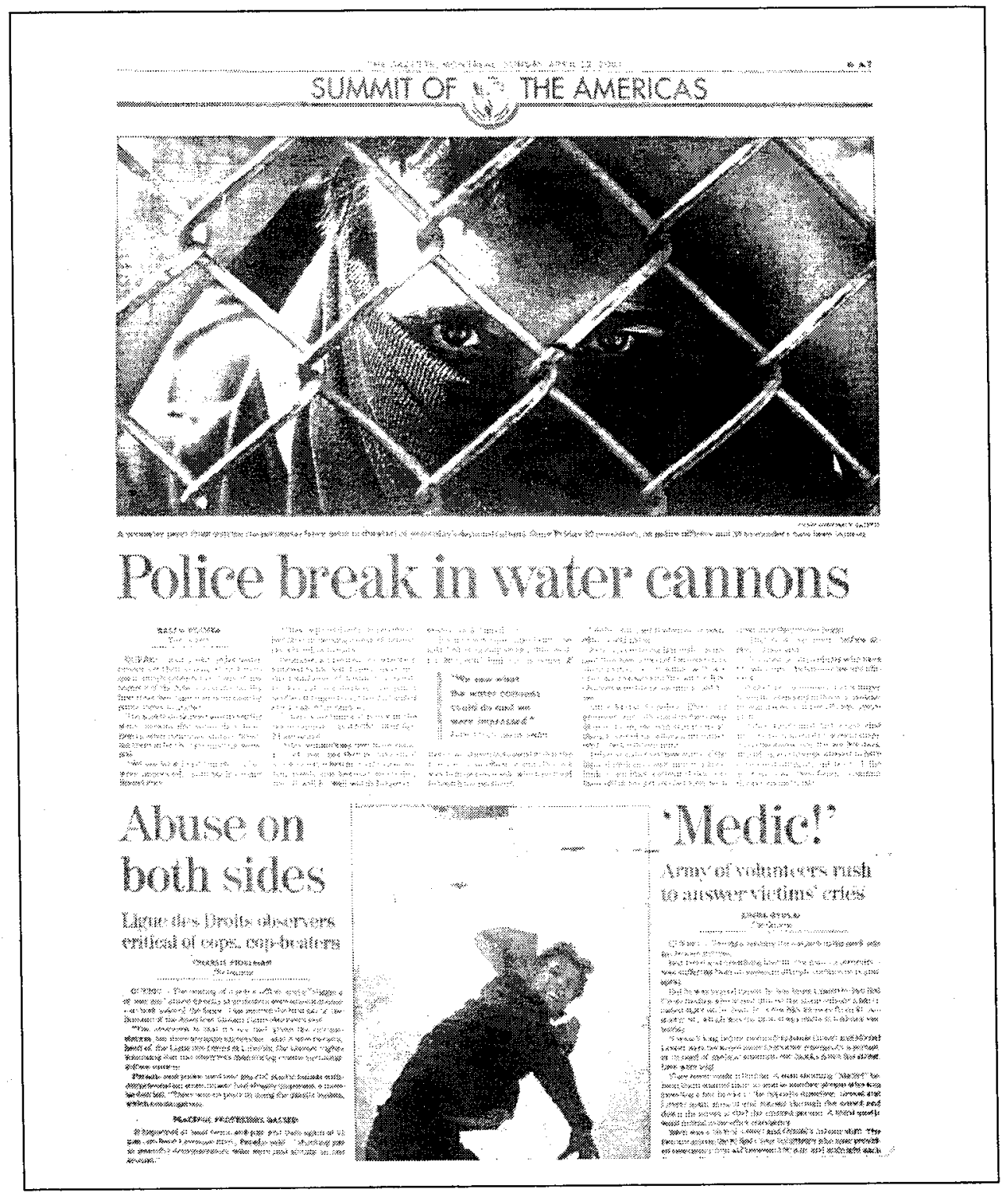

Figure 1.6. Montreal Gazette, Sunday, 22 April 2001, A7. 


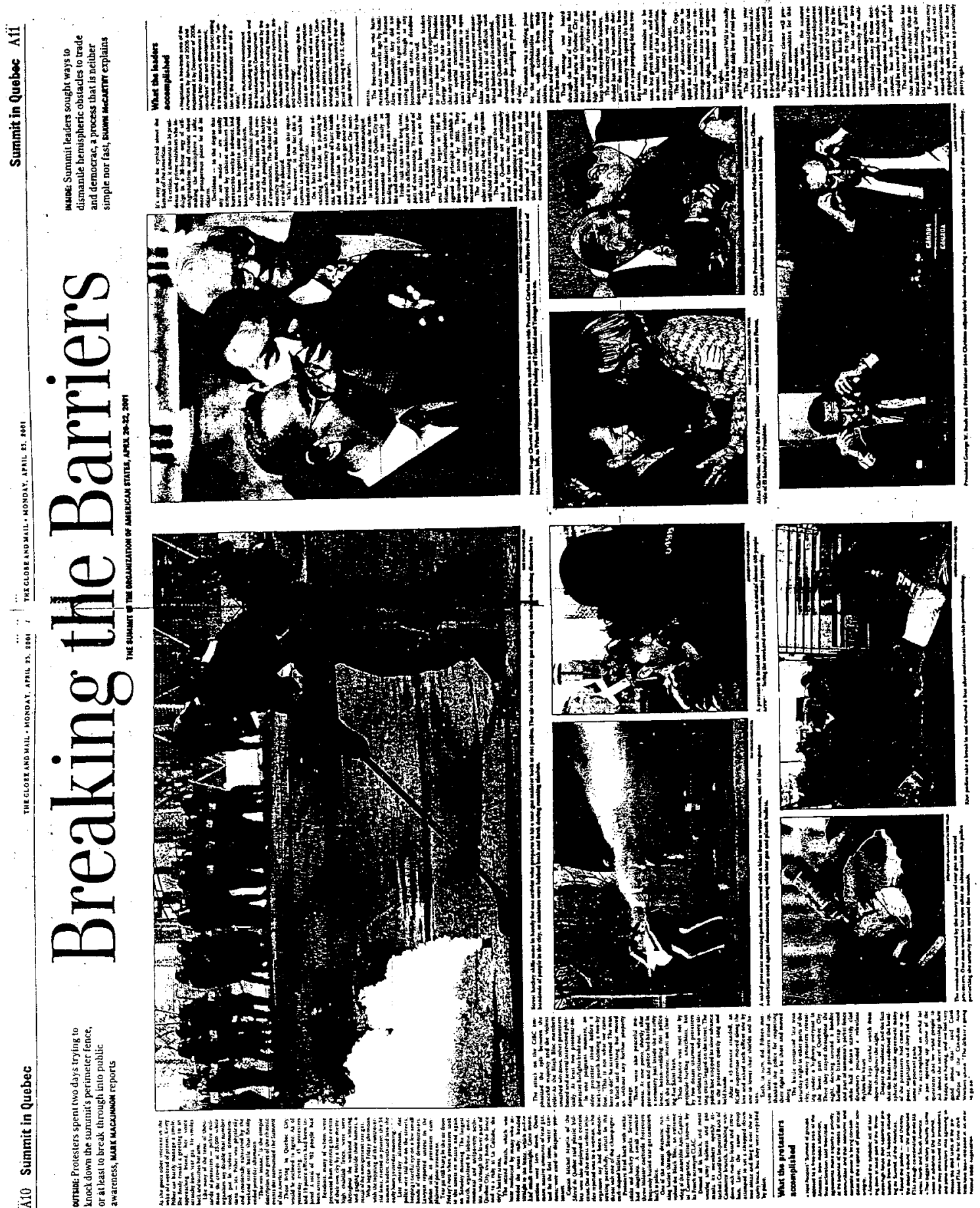

Figure 1.7. Globe and Mail, Monday, 23 April 2001, A10-A11. 


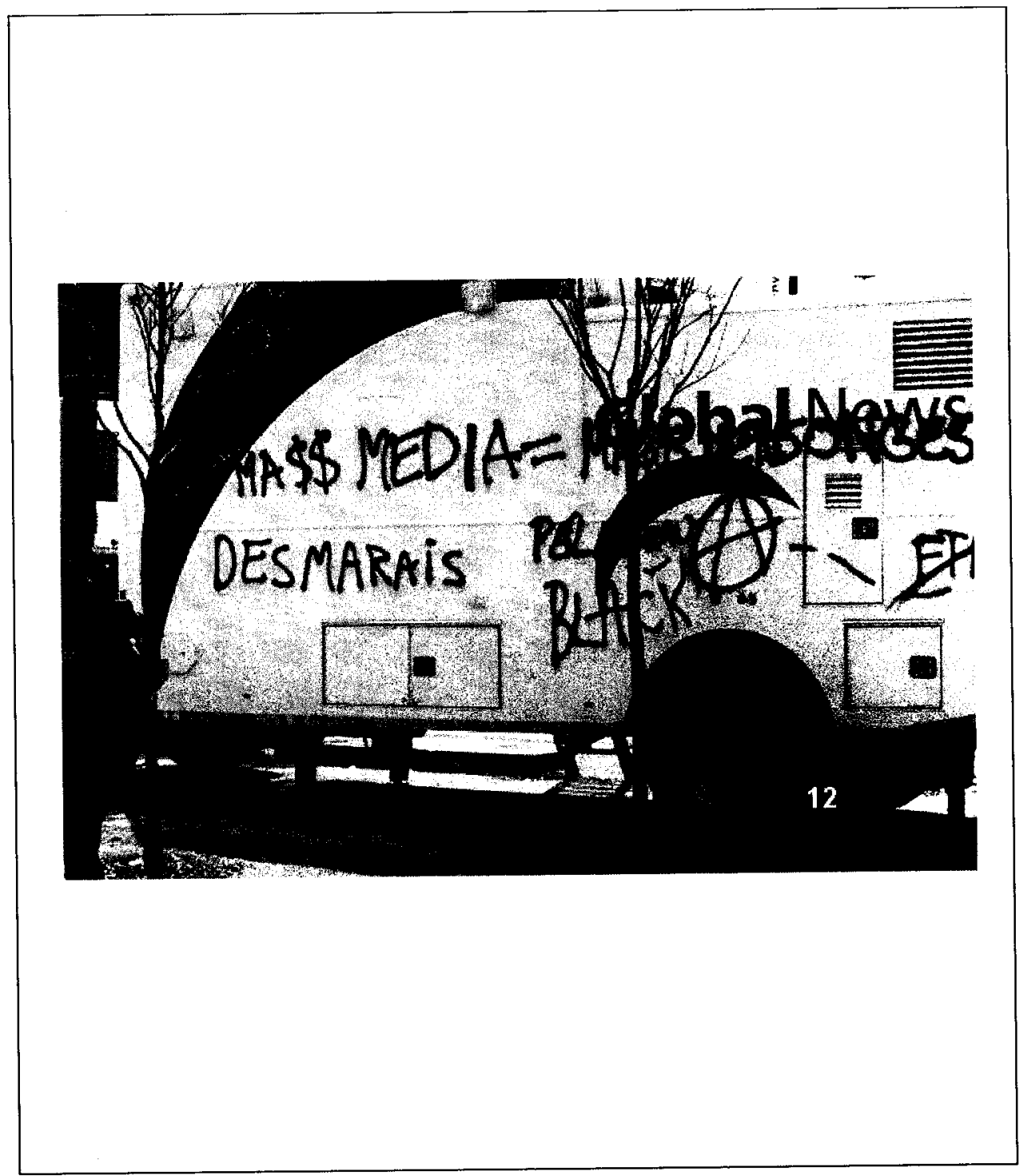

Figure 1.8. "The KKKorporate media gets a rough ride at this event!" Graeme Bacque, Quebec City, 2001. 


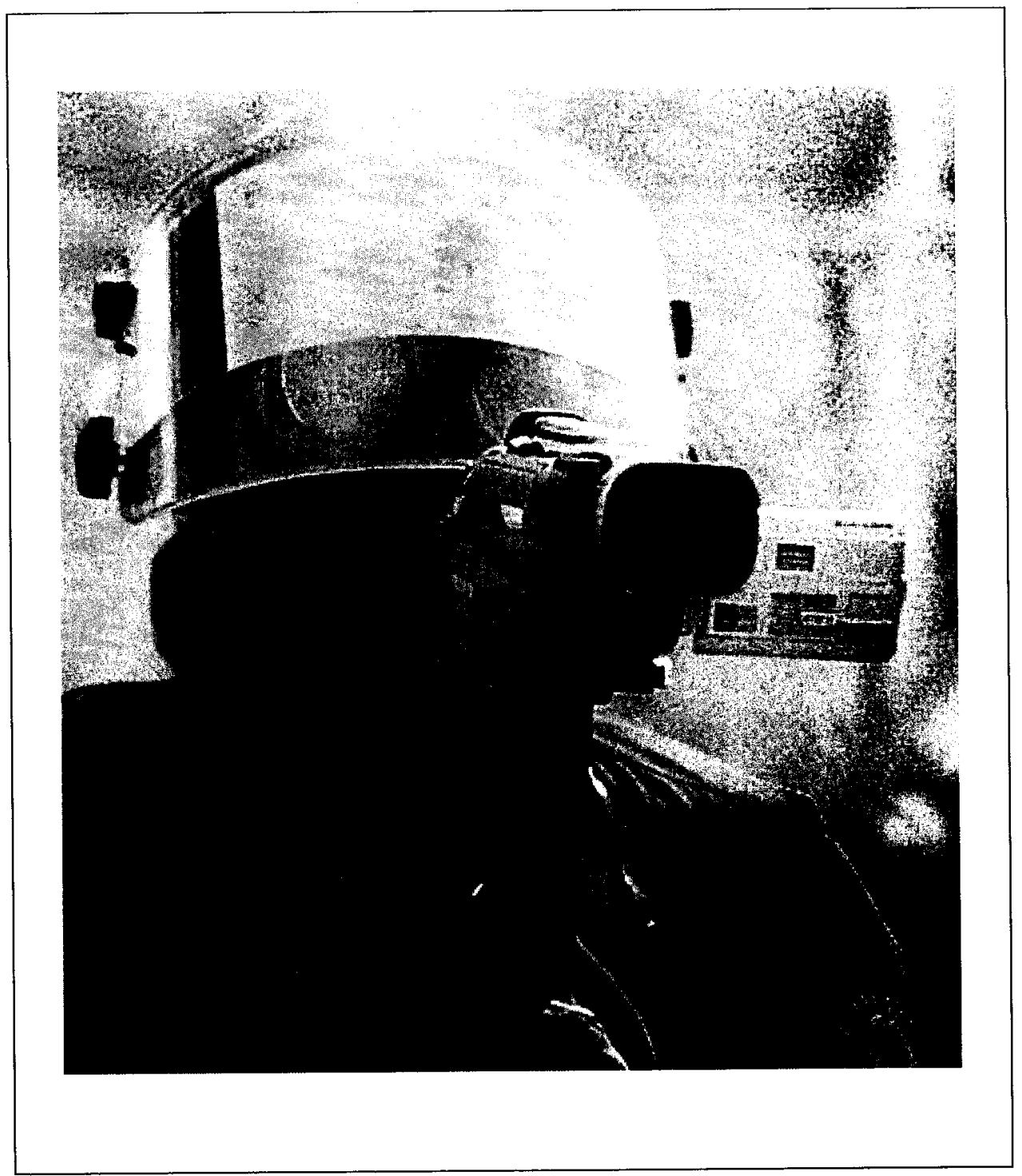

Figure 1.9. "This officer got as good a shot of my face as I did of his." Rob Breadner, Quebec City, 2001. 


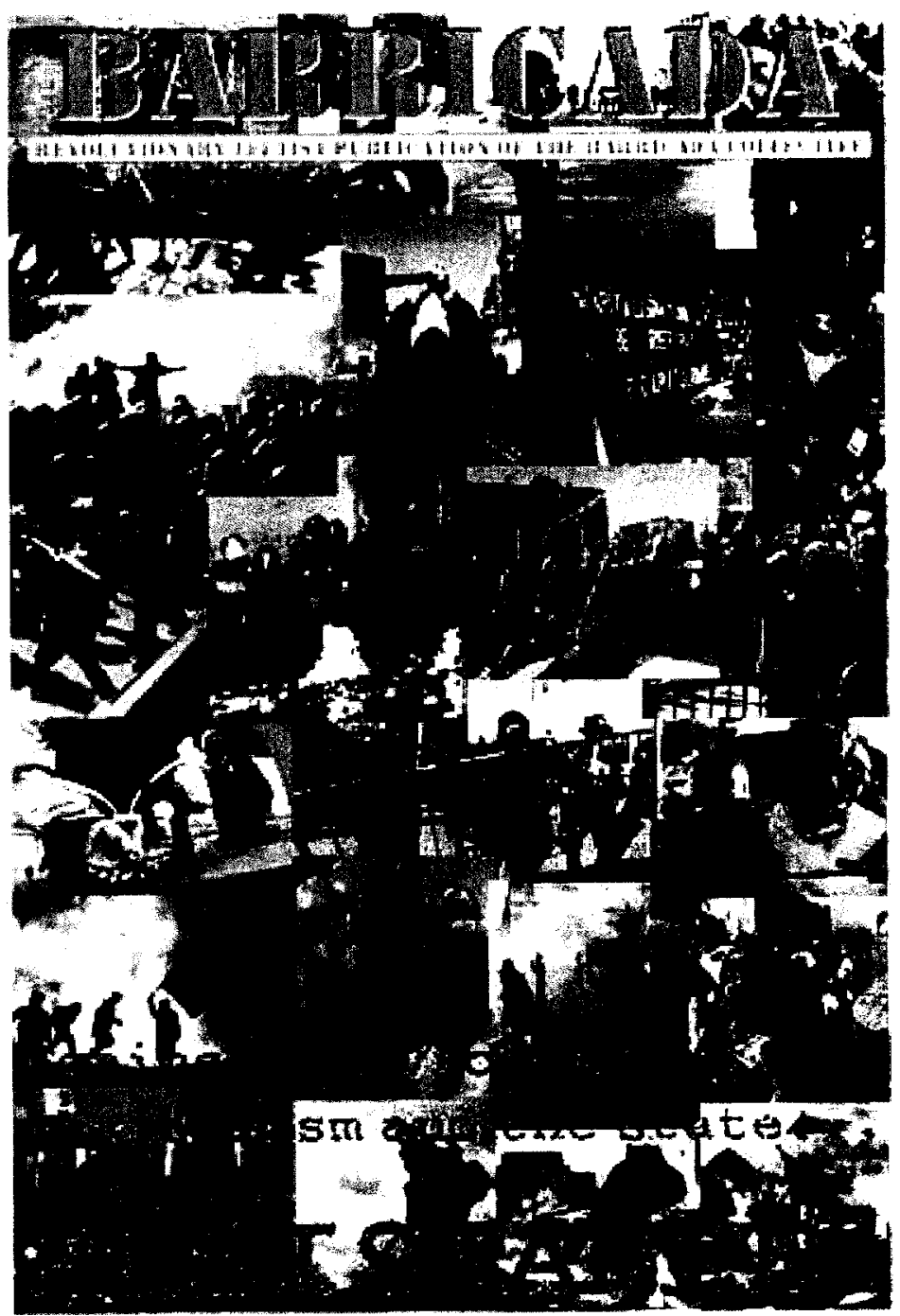

Figure 1.10. Barricada (Boston, Mass.) 7 (May 2001), front cover. 


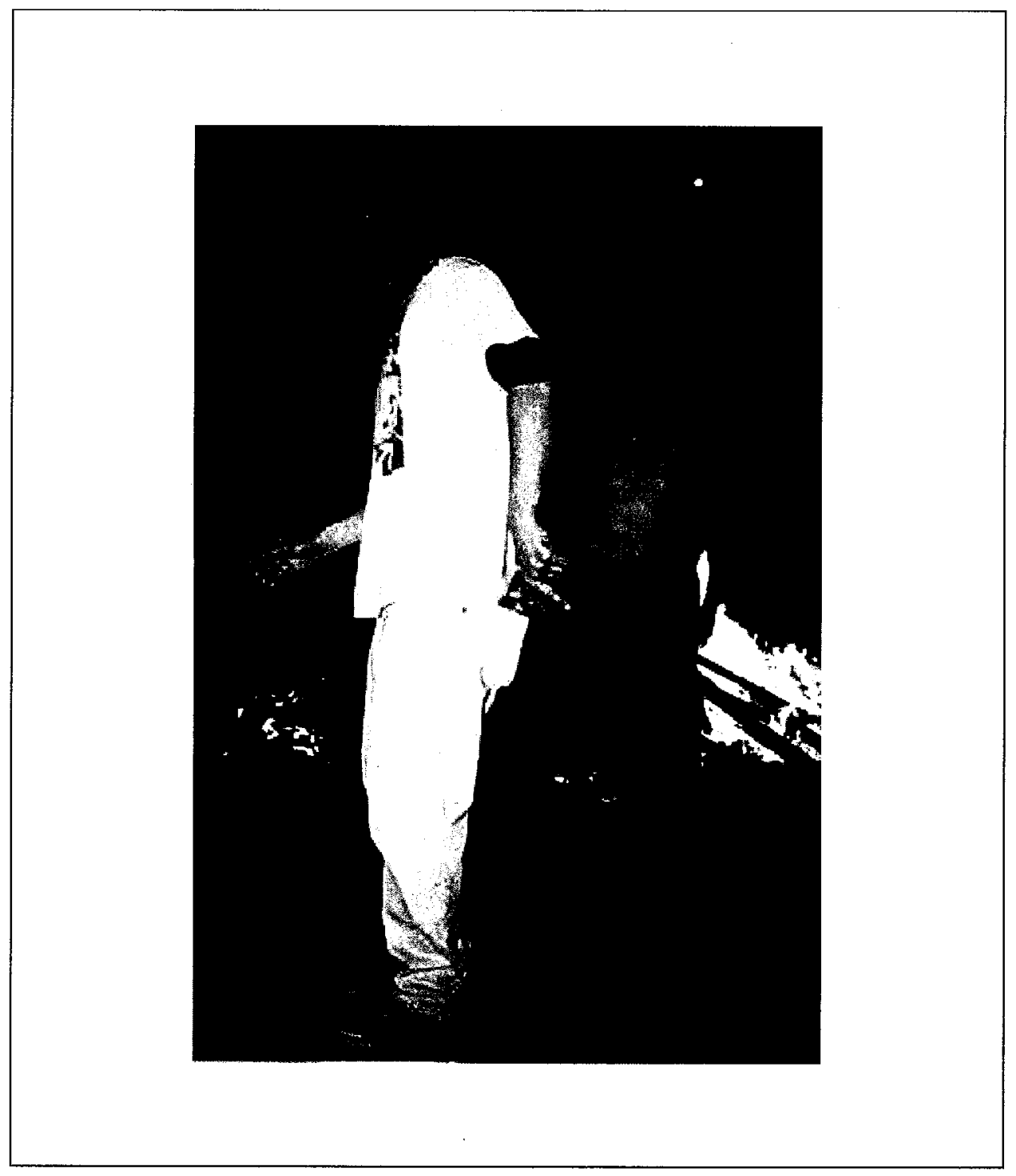

Figure 1.11. "Yours truly, taking in tribal drumming at the massive bonfire, late into the evening. It was a bonding experience of many protest-weary warriors."

Rob Breadner, Quebec City, 2001. 


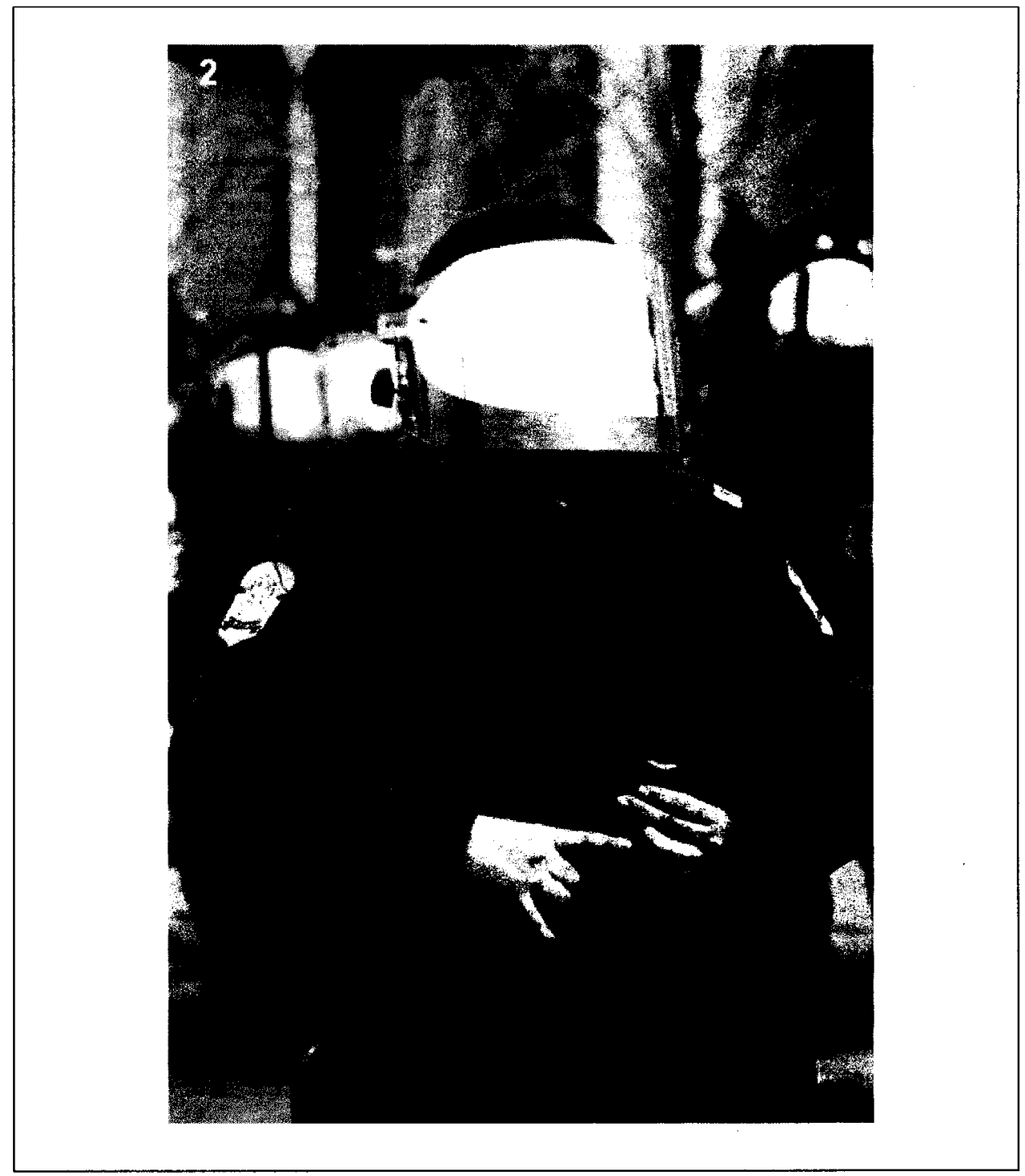

Figure 1.12. "This pig shot a concussion grenade towards my back as I retreated after taking these pics (Bastard!). Graeme Bacque, Quebec City, 2001. 


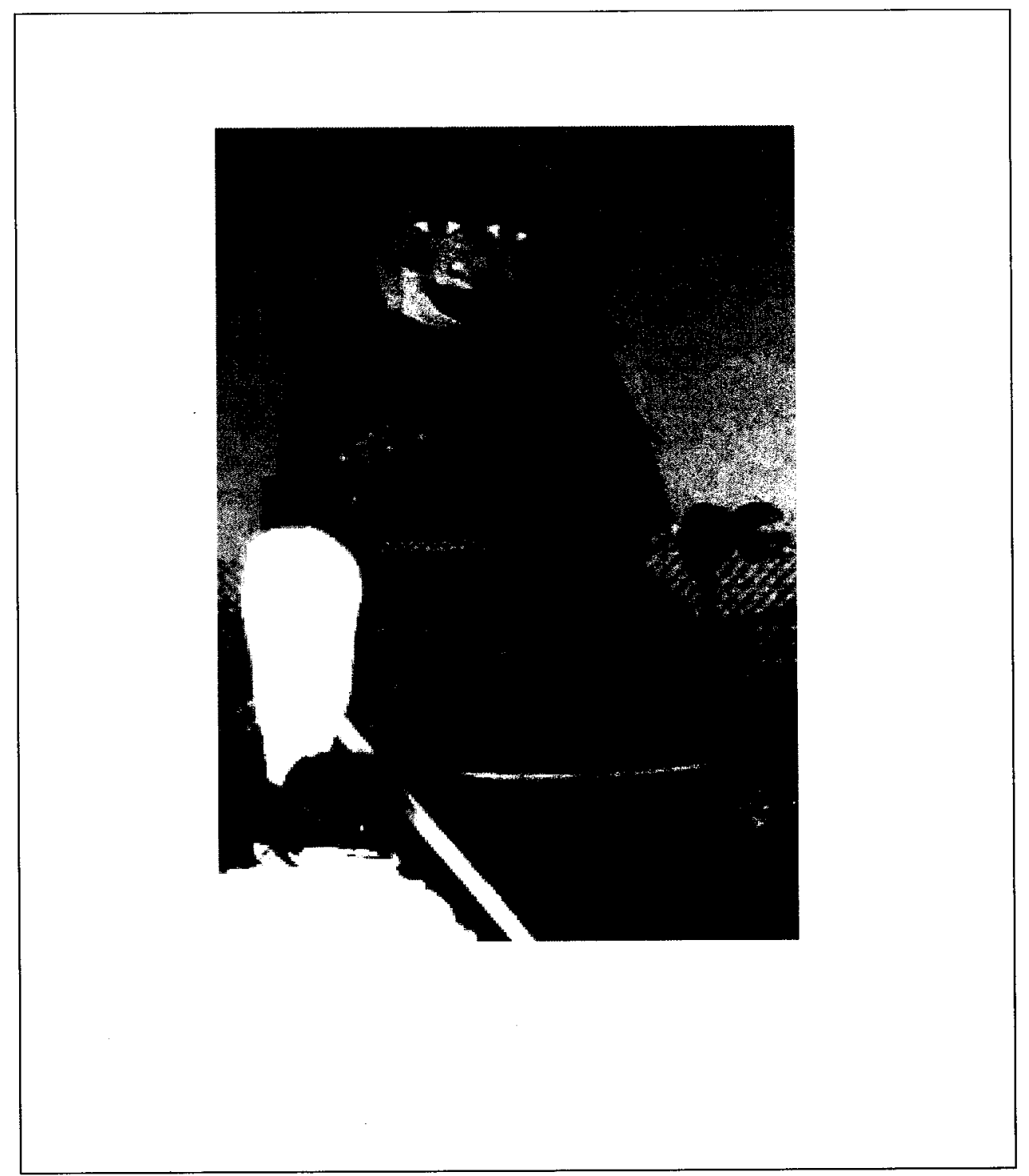

Figure 2.1. Nemesis, the Goddess of Just Anger.

Barbara Walker Graham, Quebec City, 2001. 


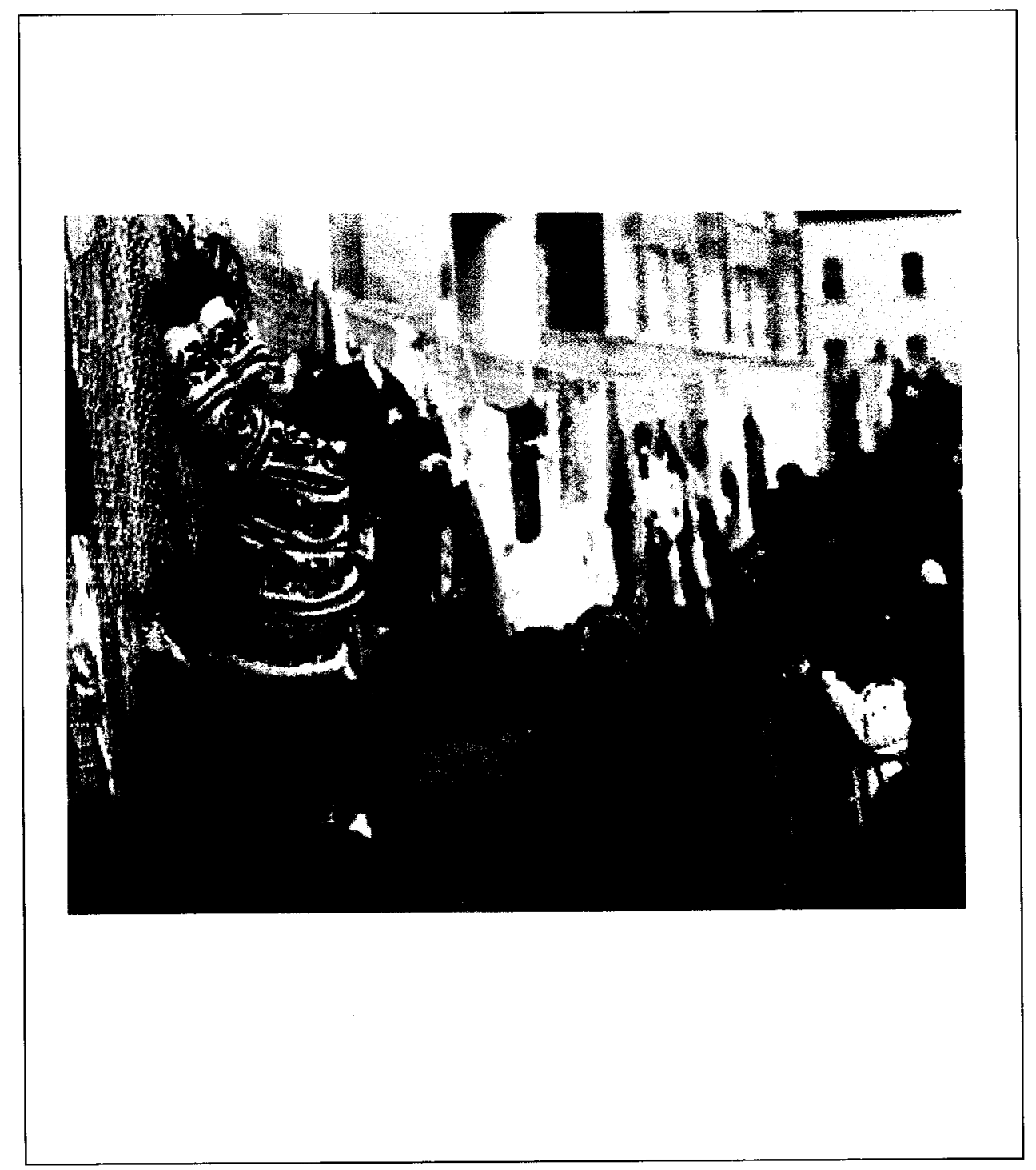

Figure 2.2. Weaving a Web of Solidarity action.

Tom Hanson, Quebec City, 2001. 


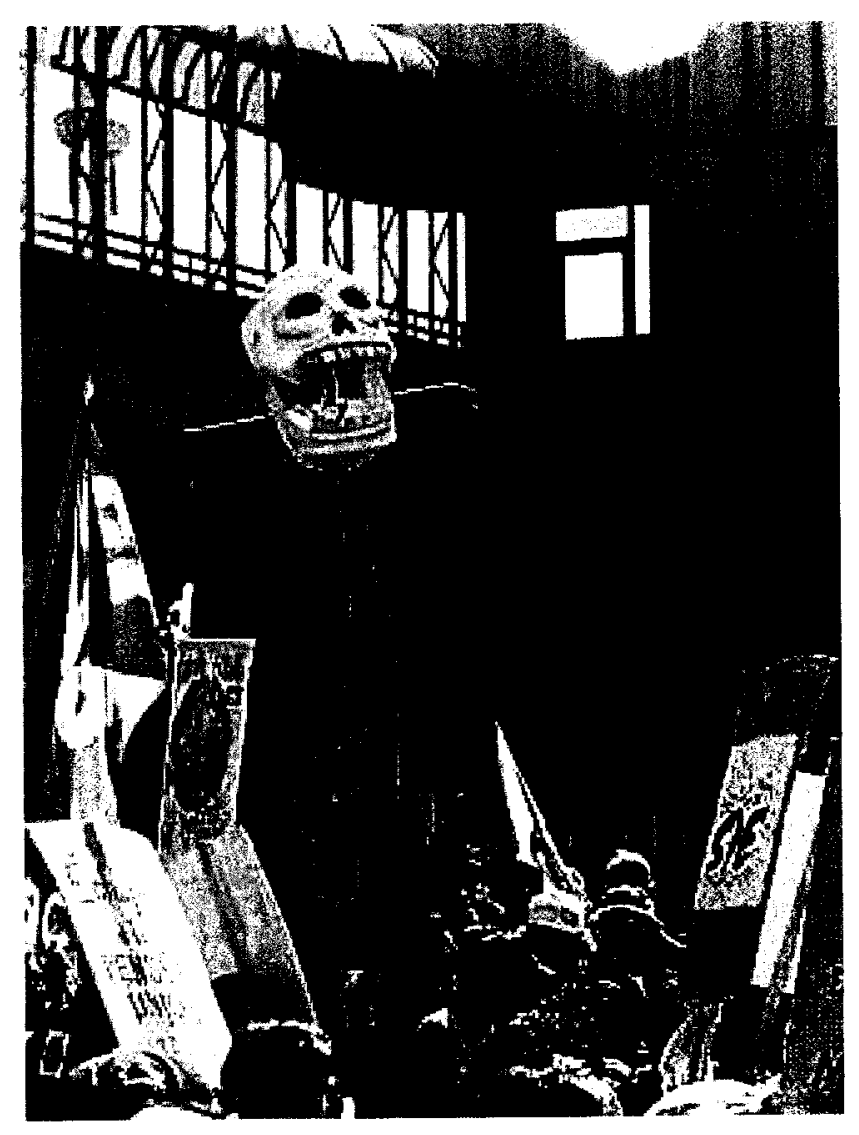

Figure 2.3. R.I.P. puppet.

Photographer unknown, Quebec City, 2001. 


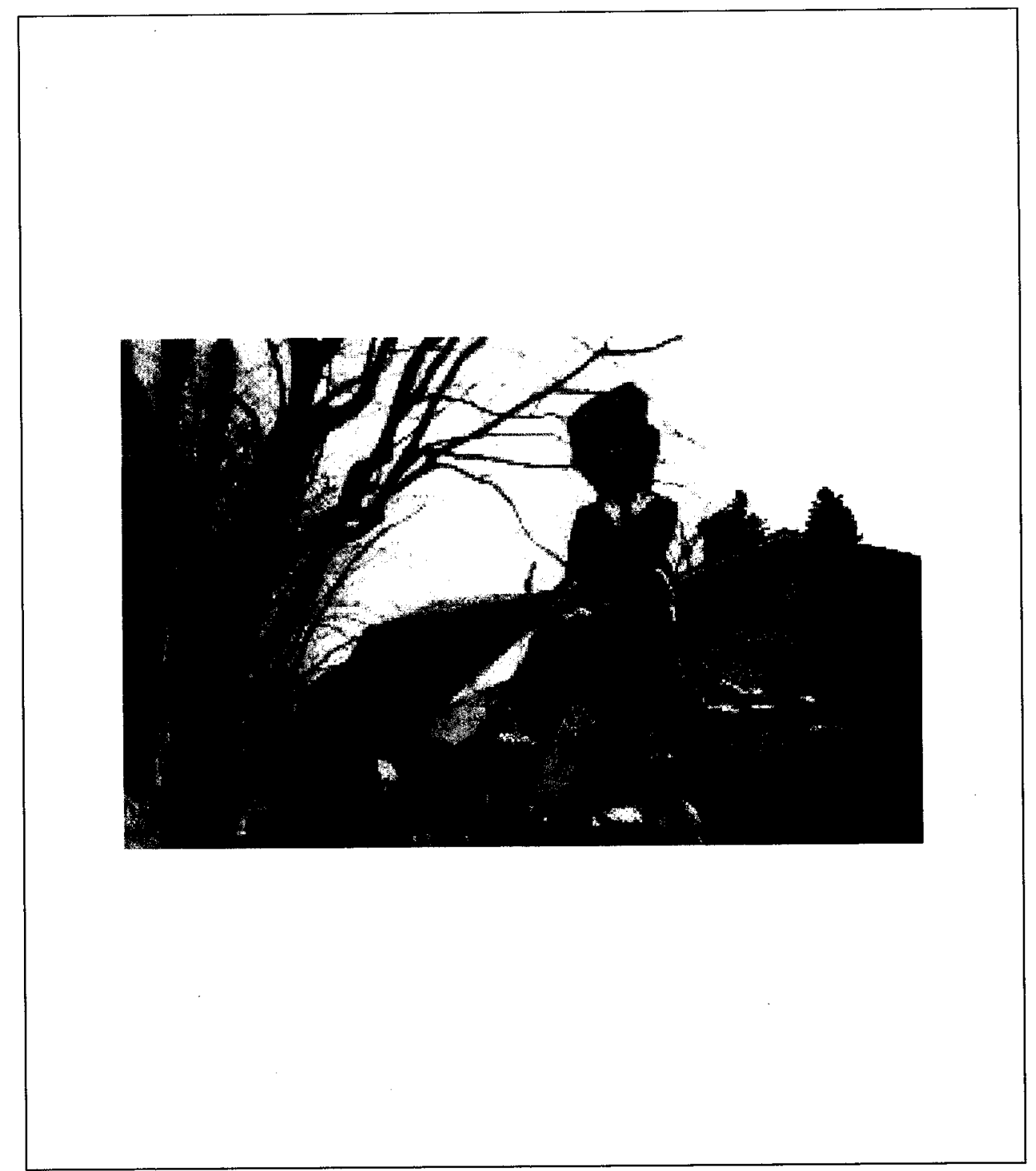

Figure 2.4. "Cycloptopus' corporate puppet with tentacles reaching into every household."

Photographer unknown, Quebec City, 2001. 


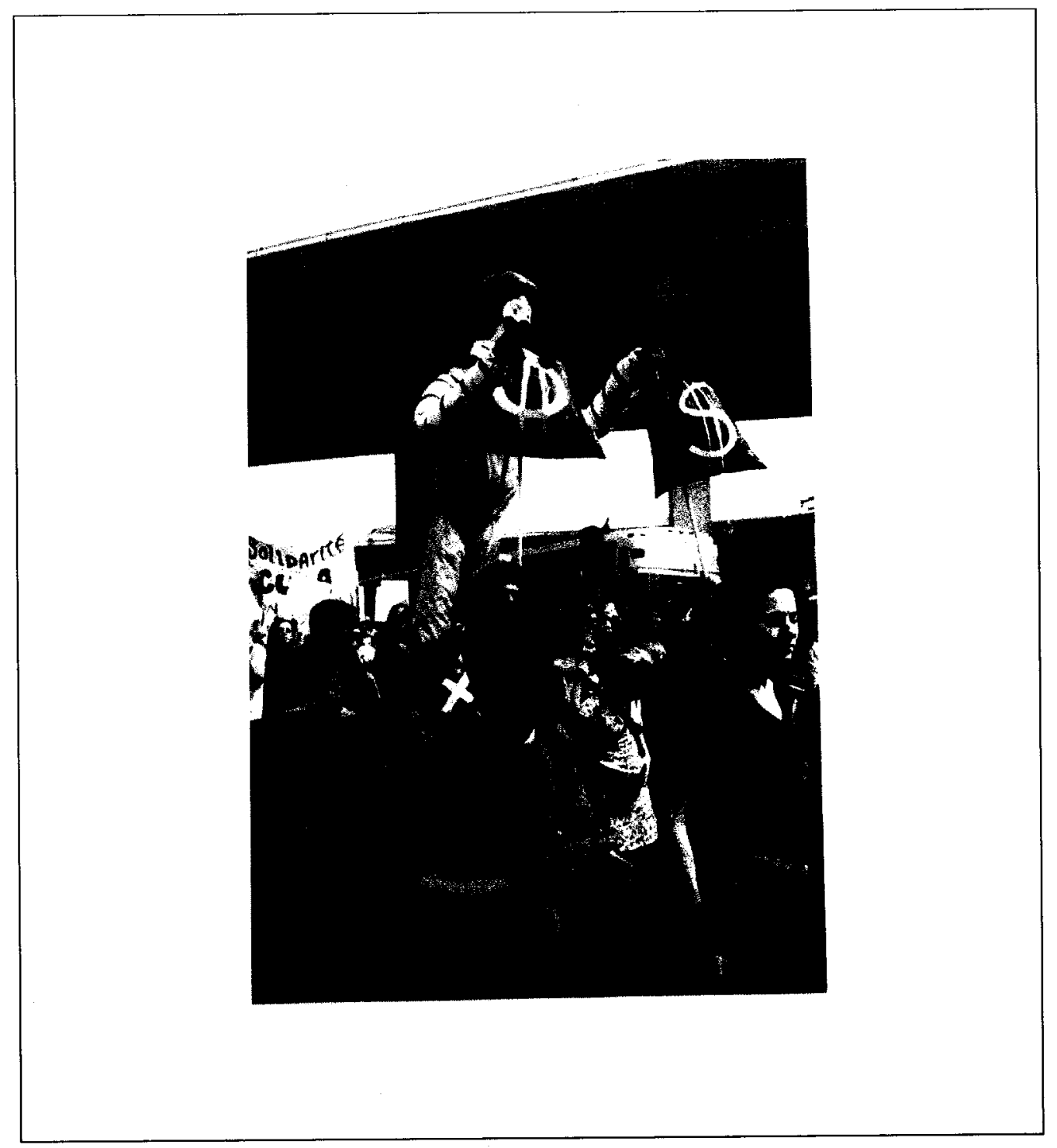

Figure 2.5. Ronald McDonald puppet during People's March. Claudette Lauzon, Quebec City, 2001. 


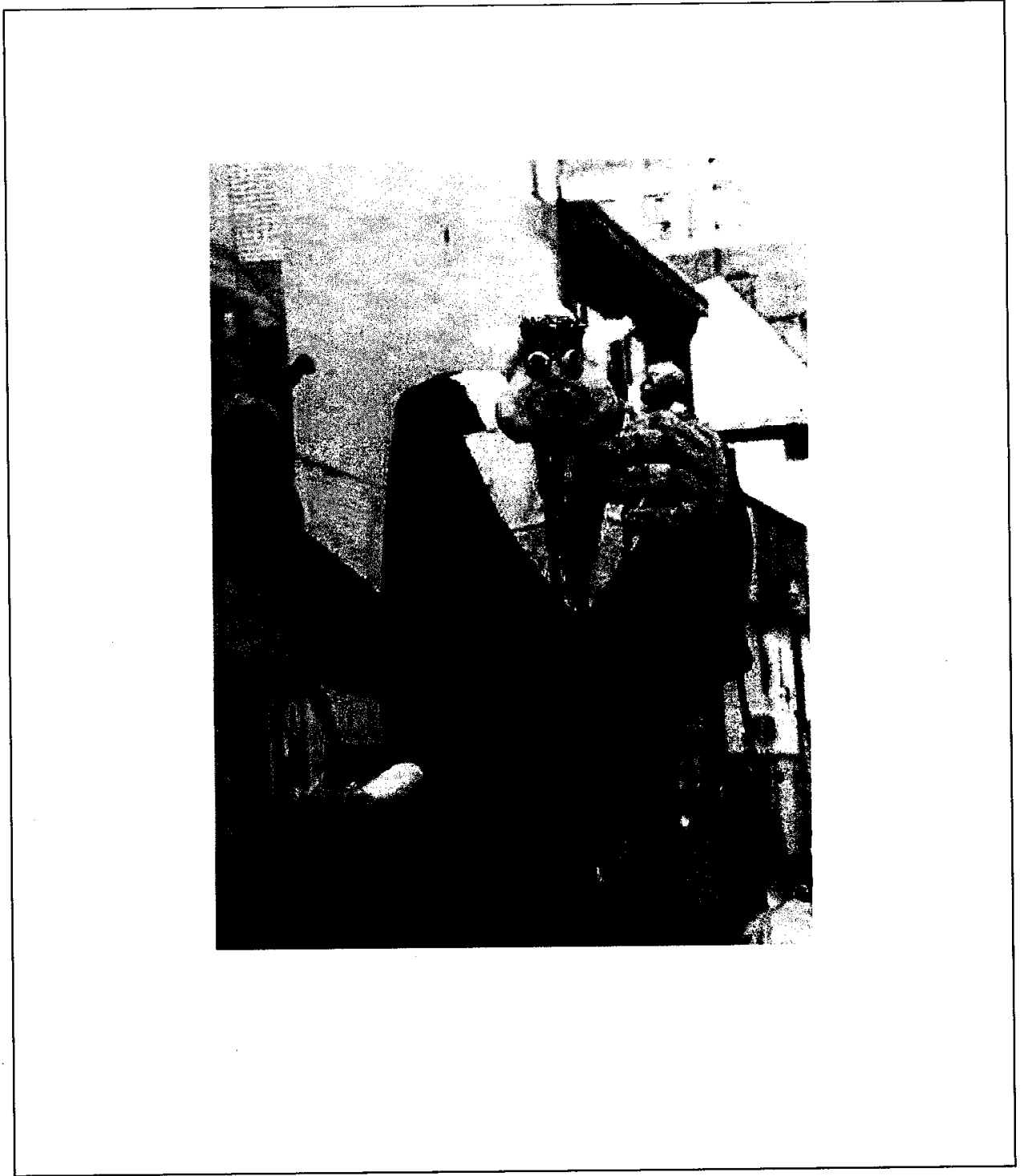

Figure 2.6. George W. Butcher.

Rob Breadner, Quebec City, 2001. 


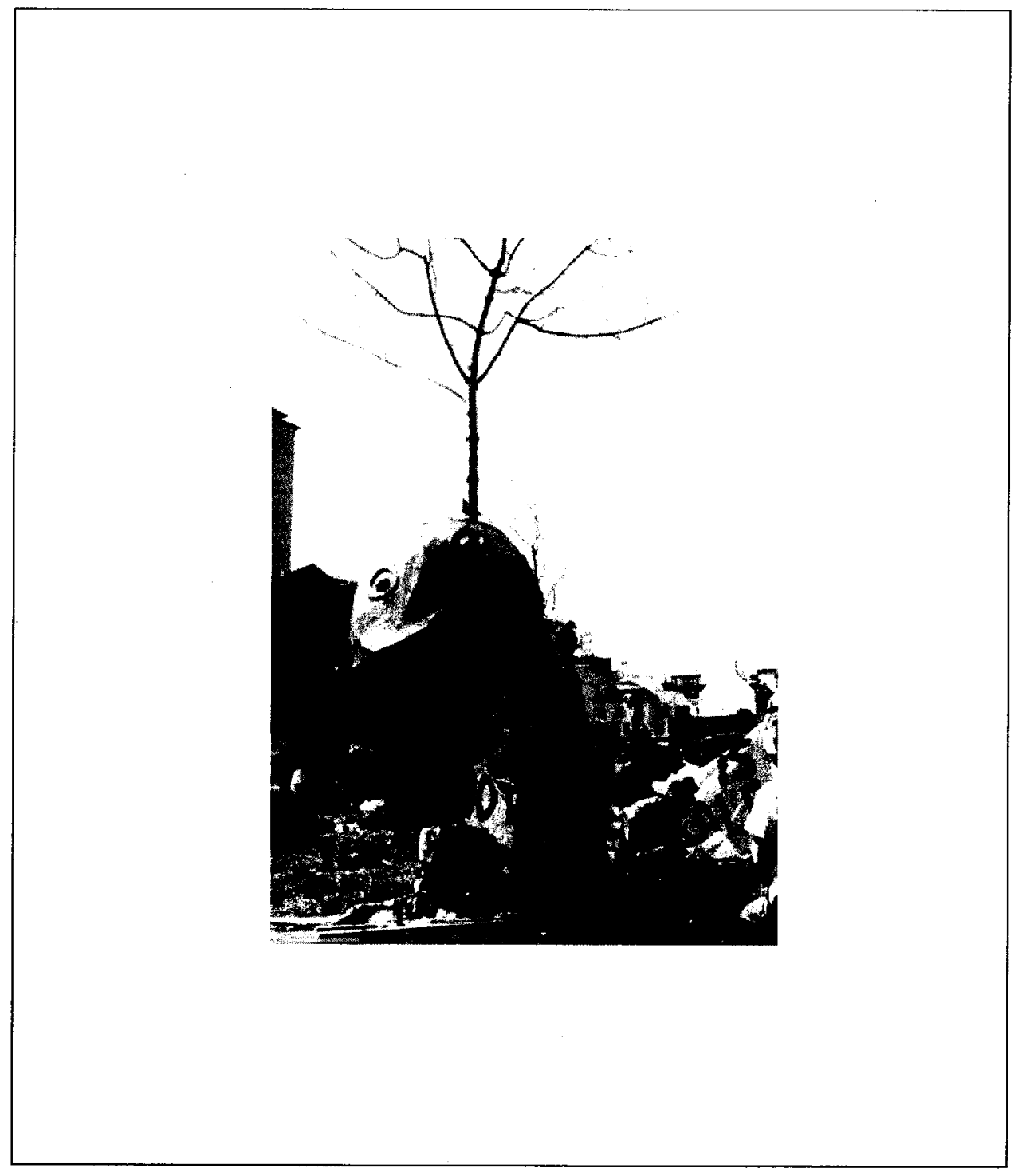

Figure 2.7. The Living River.

Claudette Lauzon, Quebec City, 2001. 


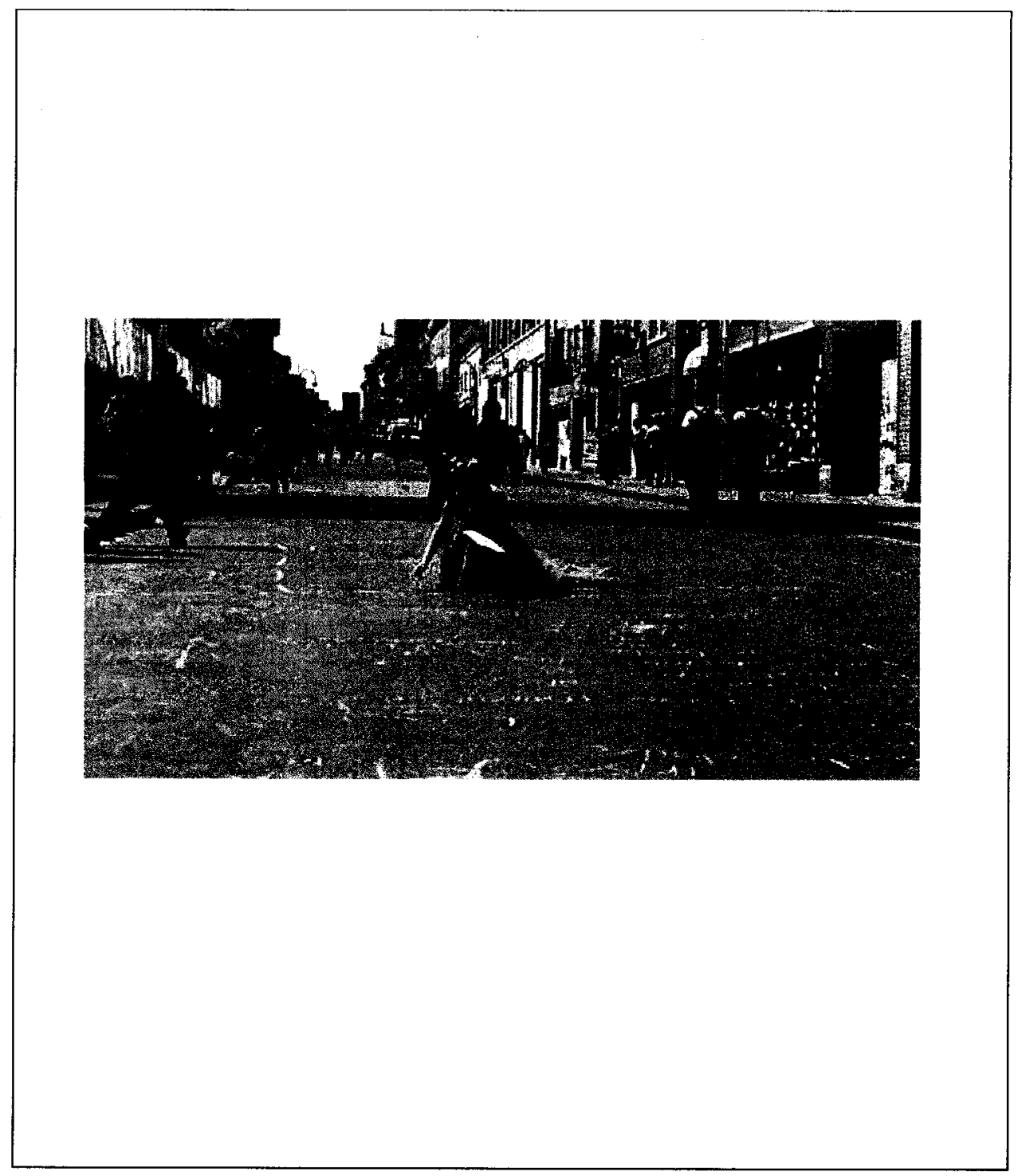

Figure 2.8. “A woman writes a poem on the streets of Quebec City, April 2001."

Tish Stringer, Quebec City, 2001. 


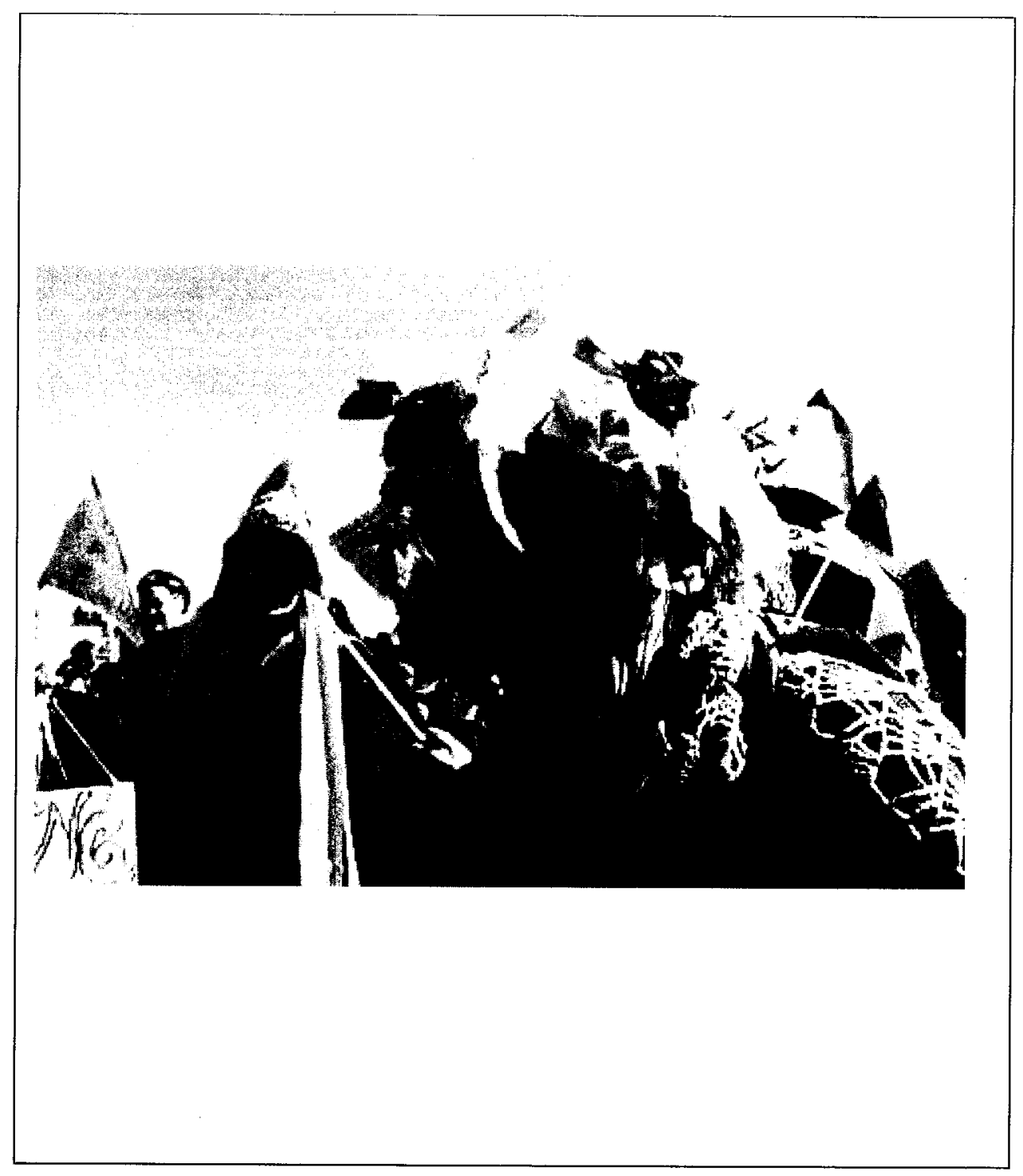

Figure 2.9. 'The 'Raging Grannies' sing anti-globalization songs before a march at the 'People's Summit,' in Quebec City, Canada, Saturday, April 21, 2001."

John Moore, Quebec City, 2001. 


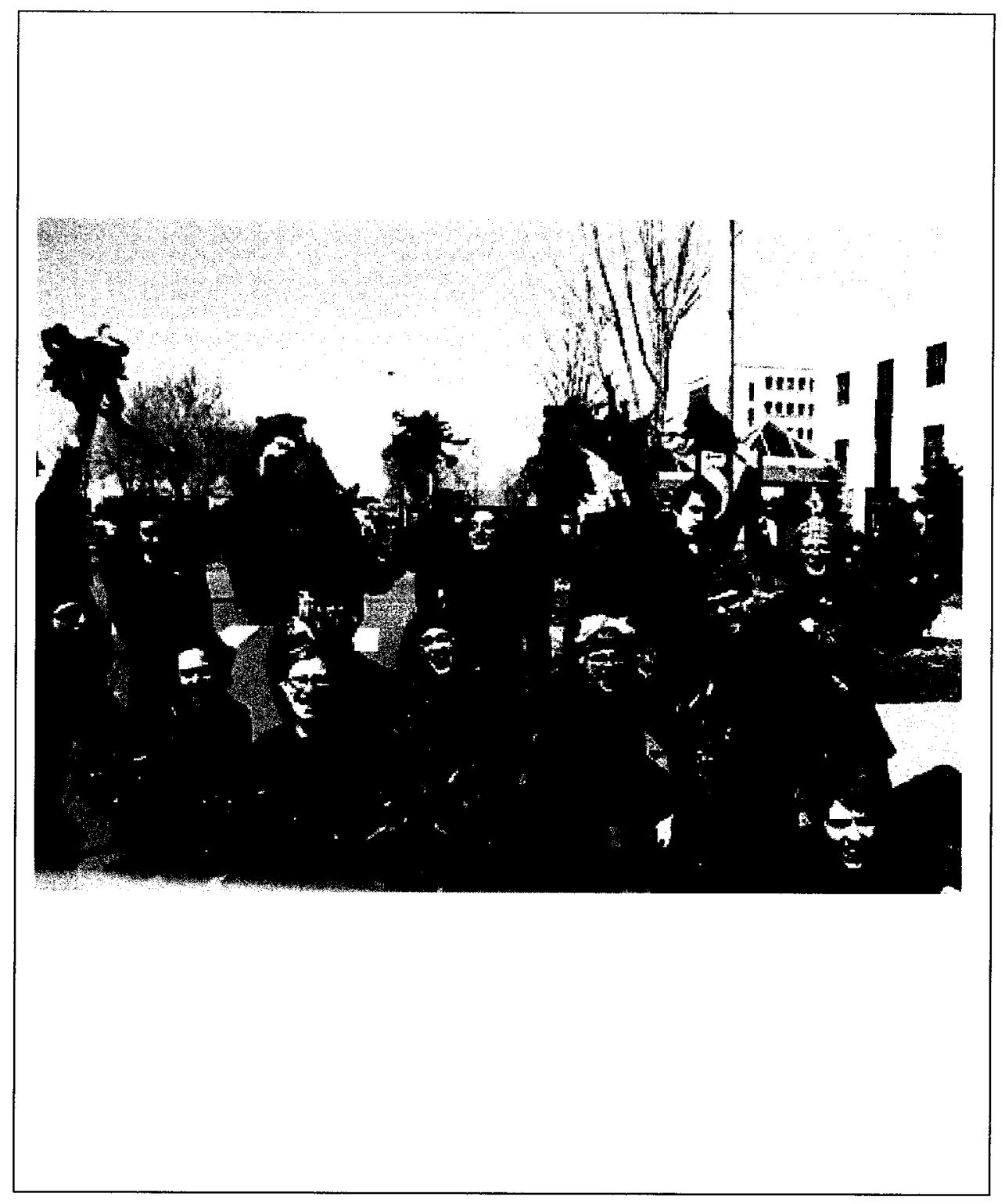

Figure 2.10. Radical Cheerleaders.

Liz Highleyman, Quebec City, 2001. 


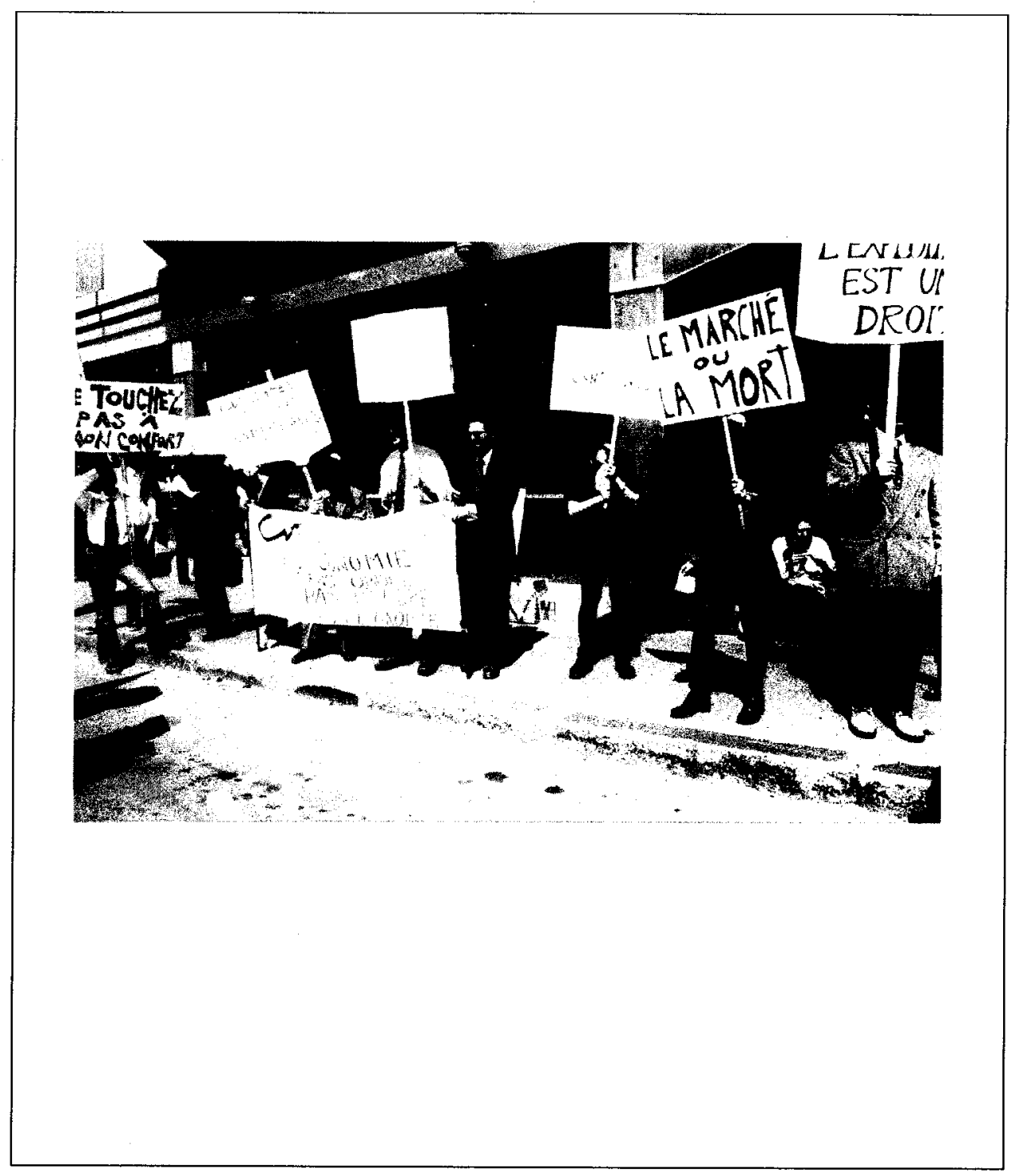

Figure 2.11. "Pro-FTAA" demonstrators.

Claudette Lauzon, Quebec City, 2001. 


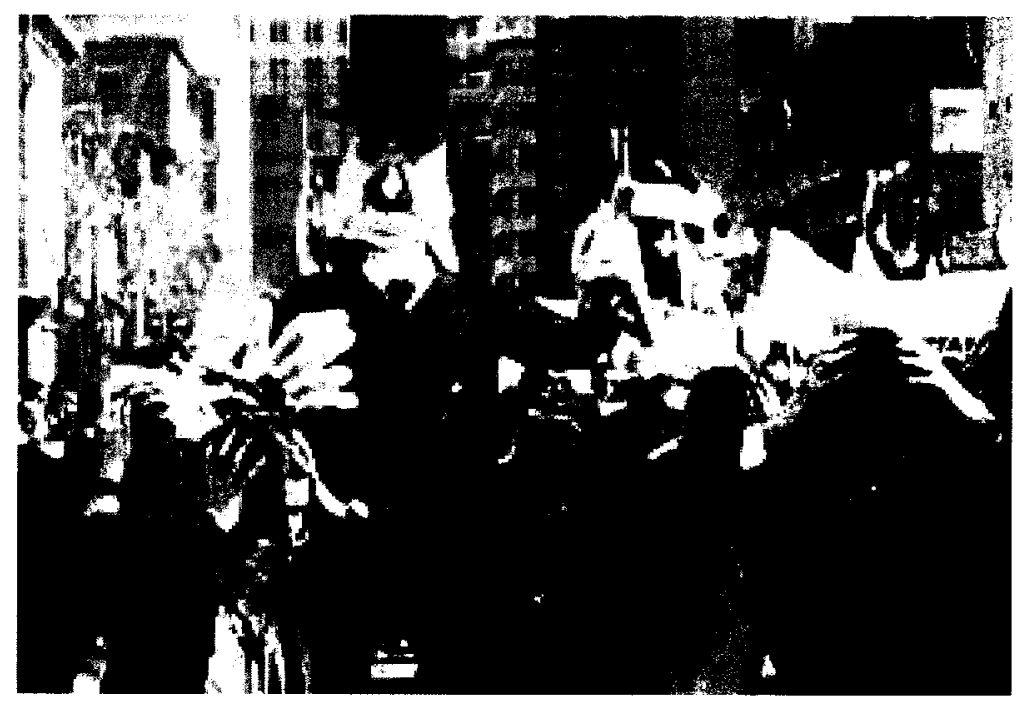

Figure 2.12. Equiterre demonstration.

Richard Swift, Quebec City, 2001. 


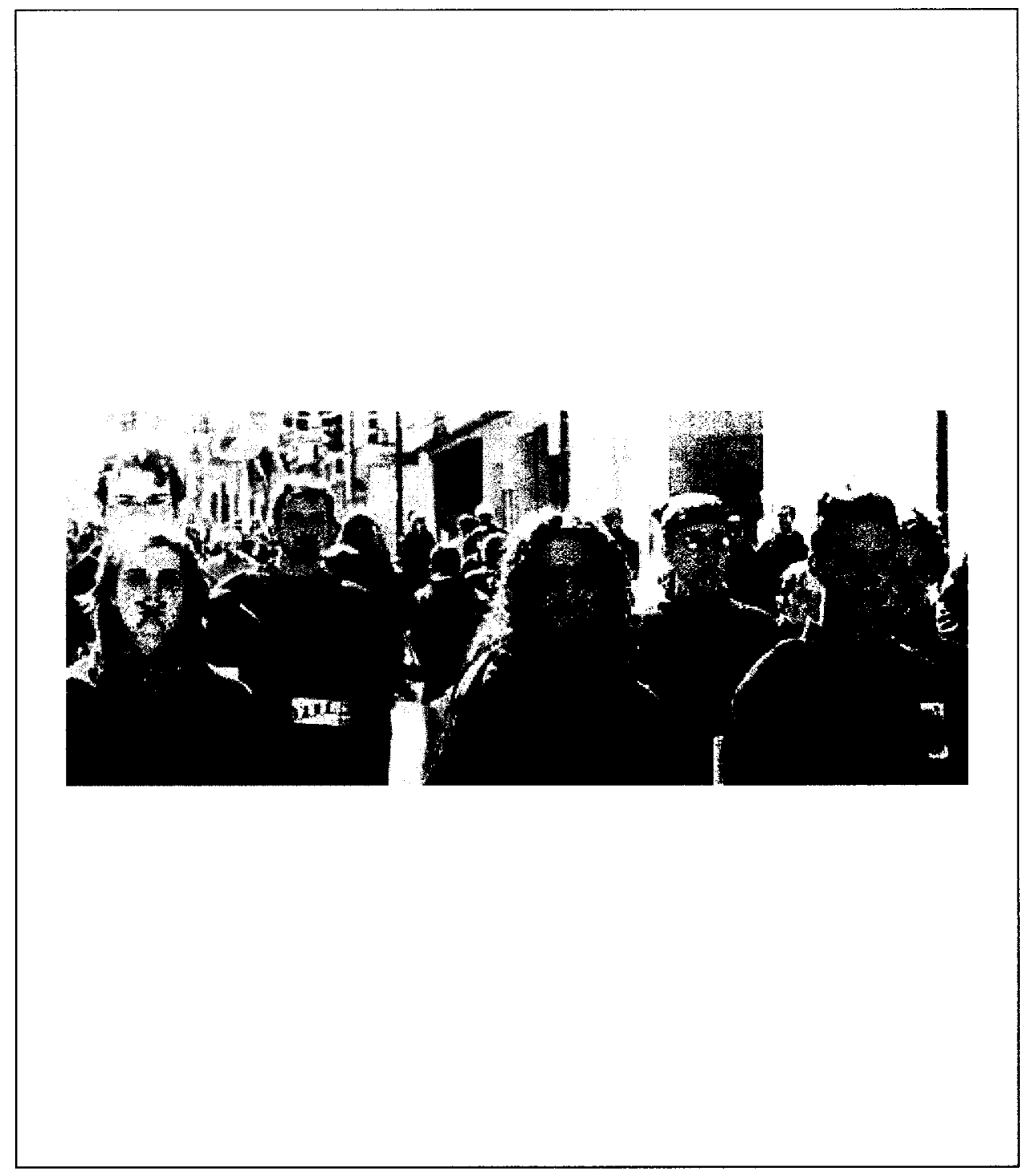

Figure 2.13. "No talk."

Richard Swift, Quebec City, 2001. 


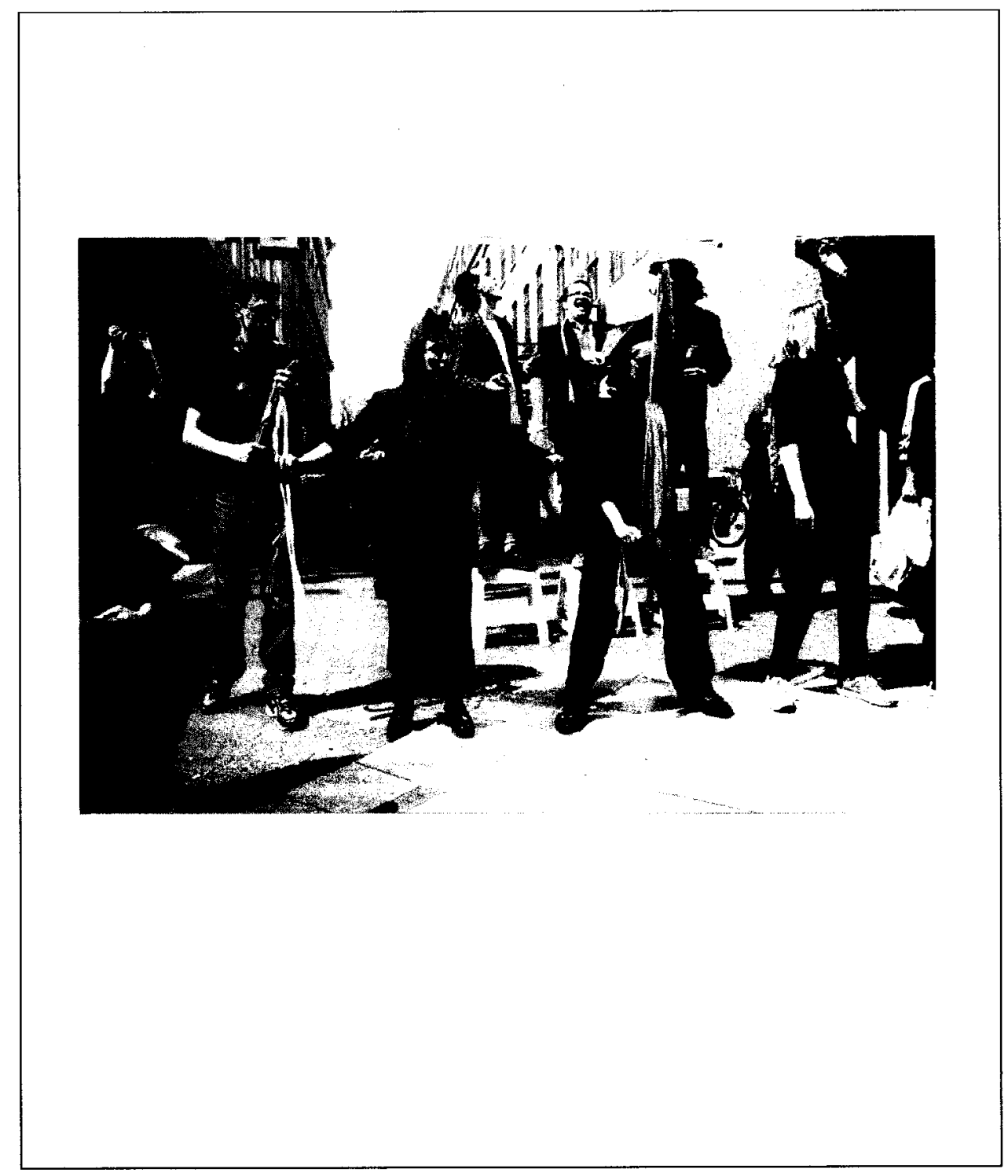

Figure 2.14. World March of Women performance.

Claudette Lauzon, Quebec City, 2001. 


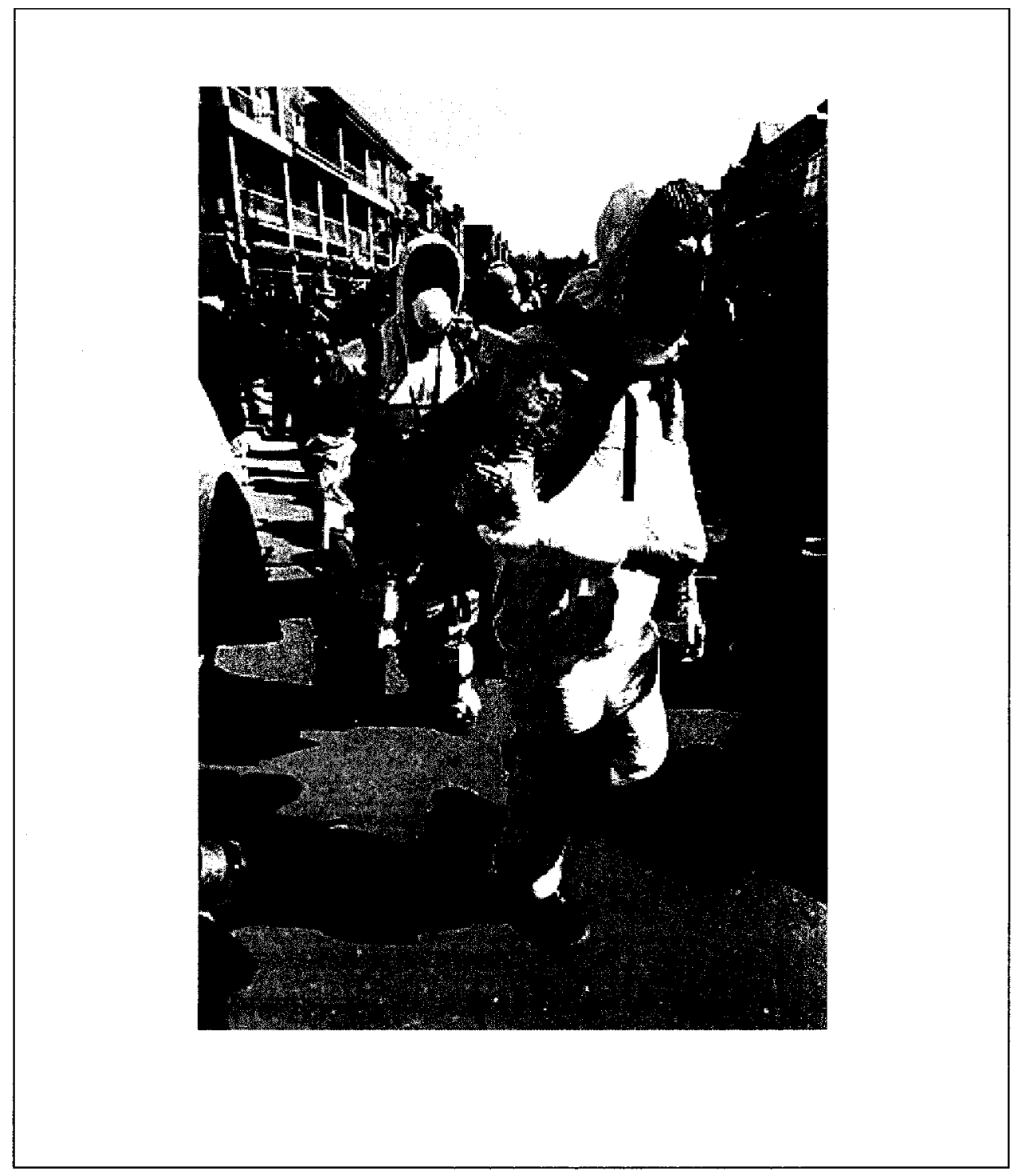

Figure 2.15. Ya Basta.

Photographer unknown, Quebec City, 2001. 


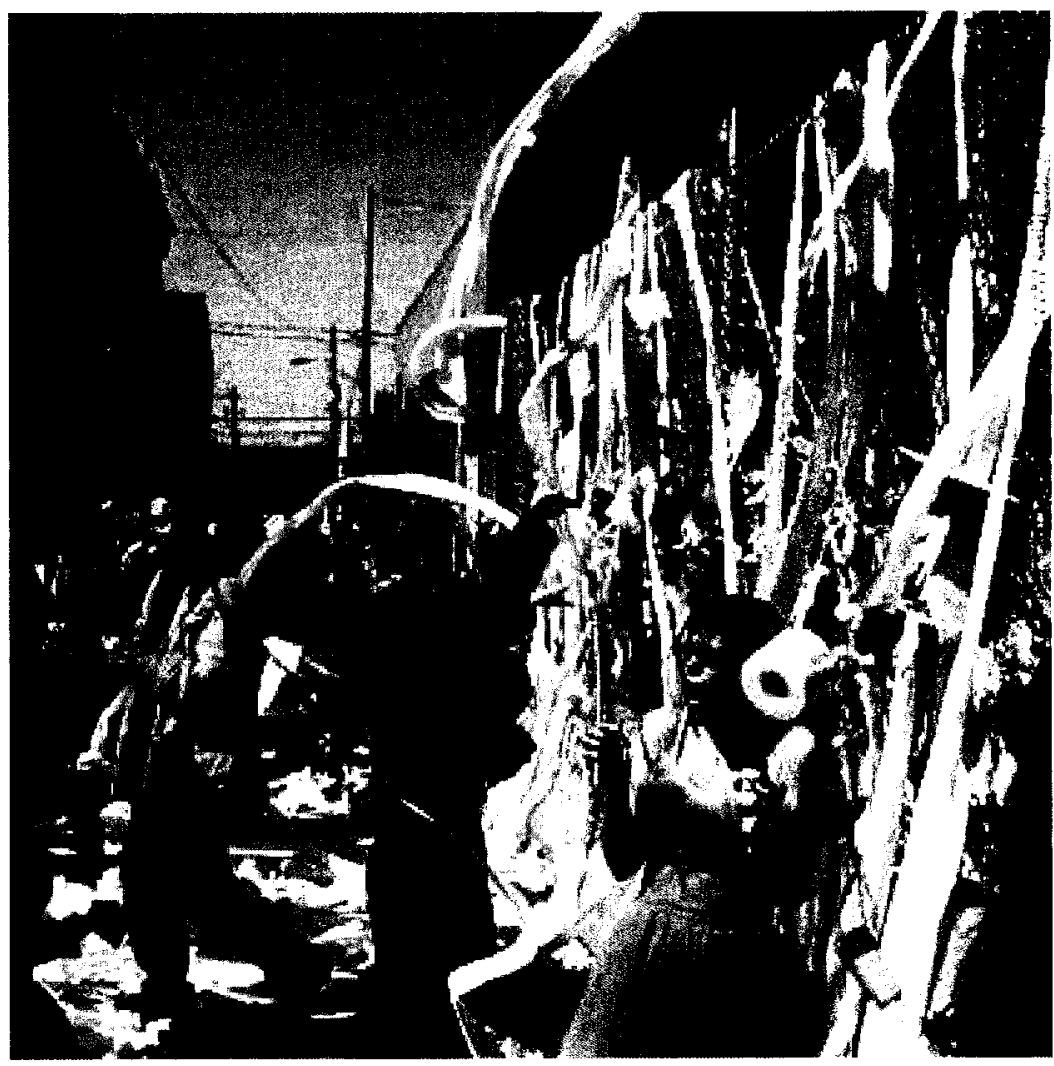

Figure 3.1. "Fairy princess blowing bubbles." Andrew Mefferd, Quebec City, 2001. 


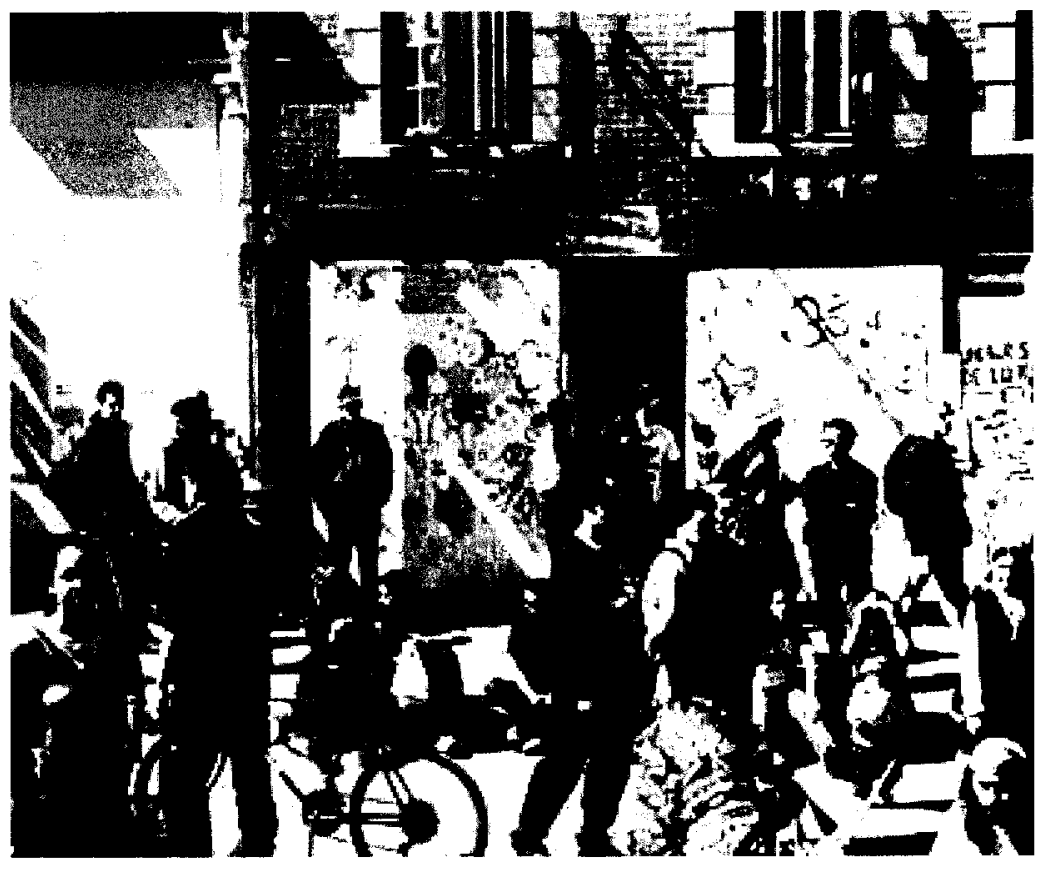

Figure 3.2. Boarded windows with graffiti.

Dru Jay, Quebec City, 2001. 


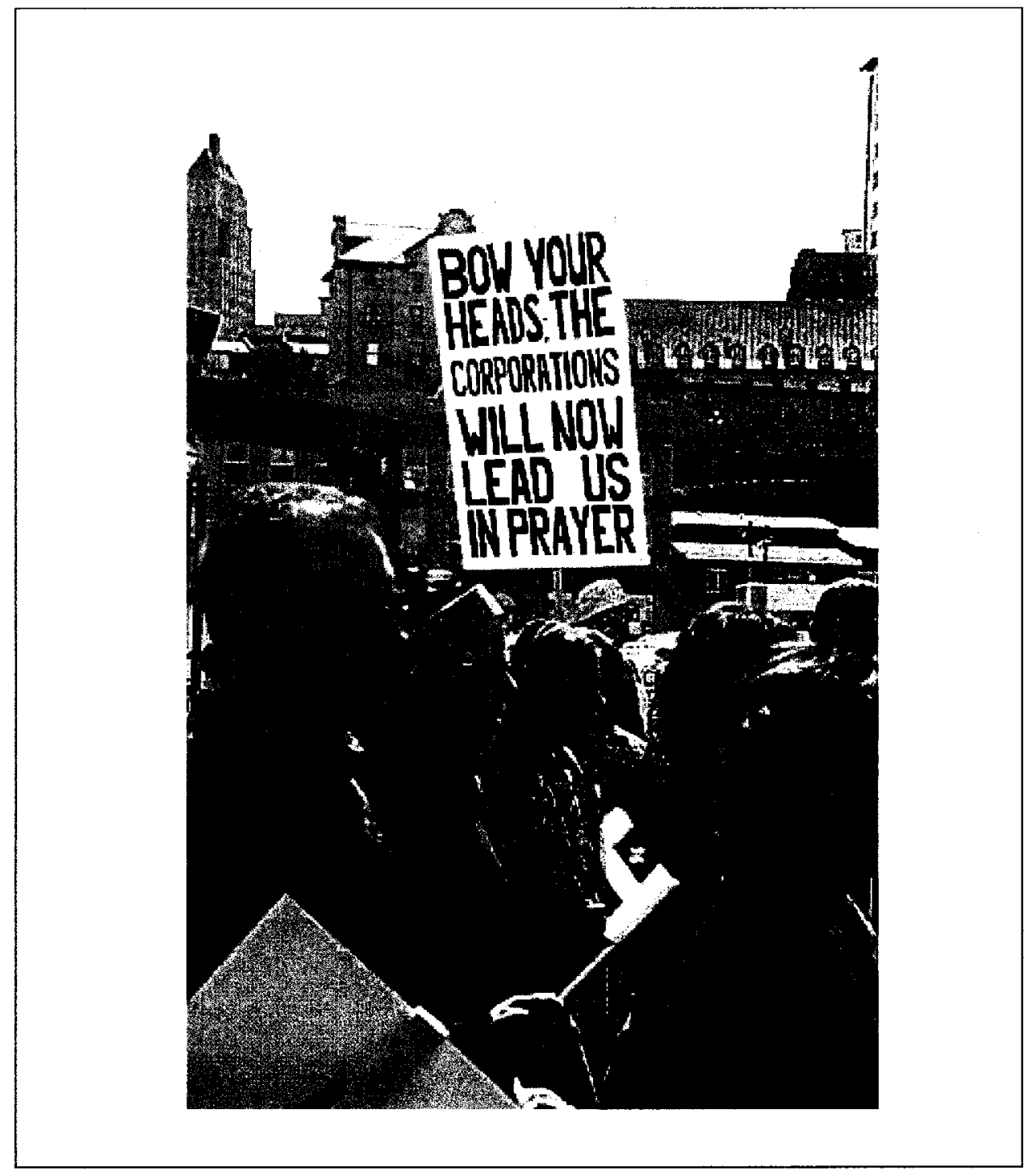

Figure 3.3. "The parade boasted numerous thoughtful statements." Rob Breadner, Quebec City, 2001. 


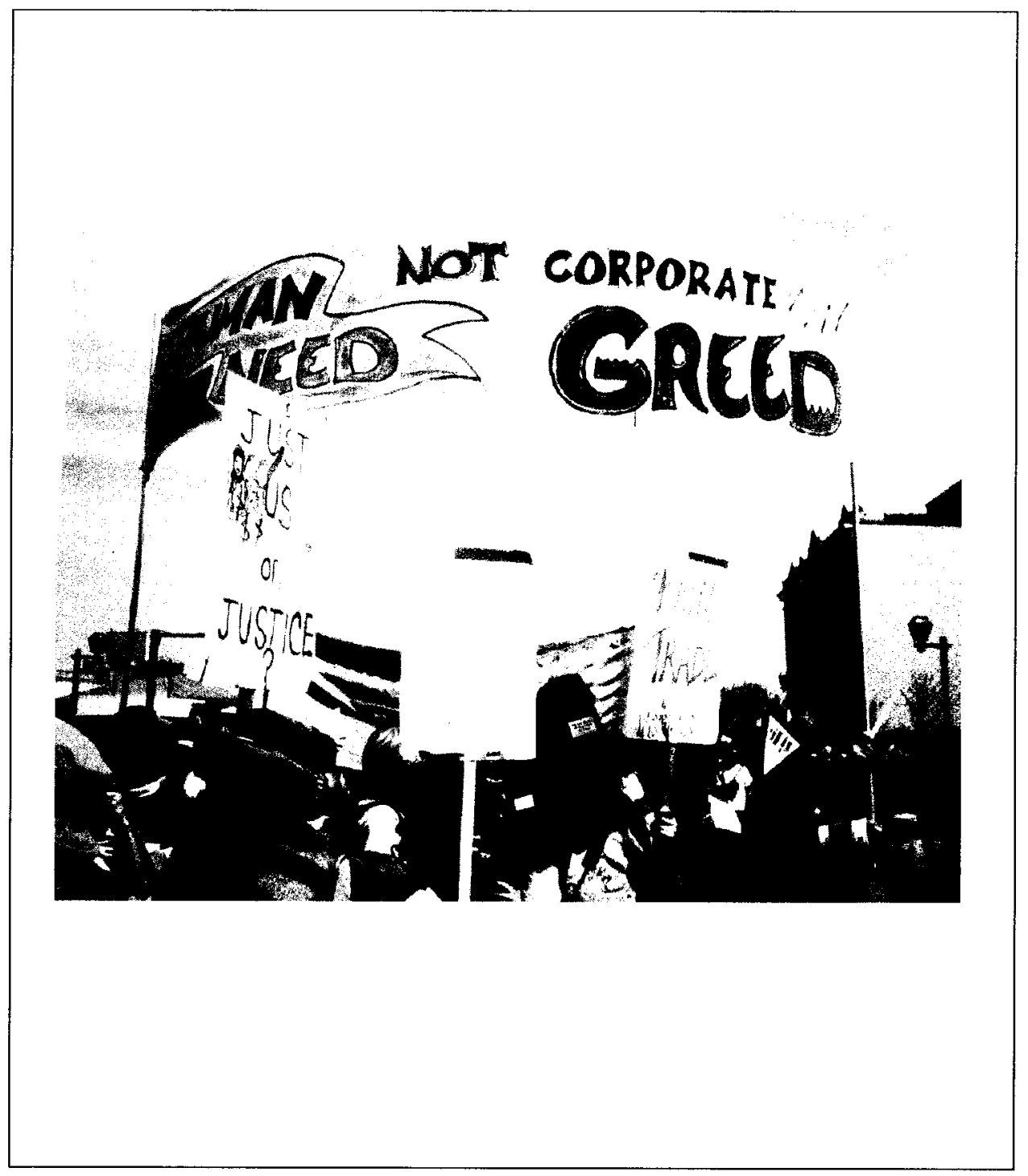

Figure 3.4. "The People's March."

Photographer unknown, Quebec City, 2001. 


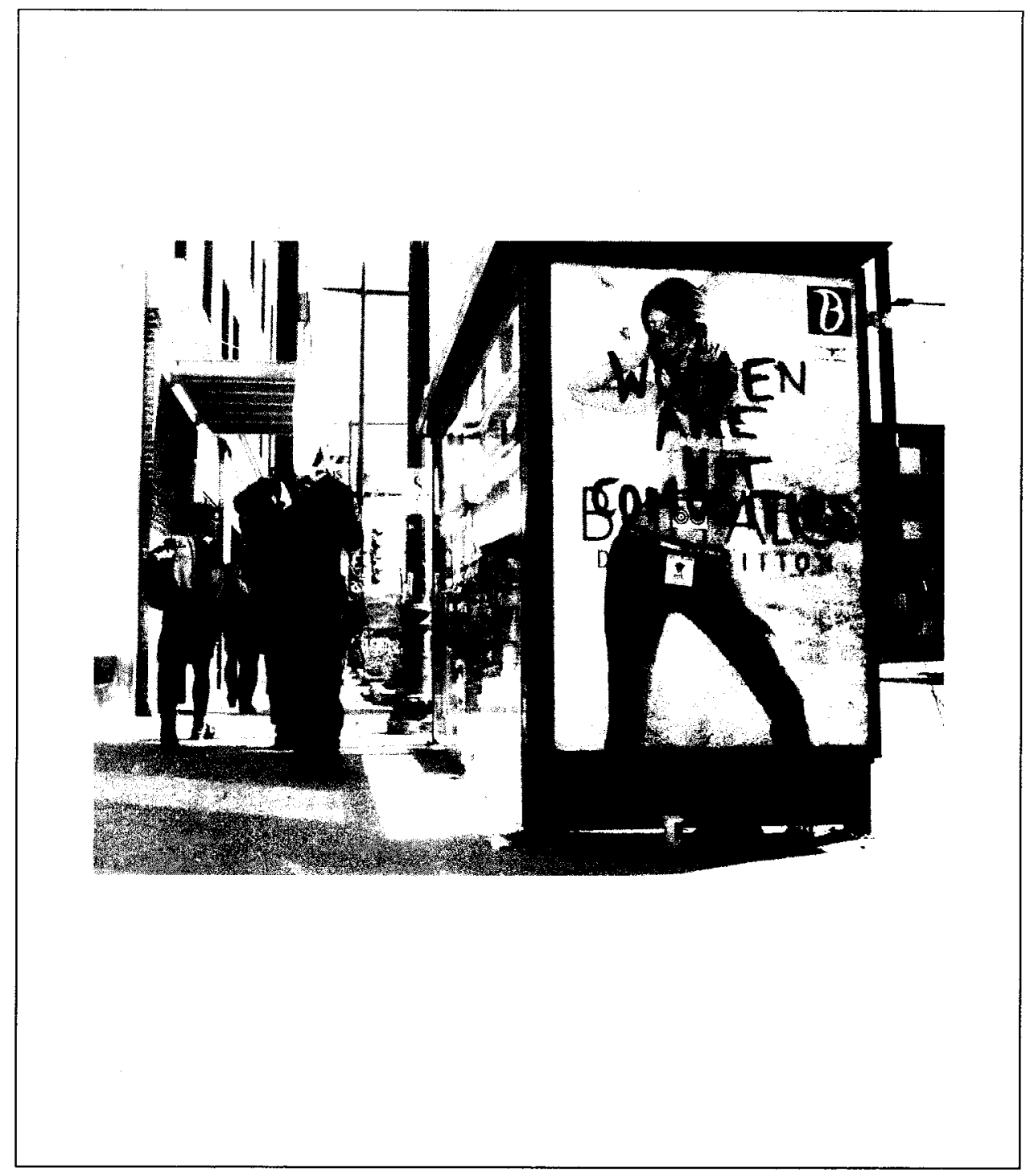

Figure 3.5. Billboard jam.

Claudette Lauzon, Quebec City, 2001. 


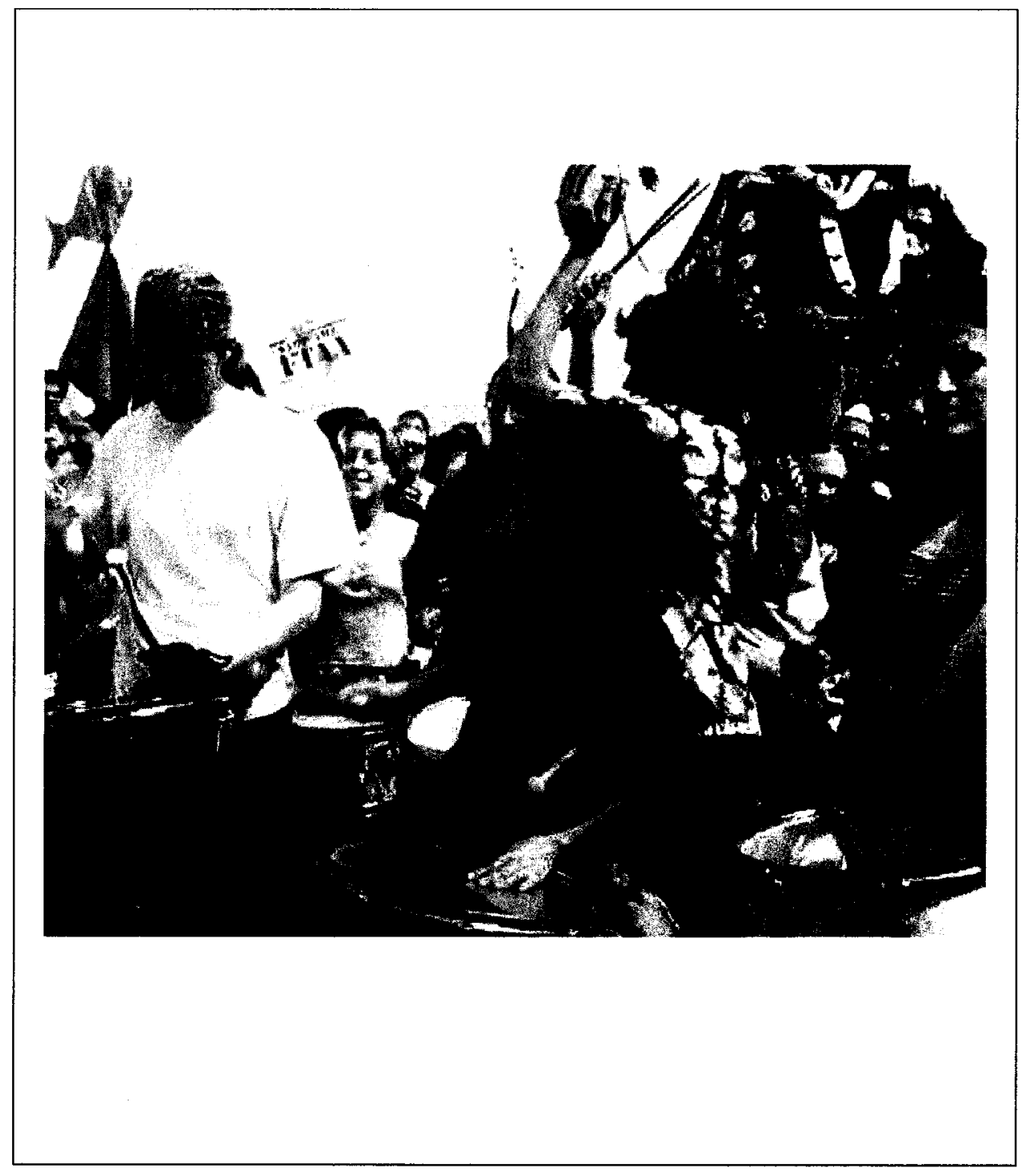

Figure 3.6. "Drummers."

Chaitanya K. Kalevar, Quebec City, 2001. 


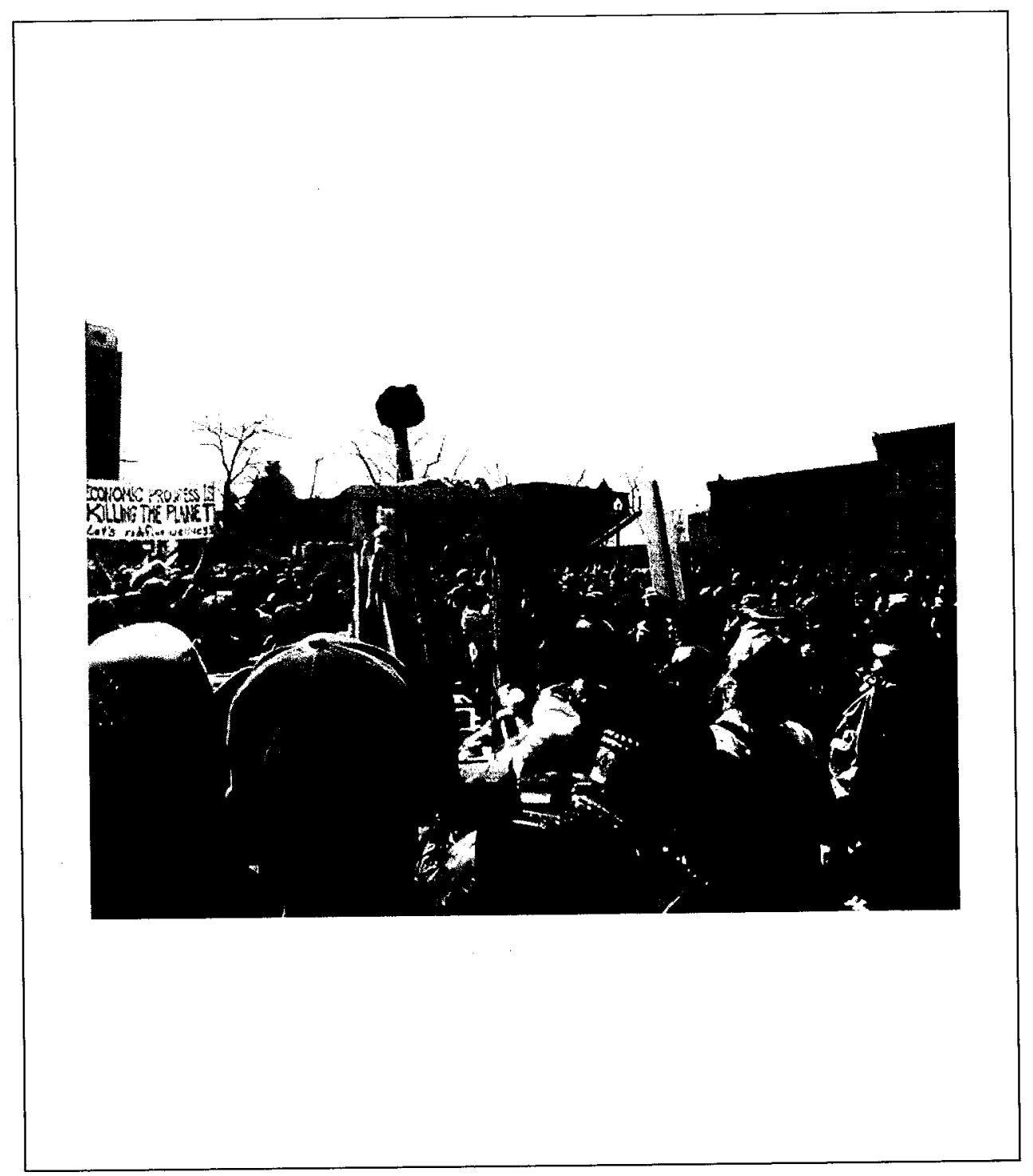

Figure 3.7. Deconstructionist Institute for Surreal Topology catapult. Photographer unknown, Quebec City, 2001. 


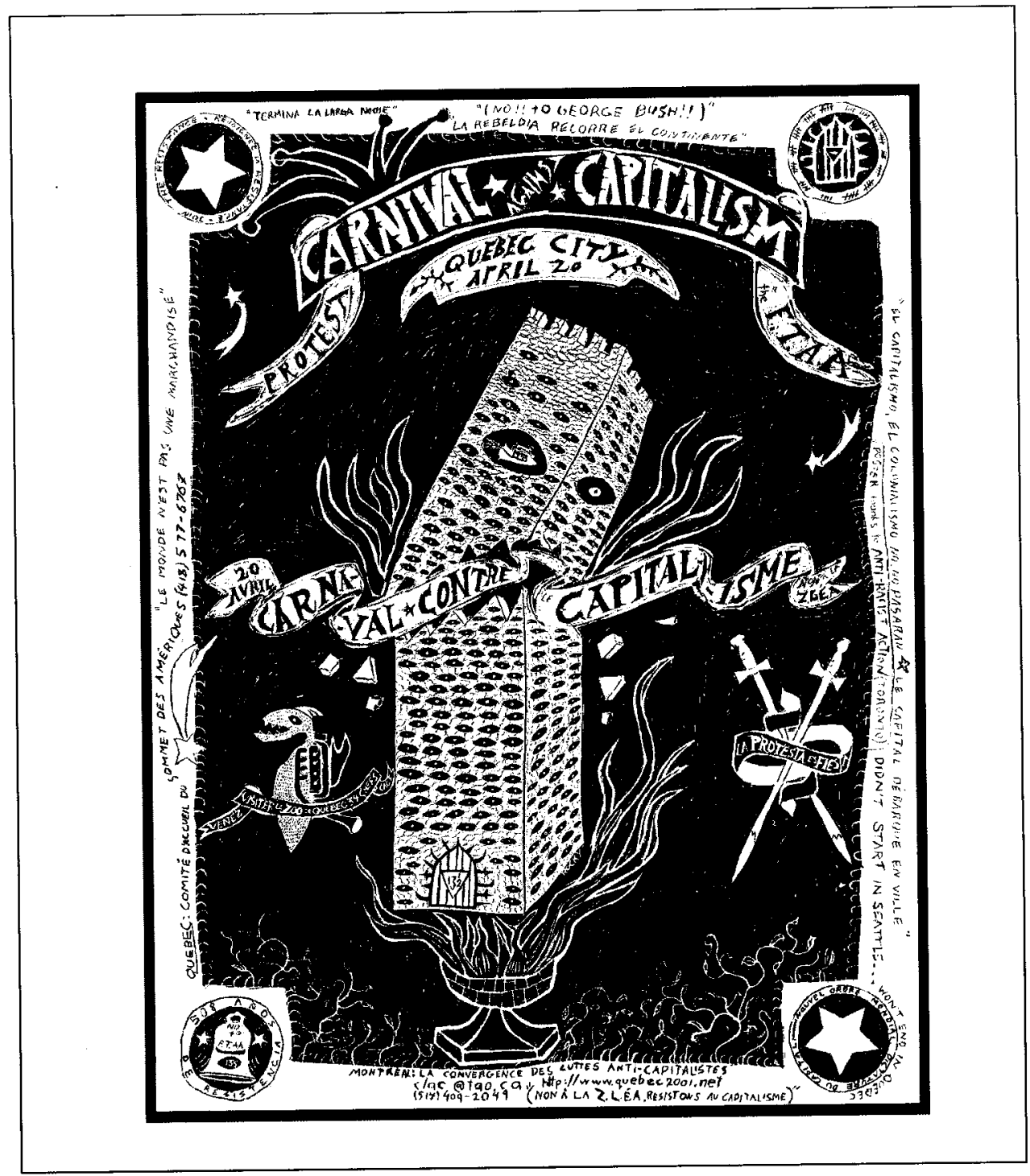

Figure 3.8. Carnival Against Capitalism poster.

Anti-Racist Action Toronto, 2000. 


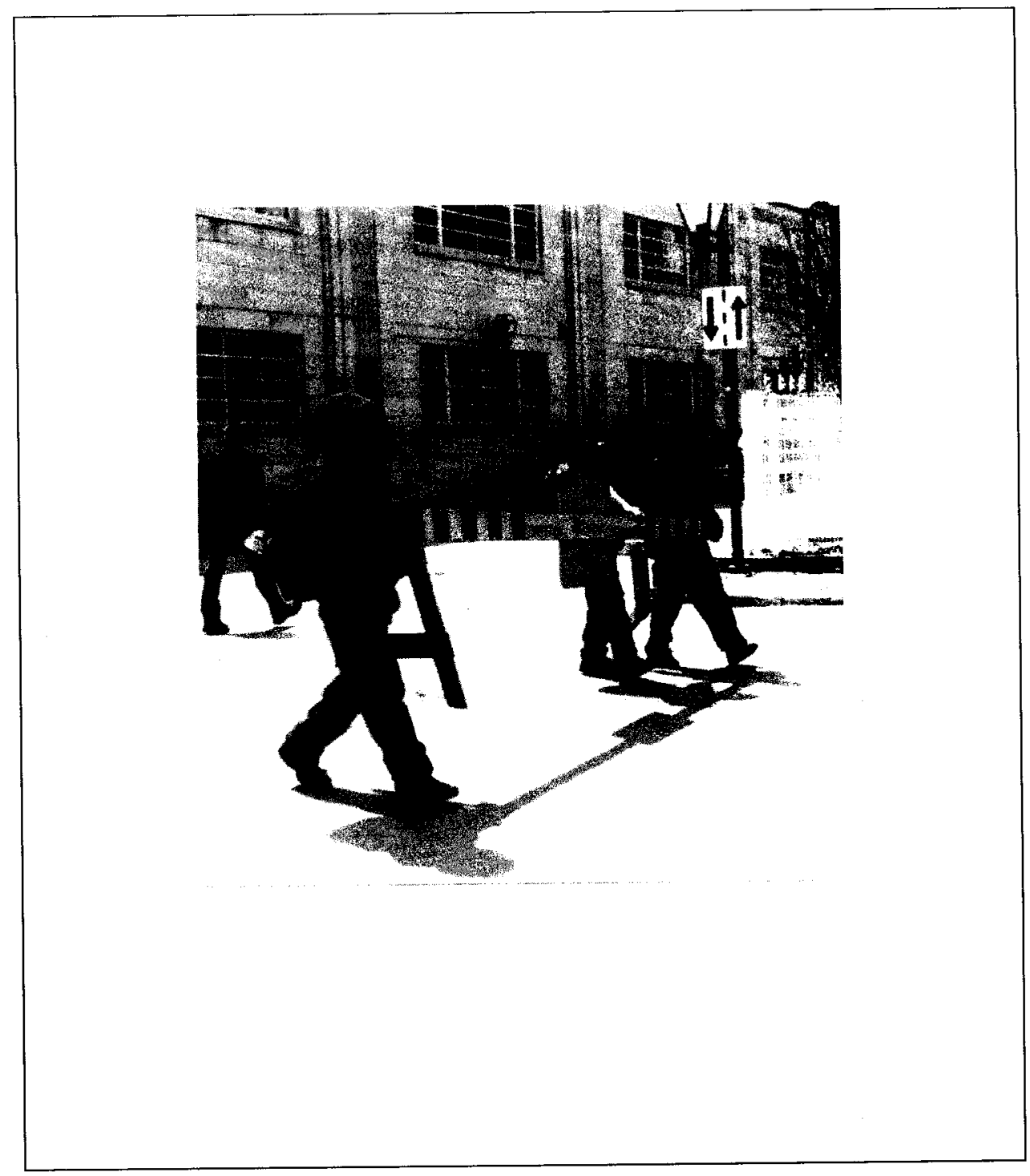

Figure 3.9. Masked Blac Bloc anarchists "reclaim" a barricade. Claudette Lauzon, Quebec City, 2001. 


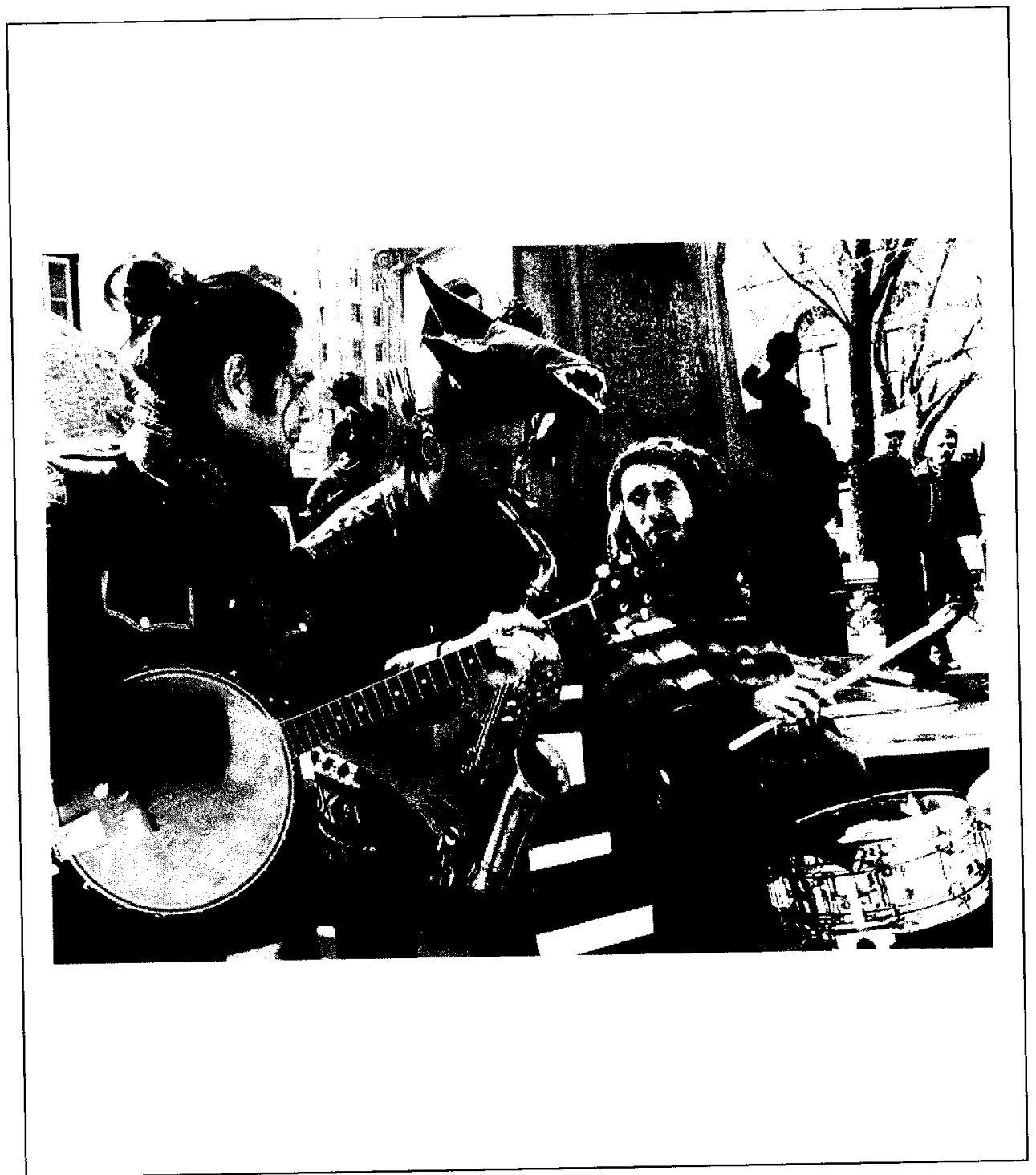

Figure 3.10. Carnivalesque activity.

Mike Reshitnyk, Quebec City, 2001. 


\section{BIBLIOGRAPHY}

\section{Primary Sources}

\section{Interviews}

Breadner, Rob. Personal communication with author, 7 March 2003.

Engler-Stringer, Rachel. Personal communication with author, 21 November 2002.

Gauld, Danielle. Personal communication with author, 13 January 2003.

Murray, Anne. Personal communication with author, 15 March 2003.

Schwandt, Marika. Personal communication with author, 20 February 2003.

\section{Newspapers}

Globe and Mail, 20-23 April 2001.

Le Devoir (Montreal), 20-23 April 2001.

Montreal Gazette, 20-23 April 2001.

National Post, 20-23 April 2001.

Ottawa Citizen, 20-23 April 2001.

Toronto Star, 20-23 April 2001.

\section{Press Releases and Declarations}

Activist Knitting Troupe. "Knitters of the World, Unite and Take Over!" February 2001. Available online at the Stop the FTAA Web site, <http://www/stopftaa.org/ organize/cta_knitters.html>. January 2003.

Anti-Capitalist Convergence. "Resist the Summit of the Americas and the FTAA-Quebec City Spokescouncil: March 24-25." Available online at the Infoshop.org Web site, $<$ http://www.infoshop.org/octo/texts/quebec_spokes.html >. June 2003. 
Anti-Capitalist Convergence Cultural Committee. "Creative People Against the Quebec City Summit," 12 March 2001. Available online at $<$ http://members.tripod.com/ infobank1>. October 2002.

"Citizen Caged," March 2001. Available online at the PEN Canada Web site, <http://www. pencanada.ca/censor/citizen.htm>. June 2003.

Coordinadora de defensa del agua y de la vida (Coalition in Defence of Water and Life). "The Cochabamba Declaration on Water: Globalization, Privatization, and the Search for Alternatives." In Global Backlash: Citizen Initiatives for a Just World Economy, edited by Robin Broad. Lanham, Md.: Rowman and Littlefield Publishers, 2002.

Hemispheric Social Alliance. "Declaration of the People's Summit," 19 April 2001. Available online at the Parliamentary Confederation of the Americas Web site, $<$ http://www.copa.qc.ca/Anglais/Reunions_missionsa/Avril2001a/Dec_Peup_A. html>. June 2003 .

Griot Photo. "Reframing Resistance." Griot Photo Web site, <http://www.griotphoto. org/resist.htm>. June 2003.

Royal Canadian Mounted Police in Quebec. "Just a Few Days Away from the Summit of the Americas." Royal Canadian Mounted Police Web site, April 2001, $<$ http://grcquebecrcmp.com/pages/english/con_p_une_e/pag_avr_e.html>. March 2003.

School of the Americas Watch. "Field Guide to the FTAA Protests." School of the Americas Watch Web site, <http://www.soaw-ne.org/FTAAGuide.html>. December 2002 (no longer operational).

Starhawk. "Weaving a Web of Solidarity-A Feminist Action Against Globalization." Peacework Magazine, 5 April 2001, <http://www.afsc.org/pwork/0104/0104 05.htm>. December 2002.

Stop the FTAA. "Why Nonviolent Direct Action?" Stop the FTAA Web site, <http://www. stopftaa.org/activist/act_directaction.html>. June 2003.

"Summit of the Americas 2001 Declaration of Quebec City," 22 April 2001. Available online at AmericasCanada.org, Government of Canada Web site, <http://www. americascanada.org/eventsummit/declarations/declara-e.asp $>$. June 2003. 


\section{Visual resources}

Anti-Racist Action Toronto. "Anti-Racist Action Art-Archive." Anti-Racist Action Toronto Web site, December 2001, <http://www.web.net/ ara.htm>. June 2003.

Bacque, Graeme. "Summit of the Americas: Quebec City, April 20-22," <http:/graemes gallery.tripod.com/Quebec/A20-21.html>. June 2003.

Barricada (Boston, Mass.) 7 (May 2001).

Breadner, Rob. "Quebec City FTAA Summit April 22, 2001," 30 April 2001, <http:// www3.sympatico.ca/hi-octane/>. May 2003.

Graham, Barbara Walker. "Whose Nemesis? Feminist Action against the FTAA." Awakened Woman e-magazine, 16 May 2001, <http://www.awakenedwoman.com/ walker_report.htm>. December 2002.

Highleyman, Liz. "Photos from Quebec City Summit of the Americas/FTAA Protest 19-22 April 2001." Black Rose Web Pages, May 2001, <http://www.blackrose.com/ quebec-photos/>. June 2003.

Jay, Dru. "Photos From Quebec City." Misnomer Web site, 28 April 2001, <http:// misnomer.dru.ca/2001/04/entries.html>. June 2003.

Kalevar, Chaitanya K. "From Seattle to Quebec City-FTAA." Citizens on the Web Web site, $<$ http://photos.citizensontheweb.com/quebec.htm>. February 2003.

Mefferd, Andrew. "Summit 4/20." Cannabis Culture Web site, 12 July 2001, <http://www. cannabisculture.com/articles/2002.html>. March 2003.

Photowire Archive. Infoshop.org Web site, <http://www.infoshop.org>. June 2003.

Progressive Valley Forum Web site, <http://www.progressivevalley.com>. December 2002 (no longer operational).

"Quebec City, April, 2001."New York City Ya Basta Collective Web site, <http://free. freespeech.org/yabasta/quebec.html>. May 2003.

"Quebec City Photos." Ecumenical Council for Economic Justice Web site, <http://www. ecej.org/people.htm>. December 2002 (no longer operational).

"Quebec Photos." Ibiblio: The Public's Library and Digital Archive Web page, 24 May 2001, <http://www.ibiblio.org/quebec/Photos/>. December 2002. 
Reshitnyk, Mike. "Summit of the Americas Photo Album." Ukrainian Directory in Montreal Web site, <http://ukemonde.com/summit.html>. June 2003.

"Special Report: Summit of the Americas." TIME Magazine Online Edition, Thursday, 19 April, 2001, <http://www.time.com/time/world/article/0,8599,106949,00.html>. June 2003.

Stringer, Tish. "Photo Diary of a Revolution." Journal of Aesthetics and Protest 1, no. 1 (July 2002), <http://www.journalofaestheticsandprotest.org/1/photodiary.html >. June 2003.

Student Christian Movement of Canada. "Quebec City-Summit of the Americas: AntiFTAA/ZLEA Protest." Student Christian Movement of Canada Web site, $<$ http://www.scmcanada.org/quebecFTAA.html>. June 2003.

Swift, Richard. "From the Streets: Live from Quebec City." New Internationalist Web site, 21 April 2001, <http://www.newint.org/streets/quebec/quebec.htm>. June 2003.

\section{Web sites}

Anti-Capitalist Convergence, <http://www.quebec2001.net>. June 2003.

Deconstructionist Institute for Surreal Topology, $<$ http://www.tao.ca/ wrench/dist.html $>$. June 2003.

Independent Media Centres, <http://www.indymedia.org>. June 2003.

Infoshop.org, <http://www.infoshop.org>. June 2003.

Mann, Steve. Wearcam.org, <http://www.wearcam.org>. June 2003.

New York City Ya Basta, <http://free.freespeech.org/yabasta.html>. June 2003.

Opération SalAMI, <http://www.alternatives.ca/salami>. December 2002 (no longer operational).

Ottawa-Outaouais Social Forum, <http://socialforum.digitalindependence.org > June 2003.

Raging Grannies of Seattle, <http://www.raginggrannies.com>. June 2003.

Radical Cheerleaders, <http://www.geocities.com/radicalcheerleaders>. June 2003. 


\section{Secondary Sources}

\section{Articles}

“3,009 Cans of Tear Gas, 502 Plastic Bullets Used at Summit." Toronto Star, Thursday, 3 May 2001, A3.

Alperf, Arnie. "Mobilizing for Quebec.” Peacework Magazine, March 2001, $<$ http://www.afsc.org/pwork/0103/010312.htm>. January 2003.

Althusser, Louis. "Ideology and Ideological State Apparatuses (Notes Toward an Investigation)." In Lenin and Philosophy, and Other Essays. Translated by Ben Brewster. New York: Monthly Review Press, 1971. Originally published as "Idéologie et appareils idéologique d'Etat," La pensée (Paris) 151 (June 1970): 3-38.

Baca, Judith. "Whose Monument Where? Public Art in a Multi-Cultured Society." In Mapping the Terrain: New Genre Public Art, edited by Suzanne Lacy. Seattle: Bay Press, 1995.

Barry, Andrew. "Demonstrations: Sites and Sights of Direct Action." Economy and Society 28, no. 1 (February 1999): 75-94.

Barthes, Roland. "The Photographic Message." In Image, Music, Text. Translated by Stephen Heath. New York: Hill and Wang, 1977. Originally published as "Le message photographique," Communications (Paris) 1 (1961): 127-138.

Bell, John. "Entertainment, Spectacle, Crime: Puppetry in the Year 2000." In Puppets, Masks, and Performing Objects, edited by John Bell. London and Cambridge: MIT Press, 2001.

_. "Louder Than Traffic: Bread and Puppet Parades." In Radical Street Performance: An International Anthology, edited by Jan Cohen-Cruz. London and New York: Routledge, 1998.

Bello, Walden. "Porto Alegre Social Summit Sets Stage for Counteroffensive Against Globalization." World Social Forum Web site, January 2002, <http://www.forum socialmundial.org.br/dinamic/eng_b_WaldenBello.asp>. June 2003.

Berger, John. "The Nature of Mass Demonstrations." In The Look of Things: Selected Essays and Articles, edited and with an introduction by Nikos Stangos.

Harmondsworth: Penguin Books, 1972. 
. "The Suit and the Photograph." In About Looking. New York: Vintage Press, 1991.

Bhabha, Homi K. "Conversational Art." In Conversations at the Castle, edited by Mary Jane Jacob. Cambridge: MIT Press, 1998.

Blackwell, Adrian. Untitled lecture. Presented during the lecture series "Unboxed: 9 Dialogues on Art and Architecture." Carleton University School of Architecture, Ottawa, 21 October 2002.

Boje, David. "Carnivalesque Resistance to Global Spectacle: A Critical Post-Modern Theory of Public Administration." Administrative Theory and Praxis 23, no. 3 (2001): 431-58.

Borovoy, Alan. "Protest Movements and Democracy." Policy Options, September 2002, 54-56.

Boski, Joseph. "The Costs of Global Governance: Security and International Meetings Since WTO-Seattle." Paper presented at the CIBER conference, "Globalization: Governance and Inequality," Ventura, California, 31 May-1 June 2002. Available online at $<\mathrm{http}: / / \mathrm{www}$.anderson.ucla.edu/research/ciber/intseminar/ciberboski.pdf $>$. April 2003.

Bourdieu, Pierre. "The Politics of Globalization." Translated by Sarah Verblow and Anthony Barnett. Open Democracy Web site, 20 February 2002, <http://www.open democracy.net/debates/article-6-27-283.jsp>. March 2003. Originally published in Le Monde (Paris), 24 January 2002.

Boyd, Andrew. "Extreme Costume Ball: A New Protest Movement Hits the Streets in Style." Village Voice, 19-25 July 2000. Available online at $<$ http://www.village voice.com/issues/0029/boyd.php>. May 2003.

Braidotti, Rosi. "Sexual Difference as a Nomadic Political Project." In Nomadic Subjects: Embodiment and Sexual Difference in Contemporary Feminist Theory. New York: Columbia University Press, 1994.

Bryson, Norman. "The Gaze in the Expanded Field." In Vision and Visuality, edited by Hal Foster. Dia Art Foundation: Discussions in Contemporary Culture. Seattle: Bay Press, 1988.

Burgin, Victor. "Looking at Photographs." In Representation and Photography: A Screen Education Reader, edited by Manuel Alvarado, Edward Buscombe, and Richard Collins. New Hampshire and New York: Palgrave, 2001. Originally published in Screen Education 24 (fall 1977): 17-24. 
Burnham, Linda. "The Men Behind the Masks." The Independent Weekly (Durham, N.C.), 12 April 2000, <http://www.indyweek.com/durham/2000-04-12/ae.html>. January 2003.

Canadian Security Intelligence Service. "Anti-Globalization-A Spreading Phenomenon." Perspectives, August 2000, <http://www.csis-scrs.gc.ca/eng/miscdocs/200008_ e.html>. June 2003.

Chesters, Graeme. "Bodies as Barricades: Bodies as Messages." Paper presented at the British Sociological Association Annual Conference, University of Edinburgh, April 1998. Available online at the Shifting Ground Resource Area Web site, $<$ http://ktru-main.lancs.ac.uk/CSEC/NSCMRsrc.nsf/0/e204d0a20923e73b802565e 6003913c1/\$FILE/BSAPAP\%7E1.htm>. May 2003.

Clarke, Tony. "The Recriminalization of Dissent." Policy Options, September 2002, 49-50.

Cleaver, Harry M. Jr. "The Zapatista Effect: The Internet and the Rise of an Alternative Political Fabric." Journal of International Affairs 51, no. 2 (spring 1998): 621-40.

Cohen-Cruz, Jan. "At Cross-Purposes: The Church Ladies for Choice." In Radical Street Performance: An International Anthology, edited by Jan Cohen-Cruz. London and New York: Routledge, 1998.

_. "Theatricalizing Politics: An Interview with Augusto Boal." In Playing Boal, edited by Mady Schutzman and Jan Cohen-Cruz. London: Routledge, 1994.

Cornellier, Manon. "Le Sommet des petits pas." Le Devoir (Montreal), Saturday, 14 April 2001, A11.

Deibert, Ronald J. "Civil Society Activism on the World Wide Web: The Case of the AntiMAI Lobby." In Street Protests and Fantasy Parks: Globalization, Culture, and the State, edited by Janice Gross Stein and David R. Cameron. Vancouver and Toronto: University of British Columbia Press, 2002.

Delauney, Sophia. "Women March Peacefully on A19, Hang Banners on Wall in Quebec." Chicago IndyMedia Web site, 20 April 2001, <http://chicago.indymedia.org/front. php3?article_id=1969\&group=webcast $>$. January 2003.

Derosiers, Eric. "Rendez-vous à Porto Alegre pour le prochain Sommet des peuples: La grande marche de samedi aurait attiré près de 60,000 manifestants." Le Devoir (Montreal), Monday, 23 April 2001, A3.

Desai, Manisha. “Transnational Solidarity: Women's Agency, Structural Adjustment, and Globalization." In Women's Activism and Globalization: Linking Local Struggles and Transnational Politics, edited by Nancy A. Naples and Manisha Desai. New 
York and London: Routledge, 2002.

Drainville, André C. "Québec City and the Making of Transnational Subjects." In Socialist Register 2000: A World of Contradictions, edited by Colin Leys and Leo Panitch.

London, Ont.: Merlin Press; Halifax: Fernwood, 2001. Available online at $<$ http://www.yorku.ca/socreg/Drainville.htm>. June 2003.

Durland, Steven. "Looking For Art in the Process." In Conversations at the Castle, edited by Mary Jane Jacob. Chicago: University of Chicago Press, 1998.

."Witness: The Guerrilla Theatre of Greenpeace." In Radical Street Performance: An International Anthology, edited by Jan Cohen-Cruz. London and New York: Routledge, 1998. Originally published in High Performance 40 (winter 1987): 3035 .

Elam, Harry J. Jr. "Social Urgency, Audience Participation, and the Performance of Slave Ship by Amiri Baraka." In Crucibles of Crisis: Performing Social Change, edited by Janelle Reinelt. Ann Arbor: University of Michigan Press, 1996.

Erlanger, Steven. "Berlusconi Vaunts West's 'Superiority'." International Herald-Tribune, Thursday, 27 September 2001, 1.

Fidelman, Charlie. "Abuse on Both Sides: Ligue des Droits Observers Critical of Cops, Cop-beaters." Montreal Gazette, Sunday, 22 April 2001, A7.

Gablik, Suzi. "Connective Aesthetics: Art After Individualism." In Mapping the Terrain: New Genre Public Art, edited by Suzanne Lacy. Seattle: Bay Press, 1995.

Gauld, Danielle. "There Ain't No Power Like the Power of the People: My Experiences in Quebec City." Women's Voices Newsletter (Kenora, Ont.), summer 2001, $<$ http://www.voyageur.ca/ womens_place/summer\%202001.html>. April 2003.

Geer, Richard Owen. "Of the People, By the People and For the People: The Field of Community Performance." High Performance 64 (spring 1993): 28-31.

Gomez-Peña, Guillermo. "The Subcomandante of Performance." In First World, Ha Ha Ha!: The Zapatista Challenge, edited by Elaine Katzenberger. San Francisco: City Lights, 1995.

Graeber, David. "The New Anarchists." New Left Review 13 (January-February 2002): 6173.

Graham, Barbara Walker. "Water is Sacred: Support for the Cochabamba Declaration." Awakened Woman e-magazine, 16 May 2001, <http://www.awakenedwoman.com/ cochabamba.htm>. December 2002. 
Grossberg, Lawrence. "Identity and Cultural Studies: Is That All There Is?" In Questions of Cultural Identity, edited by Stuart Hall and Paul Du Gay. London: Sage Publications, 1996.

. "Is There a Fan in the House? The Affective Sensibility of Fandom." In The Adoring Audience: Fan Culture and Popular Media, edited by Lisa A. Lewis. London and New York: Routledge, 1992.

Gwyn, Richard. "Hearing the Protest Message." Toronto Star, Sunday, 18 March 2001, A17.

Hall, Stuart. "The Determination of Newsphotographs." Working Papers in Cultural Studies 3 (fall 1972): 53-87.

Hamilton, Graeme. "Police Foil Protesters by Locking Summit Gates." National Post, Friday, 20 April 2001, A15.

_. "Security Fence is Justifiable, Judge Rules." National Post, Thursday, 17 April 2001, A17.

Hénaff, Marcel, and Tracy B. Strong. "Introduction: The Conditions of Public Space: Vision, Speech, and Theatricality." In Public Space and Democracy, edited by Marcel Hénaff and Tracy B. Strong. Minneapolis: University of Minnesota Press, 2001.

Herbst, Robbie. "My Friends Are the Universe: Globalization's Protests Expand the Political." Journal of Aesthetics and Protest 1, no. 1 (July 2002), <http://www. journalofaestheticsandprotest.org/1/globalization/index.html>. December 2002.

Hinkel, Joanne. "A Parade of Puppeteers: How Art is Helping Activism." Attnspan Web site, 29 April 2001, <http://www.attnspan.com/revolution/1>. March 2003.

Hyde, Gene. "Independent Media Centres: Cyber-Subversion and the Alternative Press." First Monday 7, no. 4 (April 2002), <http://firstmonday.org/issues7_4/hyde/ index.html>. June 2003.

Jaimet, Kate, Mike Trickey, and James Baxter. "Black-Masked Anarchists Set the Stage for Today's Larger Demonstration." Ottawa Citizen, Saturday, 21 April 2001, A5.

Jiménez, Marina. "Anti-Globalization Activists Practice for this Weekend's G8 Summit in Genoa." National Post, Monday, 16 July 2001, A8.

Jordan, John. "The Art of Necessity: The Subversive Imagination of Anti-Road Protest and Reclaim the Streets." In DiY Culture: Party and Protest in Nineties Britain, edited by George McKay. London: Verso, 1998. 
Jordan, John, and Jennifer Whitney. "Resistance is the Secret of Joy." New Internationalist 338 (September 2001): 24-25.

Jordan, Tim. "Hacktivism: Direct Action on the Electronic Flows of Information Societies." In Challenges to Democracy: Ideas, Involvement and Institutions, edited by Keith Dowding, Jim Hughes, and Helen Margetts. London: Palgrave, 2001.

Kaihatsu, Chris. "Puppet-Making at the Art Centre." Chicago IndyMedia Web site, 16 April 2001, <http://chicago.indymedia.org/front.phps?article_id=1863\&group= webcast>. November 2002 .

Kauffman, L.A. “All Has Changed." Free Radical 19 (17 September 2001), <http://www. free-radical.org $>$. July 2003.

Keating, Kate. "Raging Against the Machine (and everything else) Granny Power!" In Peace and Environment News. Peace and Environment Resource Centre, April 1998, <http://perc.ca/PEN>. June 2003.

Kingston, Laurie. "Our World at a Crossroads: Quebec City Diary." Our Times: Canada's Independent Labour Magazine, June-July 2001, <http://www.ourtimes.ca/features/ 01jun_jul_quebec.html>. June 2003.

Klein, Naomi. "The Bonding Properties of Tear Gas." Globe and Mail, Wednesday, 25 April 2001, A15.

."Keeping Us Out Before We Get There." Globe and Mail, Wednesday, 21 March 2001, A13.

___ "Talk to Your Neighbours: It's a Start." Globe and Mail, Wednesday, 2 May 2001, A11.

Kotányi, Attila, and Raoul Vaneigem. "Elementary Program of the Bureau of Unitary Urbanism." In Situationist International Anthology, edited by Ken Knabb.

Berkeley: Bureau of Public Secrets, 1981. Originally published as "Programme élémentaire du Bureau d'urbanisme unitaire," Internationale Situationniste (Paris) 6 (August 1961).

Kristeva, Julia. "The Bounded Text." In Desire in Language: A Semiotic Approach to Literature and Art, edited by Leon S. Roudiez. Translated by Thomas Gora, Alice Jardine, and Leon S. Roudiez. New York: Columbia University Press, 1980. Originally published as "La text clos," Langages 12 (1968): 103-25.

Lacy, Suzanne. "Cultural Pilgrimages and Metaphoric Journeys." In Mapping the Terrain: New Genre Public Art, edited by Suzanne Lacy. Seattle: Bay Press, 1995. 
Land, Peggy. "Raging Grannies Save Young Protesters From Police: Moments of Faith at the Wall, Quebec City April 21." Straight Goods Web site, 31 May 2001, $<$ http://goods.perfectvision.ca/FTAA/ViewBrief.cfm?REF=62>. February 2003.

Lee, Marc. "The FTAA After Quebec." Canadian Centre for Policy Alternatives Web site, September 2001, <http://www.policyalternatives.ca>. June 2003.

Levin, Thomas Y. "Denis Beaubois and the Performative Politics of Panoptical Détournement." CTRL [SPACE] Web site, <http://hosting.zkm.de/ctrlspace/ e/texts/05? print-friendly=true $>$. March 2003.

Lippard, Lucy. "Looking Around: Where We Are, Where We Could Be." In Mapping the Terrain: New Genre Public Art, edited by Suzanne Lacy. Seattle: Bay Press, 1995.

Lloyd, Robin. "And the Wall Came Tumbling Down." Nadir Web site, 30 April 2001, $<$ http://www.nadir.org/nadir/initiativ/agp/a20/tumbling.htm>. October 2002.

Lowe, Seana. "Creating Community: Art for Community Development." Journal of Contemporary Ethnography 29, no. 3 (June 2000): 357-385.

Manley, John, and Pierre S. Pettigrew. "What the Summit is Really About." National Post, Saturday, 21 April 2001, A16.

Marks, Laura U. "Plunging Into the Event: Political Struggle Between Language and the Earth." In Better Worlds: Activist and Utopian Projects by Artists, edited by Jan Allen and Laura U. Marks. Kingston: Agnes Etherington Art Centre, 2002.

"Matthew Hart: Puppet-Maker and Theatre Activist." The ArtBiz Web site, July 2002, $<$ http://www.theartbiz.com/peerarchive.asp?WHICH=21>. January 2003.

McGregor, Sarah. "Report from Quebec Ground Zero." Ottawa X Press, Thursday, 26 April 2001, 3.

McKenzie, Jon, and Rebecca Schneider. "Critical Art Ensemble: Tactical Media Practitioners." The Drama Review 44, no. 4 (winter 2000): 136-50.

McKenzie, Robert. "Quebec Defends Security Response." Toronto Star, Monday, 23 April 2001, A7.

Mitchell, W.J.T. "The Violence of Public Art: Do the Right Thing." In Art and the Public Sphere, edited by W.J.T. Mitchell. Chicago and London: University of Chicago Press, 1992.

Mogg, Kerry. "A Short History of Radical Puppetry." Fifth Estate 35, no. 1 (spring 2000): 14-15. 
Moss, Peter D. "Conflict and Containment in Television News: A Case Study." In Framing Friction: Media and Social Conflict, edited by Mary S. Mander. Urbana and Chicago: University of Illinois Press, 1999.

Mulvey, Laura. "Visual Pleasure and Narrative Cinema." Screen 16, no. 3 (1975): 6-18.

Naples, Nancy A. "Changing the Terms: Community Activism, Globalization, and the Dilemmas of Transnational Feminist Praxis." In Women's Activism and Globalization: Linking Local Struggles and Transnational Politics, edited by Nancy A. Naples and Manisha Desai. New York and London: Routledge, 2000.

Nelson, Arthur. "A Bunch of Bastas: The Inspiration for Anti-Free Trade Foes Everywhere Find Themselves at a Crossroads." NOW Magazine Online Edition 20, no. 30 (March 29-April 4 2001), <http://www.nowtoronto.com/issues/2001-03-29/ news_spread.html>. June 2003.

Niedzviecki, Hal. "Never Mind the Anarchy-Where's the Art? G8 Protesters Could Learn a Lesson from Sixties Counterculture." Globe and Mail, Wednesday, 26 June 2002, A1.

Norton, Anne. "Writing Property and Power." In Public Space and Democracy, edited by Marcel Hénaff and Tracy B. Strong. Minneapolis: University of Minnesota Press, 2001.

Panetta, Alexandra. "Quebec Summit Security will be the Tightest in Canada's History." Canadian Press, 17 February 2001. Available online at the Stop the FTAA Web site, <http://www.stopftaa.org/news/news_qcsecurity.html >. June 2003.

Peeps, Claire. "Getting in History's Way." In Activists Speak Out: Reflections on the Pursuit of Change in America, edited by Marie Cieri and Claire Peeps. New York: Palgrave, 2001. Available online at the Community Arts Network Web site, $<$ http://www.communityarts.net/readingroom/resmul.php>. April 2003.

Pile, Steve. "Opposition, Political Identities and Spaces of Resistance." In Geographies of Resistance, edited by Steve Pile and Michael Keith. London and New York: Routledge, 1997.

"Quebec Looks to Ottawa for Lion's Share of Summit Expenses." National Post, Monday, 23 April 2001, A10.

Rebick, Judy. "Making History: It Was the Largest Protest in Human History." Canadian Dimension, 17 February 2003. Available online at $<$ http://www.canadian dimension.mb.ca/extra/d0217jr.htm>. June 2003. 
. "Of Catapults and Teddy Bears." Rabble.ca Web site, 8 May 2001, <http://www. rabble.ca>. November 2002 (no longer available).

. "Qatar Reveals Impact of September 11 on Trade Battle." Z Magazine, 17 November 2001, <http://www.zmag.org/sustainers/content/2001-11/17rebick. cfm>. June 2003.

Rinaldo, Rachel. "IndyMedia Mobilizes for the Sequel to Seattle." The Black World Today, April 2000, <http://www.tbwt.com/views/feat/feat1906.asp>. December 2002.

. "Pixel Visions: The Resurgence of Video Activism." Lip Magazine, 7 September 2001, <http://www.lipmagazine.org/articles/featrinaldo_115.shtml>. June 2003.

Séguin, Rhéal. "Quebec Summit Site is a Forbidden City, Barricaded by Police, Surveyed by Video." Globe and Mail, Saturday, 21 April 2001, A3.

Sierz, Alex. "How to Play Boal." Red Pepper, March 1995. Available online at the Theatre of the Oppressed Laboratory Web site, <http://www.toplab.org/boalint.htm>. November 2002.

Smith, Jackie, John D. McCarthy, and Clark McPhail. "From Protest to Agenda Building: Description Bias in Media Coverage of Protest Events in Washington, D.C." Social Forces 79 (2001): 1397-423.

Smith, Paul. "No Essential Femininity: A Conversation between Mary Kelly and Paul Smith." Parachute 37, no. 26 (spring 1982): 31-35.

Sontag, Susan. "Looking at War: Photography's View of Devastation and Death." The New Yorker, 9 December 2002, 82-98.

Starhawk. "Dances with Tear Gas." Beliefnet Web site, May 2001, <http://www.beliefnet. com/story/80_8008.html>. November 2002.

Tagg, John. "The Currency of the Photograph." In The Burden of Representation: Essays in Photographies and Histories. Minneapolis: University of Minnesota Press, 1993.

Taylor, Diana. "Making a Spectacle: The Mothers of the Plaza de Mayo." In Radical Street Performance: An International Anthology, edited by Jan Cohen-Cruz. London and New York: Routledge, 1998.

Thompson, Allan, and Jim Rankin. "Dozens Hurt as Protests Continue: Riots Contrast with Peaceful March by 25,000." Toronto Star, Sunday, 22 April 2001, A1. 
Thrift, Nigel. "The Still Point: Resistance, Expressive Embodiment and Dance." In Geographies of Resistance, edited by Steve Pile and Michael Keith. London and New York: Routledge, 1997.

Tinguely, Vince. "The Politics of Appearance (and Disappearance) at the FTAA Summit in Quebec City." La Voce del Popolo (Montreal) 1 (fall 2001), <http://www.casadel popolo.com/voce010-/0109threeviews.html\#appearance>. January 2003.

Tuer, Dot. "Parables of Community and Culture for a New World (Order)." In Questions of Community-Artists, Audiences, Coalitions, edited by Daina Augaitis, Lorne Falk, and Sylvie Gilbert. Banff: Banff Centre Press, 1995.

"When Masks are Outlawed... Only Revolutionaries Will Wear Masks!" Maori Independence Web site, 11 March 2001, <http://aotearoa.wellington.net.nz/ int/mask/masks.htm>. April 2003.

Whitney, Shawn. "Outside the O-fence-ive Barricade: The Journal of an Artist in Town to Do a Little Street Theatre." Briarpatch 30, no. 5 (June 2001): 8-11.

\section{Audio-visual resources}

Antliff, Alan. "Art, Anarchy, and Activism." Ideas. Canadian Broadcasting Corporation, 15 October 2001. Radio broadcast.

Isacsson, Magnus, and Paul Lapointe. View from the Summit: Quebec City-April 20-22, 2001. 75 min. National Film Board of Canada, 2002. Videocassette.

\section{Monographs}

Bakhtin, Mikhail M. Rabelais and His World. Translated by Hélène Iswolsky. Bloomington: Indiana University Press, 1984. Originally published as Tvorchestvo Fransua Rable (Moscow: Khudozhestvennia literatura, 1965).

Barlow, Maude, and Tony Clark. Global Showdown: How the New Activists are Fighting Global Corporate Rule. Toronto: Stoddart Publishing, 2001.

Barthes, Roland. Camera Lucida: Reflections on Photography. Translated by Richard Howard. New York: Hill and Wang, 1981. Originally published as La chambre claire: note sur la photographie (Paris: Éditions Gallimard, 1980).

Berger, John. Ways of Seeing. London: British Broadcasting Corporation and Penguin Books, 1972. 
Bey, Hakim. TAZ: The Temporary Autonomous Zone: Ontological Anarchy, Poetic Terrorism. New York: Autonomedia, 1985. Available online at the Public Netbase t0 Institute for New Culture Technologies Web site, <http://www.t0.or.at/ hakimbey/taz/taz.htm>. May 2003.

Bhabha, Homi K. The Location of Culture. New York and London: Routledge, 1994.

Boal, Augusto. Theatre of the Oppressed. Translated by Charles A. McBride and MariaOdilia Leal McBride. New York: Urizen Books, 1979. Originally published as Teatro del oprimido y altras poéticas políticas (Buenos Aires: Ediciones de la flor, 1974).

Bourdieu, Pierre. The Field of Cultural Production: Essays on Art and Literature. New York: Columbia University Press, 1993.

Brothers, Caroline. War and Photography: A Cultural History. London and New York: Routledge, 1997.

Butler, Judith. Gender Trouble: Feminism and the Subversion of Identity. London: Routledge, 1990.

Certeau, Michel de. The Practice of Everyday Life. Translated by Steven Rendall. Berkeley: University of California Press, 1984. Originally published as L'invention du quotidien. 1: Arts de faire (Paris: Éditions Gallimard, 1974).

Critical Art Ensemble. The Electronic Disturbance. New York: Autonomedia, 1994.

Debord, Guy. The Society of the Spectacle. Translated by Donald Nicholson-Smith. New York: Zone Books, 1994. Originally published as La société du spectacle (Paris: Buchet-Chastel, 1964).

Dery, Mark. Culture Jamming: Hacking, Slashing and Sniping in the Empire of Signs. San Francisco: Open Magazine Pamphlet Series, 1993. Available online at $<$ http://www.levity.com/markdery/culturjam.html>. June 2003.

Deutsche, Rosalyn. Evictions: Art and Spatial Politics. Cambridge: MIT Press, 1996.

Dewey, John. Art as Experience. New York: Minton, Balch \& Company, 1934; New York: Putnam, 1958.

Douglas, Susan J. Where the Girls Are. New York: Time Books, 1994.

Evans, Robert. "Re-presenting Colonial Canada through Collected Photographs: Interpretations of Travel Albums Assembled by Nineteenth-Century British Army Officers." Master's Thesis, Carleton University, 2002. 
Fanon, Frantz. Black Skin, White Masks. Translated by Charles Lam Markman. New York: Grove Press, 1967. Originally published as Peau noire, masques blancs (Paris: Éditions du Seuil, 1952).

Foucault, Michel. Discipline and Punish: The Birth of the Prison. Translated by Alan Sheridan. New York: Pantheon Books, 1977. Originally published as Surveiller et punir: Naissance de la prison (Paris: Éditions Gallimard, 1975).

The History of Sexuality. Volume 1: An Introduction. Translated by Robert Hurley. New York: Vintage Books, 1990. Originally published as La volenté de savoir (Paris: Éditions Gallimard, 1976).

Freire, Paolo. Pedagogy of the Oppressed. Translated by Myra Bergman Ramos. New York: Herder and Herder, 1970. Originally published as Pedagogía do oprimido (Rio de Janeiro: Editora Paz e Terra, 1968).

Gardiner, Michael E. Critiques of Everyday Life. London and New York: Routledge, 2000.

Greene, Maxine. Releasing the Imagination: Essays on Education, the Arts, and Social Change. San Francisco: Jossey-Bass, 1995.

Habermas, Jürgen. The Structural Transformation of the Public Sphere: An Inquiry into a Category of Bourgeois Society. Translated by Thomas Burger with Frederick Lawrence. Cambridge: MTT Press, 1989. Originally published as Strukturwandel der Öffentlichkeit (Berlin: Luchterhand, 1962).

Halleck, Dee Dee. Hand-Held Visions: The Impossible Possibilities of Community Media. New York: Fordham University Press, 2002.

Hertog, James K., and Douglas M. McLeod. Anarchists Wreak Havoc in Downtown Minneapolis: A Multi-Level Study of Media Coverage of Radical Protest.

Journalism and Mass Communication Monographs, no. 151. Columbia, S.C.: Association for Education in Journalism and Mass Communication, 1995.

Hetherington, Kevin. Expressions of Identity: Space, Performance, Politics. London: Sage Publications, 1998.

Hutcheon, Linda. The Poetics of Postmodernism: History, Theory, Fiction. New York: Routledge, 1988.

- A Theory of Parody: The Teachings of Twentieth Century Art Forms. New York and London: Methuen, 1985.

Jones, Amelia. Body Art/Performing the Subject. Minneapolis: University of Minnesota Press, 1998. 
Kelly, Mary. Post-Partum Document. London: Routledge; Boston: Kegan Paul, 1983.

Kelly, Owen. Community Art and the State: Storming the Citadels. London: Comedia Publishing, 1985.

Kershaw, Baz. The Politics of Performance: Radical Theatre as Cultural Intervention. London and New York: Routledge, 1992.

Klein, Naomi. No Logo: Taking Aim at the Brand Bullies. Toronto: Vintage Canada, 2000.

Lacan, Jacques. The Four Fundamental Concepts of Psycho-analysis. Translated by Alan Sheridan. Harmondsworth: Penguin Books, 1977. Originally published as Le Séminaire de Jacques Lacan, Séminaire XI: Les quatre concepts fondamentaux de la psychanalyse (Paris: Éditions du Seuil, 1964).

Lefebvre, Henri. The Production of Space. Translated by Donald Nicholson-Smith. Oxford: Basil Blackwell, 1991. Originally published as La production de l'espace (Paris: Éditions Anthropos, 1974).

Lutz, Catherine A., and Jane L. Collins. Reading National Geographic. Chicago and London: University of Chicago Press, 1994.

McGrath, John. The Bone Won't Break: On Theatre and Hope in Hard Times. London: Methuen, 1990.

Mitchell, W.J.T. Picture Theory: Essays on Verbal and Visual Representation. Chicago and London: University of Chicago Press, 1994.

Muñoz, José Esteban. Disidentifications: Queers of Color and the Performance of Politics. Minneapolis: University of Minnesota Press, 1999.

Parker, Rozsika. The Subversive Stitch: Embroidery and the Making of the Feminine. London: Women's Press, 1984.

Ricoeur, Paul. Lectures on Ideology and Utopia, edited by George H. Taylor. New York: Columbia University Press, 1986.

Robbins, Bruce, ed. The Phantom Public Sphere. Minneapolis: University of Minnesota Press, 1993.

Schechner, Richard. The Future of Ritual: Writings on Culture and Performance. London and New York: Routledge, 1993.

Schumann, Peter. Puppetry and the New World Order. Vermont: Bread and Puppet Press, 1993. 
Schutzman, Mady, and Jan Cohen-Cruz, ed. Playing Boal. London: Routledge, 1994.

Scott, Clive. The Spoken Image: Photography and Language. London: Reaktion Books, 1999.

Sontag, Susan. On Photography. New York: Farrar Strauss and Giroux, 1977.

Tickner, Lisa. The Spectacle of Women: Imagery of the Suffrage Campaign, 1907-14. Chicago: University of Chicago Press, 1991.

Turner, Victor. The Ritual Process. Chicago: Aldine, 1969.

Vaneigem, Raoul. The Revolution of Everyday Life. Translated by John Fullerton and Paul Sieveking. New York: Black and Red, 1972. Originally published as Traité de savoir-vivre à l'usage des jeunes générations (Paris: Éditions Gallimard, 1967). 